\title{
PERIGLACIAL PHENOMENA IN SCOTLAND
}

$$
\text { by }
$$

Robert W. Galloway. M.A.

Thesis submitted to the University of Edinburgh for the degree

of

Doctor of Philosophy

1958

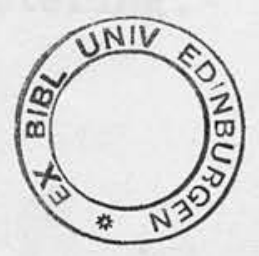


The purpose of this thesis has been primarily to show that harsh periglacial conditions have prevailed in Scotland during the last glacial retreat, and that less severe periglacial conditions still exist on high ground. The distinctive geomorphic agencies associated with these conditions have been discussed, together with their effects on the landforms.

After an introductory section outlining the main ideas in periglacial studies, and presenting the proposed chronological framework based on studies of glacial moraines and pollen analysis, the evidence for cryoturbation in Scotland is presented. Consideration of the fossil wedges and involutions to be found in unconsolidated material in Scotland has shown that very severe climatic conditions with permafrost prevailed to the very end of the ice age. Contemporary cryoturbation exists today on high ground but is of a superficial type associated with a much milder climate.

The severe climate in the past has led to extensive shattering of the bedrock in areas that were not shielded by overlying ice or glacial drift. The presence of the resulting angular loose rock debris and of permafrost greatly favoured periglacial mass wasting and solifluction deposits are widespread, especially in the $\mathrm{E}$. of the country. The work of running water seems to have been mainly the evacuation of the debris furnished from the slopes by frost shattering and solifluction. Wind did not play an important role. The effectiveness of the modification of the landforms induced by periglaciation is shown to depend not only on the nature of the rock and the duration and intensity of the cold climate, but also on the nature of the pre-existing landscape. Modification has gone furthest in NE. Scotland and in the Eastern parts of the Southern Uplands where chemically rotted and fissile rocks respectively have assisted the work of fairly prolonged frost shattering. The forms produced 
include altiplanation benches, niches, tors, straight slopes of mass wasting and trough-like valleys. Corresponding to this erosion, important gravel accumulations have developed at the margins of hill masses and on the floors of main valleys. In the heavily glaciated $W$. of the country, periglaciation has done little to modify the landforms and indeed throughout Scotland has only retouched a landscape that is the work of agencies associated with other climates.

The mild variety of periglaciation prevailing today on high ground has produced a wide variety of mass wasting forms, including lobes, terraces and block streams which can with difficulty be distinguished from the features initiated under more extreme climatic conditions in the past. Contemporary mass movement and disturbance of the ground by frost is most marked in areas where the vegetation is scanty and it has been shown that one of the main factors in restricting its growth on hill tops is wind. Consequently the lower limit of very active periglaciation today is much nearer sea level in the NW. and rises progressively SE. ward.

It is concluded that the study of periglaciation in Scotland is of the greatest significance for an understanding of the Pleistocene history of the country and the evolution of the soils. 
The origin of this thesis goes back to I95I when, thanks to financial help from the University of Edinburgh and the Carnegie Trust, and to the arrangements made by and the encouragement of the late Professor Ogilvie, Professor R. iviller and Dr. A. Geddes, I was priviledged to spend a year in France and Germany studying recent ideas in geomorphology, with especial emphasis on periglaciation, under the guidance of Professors J. Tricart, A. Guilcher and H. Poser. At a later date it was possible to see something of contemporary periglaciation in the Arctic in Northern Norway with the Edinburgh University Lyngen Expedition (I953) and in East Greenland, at Mesters Vig, while undertaking cartographic work for Profesøor A.I. Washburn (I957). Completion of the thesis has been delayed by the intervention of National Service in I954 and I955.

My warmest thanks are due to all those who have helped me by precept and discussion in undertaking this study. I should particularly like to mention Professor J.W. Watson for his sympathetic consideration and $M r$ F.M. Synge for many useful discussions in the field and in correspondence.

The location of some of the places mentioned in the text is given by simple four or six figure grid references, as it has not been considered necessary to give full references. Some of the descriptions of sections have been made in the past tense, because they refer to exposures of a temporary nature where the phenomena described can no longer be observed. Reference in the text to "East Greenland" or "North Norway" refer to the Mesters Vig and Lyngsdal areas respectively. 
Page.

SUMMARY.

PREFACE.

PART I. Introduction.

Chapter I.

Aims.

2 .

Chapter II. Outline of periglacial studies. 3.

Chapter 琼.

Chronological framework.

15.

PART II. Cryoturbation.

Chapter IV. Ice wedges and ice veins. 19.

Chapter V. Involutions. 55.

Chapter VI. Contemporary cryoturbation. 79.

PART III. Geomorphological Processes.

Chapter VII. Weathering.

89.

Chapter VIII. Mass movement.

101.

Chapter IX. Running water.

157.

Chapter $\mathrm{X}$. Wind.

162.

PART IV. Landforms.

Chapter XI. The pre-periglacial landscape.166.

Chapter XII. Tors.

176.

Chapter XIII. Benches.

186.

Chapter XIV. Niches.

192.

Chapter XV. Evolution of slopes and

talwegs.

204.

Chapter XVI. Post-periglacial erosion. 
PART V. Periglaciation of scotland as a whole.

Chapter XVII. Periglacial climates.

Chapter XVIII. The general distribution

and significance of

Periglaciation.

242.

Chapter XIX. Some problems for further

study.

258.

TABLES.

261.

APPENDICES.

A. Some early observations of periglacial phenomena. 263.

B. Pollen analysis of peat at Bridgend, Strathbogie, Aberdeenshire. 270 .

BIBLIOGRAPHY. 272.

FIGURES.

PHOTOGRAPHS.

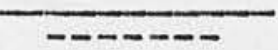


PART I.

I IN T R O D U C T I O N.

In this section the aims of the investigation will be discussed, followed by an outline of the nature of periglacial phenomena and periglacial geomorphological processes in particular. The section concludes with a statement of the chronological sequence to be followed. 
CHAPTER I.

A I M S.

The primary purpose of this study has been to show that periglacial conditions have prevailed in Scotland. An attempt has been made to assess the location, duration and intensity of these conditions. Most of the evidence for this has come from consideration of cryoturbation phenomena such as fossil ice wedges, involutions and patterned ground. The opportunity was taken to investigate the mode of development of these phenomena

The second aim has been to point out the nature of the geomorphological processes which have fashioned the landforms of Scotland under periglacial conditions. This has involved consideration of weathering, mass movement, and the work of streams and wind.

The third aim has been the assessment of the landforms produced by these processes. Only a minute fraction of the evidence could be examined in the time available. The analysis of the periglacial landforms of Scotland is essentially a work for the future. Consideration had to be given to the pre-periglacial landforms and the effects of post-periglacial modifications.

The fourth aim has been to contribute to the knowledge of the history of the Pleistocene period in Scotland. 
CHAPTER 2

OUTLINE OF PERIGLACIAI STUDIES

I. Introduction.

It has long been recognised that in regions of cold but not glacial climates distinctive processes of erosion, transport and deposition prevail, and that these processes have operated in the past in areas now enjoying milder climatic conditions. Nevertheless recognition of the full importance of these processes in shaping the landscape has come only in recent decades although most textbooks on geomorphology and the Pleistocene now include a section on these topics as a matter of course. (IHORNBURY I954, FLINT I957). Study of these phenomena is now rapidly acquiring the status in geographical knowledge long enjoyed by the study of glacial phenomena, and a body of more or less generally accepted knowledge exists, although acute controversy rages on many points. Nevertheless the subject is still sufficiently new in Britain to warrant a short introductory outline of the present state of knowledge and the history of the subject. More detailed discussion of processes and landforms will be introduced later where necessary when discussing individual topics. At the same time the opportunity will be taken to introduce some of the terminology to be used in this study, although it must be admitted that "a wide measure of agreement" does not exist in this sart of the subject!

II. Definition.

Many attempts have been made to find a suitable term to embrace the geomorphological processes, landforms and climates occurring in cold but not glacierized regions. Such terms have been coined for other processes, landforms and climates. e.g. "Glacial processes of erosion produce distinctive landforms and are the product of distinctive climatic conditions. 
In I906 ANDERSON suggested "subglacial" as a suitable term to describe the zone where rapid mass movement of the upper layers of ground was proceeding in cold climates. The term has now been adopted however by the glaciologists to embrace phenomena occurring actually under glaciers. The term "subnival" used by TROLL" in I944 and I948 has not found favour. Some authors have favoured terms making use of such words as "Arctic" or "Polar", but such a usage is to be deprecated as it implies a geographical limitation of processes, climates and landforms which are to be found in all latitudes, at least on mountains.

The term which has found general acceptance is "periglacial". This adjective was introduced by LOZINSKI in I909 to denote the geological consequence in Central Europe of the Quaternary ice sheets to the N. Strictly speaking, the term should only be applied to regions in the immediate vicinity of glaciers (Greek "peri" = "around") and this would exclude wide areas of the earth's surface, particularly on the mountains of middle and low latitudes where processes of erosion, transport and deposition associated with cold conditions are widespread but which lie very far from any glacier. However the term has come to be extended to such areas and has lost its strictly geological connotation and now also embraces the climate, landforms, geomorphological processes and even the vegetation found in cold regions. It is now acceptable to speak of "periglacial climates", as well as "periglacial landforms" and "periglacial deposits". The looseness of the term requires to be restricted by careful definition.

TROLI (I947, p. I63) points out that in the "periglaziale Formenbildung de entscheidende Krafte vom Bodeneis ausgingen" The growth of ice in the ground is thus the decisive mechanism of periglacial processes and distinguishes them from those found in regions with different climates. A satisfactory definition must exclude other areas, e.g. Edinburgh, where freezing of the ground occurs but has little geomorphological significance. 
In this study periglacial phenomena is defined as "The climates and the significant geological and geomorphological processes, landforms and deposits associated with the growth of ice in the ground."

It must be admitted that the interpretation of the word. "significant" is often arbitrary and subjective, but this sort of difficulty occurs repeatedly in considering natural phenomena where one type grades imperceptibly into another.

We shall outline in this chapter the important facts about how ice develops in the ground, and then consider in turn the periglacial climates, geological/geomorphological processes and the resulting landforms and deposits.

\section{Growth of ice in the ground.}

The key factor in periglacial phenomena is the $9 \%$ increase of volume when water turns to ice. The detailed physics of the growth of ice in the ground are extremely complex, but for oar purposes it is chiefly necessary to remember that it can develop in several different forms.

1) Homogeneous ice forms in pores and as a skin around individual particles of mineral matter. Only water already in the ground at the point where freezing takes place is involved, and consequently there is only a slight increase in volume.

2) Segregated ice forms as coherent bodies ranging in size from individual crystals commonly found at or just under the surface, known as pipkraks, to large horizontal ice lenses or vertical ice veins and ice wedges of many cubic metres in volume. The growth of segregated ice involves the importation of water to the freezing surface. This importation is favoured by capillarity from below in unconsolidated material with a high proportion of silt-sized grains. The net result is a large increase in volume of the ground on freezing, and a corresponding saturation with water on melting.

IV. Periglacial climates.

The details of the classification of periglacial climates 
vary from one writer to another, but three main types may be distinguished. The effects of the growth of ice differ in each.

1) Continental tundra regions, such as N. Siberia and N. Canada today are marked by very cold winters, fairly warm summers and relatively brief periods in spring and autumn when the temperature fluctuates around freezing. In these regions the sumer warmth is insufficient to thaw all the ground frozen in winter and a permanently frozen layer, from a few decimetres to hundreds of metres thick develops under the shallow layer which thaws every summer. The permanently frozen layer is known as "Permafrost" and the overlying thawed layer as the "Active layer". (Other terms have been suggested for these layers, but discussion of the complexities and contradictions of periglacial terminology would be profitless). Comparable climatic conditions with permafrost existed in Central Europe during the cold phases of the Pleistocene.

2) Maritime tundra regions, such as Spitsbergen and S. Greenland are marked by rather less severe winters, cooler summers, more protracted periods of freeze/thaw, and higher humidity. In the more extreme parts of these regions moderately deep permafrost exists, but is absent in the milder parts. Mountains in more temperate latitudes, such as Norway and the Alps form outliers of this climatic type, although local variations are very marked due to the variety of slope and site climates. In the ice age such conditions seem to have prevailed in W. Europe, at low levels.

3) Climates of small annual range of temperature, found chiefly on very oceanic islands such as Kerguelen and high mountains in the tropics. Freeze/thaw cycles are abundant, often diurnal, but the amplitude of the cycles is slight. No permafrost exists. During glacial phases in the past such conditions must have reached lower down the mountainsides and affected islands in lower latitudes.

Transition forms exist between these climatic types of course. Today the Scottish Highlands have characteristics of both types 2) and 3). 
V. Geomorphological processes.

The growth of ice in the ground breaks up consolidated rock and helps to move unconsolidated material. As ice grows in pores and cracks great pressure can develop which burst the rock asunder. This form of weathering is known as "frost shattering". In porous rocks frost shattering tends to produce small fragments and abundant fine debris while in nonporous rocks shattering produces coarser fragments and less fine material. The debris produced by the initial shattering is often further reduced to more finely-comminuted material. The products of frost shattering are typically of angular, jagged form.

In unconsolidated material, including frost-shattered debris, the growth of ice directly induces movement of individual particles or packets of material, a process known as "cryoturbation", or helps to provide suitable conditions for mass movement on slopes, a process known as "solifluction".

One of the most striking effects of cryoturbation is the production of surface features such as stone polygons and stone stripes found in mountain areas today and in the Arctic. These features are known collectively as "patterned ground". Although cryoturbation is not the only processes involved in their formation, it is probably the most important. Certainly, except in arid areas where dessication patterns may develop, the presence of patterned ground is regarded as the clearest indication of periglaciation. In sections, the effects of cryoturbation include the formation of vertical ice masses known as "ice wedges" and the disturbance of unconsolidated material known as "involutions". Fossil wedges and involutions are sure evidence of the former existence of severe periglacial conditions.

The melting of ground ice favours solifluction in spring by providing abundant water; the moisture content can be still further increased by the presence of an impermarble frozen layer below the sodden active layer. Freezing and thawing also weaken the cohesion of the ground by inhibiting vegetation and destroying the crumb structure of the soil. Freezing also aids mass movement by the growth of pipkraks which can lift stones that settle 
back when the thaw comes a little further down the slope; a similar process can affect the entire surface of a slope every time it freezes and thaws. See figure 31. Solifluction is most effective where there is an important proportion of fine material since this favours the development of segregated ice masses which on melting provides water to lubricate the motion. In very coarse material solifluction is impossible, and loose debris remains immobile except on slopes so steep that simple gravity screes can develop.

Certain other processes in the periglacial environment, not directly concerned with the growth of ice in the ground must be mentioned. Running water can be a very effective agent of transport and erosion, aided by rapid run-off in spring over bare ground from melting snow. By washing out fine material it can inhibit solifluction.

Wind is important in some periglacial regions. Iike water, it can inhibit solifluction by exporting fine material, but it may redeposit this material and so favour solifluction elsewhere. Silt-sized grains, a typical product of frost shattering, are especially amenable to wind transport and make up much of the loess deposits of Europe. (ZEUNER 1944).

VI. Periglacial landforms and deposits.

The dominant characteristic of the landforms in periglacial regions is the rapid evolution of slopes. Frost shattering breaks up the material and solifluction removes it. This proceeds over the whole surface and produces straight slopes passing upwards by a convex curve into gently rounded summits and downwards into flat valley floors by a sharp break of slope or by a concave curve of accumulation. Bedrock lies near or at the surface in the upper, convex portion of the slope; a fairly thin layer of solifluction material covers the straight intermediate portion; the lower concave section is built up of material carried down from above.

In detail, these major slope segments are often irregular: the upper part may be broken by rugged outcrops of more resistant rocks known as tors, and show sub-horizontal benches cut at least partly in rock as altiplanation terraces; the midale slope usually shows irregularities due to accumulations of mass 
movement deposits such as solifluction lobes and terraces; the lower concave part of the slope may also have these solifluction features and in addition be cut by gullies draining water off the slopes above.

Valleys have distinctive forms in periglacial regions. In areas of low relief the rivers tend to flood every spring over vast alluvial plains depositing material provided by shattering and solifluction further up the course. In regions of moderately sloping terrain a sequence of forms can be traced down the valleys. In the uppermost part no stream is present and debris moves down the slopes and along the talweg to produce smooth hollows of rounded cross-profile. It may be that these hollows depend on the pre-existence of a stream-cut gully but it seems possible that the mass movement of frost shattered material can itdelf erode the underlying bedrock if it is weak. This process is known as "corrasion". In chalk country, the resulting forms are known in the British terminology as "coombes". In other rocks they are termed "corrasion niches" although this is not an ideal name, since it implies that the genesis of the form is known for sure. Another term for these forms is the German word "Dell". Very short valleys may consist solely of single corrasion niches, but more usually these are confined to the very head and grade into sections where the erosive power of running water is more important and more concentrated. If mass movement is more effective on one side of the valley than on the other for reasons of site climate, the valley may become asymmetric. Still further down the talweg, the role of running water becomes predominant and the stream, usually braided, undercuts its margins to produce steep-sided, flat-floored valleys.

In regions of very steep relief running water can cut striking gullies such as commonly occur on mountain sides in Greenland.

The dominant tendency in periglacial regions is for erosion to rapidly reduce hill areas and infill the valleys with alluvium, a process known as equiplanation. The reduction takes place by down-wasting on the convex upper part of the slope and parallel slope retreat in the middle portion. The infilling takes place because the rivers are not always able to evacuate 
the heavy load of material provided from the slopes.

There are three characteristic drift deposits produced by periglaciation: solifluction deposits, fluviatile deposits and loess.

The solifluction deposits tend to accumulate at the foot of slopes where the rate of removal by mass movement is checked by the decline in gradient. In the British literature these deposits are known by a bewildering variety of terms, of which the best-known is "head". Solifluction deposits consist of material that was originally in situ further up the slope. They are particularly characteristic of the Pleistocene periglaciation of W. Europe, and the maritime tundra type of environment today. The fluviatile deposits are made of material furnished to the streams by mass wasting from the valley sides. This material is so abundant that great gravel spreads develop along the main valleys. If a phase of periglacial climate is followed by another less favourable to the accumulation of alluvium, the gravel spreads may be dissected to form "climatic terraces". Transitional deposits exist which are partly solifluction, partly fluviatile in origin. In periglacial regions today, some of the most striking features of the landscape are the great gravel fans built up by the streams descending from high ground.

The eolian deposits consist of loess and sand. The loess is an extremely important product of the periglaciation of Central Europe. Sand dunes and more or less uniform sheets of "coversands" are well developed also. The scanty vegetation and the high winds of periglacial regions, as well as the abundant frostcomminuted debris explain the abundance of these deposits. Apart from Alaska, they seem rather less typical of contemporary periglacial regions, though not unknown in Svalbard and Iceland for example.

VII. Distribution of periglacial phenomena.

Vast areas of the world are affected by periglaciation today, and even wider areas were affected during the geologically very recent past. 
TRICART ( $n . d$ ) states that some $18 \%$ of the world's surface is subject to periglaciation. By far the greatest proportion of this immense area, amounting to some ${ }_{2}^{25}$ illion square kilometres, lies in the Northern parts of Siberia and Alaska, including the Arctic archipelagoes between them and the pole. Other extensive areas include the unglacierized fringes of Greenland and Antartica and the Arctic and Antarctic archipelagoes of Svalbard, Iceland, South Georgia, Kerguelen and the Aleutians. In addition mountains, at all latitudes, between the tree and the snow lines are part of this zone. Throughout this immense area the microrelief, hydrology, soils and vegetation are largely conditioed by the growth of ice in the ground.

During the cold periods of the Quaternary, even greater areas of the earth's surface were affected by periglaciation. The S. limit of low-level periglaciation in the Pleistocene is not known even in Europe. In the $W$. of the continent it extended to the Mediterranean coast of France, and occurs in $N$. Spain. (BIROT 1956). GUILCHER (1949) has observed signs of periglacial solifluction as far S. as Lisbon, and long ago GEIKIE and RAiviSA (1878) ascribed rubbly drift on the flanks of the Rock of Gibraltar to former frost shattering and mass movement under cold conditions. The writer has seen periglacial effects, on a limited scale, at low altitudes in Corsica. MicBURNEY \& HEY (1955) have reported frost shattering effects from the coast of Cyrenaica. In America, the S. boundary is also little-known, and there is practically no information available from Asia. In Australasia, extensive periglaciation reached at least as far N. as Wellington. (COTrON \& Te PUIVGA, 1955).

As a very rough guess it can be said that during the Pleistocene about $20 \%$ of the earth's surface experienced periglacial conditions and another $20 \%$ were glacierized. Throughout a vast area, including some of the most densely peopled, intensively farmed and fished, and economically important regions of the earth periglaciation with the associated pedological, biological and geomorphological conditions held sway at a period which in relation to the earth's time scale was but yesterday. 
VIII. The development of periglacial studies.

The earliest recognition of what would now be termed periglacial phenomena was made in England. Centuries ago the Cornish miners had recognised the existence of a loose rubble of rock fragments overlying the solid rock and had given a name to this material: "Head". De la BECHE introduced this term into scientific literature in 1839, and it is still widely used despite its vagueness and possibilities of confusion for nonEnglish readers.

A useful account of the early ideas on the subject has been published by DINES et al (1940). By 1880 or so it was generally, though not universally, recognised that the angular rubble $\&$ Southern England had formed under cold conditions during the ice age by frost shattering and downslope movement in a saturated state. By 1894 GEIKIE was reporting the occurrence of similar deposits over wide areas of W. Europe.

Unfortunately, despite pioneer observations and despite the graphic description of earth-sculpturing processes in the Arctic brought back by travellers such as Sir Martin Conway, periglacial studies in Britain tended to stagnate after about 1890. Interest in the topic did not revive for another twenty years, and this time it was American, Scandinavian and German workers who led the way.

These men were inspired by visits to the Arctic, e.g. LEFFINGWELI (1915) and EAKIN (1916) in Alaska, HOGBOII (1914) in Scandinavia, ANDERSSON (1906) in the sub-Antarctic, and MEINARDUS (1912) in Svalbard, Their main contributions were to show how great masses of segregated ice could grow in the siil, to suggest how the action of freezing and thawing might cause differential sorting of fine and coarse material, to analyse the effects of frost on breaking up the rocks and to realise the great importance of mass movements on slopes. Subsequently, most progress in the study of contemporary periglaciation was made in the U.S.S.R. in the 1920s and 1930s when a special bureau of periglacial studies was set up. 
The interwar years also saw an increasing interest taken by engineers in the problems of soil mechanics induced by the growth of ice in the ground. This interest in Canada and U.S.A. was enormously stimulated by the problems encountered in building the Alaska highway. These defence needs are still one of the mainsprings of studies of contemporary periglacial phenomena.

Interest in the fossil periglacial phenomena found in regions which now enjoy a temperate climate also developed in Europe before the war, e.g. BREUIL 1934, but greatly increased during and after it. Since TROLI'S classic paper of 1944 there has been an ever-increasing stream of papers on the topics related to periglaciation in Europe, North America, and recently, Australasia. There is now a special journal 'Biuletyn Periglacjalny' published in Poland dealing with the subject in all its aspects. Great strides have been made in assessing the effects of periglaciation during the Pleistocene on the landforms and drift geology of middle latitude lands. It is now clear that periglaciation is as important for Europe as glaciation. Studies of the palaeoclimates of the cold phases of the Pleistocene, largely due to the efforts of German workers, have made considerable progress.

This very brief outline of the progress of periglacial studies does show up the fundamental division of interest between contemporary and Pleistocene phenomena. The field of the former lies in polar, sub-Arctic and mountain regions, the field of the latter lies mostly in 'temperate' latitudes.

Between these two fields lies a zone which until this decade had been little studied from the point of view of periglaciation. This zone was occupied by the great ice sheets of the Pleistocene in Europe and N. America. In Europe it includes North Poland, North Germany, South Scandinavia and North Britain. Until very recent years it was imagined that little or no periglaciation had taken place in this zone. e.g. DINES et al show periglacial solifluction deposits only outside the "Newer Drift" limit in Yorkshire. (DINES et al, 1940, figure 2). BUDEL (1949) has made a similar statement about $N$. Germany. It has now been shown that periglacial processes were active in this zone also, both during the advance of the ice and as it retreated. e.g. LEIVBKE (1954), SCHULT2 (1956) and JOHNSSON. 
At the same time, interest in the periglacial features to be found within the limits of the last glaciation has grown in Britain too. A survey of work published and in progress on Pleistocene periglacial phenomena in Britain made in 1955 neatly illustrates this change in emphasis. (FITZPATRICK 1956 a). As figure 1 shows almost all of the published work had been done S. of the limit of the maximum extension of the last glaciation, but a large part of the work in progress in the mid 1950s was being carried out $\mathbb{N}$. of this limit. This thesis is a further contribution to the study of periglaciation in a country which was ice covered during the maximum of the last glaciation.

It has been found convenient to retain the dichotomy betveen fossil and contemporary phenomena in this study of the periglaciation of Scotland. This division is unmistakeable in the case of certain types of cryoturbation - - ice wedges and involutions - - associated with former severe conditions and permafrost, but is sometimes less distinct in the case of frost shattering and mass movement where it is often difficult to draw a sharp distinction between fossil and contemporary phenomena. 
CHRONOLOGICAL FRAIVEWORK.

In The Netherlands and Central Europe it has been possible to produce an entire chronology of the last glaciation based mainly on periglacial data. (HAiven van der, 1952). This is not possible in scotland but a sequence can be built up from studies of glacial deposits and pollen analysis of peat.

The chronology to be followed here is illustrated in figure 2 and summarised in table 1. For North Britain as a whole it is based on SYNGE (1954 and 1957), CHARLESWORIH (1955) and DONNER (1957). The special terminology for North East Scotland is based on SYNGE (1956). From the point of view of periglaciation the critical stage is represented by the Loch Lomond Readvance - - Moor of Dinnett Readvance, coinciding with the short (5-600 years), sharp deterioration of climate known as Zone III in the pollen sequence. This was the last time that severe periglacial conditions prevailed in areas not shielded by ice or by the marine incursions associated with the late glacial raised beaches. Some guidance on the absolute chronology in years before the present is included in Table 1, based on the review of European literature published by WRIGHT (1957). The primary purpose of this chronological table is to provide a framework into which periglacial data can be fitted, but it can also furnish useful clues as to where periglacial conditions prevailed and their duration and possible intensity.

The sequence as a whole is one of glacial retreat, the ice sheet shrinking northwards from its maximum at the Newer Drift limit running from Yorkshire to S.W. Wales. This retreat was broken by phases of colder and/or snowier climate when the shrinkage of the ice was checked and readvances may have set in. The limits of the ice during these halts and readvances are not known with certainty, except in the case of the last readvance coinciding with the Zone III cold phase. Still less is known about the extent to which the ice disappeared in the less severe phases before each readvance. 
From figure 2 it will be seen that apart perhaps from restricted nunatak areas in the N.W. Highlands the longest period of periglaciation, lasting from before the Scottish Readvance stage, and possibly throughout the last glaciation, probably prevailed in 'Moraineless Buchan': this period must have been severe when ice still covered the rest of the country.

At the succeeding Perth Readvance - Aberdeen Readvance stage most of the central and southern parts of the country and considerable areas in the N.E. were ice free and exposed to periglacial conditions, although ahigh sea level may have shielded the ground along ice-free coasts. Between this stage and the preceeding Scottish Readvance it has long been believed that an intermediate readvance, the 'Lamnermuir-Stranraer' stage, existed. (CHARIESWORTH 1926). It is however, becoming apparent that this stage does not correspond to a glacial readvance but simply to a particular phase of retreat when a wide marginal zone of the ice went stagnant and wasted away in situ leaving a belt of kames and melt-water features. Accordingly, the 'Lammermuir-Stranraer' stage is not regarded in this study as marking a readvance of significance in the chronological sequence.

At the time of the Zone III (Loch Lomond - Nioor of Dinnett) readvance most of the country outside the Western Highlands and limited high areas in the east and coastal fringe below about 100 feet $0 . D$. must have been periglaciated. This phase was one of severe climate but did not last long. In Scotland it seems that tundra conditions continued to prevail for some time into the succeeding Zone IV (Preboreal) period. (DONNER 1957). After this time periglacial conditions in Scotland retreated to high ground and never reattained the severity reached during glacial times. The climate continued to fluctuate however, and there was a notable cool and moist phase in the Atlantic period, now more usually known by the pollen analytical term of 'Zone VII'. This cool wet phase may have helped to reactivate corrie glaciers in the highest hills and brought about a corresponding increase in periglacial activity, for a short time. It must not be forgotten that the comparatively mild periglacial conditions now found on hills in Scotland have prevailed for 10,000 years or so, considerably longer than the time 
that severe periglaciation lasted in ice free lowland areas during the Pleistocene. 
PART II

CRYOTURBATION

Cryoturbation presents the most unequivocal evidence for peri-glaciation, and in this section both fossil forms, associated with permafrost and intense cold, and contemporary phenomena are discussed. 


\section{ICE WEDGES AND ICE VEINS}

Although structures resembling fossil ice wedges and polygonal crack patterns are not unknown from warm semiarid and even from equatorial climates, (IANG 1943, FERMOR 1939) and from regions where solution can produce "pipes" in the subsoil, these have no connection with the Scottish wedges which are undoubtedly periglac:ial in origin.

The classic explanation of periglacial ice or frost wedges put forward by LEFFINGWELI in 1915 is still generally accepted. The examples he described from $\mathbb{N}$. Alaska were as much as 3 metres wide and 8 to 10 metres deep, and formed a polygonal network of "Tundra Polygons" averaging about 15 metres across. He suggested that the wedges formed in the following manner:-

The whole mass of the ground, active layer and permafrost to:gether, freezes solid in autumn and contracts in winter on account of the intense cold. This sets up tensional stresses relieved by brusque splitting along vertical cracks. Melt water in spring penetrates down these cracks and freezes to form veins of ice a few $\mathrm{mm}$. thick. The following winter the process repeats itself and the ground cracks along the same lines as before, admitting more water the following spring which freezes in its turn and so the ice mass gradually gets wider and wider year by year. IEFF:INGWEII suggested that the largest wedges might take as much as 1,000 years to develop.

TABER (1943) put forward the view that wedges grow by freezing of water already in the ground rather than by water descending 
from above, but this view has found little support.

The growth of such large ice bodies in the ground leads to displacement of the surrounding material. This takes place either by crumpling of the neighbouring material or uplift en masse of the entire area enclosed by the polygon. Recent descriptions of contemporary wedges are few, but BLACK (1953) has given some further details of examples in Alaska. He points out that they generally have inclusions of mineral and organic matter. Iike IEFFINGWEI he makes no genetic distinction between narrow ice veins and broad, long-established ice wedges. He makes the suggestion in another paper (BLACK 1952) that similar features can develop in sub-Arctic areas without the growth of an ice mass. The exact mechanism he envisages is unexplained, but perhaps he has in mind the possibility of material being washed into cracks in spring and there performing the same function as an initial ice vein by causing a zone of weakness which would re-open every winter, when the ground contracted.

Ice wedges disappear when the cold conditions associated with their formation pass away, but the structure may be "fossilised" by replacement of the ice body with material slumped in from above or from the sides. Such fossil features will simply be termed "ice wedges" or "wedges" in this study -- a rather loose but almost universal usage. Fossil wedges are widely distributed in what are now temperate areas in Europe and North America. Their presence is proof of the former existence of severe periglacial conditions 
with permafrost. A considerable amount of information on the growth, structure and disappearance of the original ice body has been gleaned from the study of these fossil examples exposed in sections.

These fossil structures can be classified according to I) size 2) shape, 3) nature of the infilling, 4) type of disturbance of the adjacent material, 5) genesis.

1) Classification by size groups wedges according to their depth and width. It is generally believed that the larger wedges corre:spond to colder conditions. (POSER 1948, DYLIK 1956b). GAII:WITZ (1949) has attacked this idea, suggesting instead that the larger wedges may have initially been quite small and grown up, pari passu with the surrounding material as it was deposited. IEFFINGWHL's classic original paper lends some suppor t to these views, but they have not been generally accepted, although recently SIBRAVA and KROUTIIIK (1957) have made use of them.

2) Classification by shape distinguishes between the narrow, un:tapered form of an ice vein and the tapered form of a wedge. Wedge forms can be grouped according to DYIIK (1956b) into a slender pointed class and a shorter broader class with blunt bottom, the former being found mainly in the frost tundra region of South Poland, the latter in the debris tundra region of North Poland.

3) Classification by the nature of the infilling contrasts wedges filled with locally derived material with wedges filled by material of non-local origin. Many of the wedges in Europe are filled with 
loess, wind-blown sand and ventifacts; the fine examples in York: shire discussed by DIMBIEBY (1952) contained a previously un:recorded suite of glacial erratics.

4) Considerable importance has been attached to the distinction of wedges according to the type of deformation of the surrounding material. POSER (1948) restricted the term ice wedge to those examples where the bedding of adjacent material was upcurled, and called those where the bedding was downslumped frost cracks ("Frost:spalten") formed in the course of a single season without the development of an ice body. LEHMANN (1948) and WEINBERGER (1944) have put forward similar ideas. GAIIWITZ (1949) on the other hand has suggested that upcurling takes place largely after the ice body has disappeared by the growth of ice crystals in a finegrained infilling of the wedge.

5) In view of the scanty knowledge of present day ice weages in the Arctic, classifications based on gentic differences believed to exist in groups of fossil wedges are to be deplored. DYIIK (1956a) claims to distinguish between "contraction wedges" and "expansion wedges", but the basis of his distinction is obscure. Ultimately a genetic classification may be possible. 
II. Identification of wedges in Scotland

The wedges in contemporary periglacial regions appear on the surface in the form of tundra polygons and can be readily identi:fied on air photographs of suitable scale. (BIACK 1952). In regions of former periglacial conditions this is rarely possible, though two cases have been identified in this way in England: near Oxford (ARKELI 1947) and on the North York Moors by DIMBIEBY (1952). In Scotland the writer has flown at low altitudes and speeds over wide areas in the central and southern parts of the country without detecting any trace of wedge patterns. Nor has examination of air photographs on a scale of c. 1:10,000 of areas where wedges were detected during ground field work revealed any trace of these structures. It is not known whether the failure to detect wedges on these photographs is due to their having no influence on the overlying vegetation, to a considerable depth of overlying soil, or simply to the small scale of the available photographs. It would seem that the vegetation would be little affected since the infilling of Scottish wedges is purely locallyderived, while in the case of the English examples mentioned, foreign material was probably involved, giving a different type of overlying soil and so rendering the structures as visible as a buried Roman encampment.

All the wedges studied in Scotland are therefore known only in section, and have been found by examination of natural and artificial exposures. 
When wedges were identified in a section, attempts were made to measure their depth and width, the direction of their axis and the thickness of overlying material. Notes were made of the nature of material surrounding the wedge, in it, and overlying it. Disturbance of adjacent material and the arrangement of stones in and near the structure were observed. Usually a sketch was made of the feature and a photograph taken. It was found that these structures were only to be seen in sands and gravels in scotland, best exposed in artificial pits and cuttings.

Wedges must be carefully distinguished from other structures not uncommon in such material. Faults and stone polygons in section can resemble wedges: in all three types of structure narrow columns of up-ended stone s occur. However, the columns widen downwards in the case of polygons but taper downwards in the case of wedges. There is also a distinct tendency for the material in a wedge to look as if it had slumped downwards while material in a sectioned polygon looks as if it had been squeezed upwards. (See figure 3). Furthermore, stone polygons tend to be found in groups rather than singly like wedges, or at least more closely spaced along an exposure. Wedges can be readily distinguished from faults by the displa cement of the beding on either side of the latter. Photograph 1 shows an example of a fault with pebbles along the fault plane clearly erected as in a wedge, but with displacement of the bedding on either side. 
From the point of view of periglacial studies confusion of faults and stone polygons with wedges is not a serious matter since all three indicate the presence of deeply frozen ground at the time of their formation. e.g. The gravels displayed in photograph $I$ are quite unconsolidated today but must have been frozen rigid to a depth of several metres at the time the dis:turbance took place.

More serious is the possibility of confusion between ice wedges and disturbance of sands or gravels produced by the thrust of overriding ice or the melting out of dead ice bodies. In a few cases no sure distinction could be drawn between disturbances produced in this way and those produced by periglacial processes. These cases were not included when listing wedges or involutions in Scotland, except in one case in Galloway. See figure 14.

The form of a fossil wedge as exposed in a section depends not only on its real shape and dimensions but also on 3 other factors. See figure 4.

1) If the face of an exposure cuts the axis of a wedge at an angle more acute than about 50 degrees, only a vague disturbance is to be seen. In the case of very narrow wedges this angle of intersection can be more acute without concealing the nature of the structure. Some recorded descriptions of wedges do not seem to take sufficient account of such elementary considerations. About half the wedges exposed cannot be identified for sure be cause of this difficulty. The position is complicated by sloping exposure faces and oblique wedges. 
2) The point where the section cuts the wedge can profoundly affect the apparent depth of the structure. Wedges described by PATERSON (1940) from near Cambridge had the shape of a narrow canoe, a shape that seems typical of these structures. If the section cuts the wedge near the "bow" or the "stern" of the canoe, it will appear to be a smaller structure than if sectioned "amid-ships". See figure 5 .

3) Material may have been removed by erosion, or artificially, from the upper part of the wedge, reducing its apparent size. This factor may have operated to a considerable extent, but in the case of erosion there is no means of assessing its effect. Accurate measurement of wedges is hindered also by uncer: tainties as to their depth and width. The full depth is often not visible and can only be estimated roughly by estimating at what depth the tapering sides of the structure would meet in a point. The wedge itself may only be the upper, widened-out part of a crack extending several metres deeper as can be seen in Figure IA in COMMON and GAIIOWAY (1958) for instance. Such cracks were ignored in measuring the depth of a wedge. In sandy material, the margins of a wedge are usually clear-cut but in gravels the material on either side of the structure have often slumped downwards making it hard to decide the exact width of the feature. The uppermost part of a wedge often flares out: wards and breadth measurements were taken just below this flaring. 
In consequence of these difficulties, the dimensions of wedges are given only approximately in this study. A brief description will be given of a number of wedges known in Scotland and the information summarised in Table 2 .

\section{Description of wedges}

The first record of wedges in scotland is to be found in a paper by ANDERSON (1940), He described two examples observed in sandpits near Roslin, Midlothian, 6 and 10 feet deep and $2 \frac{1}{2}$ and 1 feet wide respectively. This is also the earliest record in Europe of these structures within the limits of the last glaciation, as far as the writer knows. The wedges were rather unusual in that they were filled with and overlain by till. Although CARRUTHERS claimed that these structures were due to postglacial cold conditions striking down through the overlying till, his views carry little conviction and there is no doubt that the wedges formed in an interstadial phase when the ice withdrew temporarily as ANDERSON suggested. (CARRUTHERS and ANDERSON 1941, 1942).

Recently COMMON and GAIIOWAY (1958) have published des: criptions of seven other wedges observed in sand pits in this area between 1952 and 1957. These wedges were from $2 \frac{1}{2}$ to 8 feet deep and 6 to 24 inches wide. They were exposed in this area.

FITZPATRICK (1956a) has briefly mentioned 5 wedges seen in Northeast Scotland:- 2 small wedges about 1 metre deep in Iower 
Deeside observed by SYNGE (c.f.SYNGE 1956), and a single minor example in gravel near Edzell aerodrome. GAIIOWAY is also mentioned as having seen 2 wedges in the Strathbogie district of Aberdeenshire: fuller details of these two are given below. Geological Survey photograph No. C 4231 shows ice vein structures cutting sands and gravels in Broomhouse gravel quarry, Lanari.

In addition to these 15 recorded examples further field work has now revealed 86 more examples in many different parts of Scotland. These will be listed according to their location, working southwards along the East Coast and then over Central Scotland to the West. Dimensions are given in metres. Beauly area. In a large gravel pit $3 \mathrm{~km}$. SW of Beauly, where the river Beauly debouches from the hills, two wedges were ex:posed. One was fully 3.50 metres deep and $80 \mathrm{~cm}$ wide and was filled with a mixture of brown clay and the neighbouring sand and gravel. See photograph 2. The clay appeared to be a weathering product derived from the local sand; its presence suggests that soil formation had gat under way before the ice body melted and some of the enriched B horizon was washed into the void left by the ice. Alternatively, postglacial chemical weathering pro: ceeded much more readily within the wedge than outside it. The other wedge was only partially visible but seemed of comparable size. These wedges were unique in scotland in occurring in coarse gravel, with individual stones up to $15 \mathrm{~cm}$ long.

Two smaller wedges, 1.50 and 0.80 metres deep could be seen in a pit on the east side of the main road, $4 \mathrm{~km}$. N. of Beauly. 
The material exposed in both pits is marked on the $I^{\prime \prime}$ Geological Map as part of the highest raised beach, but undoubtedly OGILVIE (1923) is nearer the mark in describing this material as a glaci-fluvial outwash spread since it contains kettle holes and is cut into by the true raised beach at an altitude of about 85 feet, slightly lower than its own height of 90 to 100 feet. The material in the outwash spread is fine towards the seaward margin but becomes coarser as one traces it up the valleys, especially in its upper layers. The outwash must be of late glacial age, possibly Zone III.

Aviemore area. In a sand pit by the main road between Carrbridge and Aviemore the wedge illustrated in figure 6 was observed. The material has been deposited by glacial meltwaters in the form of a low kame or kame terrace, and passed downwards from gravel and coarse sand to sand with clay bands. The coarser beds were slightly downslumped against the margin of the wedge, but the finer sand with clay bands could be seen to be crumpled and contorted at the edge of the structure. This was the sole wedge observed within the Highlands proper and must be of late glacial age.

Elgin area. In a gravel pit opposite Quarry Hill, some $3 \mathrm{~km}$. $W$ of Elgin a single wedge about 2 metres deep and 0.30 metres wide was observed. It occurred in the part of the exposure where the finest gravel was to be seen. The material, like that at Beauly, is probably late glacial outwash. 
Strathbogie area. One wedge was found in a gravel pit at Ruthven, a few km. N of Huntly. The gravel had been laid down as a fan by glacial melt waters coming from the west through the deep Den of Pitlurg spillway. Depth of the wedge was 3 metres, maximum width $40 \mathrm{~cm}$. The infilling was identical to the sur:rounding gravel, except that most stones were on end or on edge. Neighbouring bedding was slumped down towards the wedge. Other periglacial structures, discussed below on page 61 were found in this exposure.

The upper part of a wedge was seen in a small gravel pit in a kame between Rhynie and Lumsden to the S. of Huntly. This kame had been laid down at the margin of a tongue of ice extending down Strathbogie from Donside. The depth of the structure could not be determined.

Garioch, Aberdeenshire. A single wedge was observed in a terrace of fine gravel at Pitcaple in the Ugie valley. Only the uppermost part of the structure could be seen.

Buchan. A striking assemblage of wedges was noted in this area where 26 wedges were found.

At South Tarwathie, $3 \frac{1}{2} \mathrm{~km}$. N. of Strichen, two pits exploit the sand and gravel of kames which mark the local southward limit of the Moray Firth glacial stage, the last to reach this area. (SYNGE 1956, CHARLESWORTH 1955). In 1956 in one pit 8 wedges could be seen and 3 in the other. They were of 
variable size, from $70 \mathrm{~cm}$ to 3 metres deep and from 15 to $70 \mathrm{~cm}$ wide, although most were of the larger size. It was apparent that they formed a network in plan with wedges intersecting each other, but this plan could not be deduced from the available evidence. The infilling consisted of sand and erected pebbles from the local gravel. The bedding of surrounding material was slightly slumped downwards at the margin of most of the structures. At Denhead, $6 \mathrm{~km}$. SE of Strichen, seven sand pits exist in a broad sloping terrace on the $N$ bank of the Ugie. Several of these are slumped and abandoned, but others give fresh exposures of the material which is probably outwash connected with the Moray Firth ice. Wedges were observed in three of these exposures, extending as is usually the case in Scotland downwards from just below the $B$ horizon of the soil. In coarse gravelly material there was some trace of slumping of the neighbouring bedding, while wedges in sand cut off the stratification more cleanly. 2 of the 11 wedges seen here had a twisted appearance caused presumably by lateral pressures from the surrounding material. See photograph 3. The wedges were 1 to $2 \frac{1}{2}$ metres deep.

At Rora Bridge, $9 \mathrm{~km}$. W of Peterhead, a wedge 2 metres deep by $40 \mathrm{~cm}$ wide and a narrower crack-like structure of the same depth could be seen in 1956. In a small sand pit $1 \mathrm{~km}$. to the N. a very small wedge $60 \mathrm{~cm}$ deep by $10 \mathrm{~cm}$ wide could be seen in 1958. Both these pits were exploiting material in a terrace of the Ugie probably of the same origin as those previously mentioned at Denhead. 
Just east of Ellon a gravel pit has been opened in a terrace of the Ythan about 50 feet above sea level at this point. The pit had transected a wedge 1.80 metres deep which could be observed on two faces some 15 metres apart. See figure 7. This was one of the few cases where the elongated nature of these features in Scotland could be demonstrated. The terrace con:tinues eastwards into the terrace at the mouth of the river mentioned by SYNGE (1956) as having fossil stone polygons.

A statistical study was made of the orientation in the horizontal plane of 50 stones on end or on edge within the wedge. The average orientation agreed with the direction of the continu:ation of the wedge on the other side of the pit. See figure 7. This offers a new means of determining the direction of trend of a wedge visible in vertical section only. Northeast Strathmore. The floor of Strathmore is littered with sand and gravel accumulations resulting from the wasting away in situ of dead ice and from the outwash of glaciers that descended the Highland valleys. Several wedges have been noted in these a ccumulations.

South of Auchinblae, Kincardineshire, a large delta has been built out into what must have been an ice-dammed lake in that part of Strathmore by melt water issuing from the large channel behind Strathfinella Hill. The delta has been dissected since its for:mation, but important remnants, each with a gravel pit, survive on both sides of the present stream. The gravel pit on the $W$ has 
no wedges, but four were observed in the eastern exposure. Only one of these was fully visible and it proved to be about 3.50 metres deep and $60 \mathrm{~cm}$ wide and filled with local sand and gravel together with a little brown clay, possibly a weathering product. At the margins of the structure the beding was downslumped.

On the east side of Edzell Golf Course, just inside Edzell Wood, a sand pit has been opened in a flat-topped ridge some 3-5 metres high at this point. SYNGE (1956) has mapped this ridge as a terminal moraine of a glacier descending Glen Esk, but it is more likely to be a narrow remnant of an outwash fan from this glacier reduced to a ridge by lateral erosion from the west water and the Esk. The wedge was nearly 4 metres deep and $70 \mathrm{~cm}$ wide. Most of the infilling was derived from the material on the sides of the structure but as figure 8 shows, some of the overlying gravel had penetrated right to the bottom of the wedge along the centre in a narrow belt of erected stones. The true margins of the wedge were indicated by a thin lining layer of clay derived from the neighbouring sand which contained a few clay bands. Central Strathmore. A couple of wedges were seen in gravel pits in kames a few $\mathrm{km}$. E of Forfar. One of these, illustrated in photograph 4 was 2 metres deep and $25 \mathrm{~cm}$ wide. In appearance, dimensions, and nature of material it may be regarded as typical of wedges in Scotland, although rather more down-slumping of adjacent gravel is usually to be seen. The dimensions of the other wedge could not be ascertained. 
In passing it may be mentioned that although no wedges were seen in a gravel pit near Kinnel in the same area the manager did describe narrow fissures 2 to 3 metres deep and 30 to $50 \mathrm{~cm}$ wide which had not uncommonly been exposed in the upper layers of gravel. From his description these are probably wedges.

The upper part of a wedge was observed in well bedded sand and gravel at Iogie, $9 \mathrm{~kW} \mathrm{~W}$ of Forfar. The structure had a narrow lining of clay but was mostly filled with gravel. Kinross area. $\quad 3 \mathrm{~km}$. S of Kinross a gravel pit lies between the Edinburgh road and the railway. Three small wedges were observed in this exposure. Two of them were about $I$ metre deep and $5 \mathrm{~cm}$ wide; a bulldozer had removed the upper part of the third wedge which was probably initially no bigger. See photograph 5. Iron staining extended downwards in a narrow band for a further 30 or $40 \mathrm{~cm}$ below one of these wedges, giving the impression it was deeper than was in fact the case. Apparently the wedge with its filling of erected stones offered a favourable route for the downward percolation of ground water. CF. GOLAB (1956) has described how fossil wedges form favoured routes for the downward percolation of ground water in Poland. Traces of involutions periglacial wind action were also found in this pit and will be described below. (Chapter $\mathrm{X}$ ).

Kincardine (Fife). A very small wedge, $60 \mathrm{~cm}$ deep and only $4 \mathrm{~cm}$ wide was noted in a sand pit in a kame some $3 \mathrm{~km}$. NE of the town. It was unusual in being oblique rather than vertical. 
Midlothian. Two further wedges have recently been observed in this area. In a sand pit $3 \mathrm{~km}$. SW of Bonnyrigg a wedge could be seen cutting through current bedded sand and a lens of gravel. The infilling of the wedge was derived from the surrounding material, and unlike all other known examples in Midlothian there was no till overlying the sands and gravels. It could not be determined if this was because the gravels dated from the final retreat of the ice in the area or because a former till cover had been removed by erosion -- the site is a sloping one where such erosion could well be possible. Periglacial involutions, described below in chapter $V$ were also noted in this exposure.

Straiton sand pit exposes well-bedded sands and silts overlain by 1-2 metres of till. In the upper part of the sand a narrow wedge ran obliquely downwards to a depth of 2 metres. It tapered from a width of $10 \mathrm{~cm}$ at the top to a point and was lined by a $5 \mathrm{~mm}$ thick layer of clay. The centre was filled not with the overlying till but with sand. The uppermost part of the structure had been removed.

Reston, Berwickshire. At Reston the Eye water has undercut its $s$. bank exposing 3 metres of gravel overlain by $3 \frac{1}{2}$ metres of till with well striated erratics, overlain in its turn by 1 metre of fine gravel. See figure 9. Two wedges were noted in the lower gravel. The larger, whose full depth was not exposed, must have extended to a depth of at least 3.5 metres and was $70 \mathrm{~cm}$ wide approximately, e.lthough no exact estimate could be made since the adjacent gravel 
beds were heavily slumped downwards. See photograph 6 . The smaller wedge was 1.20 metres deep and $30 \mathrm{~cm}$ wide.

Both were filled with gravel identical to that which surrounds them, a high proportion of the stones in the infilling being on end. These wedges are nearly unique in scotland in that they occur within the body of the gravel rather than at the top. i.e. Their forma:tion was completed while the gravel, probably a glaci-fluvial deposit washed out of ice lying to the north in East Iothian, was still in course of deposition.

Bathgate. Old sand and gravel workings have almost entirely removed a kame on the edge of Bathgate golf course, but some of the deposits are still to be seen in a section on the southern edge of the site. Figure 10 and photograph 7 show the nature of this wedge. It was difficult to decide where the lower end of the structure lay since towards the foot thin clay bands could be traced right across what was apparentzy the wedge and these bands continued in the undis:turbed sand on either side. Where they crossed the wedge they were heavily distorted and crumpled, but still recognisably continuous.

Carstairs. The origin of the gravel and sand mounds in the Car:stair-Carnwath district has attracted much attention. In view of the high proportion of Southern Uplands erratics in the material the structure has often been ascribed to a glacial advance from that area, although the deposits are very much coarser towards the northward edge of the mounds. 
Several sand and gravel pits were examined in this locality. A single wedge was observed in Auchenlea pit, $1 \mathrm{~km}$. $\mathrm{N}$ of Carstairs. It was $15 \mathrm{~cm}$ wide and fully $1.20 \mathrm{~cm}$ deep. See photograph 8. This wedge is notable in that it occurred in deposits of the same general age and predominantly Southern Upland origin (MCCALI and GOODLETT 1952) as the sands and gravels around Dolphinton which COMMON and GAIIOWAY (1958) erroneously suggested were deposited after con:ditions suitable for wedge formation had passed away. No wedges were to be seen in sand pits to the south of Auchenlea, but the sand was heavily faulted as if it had at one time been cracked while frozen rigid.

Kelvin Valley. North of Glasgow several large sand pits provide excellent sections of the upper Pleistocene deposits on the southern margin of the Kelvin valley. The sections exposed in these pits were broadly similar and consisted of 50 to $100 \mathrm{~cm}$ of irregularly bedded sands and gravels - not always present - overlying red till full of striated Highland erratics, 2-6 metres thick, underlain in turn by as much as 7 metres of current bedded sands, silts and gravel, which it has been suggested were laid down in an ice dammed lake. (CLOUGH et al 1925). They have furnished a rolled fossil of wooly rhinoceros. (HLETT 1927). The existence of disturbances of an unusual kind in this sand and gravel has long been known. In 1937 ROBERTSON and HAIDANE mentioned "dyke-like structures" in pits at Cadder and Bishopbriggs. One of these ran roughly 300 yards with an average width of 18 inches: it was filled with 
sand grains firmly bound with manganiferous material. Heretofore these disturbances have been ascribed to overriding by the ice which deposited the overlying till. Re-examination in the field has shown that in fact many can better be explained on a hypothesis of a periglacial origin. The involutions noted will not be dis: cussed here but in chapter $V$.

In Keir and Cawdor No. 3 pit, 1 mile south of Balmore, the remarkable structure illustrated in figure 11 and photograph 9 was observed. It was near the top of the sands and silts but was capped by a discordant layer of gravel which in its turn must have been overlain by till before its removal in the course of working the pit. The structure as a whole might be ascribed to the melting out of a small ice block left in the glaci-fluvial deposits, and the contorted bedding within and to the left of the structure might be ascribed simply to slumping into the resulting void. Altematively, the structure could be explained as the infilling of a gully that once cut the sands. But both these explanations fail to account for the clay-filled seam $\mathrm{X}-\mathrm{X}$ which runs parallel to the bedding at some points and transects it sharply at others. It is an element alien to the sedimentary sequence introduced later from above. It could not have been introduced by the direct pressure of overlying ice since a layer of gravel is inter:posed between the structure and the till. The most likely origin for the seam $X-X$ is that it is a replacement of a former ice vein. The separation of the lower part into distinct fingers would be in accord with this idea as is the narrow belt of involutions which 
margin the seam. See photograph 10. Nearbye there is independant evidence that the sands were once frozen to a depth of at least 7 metres, as the bedding of the sand is abruptly cut off by a verticalwalled channel filled with gravel. As there is not the least sign of slumping at the sand/gravel contact it is reasonable to assume that the former must have been frozen solid when the channel was cut.

The detailed structure of this presumed fossil ice vein con: sists of narrow clay bands altemating with sand probably derived from the surrounding material. If the seam $X-X$ is inderd a peri: glacial structure it is not unlikely that the entire disturbance as a whole is the trace of a former very large ice wedge: this cannot be decided on the available evidence.

An equally impressive wedge-like structure was observed in an abandoned sand pit $I \mathrm{~km}$. to the east on the $\mathrm{N}$ side of the Forth and Clyde canal. This pit shows the same sequence of red till overlying well bedded sands, silts and gravels. The till itself shows signs of structures resembling ice veins but no definite identification could be made. The structure occurred in the sands and gravels: the upper part had been removed and the lower part was not visible. See photograph 11. The total original depth of the structure cannot have been less than 5 metres. The maximum width visible was $60 \mathrm{~cm}$. The structure was not quite vertical, but the sloping face of the section has much exaggerated the apparent obliquity in the photograph. The infilling includes packets of the surrounding material not greatly displaced. Faulting 
has played a part as well as the growth of an ice body in the development of the structure since there is a slight displacement of the beds on either side of the wedge; ef. figure 13 for another example in this pit of the conversion of a fault into a wedge.

Several true faults were seen in the sand elsewhere in this pit often with stones neatly erected along the plane of movement. Displacement must have taken place while the material was frozen rigid, otherwise such sharply derined faut planes could hardly have developed in unconsolidated material. A vertical clayfilled ice vein about $5 \mathrm{~cm}$ wide and at least 4 metres deep (see photograph 12) was also observed in this exposure, together with a further two small wedges in the body of the glaci-fluvial sands. Periglacial conditions must have prevailed during the deposition of these sands and after deposition had ceased.

4 ice veins of unknown depth were noted in an abandoned sand pit just across the Forth and Clyde canal from this section. In accordance with the usual occurrence in this district they were found in sands overlain by red till. Periglacial involutions discussed below in chapter $V$ were also noted in this section. The sequence of events in this district seems to have been as follows:-

1) Outwash sand and fine gravels perhaps with included blocks of dead ite were laid down under cold conditions. A few wedges developed in the body of this deposit as it accumulated.

2) The sands and gravels were subjected to still more severe climatic conditions leading to the development of ice veins, ice 
wedges and faults, all extending from the top of the deposit downwards. i.e. They formed after the deposition of the sands. 3) The sands were partially eroded while still frozen and coarse gravels laid down unconformably over them.

4) Ice advanced over the area from the Highlands and deposited the overlying red till.

5) The ice retreated and the scanty overlying gravels were laid down as outwash or by the River Kelvin. Periglacial conditions again prevailed during this phase as is indicated by traces of ice veins and other disturbances in the upper till.

Strathaven district. In western Lanarkshire a notable belt of glacifluvial deposits extends along the valley of the Avon water and terminates near Loudon Hill in a mangificient ice-contact face. The sands and gravels have accumulated in a lake held up by stagnant decaying ice. (RICHEY et al 1930). Several sand and gravel pits expose good sections in these deposits and in many cases the ex:posures revealed an abundance of ice wedges and other cryoturbation phenomena.

In Drumclog pit 9 wedges were recognised for certain, together with 7 possible ice vein or crack structures. The wedges were narrow, hardly wider than the cracks. They were from 1.4 to 2.6 metres deep. See photograph 13. One wedge could be seen on both sides of a trench some 12 metres wide, so its length must have been greater than this. The infilling of the wedges was strictly of local material. Marked downslumping was apparent only at the margins of a few of the wider examples. 
The cracks on the other hand were only some $60 \mathrm{~cm}$ deep, occurred near, but not at the surface and displayed a slight relative dis: placement of the material on either side in some cases. They can best be explained on a hypothesis advanced by SIBRAVA \& KROUTIIIK (1957):- in autumn the rigid frozen upper layer of the ground is fractured by the pressure of water trapped between it and under:Iying permafrost. other forms of cryoturbation, discussed in the chapter on involutions were noted in this exposure.

In Stoneyford pit 3 small vertical structures, about 1 metre deep - probably wedges - were noted at the top of an exposure of sand and gravel.

In Avonside pit 3 wedges were seen. One was visible for most of its depth and cut well-bedded sand and gravel. Similar material formed the infilling, incoherently arranged in the upper part but having some $80 \%$ of the stones erected in the lower portion. As usual, adjacent gravel layers were slumped downwards, while sand layers were cut off cleanly.

Two small wedges about 1 metre deep and 6 to $10 \mathrm{~cm}$ wide were exposed in a sand pit at Iarkhall, near Stonehouse. Clay seams in the adjacent fine sand could be traced, heavily contorted, into the wedges. See photograph 14. Both had a rather rounded bottom, though one was continued downwards by a vague crack. DYIIK (1956b) has claimed that this form represents the work of less severe, late glacial conditions, but as far as Scottish wedges are concerned it 
has no special significance. It could be clearly seen how these wedges had acted as channels for the downward penetration of ground water as the sand below them was damp and discoloured by iron com:pounds. cf. HOIIINGWORTH commenting on a paper by PATERSON (1940) mentions that water was seen to be passing readily down wedges in The Midlands.

In whitehills gravel pit near strathaven an indistinct crack 3 metres deep was observed. It was probably of periglacial origin. Newton Stewart area. In the course of a rather hurried tour of SW Scotland three wedge-like structures were noted. All were partially obscured by debris and could well have been fault, slump, or even ice thrust structures. In view, however, of the long-established presence of these features across the North Channel in Northern Ireland, it is highly likely that genuine wedges do exist in that part of Scotland. (KIIROE in WIIKINSON et al 1908).

9 or $10 \mathrm{~km}$. SE of Newton Stewart a bench-like feature runs along the hillside 60 to 100 feet above the sea. This bench, which might be a denuded remnant of a raised beach but is more likely to be an ice margin feature, was built of disturbed and contorted gravel. A section, sketched in figure 14 revealed coarse ill-sorted gravel with contorted lenses of sand and a wedge-like structure in which the pebbles stood on end.

At Challoch, $3 \mathrm{~km}$. N of Newton Stewart a gravel pit in a kame or terrace fragment showed what appeared to be the upper portions of two wedges. Unfortunately, the exposure was very slumped and unequivocal identification was not possible. 
IV. Formation of the wedges

None of the wedges observed in Scotland conflict with LEFF:INGWEI's theory of the origin of these structures. The idea that it was surface wash rather than ice which accumulated in cracks of thermal contraction may be discounted as the stones infilling the fossil wedges in Scotland are much too large to have been able to penetrate down the narrow openings produced by this contraction. There can be no doubt that all the scottish examples contained an ice body at the time of their initial for:mation. Only the wedges at Reston, Berwickshire could perhaps be cited in support of GALIWITZ's idea of upward growth of the ice body pari passu with the sedimentation. It is not possible to believe that this process is important in wedge development, because many more of the Scottish examples would in that case be found within, rather than at the top of, sedimentary material. It is apparent that wedges in this country developed in almost all cases after deposition of the surrounding material had ceased. Many of the ice bodies must have had inclusions of mineral matter derived from the adjacent material, and these inclusions have been in some cases preserved, as in some of the structures seen in the Kelvin valley. The growth of the ice body seems in many cases to have favoured extra intense cryoturbation in a narrow zone immediately beneath -- many wedges in fine material continue below in the form of a narrow zone of contorted but unbroken clay 
and sand layers. e.g. The wedges near Bathgate, Aviemore and Stonehouse, Strathaven. Presumably surface water passed downwards more readily along the wedge leading to a local water enrichment and increased cryoturbation immediately beneath.

All wedges in Scotland have an infilling of local origin deirived from adjacent or overlying material. When the ice body melted its place was taken by material from the sides or washed in from above. FIINT (1957) states that ice wedges disappear by . downmelting from the surface while PATERSON (1940) suggests that melting inwards from the sides may be important.

The relative importance of contributions to the infilling from above or from the sides depends on the way the ice melted and on the coherence of the material transected by the wedge. Downmelting of the ice body would favour replacement by material from above, while melting inwards from the sides would favour replacement by neigh:bouring material and the development of a lining layer to the structure as PATERSON suggests. In most cases melting was a com:bination of both processes as most wedges contain a central core of material derived from above and a lining, of varying width derived from the sides. The lining layer is usually thin if made of fine material like clay but broader if made of sand.

Where a wedge has passed through layers of contrasted cohesive:ness the greater part of the infilling is derived from the less coherent layers. Thus clay, silt and sand layers tend to be cut off cleanly against the edge of a wedge while gravel layers are 
slumped downwards into it. Only when the clay or sand was near the surface and therefore liable to become incoherent when final melting started did it contribute much to the inflling or show signs of downslumping.

The absence of upcurling at the margins of scottish wedges, except for a single case in Nidlothian mentioned by COMMON \& GAIIOWAY, is not because they were formed as "Frostspalten" in PCSER's sense (see page 22 above), but is because of the fairly coarse material in which they occur. This coarse material favoured downslumping of the margins when the ice body melted, destroying any upcurling that may have existed. Also the coarse grain of the infilling inhibited the development of lateral pressure within the infilling by cryoturbation after the initial ice body had melted. The Scottish evidence conflicts with POSER's ideas on this point.

The concentration of Scottish wedges in what must have been some of the driest sites in the tundra - terraces and kames - con:flicts with IEFHINGWEI's description but agrees with ROZYCKI's observations in spitsbergen. (1957). The former specifically stated that in the area he investigated wedges only occurred in "muck" a mixture of fine-grained organic and mineral matter, and were absent in silts, sands, gravels and soft shales. The latter emphasises their frequence on dry sites where insulating snow cover would be thin. In East Greenland tundra polygons, pre: sumably underlain by ice wedges, tended to form on sandy and gravelly raised beaches and deltas. 
This concentration of wedges in relatively coarse material may not be genetic and may be more apparent than real since there are few exposures in Scotland of fine grained material that might have been exposed to the severe periglacial climate needed to form wedges. COMMON (1954) has mentioned a possible wedge in lateglacial clays in Northumberland.

After infilling of the wedges was completed and with the advent of milder postglacial conditions modification of wedges had continued by pedological processes. As pointed out above (page 43) ground water percolates more readily down through wedges than elsewhere and this speeds up chemical processes within the structure leading to a concentration of clay minerals and sometimes to a light cementing. of stones by iron and manganese compounds. The clay and the cement:ing make wedges slightly more resistant than the surrounding material and so they tend to stand out a few $\mathrm{cm}$ from the face of sections which have been left to the weather, untouched, for a few years. This is an almost universal feature in scotland.

\section{Distribution}

Until many more potential sites have been examined, particularly in SW Scotland and in the Highlands it is difficult to draw sound conclusions. Nevertheless a few broad statements are permissible. The distribution of known wedges in Scotland is shown in figure 16. 1) Wedges occur throughout the country outside the Highlands and Islands and the Southern Uplands. The solitary wedge near Aviemore 
is a surprise in this connection and serves as a reminder that the rarity of wedges in these areas may well be a reflection of less field work, predominantly coarse material, and few good sections. Even the Aviemore wedge, however, lies outside the limits of the Zone III glacial stage as indicated by CHARLRSWORTH (1955). 2) Four main groups of wedges exist:- around Edinburgh and Glasgow, in Buchan and in the Strathaven district. These con: centrations are not only the consequence of a large number of suitable sections having been found in these areas, associated with industrial demands for send and gravel, but also reflect the existence of a higher proportion of exposures with wedges. About 1 exposure in 3 in these areas has wedge structures, whereas else: where the proportion is more like 1 in 10. The concentrations near Glasgow and Edinburgh underlie glacial till and may be a relic of a landsurface once exposed to an especially severe periglacial climate. The concentration in Buchan may be the consequence of an ice free area here during much of the last glaciation, but the existence of an equally striking group in Strathaven suggests rather that the cause is lithological, not climatic: in both districts the glacial deposits in which the wedges occur are predominantly sand and fine or medium sized gravel. Coarse gravel which seems to inhibit wedge development is rare, but where it does occur in these areas, wedges are absent. e.g. No wedges occur in a gravel pit in Loudon Hill only a short distance from sections in finer gravel having abundant wedges. 
It is the coarse nature of the material rather than any climatic cause or protection by dead ice which accounts for the absence of wedges in all the numerous gravel pits around Doune and around Denny .

3) Wedges overlain by till are confined to an E-W belt from Reston to Glasgow. There is admittedly no proof that these wedges are strictly contemporary, but they do suggest that there was an important interstadial stage when ice vacated Central Scotland only to returm and deposit the overlying till. During this interstadial phase which perhaps preceeded the Scottish Re:advance or the Lammermuir-Stranraer stage, periglacial conditions prevailed in Central Scotland. Since no cases of wedges under till are known elsewhere presumably the rest of the country was still shrouded in ice during the interstadial.

4) There was no apparent climatic contrast between the $E$ and $W$ of the country. Doubtless the former was a little more 'continen:tal' than the latter and had a thinner snow cover and colder winters, but the difference has not apparently been sufficient to affect wedge development. The rarity of wedges in the $\mathrm{SW}$ is more readily explained by the few suitable sections seen in that area than by a hypothesis of oceanic amelioration of the climate. 5) The distribution is overwhelmingly lowland. All occur below 800 feet and almost all below 400 . This may be a reflection of climatic conditions during the glacial/periglacial phases of the 
Pleistocene when the existence of intense temperature inversions has been suggested. (MORTEIVSEN 1952, 1956). On the other hand it is just as likely to be a consequence of the greater number of good exposures visible at lower altitudes:

6) There is little sign of significant regional groupings by size. In every area small wedges no more than a metre deep occur with larger wedges 3 metres deep or more. only in the case of the group $\mathbb{N}$ of Glasgow is there perhaps a significant concentration of large structures, deeper than 4 metres.

\section{Dating}

Wedges cannot be older than the material in which they occur nor younger than overlying deposits. CARRUTHER's (1941) conten:tion that they can form under till after disappearance of the overlying glacier carries little conviction. As wedges in scotland occur in stratified drift of glacial origin it is possible to date some of them in relation to the glacial sequence outlined in chapter III above. Unfortunately dating in this way at this stage of knowledge precludes the use of the method in reverse:- the glacial sequence cannot be dated from the presence of wedges without running the risk of arguing in a circle. In most cases it is possible only to give the maximum possible age, but not the actual age relative to the sequence. The suggested datings are shown in figure 15. 
The oldest wedges known in Scotland are those found under till in the Central Iowlands. They may date from before the Scottish Readvance stage and it is significant that the largest wedges in the country occur here. All other wedges in Central scotland must post date the Scottish Readvance stage, as they occur in sands and gravels laid down at the time the last ice sheet to cover the area was disappearing.

Although "Moraineless Buchan" may have been ice free for the entire duration of the last glaciation (SYNGE 1956), no wedges of an age comparable to those round Glasgow and Edinburgh are known. All the wedges occur in material of glacial origin formed at the margins of the area during the Moray Firth-Strathmore glaciation, and must therefore be younger than this stage. Similarly all the wedges in Strathmore must be jounger than the Strathmore glaciation since they occur in deposits laid down during its retreat.

A late glacial age, probably Zone III, must be assigned to the wedges at Ellon, in a terrace graded to a late glacial sealevel well below 50 feet, at Elgin and Beauly in glacial outwash likewise probably related to a late glacial sea level, and at Aviemore in a district which must have been ice covered until the Aller $\phi$ d retreat.

These late glacial wedges are significant proof of the con:tinuation of severe climatic conditions in scotland right till the close of the Ice Age, even in a markedly "oceanic" situation. The presence of these wedges support the interesting evidence 
put forward by FITZPATRICK (1956b) for permafrost in scotland in late glacial times, and the data from pollen analysis which reveals a very poor flora even in the relatively mild Allerdd interval. (DONNER 1957).

Half a century ago KILROE (1908) realised that late glacial outwash in Northern Ireland had been deeply frozen. Nuch more recently evidence has been accumulating that severe conditions on the Continent lasted till late glacial times. (HAMMEN, van der 1951, 1952; DUCKER 1954; IEMBKE 1954; PIERSCHAIKO 1956). SOME of these writers e.g. DUCKER (1954) doubt if there were actually permafrost at this time, but the Scottish evidence leaves no doubt on this point. Permafrost prevailed in scotland as recently as 10,000 years ago, during Zone III times.

\section{Summary of conclusions}

1) Fossil ice wedges are not uncommon in Scotland: about 100 examples are now known. They provide unequivocal proof that periglacial conditions with permafrost have prevailed over wide areas of the country at one time or another.

2) The wedges are found in areas beyond the limits of the Zone III glacial readvance. Without further field work it cannot be stated categorically that they do not also occur within these limits.

3) They range in age from an interstadial phase of the last 
glaciation down to Zone III times. Permafrost and severe peri: glacial conditions therefore prevailed in Scotland till the very close of the Ice Age.

4d The presence of the oldest and largest wedges in Central Scotland under till, is evidence of an important interstadial phase followed by a readvance of ice from the Highlands (Glasgow area) and the Southern Uplands (Midlothian area). During this interstadial a harsh periglacial climate prevailed, since some wedges are actually found within stratified deposits laid down at this time.

5) Apart from the group of wedges and other structures found $\mathbb{N}$ of Glasgow there is no evidence for significant differences in size between groups of wedges formed at different times or in different places. Some wedges formed probably in zone III times (Beauly) are as large as those which could have been formed earlier when conditions were presumably more severe. In central and southerh Scotland wedges are as large and well developed in the west as in the east.

6) The permafrost associated with the wedges must have been at least 7 metres deep at the time the structures under till were formed. It may well have been much deeper.

7) Wedges occur most commonly in sand and fine to medium sized gravel.

8) The frequent downslumping of strata at the margins of scottish wedges is a consequence of the incoherence of the material and the mode of ice melting. It is not of genetic significance and no 
valid distinction can be made on this basis between ice wedges and "Frostspalten". Nor can any real distinction be drawn between ice wedges and ice veins; the latter are simply narrower versions of the former, as far as can be told on present evidence. However, certain crack structures, observed in Strathaven may be due to fracturing of the surface by hydraulic pressure from below rather than by the growth of an ice mass.

9) The infilling of all wedges is of local origin, and in some cases includes coherent little packets of the surrounding material suggesting that many of the wedges were built up of a number of closely anastomosing ice veins.

10) Most wedges developed in one unified phase after deposition of the surrounding material had ceased, and not pari passu with its accumulation.

11) There seems to be no important genetic cause for the occasional appearance of wedges with rounded rather than pointed lower ends. 12) Wedges favour the downward percolation of ground water, both while the ice body was still in existence and after infilling by other material has been completed. This water favours the down:ward extension of the wedge by the growth of extra ice in the ground immediately below, and also aids the weathering and cementing of the subsequent infilling. 
CHAPTER V.

INV OLUTI ONS.

L. Introduction.

DENNY introduced the term "involution" into periglacial literature in 1936, as a name for complex disturbances of stratified drift under the action of frost. Analogous terms, often illdefined, include festoons, injections, plications and pockets. In a useful discussion of the origin of these structures, JAHN (1956) has extended the meaning of the word to include all disturbances of the structure of the active layer on more or less level ground under periglacial conditions. He uses prefixes to describe more closely the structures under discussion: e.g. "fold involutions", "pillar involutions", "amorphous involutions". He distinguishes between "bound" and "free" types of involutions. The former involve entire packets of material while the latter involve individual discrete particles.

DYLIK (1956a) following JAHN believed that involutions are the subsurface expression of patterned ground: free involutions being related to sorted structures such as stone polygons and stone rings formed where vegetation is scanty, while bound involutions are correlated with the formation of vegetation tussocks of "thufurs" typical of vegetated tundra. This genetic connotation of the distinction between bound and free involutions is unfortunate at this stage when the processes of formation of patterned ground in 
the Arctic today are still far from clear. (WASHBURN 1956). Some types of free involution, notably the erection of individual pebbles below the surface certainly cannot be correlated with former patterned ground. Bound involutions occur in predominantly fine grained material, free involutions in coarser material in which, nevertheless, a fine fraction must be present.

JAHN' $^{\prime}$ classification will be used in this study, on account of its simplicity and descriptive value, without necessarily agreeing with its genetic implications.

Three processes are generally suggested to account for involutions.

1) The volume of water in the ground changes abruptly with freezing and thawing, thus setting up pressures which distort the pre-existing structure of the material. This distortion is greatest where ground water is abundant and there is a high proportion of silt-sized particles favouring the development of segregated ice masses.

2) When the active layer begins to refreeze in autumn a stratum of saturated, unfrozen material is compressed and contorted between the permafrost and the frozen crust. Sometimes, when a column of soft material is compressed in this way against the solid permafrost table or the underside of the overlying frozen layer, the end is flattened out into a mushroom or dumbell shape. (MAARLEVELD 1956 ). 3) The upper of two superimposed layers of saturated loose material may become denser than the lower and sink into it in pockets to form "Tropfenboden". (No English equivalent of this term is known to the writer). See photograph 15. This density contrast may be augmented if the water near the surface is at a temperature 
of around 4 degrees Centigrade and therefore denser than the colder water below.

At one time, theories based on convection were popular but these have been shown to be untenable because the warmth comes from above, not from below.

There is no agreement on whether involutions necessarily demand the presence of permafrost for their formation. e.g. DENNY (1951) and DUCKER (1954) do not think so, but TRICART and CAILIEUX \& TAYLOR (1954) imply that it is.

On sloping ground related structures develop but are distorted and elongated down the slope by mass movement. The "trail" of some early English workers seems to be of this nature. The terminology of periglacial slope deposits is rather confused and this confusion extends to the structures found in them. JAHN and DYLIK make the same distinctions as in involutions between bound and free forms involving packets of material and individual particles respectively. Free slope deposits contain no structures other than a crude bedding and a preferred orientation of the stone down the slope. Bound slope deposits on the other hand may have a layered, plicated or cylindrical structure. (JAHN 1956). The structures in slope deposits will be considered here, while the deposits themselves will be discussed later in chapter VIII.

\section{Identification.}

In Scotland fossil involutions and slope deposit structures can only be identified by examining exposures. When examples were discovered, after clearing the exposure a sketch was made and/or a 
photograph taken, the nature of the materials noted together with the general orientation of stones in the structure, and the dimensions of the structures recorded. Involutions can hardly be enumerated individually, and they are listed below, according to the exposures in which they occur.

In studying these structures in Scotland the greatest problem was simply to find them: they are not common in the drift deposits of the country. When found, there was often difficulty in deciding whether the structures were of periglacial origin or not. Passage of ice over weakly consolidated material can produce structures closely resembling involutions. In some cases distinction was possible because drag structures were distorted in the direction of ice movement. A specially difficult case was presented by structures in late glacial marine deposits believed to be the work of grounding icebergs which might have been drifting in any direction. Lateral ice thrust in moraines can also produce fold and fault structures like some types of involutions, but the associated topography usually gives a clue to the process involved.

Slump structures identical to some slope deposit structures can form under a wide variety of sub-aerial and sub-acquatic environments. In many cases there is no distinguishing criterion, and a periglacial origin can only be assigned to a feature when it is associated with other definite evidence of severe cold such as wedges. In certain cases, the wedges themselves, can be a confusing factor, since, as pointed out in chapter IV. they can resemble a certain type of free involutions. 
Involutions are relatively shallow phenomena liable to modification or destruction through erosion, and man's activities. It is even possible to confuse fence post holes with free involutions! On the other hand, the full depth of the structures is usually exposed in a section, unlike the wedges which so often extend below the bottom of the face.

\section{Description.}

There are many references in the 19th Century geological literature to contortions in the material of the late-glacial "100 foot raised beaches" in Central Scotland. See GEIKLE 1902 and Appendix A. These structures are usually ascribed to grounding of icebergs impinging on the sea bottom where the clay was accumulating, but a periglacial origin cannot be excluded especially as the material, clay and silt with sand partings, is particularly suitable for the development of involutions. The considerable thickness of the disturbed layer is not a valid argument against a theory of periglacial origin since involutions of at least comparable depth are known from similar material in the Low Countries. (EDELMAN, FLORSCHÚTZ \& JESWIET, 1936).

The disturbances in the raised beach deposits have continued to be ascribed to grounding icebergs in this century. e.g. DINHAM (1927) around Stirling, CLOUGH et al (1925), FLETT (1927). More recently the possibility of periglacial action has been considered. e.g. The caption to Geological Survey photograph No.C4232, 
reproduced here as photograph 16 states that the disturbances illustrated in Foxley Sand Quarry, Lanarkshire, are "folding and faulting in sands and silts of ' 100 foot' beach deposits, possibly due to the action of permafrost".

Elsewhere in Scotland contortions have been recorded in glacial lake clays. In the past, these disturbances have been ascribed to ice thrust. (PEACH et al 1910 in Skye; BAILEY 1931 in Glen Roy; BARROW et al 1905 in the Tay Valley). More recently, the Geological Survey has ascribed contortions in glaci-lacustrine silts in the Spean Bridge area to periglaciation. See captions to Geological Survey photograph $\mathrm{C}_{4} 092$, reproduced here as photograph 17.

A wider range of involution features has been described in recent years from NE Scotland. S. SIMPSON (1948) has discussed contortions in solifluction deposits just $S$ of Aberdeen and fossil stone polygons or stone stripes (i.e. free involutions) at the summit of a cliff at the Bay of Nigg nearby. See photograph 18 . SYNGE (1956) has recorded fossil polygons in a raised beach near Ellon and mentions festoons of shattered gneiss at Tillycorthie $16 \mathrm{~km}$. $\mathrm{N}$ of Aberdeen. Involutions at Colliestone noted by SYNGE and at Roehill and Garralburn by the writer have been briefly mentioned by FITZPATRICK (1956a). They are considered more fully below.

Further field work has revealed 26 more occurrences of involutions in many different parts of the country.

Banffshire coast. In Tochineal quarry $2 \mathrm{~km}$. SSE of Cullen, the free involutions illustrated in photograph 19 were found in a layer of till, 1-2 metres thick, over quartzite. The till was 
predominantly red but contained wisps of grey boulder clay picked up probably from that deposited by some early glaciation of the area. (At some points in this district, notably near Orton bridge over the Spey, at G.R. 324516, red till was seen to overlie grey till with erratics from the C. c.f. BREMNER 1934.). The involutions probably are old sorted circles or polygons seen in section.

Around Ladysbridge station, $3 \mathrm{~km}$. W of Banff there is an area of kames, relics of the last ice sheet, the Moray Firth Ice, to affect this area. (SYNGE 1956). In a sandpit in one of these kames the bound pillar involution sketched in figure 17 was discovered. It is significant that this solitary involution occurred at a point where silt and clay bands were included in the generally sandy material. From its shape and isolation it seems unlikely to have been formed by ice thrust, ice drag, or slumping, and a periglacial theory of origin is the most likely. Strathisla-Strathbogie district. Free festoon involutions, illustrated in photograph 20 occurred in the same gravel pit at Ruthven where the wedge mentioned on page 30 was observed. There were five columns of upended stones, the relic probably of vanished stone rings or polygons. The upper part of the columns reached the B horizon of the soil, some $60 \mathrm{~cm}$ below the surface, while their base lay at a depth of about $1 \cdot 20$ metres. Between the columns the stones lay flat as a rule. These involutions occurred in the only part of the quarry where there was a notable proportion of silty material. In the coarser gravel, cryoturbation took the form of a wedge or was absent. It cannot be determined whether 
the wedges and involutions are strictly contemporary with each other or developed at different periods in response to different climates.

At Roehill, on the east bank of the Burn of Aultmore, the structures illustrated in figure 18 were observed in silt and clay layers overlain by $1-2$ metres of what are probably solifluction deposits. The structures appear to be cryoturbation phenomena extended to the left by mass movement. The overlying material is now motionless as shown by a well-developed soil profile, so the structures are fossil and almost certainly periglacial.

Nearby, at Garralhill on the opposite bank of the Burn of Aultmore. a bed of grey silt containing a thin contorted peat band was discovered. This silt was about $70 \mathrm{~cm}$ thick, overlay 1 metre of coarse gravel resting on till and was itself overlain by nearly a metre of stony material which may be till, solifluction deposits or postglacial hillwash. The whole was capped by 50 $\mathrm{cm}$ of peaty soil. This section may be of importance in dating late Pleistocene events in Scotland (DONNER 1957) but unfortunately from the point of view of periglacial studies its value is limited by uncertainty as to the origin of the contortion which ould be a periglacial bound involution, a periglacial mass movement or slump structure, or, if the overlying material is till, an ice drag structure.

Buchan. At Mains of Birness $6 \mathrm{~km}$. NE of Ellon the gneiss in a quarry was deeply altered and shattered to a depth of some 4 or 5 metres. The free involutions illustrated in photograph 21 were discovered in the upper layers of this weathered rock, overlain 
by a podsol containing one or two eratics. These involutions seem to be the sub-surface relics of patterned ground of some sort. At Braehead farm, $3 \mathrm{~km}$. NW of New Pitsligo, the exposure illustrated in photograph 22 and figure 19 was observed. Deeply altered and extensively shattered underlying schists passed up into 1-3 metres of solifluction deposits comprising angular chunks of the underlying rock, plus a few erratics, in a pasty mixture of weathered schist. A quartz vein, A-A, splintered but not chemically altered, rose vertically through the weathered bedrock. It was truncated at the junction with the overlying periglacially displaced material, within which it continued upwards but twisted and contorted by cryoturbation and mass movement, and ended in a few small involutions.

A similar case of a quartz vein distorted by cryoturbation and mass movement was observed in a quarry at Loudon Wood $6 \mathrm{~km}$. S of Strichen. A quartz vein about $10 \mathrm{~cm}$ wide could be traced up through quartzose granite shattered but still in situ into overlying solifluction deposits 1-3 metres thick, made up of angular quartzitic fragments in a sandy matrix. Where the vein passed into this overlying material it bent downslope, tapered, and died out in miniature involutions. A further contortion structure was observed at the back of this quarry in altered and discoloured rock. As the site was sloping, it could not be definitely stated that this was a periglacial structure, but in view of the overlying soil profile this seems most probable.

Two bound, fold involutions or plicated mass movement structures were observed in a sloping site in a quarry at Northseat, $10 \mathrm{~km}$. N 
of Ellon. A podsol overlay the structures which were certainly fossil and most probably periglacial.

At Gurgedykes quarry, $2 \mathrm{~km}$. SE of Methlick occurred bound pillar involutions illustrated in figure 20. The material involved was predominantly coarse sand together with some alteration products.

In a small roadside exposure $2 \mathrm{~km}$ SW of New Pitsligo the bound amorphous involutions illustrated in photograph 23 were observed. The schist had been weathered into a yellow and orange pasty mass, then cryoturbated and finally a postglacial soil profile had developed on top. The exposure is a record of three successive and very different climates: warm humid, periglacial, and cool humid. Each of these in turn must have notably modified the landscape.

A few bound involutions were seen in beds of sand and clay in a sand and gravel pit at Denhead, $5 \mathrm{~km}$. S.E. of Strichen. Several wedges were also noted in this exposure. See Chapter IV.

A small section in the Plioceno hilltop gravels of Buchan (FLETT \& READ 192l) was noted at Windyhills $3 \mathrm{~km}$. ENE of Fyvie. A high proportion of the small, beautifully rounded quartz pebbles were erected, almost certainly as a result of periglacial processes. cf. CAILLEUX \& TAYLOR (1954). Plate XI, figure 113, Northeast Strathmore. At Dalbog at the mouth of Glenesk a fine series of terminal kame moraines of the Esk glacier lie on the W side of the river. A section in hummocky terrain fronting the moraine proper, revealed the structure illustrated in photograph 15. The columns of sand which can be seen in the photograph rising amid pockets of gravel proved on excavation to be circular in plan. 
They appear to have been injected in a wet state into overlying gravel. The injection may have taken place suddenly, when the stability of the material was broken down by a high water content, and during the course of the autumn freeze-up as the top of the sand columns has been flattened into a mushroom form where its rise was checked by an overlying rigid "roof" of solidly frozen material. The depth of the active layer appears to have been about 1.80 metres at this point when this took place.

Near Gallery House, $7 \mathrm{~km}$. SW of Laurencekirk, the North Esk has undercut its south bank to leave a steep bluff some 10 metres high. The greater part of this bluff is red till with an undulating upper surface on which lies a layer of exceptionally fine, slippery clay. This in turn is overlain by $1-2$ metres of fine gravel and coarse sand in which three different involutions structures were observed. See figure 21. A rapid examination of the valley of the Esk downstream from this point suggested that the gravel graded into the highest raised beach on the coast, which would imply a late glacial, probably Zone III age。

One of the structures took the form of a pocket about $50 \mathrm{~cm}$ deep and $40 \mathrm{~cm}$ across, perhaps an example of "Tropfenboden". The outline of the pocket was emphasised by a zone of iron and manganese staining, while a considerable number of stones in the structure were erected. At this point also the B horizon of the soil was sharply truncated, reminiscent of features described elsewhere in Northeastern Scotland, and believed to be fossil permafrost。(FITZPATRICK 1957)。 This is the only point where 
the writer has een such a feature.

Further along the exposure the bedding of the sand was curled upwards and sharply truncated at the bottom of the present soil. A wisp of peat was twisted in with the gravel. This has been submitted to Dr. S.E. DURNO for pollen analysis but the results are not available at the time of writing.

Towards the $W$ end of the exposure free involutions $30-50 \mathrm{~cm}$ deep were observed in sand and fine gravel. A distance of a metre to a metre and a half separated the columns of erected stones. The whole resembled a shallower version of the free involutions at Ruthven, (see photograph 20) and like them were probably relics of former patterned ground.

Kinross area. A sand pit $3 \mathrm{~km}$. S of Kinross has already been mentioned in connection with wedges. Along one face of the pit an exposure of erected pebbles extended for about 10 metres. See figure 22. The pebbles were overlain by a fine gritty silt. 73 out of 100 pebbles in the layer were on end or on edge, while the comparable figure for the underlying undisturbed glaci-fluvial material was 2l. The junction between the erected and flat lying layers probably corresponds to the upper surface of the permafrost at the time the cryoturbation took place. This indicates an active layer about 1.10 metres deep. CAILIEUX \& TAYLOR (1954) state that the origin of this txpe of cryoturbation is obscure. 
Midlothian. In Oatslie sandpit near Roslin a fold involution, was observed in bedded silts, sands and clays. It was in the upper part of these deposits which are here overlain by 3 metres of till; it was the sole cryoturbation phenomenon to be seen in an exposure of total length about 400 metres. This single occurrence is unlikely to be due to ice drag which would have affected considerable stretches of the deposit at the same time.

In an abandoned limestone quarry at Macbiehill in the southern part of the county split and weathered plates of rock were seen to be contorted to a depth of around $40 \mathrm{~cm}$. A few erratic pebbles and a partially developed soil profile overlay the disturbance. It was not clear if it were periglacial or the work of ice drag. Tied involutions, illustrated in figure 23 were noted in a pit $3 \mathrm{~km} \mathrm{SW}$ of Bonnyrigg. Clay layers in the sand had been thrust upwards in irregular columns, distorting the overlying material. As the involutions are some 4 metres below the surface it seems probable that cryoturbation took place during the course of the deposition of the stratified material from melting ice. Eastern Lammermuirs. $\quad 3 \mathrm{kms}$. S of Cockburnspath, in a section opened in connection with a road improvement scheme the free involutions sketched in figure 24 could be seen. The section was near the foot of a slope about 15 degrees and possibly represented fossil stone stripes. The stratum in which the involutions occurred was overlain and underlain by about 1 metre of solifluction deposits derived from material weathered off the slope above.

Small bound plicated solifluction structures, sketched from a photograph in figure 45 were seen at the bead of a gully dissecting the material lying in the bottom of a wide open hollow in the 
Iammermuirs known as Tavers Cleugh. (G.R. 6266). The structures occurred at the junction of a greenish clay with overlying gravel, solifuction material and glacial erratics presumably washed off the neighbouring slopes. In a neighbouring exposure pebbles in the gravel had been erected by cryoturbation.

Teviotdale. In a section on the $\mathrm{N}$ bank of the river Teviot $2 \mathrm{~km}$. SW of Ancrum, marly Old Red Sandstone was overlain by 2 metres of till with interbedded gravel. In the weathered upper layers of the rock occurred the contortions illustrated in photograph 24 . These were perhaps ice drag structures since they occurred under till and extended in the direction of ice movement down the valleys, but there was no reason to definitely exclude a periglacial origin. Bonnybridge. Since many brickworks in Central scotland have closed it has been difficult to find sections in the "l00 foot raised beach" of the area. The only exposure seen, and not a very good one, was on the $S$ bank of the River Bonny, at Bonnybridge. The clay and its associated sand partings were churned and contorted to a depth of at least 6 metres. One of these contortions is illustrated in photo:graph 25 and another is sketched in figure 25. The evidence was insufficient to decide between the iceberg impact and the cryoturbation hypotheses, but the disturbances certainly resembled some of known periglacial origin illustrated in the European literature. e.g. STEEGER 1944. This problem requires further investigation. Kelvin valley. Three instances of tied involutions were noted in exposures in this area in material overlain by till. 
Involutions are associated with the remarkable disturbance in Keir \& Cawdor No. 3 pit discussed in the previous chapter and illustrated in figure 26 and photographs 9 and 10. As already pointed out those in the centre of the structure may be slump phenomena, but their appearance in no way denies the possibility that they are of periglacial origin. The narrow belt of involutions margining the clay seam $X-X$ are certainly of this nature.

In another part of this exposure the involutions portrayed in figure 26 were seen at the junction of the till and the underlying glaci-fluvial material. A long tongue of the latter penetrated into the till, which in its turn penetrated in places into the sand. It may be claimed, however, that this structure has been caused by overriding ice.

Bound involutions forming a horizon some 50 d.rm.deep about 2 metres below the surface were observed in an abandoned pit about $1 \mathrm{~km}$. SW of Cadder. They were clearly associated with a clay-rich layer in the stratified material.

Strathaven district. In Drumclog pit the involutions illustrated in figure 27 and photograph 26 were seen. They occurred within the body of glaci-fluvial or glaci-lacustrine deposits, (RICHEY et al 1930), and were unconformably overlain by further layers of sand and gravel. A narrow wedge penetrated the whole sedimentary sequence. The development of the involutions was clearly related to the occurrence of a clay-rich layer which had squeezed upwards in columns through the overlying sand, dragging some of the latter with it. Figure 27 shows a suggested sequence of development. Further aspects of this exposure are discussed below when considering the dating of involutions and mass movement structures. 
Galloway. Contortions of sand and gravel in the exposure discussed on page 43 above and illustrated in figure 14 may be the work of periglacial processes, but slumping in relation to the melting out of dead ice seems more likely.

\section{Development.}

The dependance of involutions on the presence of fine-grained material, particularly silt or clay, is very apparent from an examination of the Scottish examples. e.g. The free involutions at Ruthven were restricted to the one portion of the exposure with a liberal admixture of silt. As many laboratory studies have shown (e.g. TABER 1930) the presence of this sort of material greatly favours the development of segregated ice bodies. Although usually present in the form of water-laid deposits, the necessary fine material was provided in some cases by glacial till (e.g. Tochineal, Banffshire Coastal region), or by chemical weathering dating from past warmer climates (.e.g. Loudon Wood and Mains of Birness). Unlike Europe, in Scotland eolian processes seem to have played no part in providing this important fine fraction, except perhaps in the case of the erected pebbles near Kinross.

Neither bound nor free involutions in Scotland lend much support to the most popular theory of origin of these deposits -squeezing in autumn between permafrost and a frozen upper crust -since the structures show no flattening at top or bottom against the postulated rigidly frozen layers. The one example which shows such a feature at Dalbog, Glenesk is truly an "exception which 
proves the rule", since it is the only involution known to the writer which contains no material finer than sand. Presumably its mode of origin, which does seem to be related to rigidly frozen layers above and below, differs from that of all the other structures examined. It seems more probable that involutions generally develop as a result of the stresses and loss of cohesion induced by the growth and melting of segregated ice masses. This can take place, albeit less readily than above permafrost, both inside permanently frozen ground, and where no permafrost exists.

The free involutions observed in Scotland certainly seem to have been associated with patterned ground as JAHN (1956) suggest, but there is no evidence for or against associating the bound structures with surface features at the time of formation. The structures observed in deposits on slopes are too few to allow one to draw reliable conclusions about their mode of formation, in which mass movement has of course played a large part. Of the thirty-odd involutions listed here only 5 can be safely correlated with surface patterned ground. (Nigg Bay; Ellon; Tochineal; Gallery House; Cocksburnpath.)

There seems to be no type of site specially favourable to the development of involutions. The material is far more critical than slope or moisture conditions.

It has been suggested that the bottom of involutions marks the upper level of the contemporary permafrost. POSER (1948) drew conclusions about the summer temperatures in Central Europe during the last glaciation from the depth of this level. No satisfactory deductions can be made in this way from the Scottish 
evidence. Only free involutions offer any hope, since, as we have seen, bound involutions may develop at considerable depths and are not necessarily related to permafrost. Even this hope is illusory. There is no means of telling whether the overlying material has been partially eroded away or partially accumulated since the structures formed, and it is in any case unjustifiable to assume that all involutions were developed at exactly the same time under the same climatic conditions. Furthermore, the depth of the active layer under present conditions is extremely variable according to exposure, vegetation cover, slope, water content and season. e.g. In a very limited area of East Greenland the depth of the active layer was found to vary from $30 \mathrm{~cm}$ at one point to fully 3 metres at another. For what it is worth, the base of free involutions in Scotland lies between one and two metres below the present surface and this perhaps implies that there was a considerable degree of summer thawing. On the other hand, FITZPATRICK's investigations indicate a depth of the active layer in Scottish soils of only $40-60 \mathrm{~cm}$ even in late glacial times. (FITZPATRICK 1965b).

V. Distribution.

The distribution map, figure 28 resembles that of wedges, figure 16. The enigmatic contortions of the "100 foot raised beach deposits" have not been plotted. There are concentrations in NE Scotland, just $\mathrm{N}$ of Glasgow, and at least one or two examples in the Edinburgh and Strathaven area. Examples under till are confined to the Central Lowlands, except for one possible instance in the Teviot balley. Isolated, but climatically significant, 
examples exist well within the limits of the Highlands at Spean Bridge, just like the wedge found near Aviemore. Essentially, however, the distribution is a Lowland one perhaps reflecting climatic causes but also related to a greater amount of field work, better exposures and finer material in the lower areas.

The concentration of these features in $\mathrm{NE}$ Scotland is striking. Here climatic conditions (may) have been especially suitable in an unglaciated area (SYNGE 1956, CHARLESWORTH 1955), and favourable material has certainly been provided by the deeply rotten rock so common in that area. (PHEMISTER \& SIMPSON 1948). The latter factor has undoubtedly been the more important. It is interesting to note that the involutions described from this part are mostly found within the area of "Moraineless Buchan", while all the wedges are confined to glaci-fluvial deposits on the margin.

Although all the free involutions known are confined to the $\mathrm{E}$, the total volume of evidence is so small that no climatic contrast between the two sides of the country can be deduced from this.

Perhaps one potentially suitable section in twenty in Scotland shows involutions, the proportion rising to about one in ten in Buchan, although it may be much higher in the "loo foot raised beach".

VI. Dating.

Involutions are shallow features, readily destroyed by erosion, so it is highly unlikely that any can have survived from glaciations previous to the last. (cf. DYLIK 1956b). On the other hand, 
probably none could have formed after early Zone IV times when severe climatic conditions terminated (DONNER 1957).

Iike wedges, they can be more closely dated by considering the material overlying them and in which they occur. In addition, there is a possibility of dating by pollen analysis in two cases where peat is involved in the cryoturbation (Garralhill and Gallery House), and by correlation with late glacial sea levels. Weathering data is too imprecise to materially assist dating although it may be mentioned that all involutions and many of the slope structures are overlain by fully developed soil profiles, and many involve fine material provided by pre- or inter-glacial chemical weathering.

The structures observed on sloping sites are harder to date since mass movement can take place under a wide variety of climates. The oldest involutions, like the oldest wedges, are those under till near Glasgow and Edinburgh (and possibly also in Teviotdale). They may tentatively be correlated with an important interstadial in early or mid-glacial times. cf. The dating suggested for wedges in this area. Ice may finally have disappeared from 'Moraineless Buchan' at, or even before this time, in which case the involutions there could be fully as old, but they cannot be dated since they are not associated with any deposits of known age.

The Strathaven involutions can be correlated with the retreat from the Scottish Readvance stage. They occur within material deposited in an ice-dammed lake; the existence of an unconformity cutting the structures and overlain by more sand and gravel shows that they developed while the sediments were still accumulating. More exactly, the involutions developed during a brief pause in the 
accumulation, a pause perhaps associated with a temporary relapse in climate which checked the melting of the ice and favoured the development of involutions. Other involutions within the body of a sedimentary deposit cannot be correlated in this way with the phase of accumulation if no unconformity is present because the structures could well have developed at depth long after the accumulation of the overlying material.

The erected pebbles at Kinross must also post-date the Scottish Readvance stage. The structures in the kame moraine at Dalbog, Glenesk, must be later than the last ice in this area which according to SYNGE (1956) was part of the Aberdeen Readvance stage. The free involutions at Ruthven and at Tochineal near cullen cannot be older than the Moray Firth-Strathmore stage since they are developed on deposits (outwash and till) of this glaciation.

A rather closer dating can be made in the case of involutions occurring in raised beach deposits. The free involutions mentioned by S. SIMPSON (1948) as the Bay of Nigg are in beach deposits re:lated to a sea level 80 to 90 feet above that of today. The same is true for the involutions at Gallery House on the North Esk, Angus which occur in a terrace graded to the same high sea level. It is not clear if this raised beach dates from Zone I times as GODWIN (1956) suggests or from Zone III times as the evidence at Ioch Lomond would suggest. (J.B. SIMPSON 1933). Some other periglacial structures seen by S. SIMPSON near the mouth of the Dee, and the free involutions reported by SYNGE from Ellon must be rather younger since they occur in deposits which can be correlated with a rather lower sea level around 30 to 40 feet $0 . D$. This lower raised bech 
perhaps the equivalent of the "50 foot beach" of GEIKIE (1894) is almost certainly of late glacial, Zone III age. The occurrence of involution structures within it shows that severe climatic conditions continued in Scotland right to the close of the Ice age. If the disturbances in the raised beach deposits of central scotland are indeed of periglacial origin they will be of an age comparable to those round Aberdeen. i.e. Also late glacial, either Zone I or Zone III or both.

The contorted peat at Garralhill has been assigned by DONNER (1957) to the Allerdd, Zone II, climatic amelioration. It would then be logical to assign the contortion to the succeeding colder conditions of Zone III times. Van der HAMMEN (1951) has success: fully dated cryoturbated peat in the Netherlands in this way. Unfortunately it is not certain if the Garralhill structure is really the work of cryoturbation. Pollen dating of the peat from the Gallery House exposure is not available at the time of writing.

The involutions at Spean Bridge must be the youngest of all and can best be ascribed to the early part of Zone IV when the climate was still harsh.

Reviewing the evidence of dating as a whole it is apparent that involutions formed in Scotland at many different times right to the end of the glacial period and even later.

\section{Summary of conclusions.}

1) A fair number of involutions have been found in scotland, but their distribution is so erratic that absence of them certainly cannot be taken as absence of periglaciation. 
2) The structures are found outside and just within the limits of the Zone III glacial readvance. Without more field work it cannot be stated categorically that they do not occur also well inside this limit.

3) They range in age from a glacial interstadial to the close of Zone III times and possibly into Zone IV times.

4) The climatic connotations of involutions are less well-known than those of wedges and it is not certain if they require the presence of patterned ground, but they support the evidence of wedges that very severe climatic conditions existed at many periods in Scotland and continued to the close of the Ice Age.

5) The involutions indicate a general depth of active layer of 1 to 2 metres, but little reliance can be placed on this figure. 6) The presence of involutions under till supports the evidence of wedges that there was an important interstadial in Central Scotland.

7) There was no significant variation in type of structure from one part of the country to another, or between structures of different age.

8) The involutions require the presence of a good deal of fine material, suitable for the development of segregated ice masses, except for one case where saturated sands and gravels seem to have moved relative to each other.

9) The most probable process of formation is the pressures and the lack of cohesion induced by the growth and melting of ice, favoured by, but not dependant on, the existence of permafrost. 
The possibility that involutions may develop at considerable depths within permafrost by a slower growth of segregated ice masses must be borne in mind. If this can happen there is little point in trying to deduce the depth of the active layer from the depth of the features.

10) It may be that involutions are extremely frequent in the deposits of the 100 foot raised beach in Central Scotland -they certainly exist in material of comparable age in the North:eastern part of the country, though these examples do not extend to comparable depths beneath the surface.

11) Correlation between free involutions and former pattermed ground seem probable, but the same cannot be said for the suggestion that bound involutions also had a surface expression at one time -- in Scotland there is no definite evidence on this point. 


\section{CHAPTER VI}

\section{CONTEMPORARY CRYOTURBATION}

I. Introduction.

The study of contemporary cryoturbation meets with the difficulties of delimitation and classification so common in con:sidering natural phenomena where boundaries and distinctions are rarely clear-cut. Cryoturbation merges into mass movement which may or may not be associated with frost in the ground. Patterned ground is associated with cryoturbation and is diagnostic of periglaciation but well-developed patterned ground can merge in a few yards into confused, unsorted debris which is certainly equally exposed to frost and no less "periglacial". It is often difficult to distinguish between phenomena of present day origin, of origin in the immediate past, or several thousand years old. Arbitrary distinctions must be made.

In this chapter we shall consider cryoturbation observable on the surface as contemporary. This excludes the undoubtedly fossil forms of cryoturbation including wedges and involutions which are known only in section, but may include forms no longer actively developing such as the polygons on the summit of Merrick. (GREGORY 1930). Also excluded are forms on slopes such as lobes and terraces which are more directly related to mass movement than to cryoturbation and are incidentally among the most difficult features to assign to a particular period of formation. 
This leaves amorphous cryoturbation and patterned ground as the subjects of this chapter. The former is actually by far the most extensive and important in the periglacial environment, affecting much larger areas than the latter in the mild conditions of Scotland and also in the severe climate of Greenland, but attention has been concentrated on the latter and a vast literature has grown up on this topic. Order has been introduced into the chaotic terminology by WASHBURN (1956) and his nomenclature will be used here. WASHBURN distinguishes between sorted and nonsorted patterms. The former are expressed by contrasts in the size of fragments involved in various parts of the pattem, the latter by contrasts in vegetation. Within each of these two main groups he recognises circles, nets and polygons on generally flat areas and steps and stripes on sloping ground.

There can be no doubt that growth of ice in the ground is the most important single agency in the development of patterned ground outside warm arid regions, but a wide variety of other processes are involved: dessication, solifluction, thawing, plant growth. A good proportion of fine material seems to favour the development of patterns, though it may not be essential.

In amorphous cryoturbation there has been disturbance of the individual particles, but no definite pattern has emerged. Amorphous cryoturbation is very widespread wherever the vegetation is scanty. On slopes it tends to be masked by the effects of mass movement.

One of the significant facts about present day cryoturbation in Scotland is that it is essentially a surficial phenomenon, extending to a depth of only a few $\mathrm{cm}$. By contrast, patterned ground features 
excavated by the writer in North Norway and East Greenland extended to depths of several decimetres, though some surficial patterns were also observed. The Scottish patterns are generally fairly small. e.g. Actively developing sorted polygons have diameters measureable in tens of centimetres.

II. Identification.

Amorphous cryoturbation is widespread in Scotland wherever bare, undisturbed ground is to be found. It can be recognised by the soft loose surface and the frequent presence of stones resting on it, which have been heaved up from below.

Patterned ground, in which the frost action has helped to pro:duce a certain regularity of form is much less common. In the course of field work only a few examples were found. Notes were made of the type and dimensions of the pattern, the nature of the site and the size, form and orientation of the stones involved.

No special difficulties arise in identifying these forms. In a few cases confusion is possible between sorted stripes and minor gullies on screes, but the latter tend to be more irregular and dendritic in patterm than the former. occasionally dessication can produce patterns reminiscent of cryoturbation.

Greater difficulties must be faced when attempting to date the period of origin of some surface features, especially the nonsorted patterns expressed in the vegetation. On excavation of some of these patterns (Ben Wyvis) it was found that they corresponded to 
underlying sorted features whose period of origin could not be precisely determined.

\section{Description.}

Amorphous cryoturbation is so widespread that there can be no point in listing places where it has been seen. It may be mentioned that frost disturbed debris occurs on many of the hills in Central and SW Scotland. e.g. The summit of Black Hill in the Pentlands. Stones lie scattered on top of a pasty mixture of earth and peat. Fugitive, half-formed patterns, often consisting of smaller stones ringed round a larger block, occur repeatedly in such material. See photograph 27. In the Highlands, disturbance of the mountain top detritus is preceeding actively today (PEARSAII 1950) although most of the material involved has been provided by more active frost shattering in late glacial times.

Patterned ground is much rarer; examples known to the writer are listed below.

Sorted stripes have been reported by MIIIER et al from Tinto Hill (1954). The patterns had developed in rubble exposed by the recent removal of peat and vegetation. It was proved conclusively that these stripes could develop in the course of a year or two. BAIRD (reported in FITZPATRICK 1956) has noted stripe patterns in the high Cairngorms; PEARSAII (1950) has illustrated an example from Skye. SPENCE (1957) has discussed some rather poorly developed examples observed in Unst, Shetland, at the remarkably low level of 150 feet. 
Sorted polygons and circles have been noted by GREGORY (1930) on the summits of Ben Lawers and Merrick, and on the tailings from an abandoned slate quarry on the shores of Ioch Iomond. This latter instance took the form of "stone roses" -- platy fragments packed on edge around a boulder. It may be that they are the work of pressures induced by waves. J.B. SIMPSON (1932) and GODARD (1958) have mentioned the presence of small but well-developed circles on Beinn Iodhair, Argyle, and on Storr, Skye. The writer has seen poorly sorted circles about $30 \mathrm{~cm}$. across in granitic debris at an altitude of 1,000 feet on the N side of Ronas Hill, Shetland and at 2,200 feet near the summit of Bencleugh, in the 0 chils.

Only two further examples of sorted stripes were found. On the $S$ face of Scaraben, Caithness, at an altitude of about 1,900 feet, a few restricted areas of striped patterns were observed on the loose quartzitic debris which clothes the slope. The stripes were 15-20 cm wide and 5-8 metres long. Young heather had partially colonised the fine material between the lines of angular stones. There seems to be a cyclic sequence of events at this site: the frost shattered quartzite rubble is initially too mobile, stony and infertile for plant colonisation, but as sorting proceeds areas of fines develop which vegetation can colonise. The coarser material between the fine stripes continues to move and material continues to arrive from further up the slope. This movement eventually destroys the vegetation and renewed sorting, followed by renewed colonisation, takes place.

Short, poorly developed stripes are to be seen on a patch of bare debris near the summit of Bencleugh in the ochils. 
Apparently non sorted patterns of greater significance have been observed on considerable areas of Ben Wyvis and on more re-

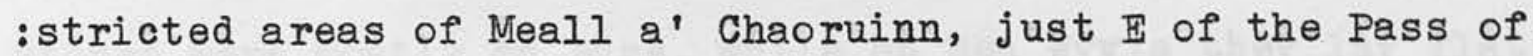
Drummochter from about 2,700 feet upwards. In both cases the pattern was developed on rhacomitrium-heath and consisted of shallow elongated hollows about 20 to $30 \mathrm{~cm}$ wide of fresh greygreen moss separated by slightly higher zones of grey-brown moss about a metre across. On flat areas, the green moss formed distinct rings $1-1 \frac{1}{2}$ metres in diameter which became elongated and distorted on gentle slopes and passed into a striped pattern on gradients steeper than about 5 degrees. On Ben Wyvis a shallow section was dug across 7 of the stripes together with the inter:vening higher belts on a 7-degree slope at an altitude of about 3,000 feet. There was some weathering just below the surface but no distinct soil profile. The material consisted of flat platy stones of the local schist in a matrix of micaceous weathered material. The largest stones were consistently found under the hollows on the mossy surface, with their long axes aligned down the slope. The upper surface of the material was also ridged and hollowed just like the moss above. In other words, the surface vegetation pattern was a response to an underlying sorted pattern in the debris of the hillside. The extra verdure of the moss in the hollows was a result of the concentration of ground water draining along the underlying hollows. The vegetation pattern is a response to underlying sorted polygons on flat areas and stripes on slopes. Figure 29 shows a sketch of such a pattern on Ben Wyvis and of an 
area of patterned ground, very actively developing, in East Greenland. The similarity is striking, although in the Greenland case the platy stones were mostly on edge, while on Ben Wyvis they lay flat.

It is not easy to decide when the initial formation of the sorted pattern under the rhacomitrium developed. It must have been at some period in the past, since it is impossible for sorting to take place today under the moss and other plants of the area. Yet the vegetation cover is really very thin -- only a few $\mathrm{cm}$. -- and may well be a recent colonisation. PEARSALL (1950) states that rhacomitriumheath represents an early stage in plant colonisation of bare debris in the Highlands. On the other hand, it is possible that the present conditions are stable and have lasted for a long time, growth of the moss just balancing losses by wind and water. (Shreds or moss are common on snow patches on Ben Wyvis). Initially the stones in the stripes may have been lying flat like those in the contemporary examples on Tinto or they may have been on edge like the Greenland examples and settled into a flat position once the dynamism of the sorting had been checked as vegetation colonised the area. The most probable conclusion is that the patterns developed at some period within the last millenium, and are nearly in tune with present day conditions. Probably if the vegetation cover could be removed for a few years, the cryoturbation would once again become active. However it must be pointed out that one fact is against such a conclusion: the large size of the features, more reminiscent of cryoturbation seen in the Arctic than the miniature forms actively developing on Scottish hills. 
Similar patterns are probably not uncommon in the Highlands and would certainly be worth closer investigation.

IV. Formation, Distribution and Dating.

Small, surficial patterned ground features can develop rapidly under present climatic conditions in Scotland. However, not many examples have been found, so other factors must be less favourable. One of the main causes restricting the development of cryoturbation is vegetation. If the plant cover is broken by any agency, such as overgrazing on Tinto (MIIIER et al 1954) or semi-poisonous soils in Unst (SPENCE 1957) patterhs can develop to very low altitudes. Another restricting cause is the general lack of fine material in the surficial drift. Such material is readily washed or blown away in the wet and windy climate. On the other hand, comminution of peat can sometimes provide this necessary fine matrix especially in the case of amorphous cryoturbation.

The distribution of these phenomena is still too little known for useful conclusions to be drawn. They are found from near sea level in Loch Lomond and Shetland to over 4,000 feet in the Cairngorms. The lower examples are the result of special circumstances inhibiting the vegetation, and the true "natural climatic" lower limit, if such a limit exists, cannot yet be determined. It is certainly not con:stant over the whole country.

All the patterns discussed are strictly contemporary, except for those on Ben Wyvis and near the Drummochter Pass, whose time of origin cannot be fixed on present in formation. 


\section{Conclusions.}

Although the presence of actively developing sorted patterns on Scottish hills is of some interest for its own sake, and is proof of contemporary periglaciation it has little or no significance in the landscape as a whole. Amorphous cryoturbation, far more widespread, is much more important and by loosening the ground and weakening the vegetation assists contemporary mass movement on slopes to produce other sorted patterns which have not yet been considered, such as lobes and terraces. 


\section{PART III}

\section{GEOMORPHOLOGICAD PROCESSES}

The evidence of cryoturbation has shown that periglaciation has affected the surface of Scotland, both in the past when severe conditions prevailed in ice free areas, and in the present when relatively mild periglacial conditions prevail in high areas. In this section the processes that have modified the surface of the land under periglacial conditions will be discussed. 
CHAPTER VIII

WEATHERING

I. Introduction

"Weathering may be defined as the disintegration or decom:position of rock in place". (THORNBURY 1954). In periglacial regions weathering is of course overwhelmingly the work of the growth of ice in interstices of the rock. Other processes of weathering dependant on chemical and bio-chemical processes are much restricted in the periglacial environment and will not be considered here. It is usually believed that "formation of ice crystals is most effective as a weathering process when there is repeated freeze and thaw". (THORNBURY 1954). In this study, weathering by the growth of ice crystals will be termed "frost shattering".

Frost shattering is a geomorphological process amenable to experimental investigation in the laboratory. TRICART (1956) has recently published an interesting report on such an investi:gation, which throws much light on the nature of the process. His experiments showed 1) The cardinal importance of an adequate supply of moisture -- dry rock is little affected. 2) The ampli:tude of freeze/thaw cycles is as important as the number. This is a point which has been insufficiently stressed heretofore. Frequent freeze/thaw cycles of small amplitude (the 'oceanic' type of periglacial environment) tend to give fine fragments; less frequent freeze/thaw cycles of greater amplitude (the 
'continental' type of periglacial environment) tend to give larger fragments and less fine material. 3) The lithology is very impor: tant and there is an immense range of sensitivity between weak, porous and fissile rocks like chalk and compact metamorphic and igneous rocks. Frost splitting does not usually follow the more obvious planes of weakness such as jointing except in an initial stage. The resistant rocks tend also to give coarser fragments with few fines, while weak rocks produce abundant fine material. 4) The size of fragment produced is important since abundant fine material favours mass movement of the shattered debris and so reveals the underlying rock to further shattering, except at the foot of slopes where a thicker accumulation of material tends to shield the rock beneath. Coarse fragments with no fine matrix are hardly affected by mass movement.

Frost shattering at depths below the reach of annual temperature changes can scarcely be related to freeze/thaw processes. It must depend on the secular growth of segregated ice masses in cracks, and possibly also on thermal contraction.

The effectiveness of frost shattering is not only a function of rock, water and temperature. Previous climatic influences are also important. Deep chemical weathering under warm humid conditions can so weaken many rocks, that frost shattering is greatly facilitated. Glaciation can leave the landscape partially immune to attack by frost: the ice removes the more closely jointed upper layers of the bedrock and exposes smooth coherent surfaces from which water rapidly runs off without freezing in cracks. Much of the "shield" areas of the $N$ 
hemisphere, including the Lewisian gneiss areas of $\mathrm{NW}$ Scotland seem to have been "immunised" against frost shattering in this way.

In exposures of deeply frost-shattered rock there is usually an upward sequence from rock in place, through larger to smaller fragments. Locally this sequence can be reversed where a specially "frost-sensitiven layer is overlain by a more resistant one.

Frost shattering is very obviously at work on mountains today, in all parts of the world above the tree line. The scanty evidence from mine workings suggests that it is also common at low altitudes in regions of severe climate today. e.g. Ice veins could be seen in the walls of a mine gallery at Mesters Vig, East Greenland, to depths of 50 metres below the surface -- far below any possible penetration of annual temperature changes. At the surface, sand:stone in Greenland was always severely shattered, but glaciated trap knobs were little affected unless there were steep free faces towards which whole blocks could be spalled off. See photograph 28 .

Shattering by frost is also widespread in regions of former periglacial climate. e.g. CAILIEUX (1943). Depths of twenty metres or more are not uncommon. Sections show an upward sequence from coarser to finer fragments, and generally the uppermost layers have been displaced by cryoturbation and mass movement.

II. Identification.

Shattering of the bedrock occurs in many parts of the country and is readily recognisable. The best evidence for deep shattering is of course obtained from examination of quarries. Fossil 
periglacial frost shattering can be distinguished readily enough from that caused by contemporary processes by its much greater depth. Plant roots are a factor in breaking up the rock but they widen preexisting cracks rather than create new ones. Chemical processes in the subsoil may also break up the rock, but produce roughly rounded forms ("core stones") readily distinguishable from the sharply angular chunks produced by frost shattering. Shattering by tectonic dis:turbance differs from periglacial frost shattering in that it does not die out in depth. The same implies to breaking up of the rock by the use of explosives in quarries.

\section{Description.}

The Memoirs of the Geological Survey contain many references of frost shattering on hill sumits. The mountain top detritus found in the Highlands has long been ascribed to this process. Some writers (e.g. CRAMPTON \& CARRUTHERS 1914) emphasise the role of present day climatic conditions in causing this shattering, others ascribe the greater part to severer late-glacial conditions. (e.g. BAILEY \& MAUFE 1916). It should be mentioned here that DAHL (1955) has claimed that freeze/thaw is quite inadequate to produce the detritus and that much of it must have an inter or pre-glacial origin by chemical weathering processes under a wermer climate. READ (1923) mentioned shattered local quartzite under till on the Banfishire coast ascribing it, very doubtfully, to a "pre-glacial raised beach". From a photograph of this section in the possession of the Scottish Geological Survey it is quite apparent that in fact 
this is periglacial frost shattering overlain by till or solifluction material. (cf. photograph 32). BAILEY (1927) and RICHEY et al (1930) discuss shattered bedrock found in Ayrshire which they attribute to freeze/thaw processes near the margin of an ice sheet. Scattered references exist outside the publications of the Survey. HARKER in 1901 pointed out the evidence in Skye for a phase of pronounced frost shattering with formation of great block screes immediately after the disappearance of ice from the cuillin corries. THOMSON (1950) has described the present day shattering proceeding on high summits in the North West Highlands and has pointed out how much more resistant gneiss is than quartzite. SYNGE (1956) has mentioned fossil deep shattering in Buchan, and FITZPATRICK (1958) in Unst, Shetland. GREGORY mentioned shattering of granite in SW Scotland (1927). There is a striking photograph of shattering of Silurian rocks in Roxburgh in MUIR (1956). No scale is given, but the shattering appears to extend downwards for at least three metres. GODARD (1958) has described shattering from Skye; his account emphasises the importance of local weakness in the rock in locating zones of more intense shattering under the present climate.

Turning now to discuss new observations of fossil periglacial frost shattering, it is apparent that there is little point in enumerating more than a fraction of the occurrences noted. A few significant examples from different parts of the country and in different rocks will be discussed.

Orkney. Shattering to a moderate depth of 1 to 2 metres is erequent in the 0ld Red Sandstone of Hoy. See photograph 29. As a general 
rule it has produced chunky fragments in a matrix of sand, such as can be seen on the S side of Rackwick bay. See photograph 30 . Significant shattering was less frequently observed on Mainland, although in a quarry at Finstown, the section sketched in figure 30 was seen. The upper stratum, about 2 metres thick, was scarcely affected: a few joints traversed it. Beneath, the rock was much more broken. Concentration of shattering in a less resistant bed below the surface is not uncommon in stratified rocks. North east Scotland. Deep shattering, which can only be the work of periglaciation is very widespread in this part of the country. The effects of this process on several different rocks can be clearly observed and compared.

1) Quartzite. Many road metal quarries exploit outcrops of the pure Durn Hill quartzite, and in each exposure the rock can be seen to be splintered and shattered to depths of as much as 8 metres. A more usual figure is about 4 metres. See photograph 31. e.g. At Mormond Hill (G.R. 949570), Sillyearn Hill (G.R. 506514), Gallowhill (G.R. 484525). Typical products of the shattering were very angular chunks from fist to head size in a matrix of sand. In several cases the shattering stopped abruptly at a particular plane of stratification, not necessarily horizontal, below which the rock was sound. These planes may have been impermeable and prevented the penetration of the water without which frost shattering cannot take place. Shattered quartzite overlain by till can be seen near Newbigging form $8 \mathrm{~km} \mathrm{~S}$ of Cullen (G.R. 527591). See photograph 32 . 
2) Phyllite slates and schists. These platy, fissile rocks are very favourable for the development of frost shattering. Fine examples can be seen around the headwaters of the river Ythan and in the Glens of Foudland. Shattering was seen to extend to depths of 3 to 5 metres in this rock. Phyllite along the upper reaches of the Burn of Aultmore, $N E$ of Keith is similarly riven, but is here overlain by till or by soliflucted till. This rock usually breaks down into small platy fragments with a rather higher pro:portion of fine matrix than in the case of quartzite. See photograph 33.

3) Granite. The effects of frost shattering on this rock vary widely according to the degree of pre-existing alteration of the rock. Where the granite is sound as at Blackrigg quarry, Strichen (G.R. 912600) or Rubislaw Aberdeen, frost shattering has only penetrated for a metre or two and has produced only coarse fragments and a little gritty sand. cf. TRICART. Where the rock has been completely reduced to 'growan' by chemical weathering no trace of frost shattering is apparent since the cohesion of the rock has already been destroyed. In the more usual cases, as at Iongside quarry $W$ of Peterhead, and Windyfield, S of Huntly (G.R. 492280), it can be seen that chemical alteration has affected only certain parts of the rock, but that the chemically sound portions have been shattered by frost. See photograph 34 .

4) Gneiss. This behaves in the same way as granite. Where the rock is sound, frost shattering has had no great effect. Where the rock is deeply rotted, as at Mains of Birness quarry NE of Ellon, (G.R. 991340), frost action has been able to shatter the intervening 
belts of sounder rock. The chemical weathering at this point has provided suitable material for cryoturbation. See chapter $V$. The shattered rock fragments were generally about fist to head size. 5) Basic igneous rocks. These behaved similarly to granite and gneiss although the chemical weathering seemed more important and the frost shattering rather less effective. Core stones in deeply rotted rock are sometimes riven and shattered as at Mill of Fedderate (G.R. 889504); at other places they seem little affected as can be seen in the valley of the Burn of Craig, W of Rhynie. The Highlands. There is usually little sign of shattering in the valley floors and along the valley sides. Glacial debris covers much of the bedrock, and even where it is exposed it is usually iceabraded and practically intact. The advancing glaciers must have swept away any rock previously shattered, and their deposits have shielded the ground from any late glacial shattering.

At higher levels, on the other hand, there are much more im:portant signs of shattering in the mountain top detritus. As DAHL (1955) points out, the present climate is inadequate to account for the scale of disruption, to a depth of several metres, and the shattering must be attributed to conditions now no longer operative. The present day shattering on gently sloping areas is largely confined to the weathering off of small particles from larger pre-existing blocks. This weathering produces rounded forms (not smooth!). Such roughly rounded stones are overwhelmingly predominant on the granite plateaux of the Cairngorms and Ben Nevis where the sharply intersecting faces of recent frost shattering are practically unknown. See photograph 35. 
Where glacially over-steepened slopes prevail in the Highlands, providing a steep face from which blocks can be spalled, present day shattering can produce more angular debris.

One interesting case of shattered rock preserved under till towards the foot of a valley was observed in Glen Geusachan. This will be discussed further in chapter XI below.

The Lowlands. On the basis of present information fossil peri: glacial frost shattering is insignificant in Lowland areas of Scotland. Pre-glacially shattered material must have been swept away by the ice sheets whose erosive power in this region was considerable as witnessed by the well known crag-and-tail phenomenon. Accumulations of drift shielded the bedrock from periglaciation during the glacial retreat. Where bare rock does project above this drift cover it is usually resistant, compact volcanic material little subject to frost shattering. This can be seen in road metal quarries between Edinburgh and Glasgow where intact rock practically reaches to the surface. It must be pointed out that little field work has been done in lowland areas with a view to finding shattered rock exposures, and it may be rather more widespread than present information would suggest. However, there is no doubt that it is less well developed than in the North East part of the country. Present day frost shattering is of no practical significance in Lowland Scotland.

The isolated volcanic hill masses such as the Sidlaws and ochils which rise from the Lowlands have experienced a certain amount of frost shattering, as witnessed by fossil screes, now covered in vegetation. See page below. Perhaps they were exposed to a 
rigorous climate for a period while the lower areas around were still sheltered under dead ice remnants. Contemporary frost shattering is continuing to produce screes but on a smaller scale.

Southern Uplands. The platy, fissile rocks of this region are favourable to frost shattering. Shatterid rock is exposed in the walls of gullies in most parts of the region. The depth is generally moderate, rarely more than 2 metres, as far as the writer's own observations go. The rock is apparently less deeply shattered on slopes than on flat ground, since on the former the upper part of the shattered material has been removed by mass wasting. Periglacial frost shattering seems to have been a powerful factor in the develop:ment of the gullies which are so common on steep slopes in the Moorfoots. See chapter XIV. Since no examination has been made of the granite areas in the $W$ and the rocks of the rest of the region are rather homogeneous, lithological contrasts cannot be drawn as was possible in North East Scotland. However, certain belts of rock seem to have been more resistant to shattering and correspond to summits of sharper form, such as Makeness Kipps, $\mathbb{E} E$ of Peebles where the trend of the sumit ridge parallels the strike.

IV. Distribution.

Frost shattering is best developed in the North East, and on Highland summits. It is widespread, but not so deep in Shetland, Orkney and the Southern Uplands. The concentration in the NE reflects the occurrence there of suitable rock (quartzite, phyllite, schist, weathered granite and gneiss), the scanty glacial drift and 
perhaps more prolonged and intense periglaciation. Its rarity in Highland valleys and the Lowlands is a result of the dominance of glacial erosion and deposition in these areas.

V. Dating.

The shattering observed in Scotland extends far below the depth of present day frost penetration and must be a product of periglacial conditions now vanished. Deep frost shattering in the Southern Uplands postdates the last ice sheet in the area since no till in situ has (yet) been observed overlying it. i.e. It developed after the period of the Scottish Readvance. The deeper shattering in the NE may well be older; shatteried phyllite has been observed to be overlain by a till of the Moray Firth stage in the Burn of Aultmore, $\mathrm{NE}$ of Keith, Banffshire.

Dating the period of formation of the mountain top detritus is more difficult. It certainly cannot be attributed to present day processes, and a late-glacial age seems most probable, though DAHL's suggestion of an origin by interglacial chemical weathering must not be forgotten. (DAHL 1955). Frost action is still very effective today at these high levels in producing small fragments, notably individual crystals on granite areas and there is no evidence that the total volume of shattered material produced in a given time is any less now than under more extreme climatic conditions of the past. 
VI. Conclusions.

1) The widespread occurrence in Scotland of rock shattered to depths far below those reached by present day temperature changes supports the evidence brought forward in previous chapters for the former existence of severe periglacial conditions.

2) The maximum depth of shattering noted indicates a minimum depth of permafrost of 8 metres, and extends well below the depth attainable by freeze/thaw cycles.

3) The intensity of frost shattering and the calibre of debris produced varies from one rock to another. Quartzite, phyllite, shales and schists are readily shattered, other metamorphic rocks and granite in the unaltered, fresh state are less sensitive. Chemical weathering renders the rock more liable to be shattered. 4) Frost shattering is best developed in the NE of the country, where an ice-free enclave may have existed for a considerable portion of the last glaciation and where the rocks are extensively altered or are readily affected by frost.

5) Shattering of the bedrock to moderate depths is typical of the Southern Uplands and has been a factor in the recent gullying of steep slopes.

6) Present day shattering is active on high areas, but generally tends to produce finer fragments, especially in granitic districts, than were formed under the severer conditions of the past.

7) The shattering has provided abundant material for mass movement. The resulting deposits will be considered in the next chapter. 


\section{CHAPTER VIII}

\section{MASS MOVEMENT.}

I. Introduction.

In periglacial environments unconsolidated material moves readily down the slopes by mass movement. This mass movement takes place under both severe conditions with permafrost and under less severe conditions where permafrost is absent. The slope deposits produced in this way are heterogeneous mixtures of stones in a matrix of finer material. The proportions of stones and fine material vary within wide limits.

ANDERSON introduced the term "solifluction" in 1906 for a slow creeping of wet, unconsolidated material down slopes in cold regions such as Bear Island and The Falkland Islands. A few years later EAKIN (1916) used the term in quite another sense for "migration of debris under the thrust and heave of frost action". cf. DEGE (1941) attached great importance to "frost thrust" when discussing solifluction in Spitsbergen, claiming it was much more widespread and important than the more rapid but spacially restricted flowage of wet soil. Many other writers, on the other hand, have used the term simply to denote a downslope movement of wet material under any climate. SHARPE (1938) defined solifluction as the slow flowing downslope of masses of rock debris which are saturated with water 
and not confined to definite channels. This loosening of the sense of the term is not a disadvantage since the process is in fact not ultimately an effect of growth in the soil and operates wherever suitable slope, material and moisture conditions prevail. The writer's obseryations in Greenland and N Norway confirm the opinion that it is the high moisture content of the ground and not freezing that is the dominant cause of solifluction in these areas.

Two mass wasting processes ancillary to solifluction proper do depend on the growth of ice in the soil:- firstly, the oftendescribed uplifting of individual soil particles or stones by needle ice (pipkraks); secondly, the upheaving on freezing of the entire surface of a slope. (SCHMID 1955). Both processes lead to the downslope migration of material on thawing. However, neither are restricted to truly periglacial environments, many of which seem less favourable than those of cool temperate regions with frequent freeze/thaw cycles and high humidity.

While the low temperatures of periglacial regions do not cause solifluction they do provide very favourable conditions. The ground has a high water content in summer due to the melting of homogeneous ice and, especially, segregated ice masses, the low evaporation, and the presence of an impermeable layer beneath; the cohesion of the soil is reduced by ion exchanges and the poverty of the vegetation; abundant unconsolidated material is available, often with an important silt fraction which favours the absorption of water and the formation of segregated ice masses. It has often been claimed also that the upper surface of the permafrost forms a 
smooth table over which wet loose material can glide. e.g. JENNESS 1952. In fact this is hardly ever the case since the upper surface of the permafrost is more usually irregular (DEGE 1941) or not a surface at all but a vague zone as the writer has observed in Greenland.

So suitable are the circumstances that solifluction under periglacial conditions reaches an extent and importance unmatched in any other region. It can take place down gradients as low as 1 or 2 degrees. In view of this many writers, following BRYAN (1946) have adopted the term "congelifluction" (adjectival form "congeliflual") for solifluction under such conditions, e.g. JAHN 1956. This usage is to be deplored since it implies that freezing ("gel") is the essential motive force. Also in dealing with deposits no longer being formed it implies a sure knowledge of the conditions prevailing at the time of formation, perhaps many thousands of years ago. It is unrealistic to use the term "congelifluction" in such cases.

In the British literature a bewildering variety of terms exists for drift produced by mass movement under periglacial conditions in the past. One of the oldest terms, traceable back to traditional Cornish mining lore, and still used widely in this country and even in France, is "head". (DINES et al 1940). Others are "trail", "warp", "coombe rock" in chalk country, "rubble drift", "angular earthy moraine", and sometimes "colluvium". These terms are all vague and confusing, especially for non-English speaking readers and their use is to be avoided. 
In view of these considerations of terminology, the satisfactorily neutral term "solifluction" -- in ANDERSON's original sense -will be used in this study. Material moved by solifluction will be known as "solifluction deposits". Use of these terms does not commit one to postulating a periglacial origin for any deposit without proof, while in no way excluding such an origin.

Solifluction deposits may take several forms. WASHBURN (1947) has given a good account of the various types of solifluction observed on slopes in Victoria Island, Arctic Canada. He has distinguished four types of solifluction deposit.

1) Solifluction sheets extending uniformly over wide areas.

2) Individual solifluction lobes of widely variable size and shape. 3) Solifluction streams and stripes.

4) Slumps.

Most slopes present a combination of these features, some of which can produce a considerable roughening in detail while smoothing the slope profile as a whole.

The material in solifluction deposits may be the product of periglacial frost shattering, or of glaciers (till), or of weathering under fomer temperate or warm climates. A certain amount of fine material is necessary to promote mass movement on slopes less than the angle of rest of loose rock debris. (About 30 degrees). This fine material can consist of interstitial snow or ice. Uniform solifluction sheets most commonly develop if the material consists solely of fine matter. If the material contains large boulders resistant to frost shattering as well as fines, the former may appear at the surface to form a block field, often concentrated 
along a valley floor in the form of a block stream. The fine matrix may be washed out subsequently leaving only the coarse blocks. The presence of many stones in the material seems to be a favourable factor in the development of individual solifluction lobes or terraces with steep fronts built up of these stones. Vegetation can play a similar role by acting as a dam and helping to build up turf banked lobes and terraces by locally restricting downslope movement.

In section, solifluction deposits may show no apparent structure, or crude bedding, well developed stratification, contortions, and flow structures. Stones in the deposit are mostly aligned down the slope, unless in the front of a stone banked terrace or lobe when they tend to be aligned across the slope. (LUNDQUIST 1949). The deposits are generally thinnest on the brow of a hill and thicken towards the foot where they may accumulate to a depth of many metres.

The speed of periglacial solifluction varies enormously with slope, vegetation, and water content. HOGBOM (1914) thought that motion at the surface was of the order of a few $\mathrm{cm}$ or decimetres per annum. Motion at depth is much less and dies out at the foot of the active layer. Satisfactory actual measurements in Arctic regions extending over a period of years in many different situations have yet to be published.

Solifluction is widespread throughout the contemporary periglacial regions, including mountains above the tree line where steep slopes are an especially favourable factor. "Fossil" solifluction deposits have long been recognised in the Plesitocene 
periglacial regions of Europe. e.g. J. GEIKIE in 1894 mentioned its occurrence over wide areas of the Continent. More recently it has come to be realised that mass wasting under former periglacial conditions has done much to produce the landforms of today, and has played a not unimportant role even in a heavily glaciated country like Scotland. (FITZPATRICK 1958).

II. Identification.

Contemporary solifluction. Most of the evidence for contemporary solifluction comes from an examination of surface features. If solifluction is active on a slope today, walls and fences may be tilted and displaced, and the vegetation disrupted; lobes and terrace features of various forms may develop including stone-banked and turf-banked terraces, terracettes and irregularly stepped slopes. Boulders on the surface may move downwards more slowly than the fine material which piles up behind them, or they may move faster and plough down through the finer material producing an arcuate ridge of turf in front and an elongated hollow behind, like the bow wave and the wake of a ship. See photograph 36.

The larger of these features, particularly stone banked terraces, are so big that although they may be in motion today, and are therefore to be classified as "contemporary" forms, they must have a long history of development and have been initiated under tree trunks on slopes is NOT diagnostic of mass movement. 
earlier, different conditions. Determination of the share of present agencies in their formation is often difficult. Fossil solifluction. This may be a loose usage of the word "fossil" but it is a convenient term to describe processes and forms no longer active today, and attributable to past conditions.

Most of the evidence for fossil periglacial solifluction comes from examination not of the surface features but of sections in drift deposits. Recent deep artificial exposures like quarries are the most reliable source of evidence since natural exposures such as a stream bank are often at the foot of a steeply undercut slope where slumping may give a false impression of mass movement. Topographic evidence of smooth slopes is even less reliable and was used in this study only as a guide to the rough areal extent of a solifluction deposit whose existence was already demonstrated from sections.

One difficulty in a glaciated country like Scotland is to determine whether a given drift deposit has been formed glacially (i.e. is till) or periglacially. Both agencies can produce hetrogeneous material containing erratics, some of them striated, that lies thickest on valley bottoms and clothes the lower hill sides but leaves the summits clear. The presence of erratics and striated stones is not diagnostic of till since these may be incorporated in a solifluction deposit subsequent to the disappearance of the ice, and in addition it appears likely that stones can become striated during transport by solifluction. The absence of erratics is stronger, but not definitive, evidence of periglacial solifluction deposits. 
The preferred orientation of stones within the deposit is a more reliable guide. In glacial till stones usually have a preferred orientation parallel to the direction of ice motion (occasionally perpendicular). (HOLMES 1941). In solifluction deposits there is a strong tendency for stones to be aligned up-and-down the slope. Provided the direction of ice movement and that of the slope do not coincide the two types of deposit can be distinguished on this basis. The method was used in the field work for this thesis in certain cases. Where stones in glacial till show a preferred orientation down the slope different from the known direction of ice movement, the till itself must have been rehandled by mass movement and is itself strictly speaking a solifluction deposit. However, in some cases neither till nor solifluction deposits show a distinct preferred orientation.

Till generally has a tougher, more compact texture than solifluction deposits, except in the uppermost part where weathering and plant roots may have loosened it or where a superficial moraine has been deposited when the ice finally melted. Till hardly ever shows bedding, while a crude bedding is very common in solifluction deposits.

Solifluction deposits comprising shattered rock fragments, is readily distinguishable from till by the angular nature of the stones. POSER \& HOVERMANN (1949) have used this contrast very satisfactorily in distinguishing glacial from periglacial deposits in the Harz. Where there is no serious admixture of rehandled till, the criterion of smoothness of the fragments can be of use in Scotland. 
Evidence that mass movement has ceased and that a solifluction deposit is truly "fossil" can sometimes, but not invariably, be obtained. If the stones in a deposit are cemented by compounds of lime, iron or manganese this shows that movement has ceased for at least as long as required for the cementing to develop. A well developed soil profile or peat layer over a solifluction deposit is likewise proof of stability. But soils and peat can be stripped off by erosion, so their absence is not proof that the deposit is still moving down the slope. There can be no doubt of the fossil state of solifluction deposits overlain by till or gravel in situ.

Having identified a solifluction deposit and proved that it is fossil there remains the further problem of determining whether the deposit was the work of periglacial agencies or formed during some wetter but no colder phase in the past, such as the Atlantic Period. If the deposit is cryoturbated, or passes laterally into cryoturbated material such as a river terrace with wedges, a periglacial origin is almost certain, but not quite, since the sryoturbation could postdate the deposition of the terrace. Only if the cryoturbation is of such a type (e.g. wedges or free involutions) that must form at the surface and is now included within the deposit can we be sure that periglacial conditions were strictly contemporary with the solifluction. No such unequivocal cases are known in Scotland.

If the solifluction deposit contains an overwhelming proportion of angular stones, the product of frost shattering, it is reasonable to suppose that the solifluction has taken place under the same conditions as produced the shattering. Nevertheless this 
correlation is not unequivocal since the solifluction may be rehandling shattered rock fragments produced by some earlier periglacial phase.

Glacial till overlying a solifluction deposit invites one to ascribe the latter to the cold conditions concomitant with the advent of the former: again this is only supposition, not proof, as the phase of solifluction might have long predated the glaciation.

III. Description, Distribution, and Dating.

It is obviously out of the question to give an account of all the solifluction deposits of one kind or another seen in Scotland since they cover a large part, perhaps the greater part, of the countty. All that can be done is to describe a few significant examples from different areas and attempt to draw general conclusions from this information. Lowland areas will be sonsidered first, then the Highlands, followed by the Islands, and finally by the Southern Uplands and hill areas of Central Scotland.

\section{IIIa. Lowland areas.}

1) Description

North east Scotland. Throughout this district solifluction deposits are widespread and at least within the limits of "Moraineless Buchan" few sections fail to reveal it. Once the eye has become accustomed to identifying these deposits they are to be seen on every hand. These solifluction deposits have been observed in the area only in recent years, although the district has been 
investigated by highly competent glacial geologists for over a century. (Notably JAMIESON and BREMNER).

S. SIMPSON (1949) has described solifluction deposits with a maximum thickness of about 2 metres, but generally much less, around the mouth of the Dee in the outskirts of Aberdeen. SYNGE (1956) has mentioned solifluction in "Moraineless Buchan" and, possibly, in Lower Banffshire. DONNER (1957) has mentioned layers of mineral matter underlying and overlying peats of Aller dd age at Garral Hill, Banffshire. This is important since it proves that mass movement was active in the area during late glacial times. Much of the deposit appears to be a product of surface washing of bare ground, rather than a true solifluction deposit, but a few stones do occur in the material, indicating that mass movement was also at work. FITZPATRICK (1958) points out that solifluction is widespread in eastern and southern Scotland.

Excellent examples of solifluction deposits are to be seen in exposures in the area of phyllite rock lying $W$ and $S$ of Turriff。 At Bruckhills (G.R. 692379) a cutting revealed the section illustrated in photograph 37 and figure 32. The exposure was in a smooth slope of about 15 degrees that formed one side of a flatfloored valley whose origin will be further discussed below.

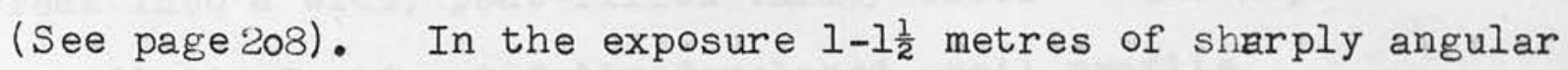
fragments of the local phyllite in a powdery mixture of sand and silt overlay and graded into shattered bedrock. A single weathered glacial erratic was observed, probably a relic of the Greater Highland glaciation. An orientation analysis of 50 pebbles taken about $50 \mathrm{~cm}$ below the surface showed that 41 lay with their long axes within 30 degrees of the direction of slope: 
an unequivocal solifluction orientation. The intimate association with the shattered rock beneath makes it certain that this is a fossil periglacial solifluction deposit. Similar exposures of angular fragments of phyllite in a powdery matrix, capped by a soil profile, and overlying shattered bedrock, can be seen in an old quarry near the headwaters of the Ythan (G.R. 630379); at Woodside, $9 \mathrm{~km}$. ENE of Huntly (G.R. 612407); and at Gallows Hill (G.R. 685437). The cleavage planes of the shattered rock can often be seen distorted down the slope by mass movement. There can be no doubt that soli:fluction deposits of periglacial origin cover almost the entire area. These deposits are thin or even absent on hill tops and thicken down the slope to $2-3$ metres as a rule. The average depth is about $1-1 \frac{1}{2}$ metres.

Very similar deposits can be seen in areas of schistose bedrock (e.g. by the roadside $1 \mathrm{~km}$. S of Strichen), in slate areas as the Glens of Foudland SE of Huntly, and in a platy facies of quartzite in eastern Buchan. A fine example of solifluction in this last type of rock is to be seen at Ardallie Bog (G.R. 999398), $10 \mathrm{~km}$. NNE of Ellon. $\quad 1-1 \frac{1}{2}$ metres of shattered platy fragments overlie shattered and slightly weathered bedrock. The exposure is near the foot of a smooth slope which passes gently without any topographic break into a wide, peat-filled valley floor. The deposit is capped by a distinct, if not fully-developed, soil profile.

Only two types of erratics could be seen in this exposure, well rounded fragments of flint and quartzite. These stones must have originated from a former bed of Pliocene(?) gravels (FLETT \& READ 1921) at the top of the slope. These gravels survive in situ on a 
neighbouring hill, but must have been entirely stripped off the summit behind the exposure in question by solifluction. Intense and prolonged solifluction has presumably also removed any vestiges of glacial till. In solifluction deposits in North East Scotland it is more usual to find packets of rather weathered till included, originating doubtless at the time of the Greater Highland glaciation - the last to cover the area entirely. (SYNGE 1956).

Slightly different solifluction deposits are found on the prominent hill of pure quartzite which rise in this part of Scotland. e.g. The Balloch, Sillyearn Hill, Durn Hill, Mormond Hill. The deposits are rather coarser than on phyllites and schists, with chunks of the country rock in a sandy matrix. The thickness of the deposit averages 1-2 metres and it grades downwards into shattered bedrock. On gentle and moderate slopes a well-developed soil profile shows that in such situations the deposit is stable. On steeper slopes, particularly at higher levels, motion continues today, favoured by removal of peat through man's action. e.g. On the knock, Banffshire, at an altitude of about 1,000 feet small stones and fine material have accumulated on the upslope side of immobile boulders.

On impure quartzites with some felspar and on quartzose granites a different type of solifluction deposit is found. Such rock was exposed in a quarry at the SW corner of Ioudon Wood. (G.R. 953493). The rock had been deeply weathered by chemical action under warmer interglacial conditions. The weathering products formed fairly regular layers alternatively dark and light in colour, a few $\mathrm{cm}$ thick, and parallel to the surface. Angular blocks of unweathered rock were occasionally included. The depth of the deposit was from 
1 to 3 metres. The layering had been produced in the course of mass movement down the slope and the whole deposit closely resembled ex:posures of deeply weathered granite described from the Massif Central by Mme. BEAUJEU-GARNIER (1953, 1956). The mass movement had certainly taken place under periglacial conditions, since involutions have been observed in the deposit. See page 63 above.

This exposure provides the closest known analogy to the "rythmi:cally stratified slope deposits" described from France and Poland. (TRICART, DYLIK 1955). The different layers with contrasted granulometry are believed to be formed by solifluction during wet and dry seasons alternatively.

Rather similar deposits, not so clearly stratified, but with chunks of fresh rock in a soliflucted matrix of weathered material may be seen at Northseat quarries. (G.R. 932407). Another example is illustrated in photograph 38 which shows a roadside section at a point $3 \frac{1}{2} \mathrm{~km}$. S of Strichen. (G.R. 957517). Chemically altered and frost shattered rock can be seen in situ at the bottom. This grades upwards, through material displaced down the 5 degree slope towards the right, into a solifluction deposit composed of weathered rock with angular stones of fresh material rafted down from further up the slope. The whole is capped by a soil profile and is entirely fossil. All the examples of fossil periglacial solifluction listed above are amorphous in that there is no surface expression such as terraces of lobes. Block field type of solifluction deposits are less common in this district, but examples do occur, usually on hill tops. In some cases the blocks originated as glacial erratics, in other they derive from the underlying bedrock. 
An example of the "glacial" type of block field extends northwards as an erratic fan from The Bin near Huntly, (G.R. 503438) almost to the coast. The basic igneous boulders are even littered on the summit of The Knock over 1400 feet above sea level. The long axes of these erratics on the upper part of the Knock showed a distinctly radial pattern, showing they had been displaced by solifluction after being deposited by the ice. See figure 33. This displacement must have happened before the peat cover on the hill developed but after the Greater Highland glaciation. i.e. at a time when periglacial con:ditions prevailed, or in early postglacial times.

An example of the "non-glacial" type of block field occurs on the summit of Mulderie (G.R. 384517). Blocks of the underlying foliated granite, generally aligned down the slope, peep up through thin peat. Probably many similar block field exist on hill in this district, but are hidden under a blanket of peat. At higher ele:vations in other parts of the country similar block fields occur without a peat cover. See photographs 35 and 45 .

Solifluction has also affected glacial till in this part of Scotland. Beyond the western margin of "Moraineless Buchan", till occurs frequently. Studies of preferred orientation were made at several points and it was usually found that the upper $\frac{1}{2}-1$ metre showed a downslope alignment of the stones, no matter from what direction the ice had come. This suggest that the till has been rehandled by mass movement after deposition, at least in the upper part. All attempts to reconstruct former directions of ice motion from the alignment of stones in till in scotland must bear in mind. Since there is no direct association with shattered bedrock or 
cryoturbation, it is not known if this mass movement took place under periglacial conditions or not.

At least one section where considerable mass movement had undoubted:Iy taken place long after the close of the ice age was observed, at Bridgend, near Huntly. (G.R. 517359). At this point about 2 metres of angular rock fragments in an earthy matrix overlies a grey silt containing peat. Pollen analysis of the peat, kindly carried out by S.E. Durno of the Macauley Institute of Soil Research, showed un:equivocally that the peat was of early Atlantic age, and the mass movement must have taken place since then. Conditions are admittedly especially favourable for mass movement at this point since it lies at the foot of a slope of some 20 degrees being undercut by the Ness Bogie. Nevertheless, the evidence means that considerable caution is called for before attributing all solifluction deposits to a periglacial origin. Fuller details of this exposure are given in Appendix B.

To sumarise, in the Lowlands of Northeastern Scotland fossil periglacial solifluction deposits involving frost shattered rock, till, and chemically weathered material, are very widespread. In "moraineless Buchan" they effectively cover the whole countryside to a depth of fully a metre. While the deposits show no characteristic surface details of mass movement their internal nature varies with lithology. Fresh quartzite produces the coarsest deposits, schists and phyllites produce finer deposits while the finest of all, sometimes showing a rythmically stratified structure, are developed on chemically altered rocks. Block fields occur occasionally on hill tops where suitable boulders have been provided by glacial action or by the 
weathering of the underlying bedrock. Mass movement continued, at least in restricted localities where conditions were especially favourable, into post glacial times.

Central Lowlands. In contrast to the area just discussed, mass move:ment deposits of periglacial origin seem to be of little importance in the Central Lowlands in comparison to the thick and varied glacial deposits. Part of this contrast may be due simply to the smaller amount of field work devoted to this area, but it can by no means be ascribed entirely to this cause. Solifluction has undoubtedly re:handled the glacial till and gravels, but the effects are not so readily detected as in the shattered rock debris of the NE. The effects of solifluction are rather more apparent on the isolated hill masses that rise from the Lowlands, such as The Pentlands and The ochils. See below.

Borings made by DONNER (1957) into late glacial sediments in lakes in Stirlingshire showed only very thin accumulation of minerogenic matter attributable to solifluction. These deposits represent but a negligible modification of the relief by periglacial mass wasting.

SE and SW Lowlands. Field work in these areas was but sketchy. The evidence obtained resembled that from the Central Lowlands: glacial deposits dominate the landscape and notable solifluction deposits were not observed. Nevertheless, there must have been some rehandling of glacial material by periglacial processes. Assessment of the significance and extent of this rehandling is a task for the future. 
2) Distribution and dating.

Solifluction deposits comprised mainly of frost-shattered rock debris cover the greater part of the surface of 'Moraineless Buchan' and are not uncommon on the other parts of the area which were ice covered in the course of the last glaciation. The distribution of solifluction dposits in other Lowland areas is harder to assess since in most cases they consist merely of rehandled glacial and glaci-fluvial drifts. It is probable, but yet to be demonstrated, that mass movement under periglacial conditions has in fact affected most of the surface of these areas, although the total modification of the forms of glacial deposition has been slight.

The solifluction deposits are almost entirely fossil, although contemporary mass movement does take place to a limited extent on steeper slopes. It would be extending the already broad use of the term "periglacial" too far to apply it to this contemporary mass movement. Close dating of the fossil deposits is not easy, especially since the possibility of considerable mass movement in early Atlantic times must be borne in mind. (See Appendix B). In the NE some solifluction took place before the Moray Firth Ice stage, since crudely bedded solifluction deposits associated with the shattered phyllite underlies till of this age on Aultmore, N of Keith, Banffshire. Mass movement must also have taken place in this area at a later period, during Zone III times, as minerogenic layers a few decimetres thick, ascribed to solifluction, are found overlying the Aller dd peats at Garralhill. (DONNER 1957). 
The solifluction in the Central Lowlands must have taken place after the Scottish Readvance stage during which the whole area was covered in ice, but on present information it is impossible to date it more closely. The amount of this Late-glacial mass movement which took place after the Allerpd period, during Zone III times, must have been slight, to judge from the extreme thinnes of the minerogenic solifluction layers detected by DONNER (1957) in borings in lakes in Stirling, Dumbarton and Argyll. There is no certain record of solifluction preceeding the Scottish Readvance though "rubbish" under till and overlying bedrock described by BENNIE (1891) may have been solifluction deposits of this age.

IIIb. The Highlands.

Northern Highlands. The classic observations of solifluction features on British hills have been made in this area. (CRAMPTON \& CARRUTHERS 1914; PEACH et al 1912, 1913a, 1913b.) Subparallel terrace features, turf banked or stone banked and a few decimetres high are the most commonly described phenomena. e.g. by PEACH et al.(1912) on Carn Ban, Meallan Ban, Beinn a' Chaisteil, and Meall a'Ghrianian. Photograph 39 is a copy of Geological Survey photograph number C1333 taken about this period on Fannich Forest, and gives a good impression of these terrace features. All these writers imply that mass movement is actively progressing today, but that the greater proportion of the material involved originated by frost shattering in late glacial times. There is no suggestion that some of the mass movement features are themselves relics of former colder conditions. 
Study of air photographs and Geological Survey photographs together with fairly rapid road traverses has shown that obvious mass movement features are practically universal on all hill rising above 2,000 feet, and are not infrequent at lower altitudes, if peat has not obscured the surface. Localities noted include the following:

Ben Loyal, Ben Hope, Ben Kelbreck, Ben More Assynt, Ben Eighe (see photograph 40), Ben Arkle, Beinn Liath Mhor a' Ghiubhais Li (Fannich Forest), and Strathvaich Forest. On all these hills the lower limit of large solifluction features detactable from air photographs or from the roadside below, was about 2,000 feet. The features include not only the terrace forms emphasised by the Geological Survey, but also lobes and stone streams which are fully as abundant.

A closer study of Ben Wyvis made in the field and from air photographs revealed a great variety of solifluction features. See figure 34 .

Ben Wyvis forms a compaet massif rising well above the surrounding terrain to an altitude of 3428 feet. Fully 3 square $\mathrm{km}$. lie above the 3,000 foot contour and PEACH et al (1912) consider that it formed an independent centre of ice dispersion, during the last glaciation since no erratics derived from the west have been found higher than 2,300 feet where a morainic bench is said to mark the zone of contact between the two ice bodies. (HINXMAN in Summary of Progress for 1903). The form of the mountain is predominantly smooth, with straight, even slopes and a rounded summit, though corries have bitten deeply into the eastern flank. The rock is 
predominantly platy pelitic gneiss and schist with a steep dip ESE, containing belts of quartz biotite granulites and siliceous schists which also outcrop on lower ground to $W$ and $E$ of the mountain. The former rocks weather into thin plates with abundant fine material; the latter furnishes blocks and slabs. Some details of the vegetation have been given by PEARSALL (1950). The mountain is unusual in that heather is absent above 2,000 feet and the dominant vegetation is rhacomitrium heath with some bilberry, wavy hair grass and nardus stricta. Peat is restricted to a few damp hollows above 2,000 feet. The l" Geological map indicates that the entire summit and upper flanks of the mountain are covered with mountain top detritus, under the thin but all-enveloping vegetation. The detritus layer is $1-3$ metres thick. PEARSALL ( 1950 p.90) indicates that the surface is not quite stable.

The four main types of solifluction features mentioned by WASHBURN (1947) were well represented on Ben Wyvis.

1) Homogeneous solifluction sheets cover the entire surface of the summit plateau. Any individual stone that projects above the vegetation has a down-slope orientation. Usually the sheets end in a fringe of small lobes at the break of slope at the edge of the plateau, but in one case a single, gently arcuate front could be traced for some 800 metres. See figure 34. This front was entirely vegetation covered and varied from $\frac{1}{2}$ to $1 \frac{1}{2}$ metres high, being higher where the slope was steeper. Such long features, usually rather more irregular, have been seen in E Greenland, but this is probably the first record in scotland. 
2) Hundreds of individual lobes exist on this mountain. They can be subdivided into stone-fronted lobes and vegetation-covered lobes.

Stone fronted lobes are found on slopes of 8-20 degrees. Their typical form is sketched in figure 35. The height of the fronts ranges from 1-5 metres; the width of the lobe from 4 to 30 metres. On gentle slopes the lobes lie more or less side-by-side to form a sort of terrace, but on steeper slopes, this order breaks down and some seem to have moved faster than their neighbours and may have overwhelmed lobes further down. There is often a downslope sequence from small, regular lobes to larger irregular lobes. These features are often fronted by an apron of fine material washed out of them by water issuing at the snout of the lobes, and from the hollow between adjacent lobes. If snow collects at the back of this apron beneath the snout of the lobes a pseudo-nivation hollow is formed. In this case, however, the hollow owes little or nothing to "snow patch erosion" (LEWIS 1937) and is a constructional feature. Hollows of this sort are not uncommon on Ben Wyvis. The material in stone-fronted lobes consists of large stones and a moderate amount of fine material. They tend to develop on slopes where the siliceous schists and quartz-biotite-granulites occur. Stones in the front of the lobes show no clear preferred orientation; between and on top of the lobes they are clearly aligned down the slope.

On Ben Wyvis, the dominant vegetation on the lobes is the rhacomitrium-heath, but hair-grass and nardus predominate on the apron of finer material in front. Vegetation may have also 
invaded the stones on the snout of the lobe. At a few points below 2,000 feet the form of stone-fronted lobes may be distinguished under heather and peat.

On slopes up to about 20 degrees, the stone-fronted lobes seem more or less immobile and the main morphological activity is the continued washing out of fine material. On slopes steeper than 20 degrees, motion of the blocks in the front has continued, leading to the destruction of the lobate form and the development of stone streams -- transitional forms can be observed. See photograph 41.

Vegetation-covered lobes have a softer, more indistinct form than the stone-fronted features. Their dimensions are more variable but they are generally smaller as are the aprons of washed material which develop in front of them. They are best developed on slopes of 5 to 15 degrees. As their name indicates, they are entirely covered with vegetation, though this cover is often locally cracked and broken. The material in these lobes is finer than in the equivalent stone-fronted forms, and they are correspondingly commonest on the pelitic gneiss and schist outcrops. These lobes seem to be a contemporary form still very much in motion where sufficient moisture is available, at the head of valleys, below snow patches and at the outer edge of aprons of fine material washed out of the stone-fronted lobes.

Terraces may be considered here as a special variety of lobe:they are in fact built up of closely juxtapositioned lobes linked by roots and so constrained to move downslope at a uniform speed. In comparison to lobes, they are not frequent on Ben Wyvis. They 
take the form of subparallel steps, 5 to 20 metres long, with treads $\frac{1}{2}-20$ metres wide and risers of about $30 \mathrm{~cm}$. They may run parallel to the contours or in a markedly oblique fashion. The material consists of medium and small stones and finer debris, never of blocks and boulders. They are restricted to two locations: on dry fairly steep sites closely associated with heather on the east of the mountain, and on the lip of the corries, where there is naturally a relatively rapid movement of material towards the void. Mass movement is actively under way in these features today, as shown by broken roots and upended stones.

3) Block streams are less widespread than lobes. They take the form of irregular belts of predominantly large stones and boulders aligned up-and-down the slope for distances of 10 to several hundred metres. The individual elements of the stream have a similar orientation, unless they are very small, when they tend to lie at any angle between the larger stones. Often the lower end of a block stream is marked by a small lobe or arcuate turf bank.

Some block streams can be seen to be the product of the disintegration of stone-fronted lones on steep slopes. cf. pagel23 above. Others take the form of a train of boulders rafted down the slope from an especially resistant outsrop. e.g. On the summit of Ant-Socach, see figure 34. These outcrops are in effect tors, although it is not clear whether their destruction by the rafting away of blocks keeps pace with, is slower than, or is faster than, their exposure by the mass wasting of the surrounding less resistant material. Block Streams derived from stone-fronted lobes are 
located on steeper slopes, principally the sides of the glacially overdeepened valleys on the east. See photograph 4l. Block streams from tors are located chiefly on the siliceous schists and granulites. There can be no doubt that the block streams are still in motion. Individual boulders sometimes have "bow waves" in front and "wakes" behind (see page 10 babove) particularly on steeper slopes. In one case a boulder about 1 metre long had left a furrow 9 metres in length behind it on a slope of around 11 degrees. At lower levels, around 2,000 feet it is possible to find block streams more or less buried in heather and peat and nearly immobile.

The vegetated sorted stone stripes discussed on page 84 above are a further example of mass movement phenomena on Ben Wyvis. They are confined to pelitic gneiss and schist areas on the $\mathrm{N}$ end of the mountain where the rock seems particularly platy.

4) Slumps are very restricted. In the case of old examples it is scarcely possible to distinguish them from the hollow to be found between adjacent vegetation-covered lobes. A few examples are to be found in especially wet hollows on the south east end of the mountain and in the Bealch Tom a'Choinnich. In the former area the slumping was related to the presence of a snow patch at the head of a fairly steep hollow where the gradient and the abundant water were favourable factors. In the latter areag slumping has produced a collection of 8 small ponds, a few metres across, retained by a puddle of peaty silt. The ponds mostly lay behind slump accumulations resembled the tundra ponds described by IVES (1940). 
The distribution and nature of solifluction phenomena found on Ben Wyvis depend on the following factors: The material available, the water content, the slope, the vegetation, the altitude, and the exposure.

If the material is coarse with little fine matter, block fields and streams result: these features are found on rock which weathers by frost shattering into large slabs. This clearly seen on Carn Gorm, built of siliceous schists and granulites and covered by a block field. Coarse material with some finer matter is associated with stone-fronted lobes. If the fines are washed out the lobes become immobile. Fine material with some stones produces vegetation-covered lobes on wet sites and terraces on dry sites and occasionally stone stripes. Predominantly fine material favours slumping.

The presence of water is necessary to all the forms of solifluction but especially to vegetation-covered lobes and to slumps. These features are therefore to be found in wet hollows at the head of streams and along the margins of the summit plateau where abundant water is available from arainage of the mountain top detritus. Vegetation-covered lobes are also frequent below snow patches and at the lower edge of outwash aprons from stone-fronted lobes where water and fine material are abundant. Water seems less important in the formation of terraces which are confined to drier sites.

Gentle slopes favour uniform solifluction sheets, without the development of individual lobes which are concentrated on moderate gradients between 5 and 20 degrees. Steep slopes bring about the disruption of stone-fronted lobes to form block fields and in wet, fine material favour slumping. On uniform gradients the lobes tend 
to be larger towards the foot of the slope where there is a greater accumulation of the necessary material.

The role of vegetation seems important only in the case of terraces where the heather roots do much to bind the fronts together and so maintain their steepness as the movement progresses by acting as a dam for mobile material behind. The vegetation cover on the lobes does not seem to seriously inhibit their motion, because the root system of the prevailing rhacomitrium is weak and shallow. Below 2,000 feet, however, the thicker heather and peat cover have immobil:ised and partially buried stone streams.

The effect of altitude is masked by other factors. Doubtless the climate is more severe above 2,000 feet but more important on Ben Wyvis is the sudden steepening of the slopes about this level and the concomitant change of vegetation from heather to dominantly rhacomitrium. It is slope and vegetation rather than altitude which decrees the change from inactive to active solifluction features about this level. Even on the very summit the climate is not sufficiently severe to destroy the completeness of the vegetation cover.

Exposure affects the development of solifluction features only indirectly:- if other conditions are equal, lobes and block streams are as common on $\mathrm{S}$-facing as on $\mathrm{N}$-facing slopes. Snow patches however tend to lie longer on $\mathrm{N}$ and $\mathrm{NE}$-facing slopes and their presence favours mass movement below them. In the deep glaciated valleys of the $E$ exposure has indirectly influenced the location of solifluction. In the last stages of the ice age, the glaciers lay under the SW side of these valleys rather than at the head, and it is this side which today presents bare rocky crags on which solifluction is impossible except 
for terraces at the lip. These crags are best developed on the siliceous schists and granulites.

There is, then, a rich variety of solifluction forms on Ben Wyvis. One has no hesitation in terming this solifluction periglacial. It is more difficult to determine the relative shares of past and con:temporary processes. The vegetation-covered lobes, slumps and indi:vidual boulders are actively moving, but the stone-fronted lobes and the stone stripes seem more or less immobile and must be ascribed to a former period or periods when mass movement was more effective. The existence of such a former period is proved by the presence of block fields and lobes under thin peat below 2,000 feet. On the other hand, the period during which the mass movement was especially active cannot have been very long because the resulting deposits are not thick apart from limited areas in valley bottoms where several metres may have accumulated. They may also have been relatively recent since only a thin rhacomitrium layer covers the fossil stone stripes.

It seems most in harmony with the available evidence to say that the mountain was not a nunatak in full glacial times but carried its own firn field. In late glacial times frost shattering was active and stone-fronted lobes formed. In post glacial times, mass movement of these lobes tended to slow down but continued actively in the form of vegetation-covered lobes, block fields, terraces, slumps, and stone stripes. At some relatively recent date the latter were colonised by rhacomitrium and stabilised. This mixture of late-glacial, postglacial and contemporary forms and processes, grading into one another 
in form, time, and space is typical of the scottish Highlands. Western Highlands. Solifluction is not so well known in this area which has been taken to include the country $S$ of a line LochalshFort Augustus. BAILEY \& MAUFE (1916) speaking of the Mamore Forest region state (page 12) "On...mountain tops the debris covering, especially where it is composed of comparatively small fragments has crept forward in a succession of steep-fronted, flat-topped waves or terraces". WATT \& JONES (1948) have briefly mentioned terrace features with fronts 4 feet high on Caisteal Abhail in Arran. Mr. T.R.M. Lawrie of the Geological Survey ${ }^{\#}$ has observed similar features on the $\mathrm{N}$ side of Cruach Innse $4 \mathrm{~km}$. S of Roy Bridge from about 2,500 feet upwards to the summit, and also on Culvain, $7 \mathrm{~km}$. N of Loch Eil, at comparable altitudes.

Examination of air photographs and Geological Survey photographs has shown similar features at other points:NW face of Aonach Dubh; Glas Bheinn Mhor, Argyll; Stob Coire an Albainaich, Argyll; Ben Alder; Chno Dearg, E of Loch Treig; and on Askival, Rhum. The lower limit of these features is generally about 2,500 feet, some 500 feet higher than in the Northern Highlands. There are wide deviations from these figures, but nevertheless they do seem to be related to a harsher climate in the North of the country. Undoubtedly many hundreds of other occurrences exist, including lobate features as well as terraces, but it would seem that solifluction forms are less common than in the $\mathrm{N}$ because of the slightly milder climate and, more important, because of much more intense glacial erosion which has produced steep craggy slopes unfavourable to these phenomena, and wide areas of bare rock. 
An ascent of Ben Nevis showed that mass movement is very active above about 2,700 feet where the mountain top detritus could be seen to be creeping actively down the slopes. The overwhelming majority of blocks have a typical solifluction orientation. The detritus is mostly very coarse with large blocks of granite and little fine material, and this may be the cause of the comparative rarity and illdefined form of solifluction forms such as lobes and terraces. The Eastern Highlands. Solifluction deposits and forms have been closely investigated in the Cairngorms by ecologists. (WATT \& JONES 1948; METCALFE 1950). PEARSAII (1950) has emphasised the instability of the soils in this as in most other British mountain areas. SYNGE (1956) has mentioned solifluction features on the Cairngorms, which have also been briefly listed and illustrated by FITZPATRICK (1956a, 1958).

Examination of air and ground photographs has shown that active solifluction features, both terraces and lobes, extend over wide areas of the Cairngorms. They also occur on Glas Maol, overlooking The Devil's Elbow; Cam Ealar and An Sgarsoch, $N$ of Blair Atholl; and on the Lochnagar-Broad Cairn massif. The phenomena around Ben Macdhui and Lochnagar were examined in the field, as were certain limited areas near the Pass of Drummochter and Glen Esk, Angus, where mass movement was not apparent on the air photographs. The lower limit of actively moving solifluction terraces and lobes rises in this part of the Highlands to around 2,700 feet.

On Ben Macdhui and on Beinn Mheadhoin the solifluction phenomena resemble those of Ben Nevis. The entire upper parts of the mountains above 3,000 feet are covered by mountain top detritus consisting of 
boulders of granite and coarse granitic sand. On even the gentlest of slopes a solifluction orientation is nearly universal. cf. Plate 25 in PEARSAII 1950. On the other hand, distinctive forms like lobes and terraces are not well developed. The $W$ side of Ben Macdhui is indeed terraced, but the forms are indistinct, probably because of the coarse nature of the material. See photograph 42. The vegetation is scanty, and appears even more so if one looks up the slope towards the fronts of the above-mentioned terraces; looking down from the same point, on to the tops of the terraces below rather more vegetation is apparent. Mass movement is not confined to the bare areas over 3,000 feet, though it is best developed there and takes place through: out the entire district, except on bare slabs of ice scoured rock, or on flat ground.

There is no doubt of the effectiveness of mass wasting at the present day on the Cairngorms: slabs of granite pushed into a vertical position, and even bent by the relentless pressure are common. The boulders and the interstitial sand at high altitudes seem to be moving at the same rate, since few cases were observed of the finer material accumulating on the upslope side of the boulders or being ploughed into by them. At lower altitudes, where heather and some peat occur, the boulders visible at the surface are moving faster than the fine material leaving gaps on their upslope ends.

A much more striking assemblage of forms was found on the Lochnagar-Broad Cairm Massif.

* Lobes are very well developed on the $N$ side however, as WATT \& JONES (1948) and METCAIFE (1950) have pointed out. 
Iarge stone-fronted lobes, the finest examples seen in Scotland, lie on Broad Cairn and Cuidhe Crom (the SE shoulder of Lochnagar) above 3,000 feet. See photograph 43. They are also found on Meikle Pap to the NE of Lochanagar, but their form has been partially de:stroyed on this hill, and the lobes are transitional to block streams, on account of the steeper slopes. The dimensions of the lobes are indicated on figure 36. The fronts were as much as 6 metres high, the largest yet known in scotland. The material involved was over: whelmingly composed of large blocks of granite, with a rounded, weathered appearance, in a scanty matrix of coarse granitic sand. The stones in the front were generally lichen-covered, while the top of the lobes bore moss and heather. The lobes generally lay side-byside to form rough benches, but occasionally one had advanced further than its neighbours and spread out laterally over the bench below.

On Broad Cairn an upward sequence of forms could be detected. At about 2,300 feet recent erosion or shrinkage of the peat has revealed a block field, with the stones bleached white by acidulated water from the peat. From about 2,500 feet the tops of some of these blocks are not white but grey and weathered with lichen: these stones must have long projected above the peat, and may never have been covered. Continuing upwards it is soon apparent that the lichen-covered stones lie in vaguely crescentic piles, whose frequence and clarity of form increases as one rises to higher levels and the peat becomes thinner. At about 3,000 feet they pass into definite terraces, still with scraps of peat on their tops. About four benches built up of a number of these lobes side-by-side exist on the south face of the summit and two 
on the north. At the very summit (altitude 3268 feet) there are traces of rocky shelves whose surface coincides with the 'sheetjointing' of the granite. (HARLAND 1957).

On Cuidhe Crom, a rather similar sequence may be seen. At the foot of the slope, around 2,900 feet, lobate forms begin to emerge from the peat and heather. From 3,100 feet up to 3,400 feet or so, the whole hill side is covered in the impressive array of stone-fronted lobes illustrated in photograph 43. Above 3,400 feet the lobes pass abruptly into a coarse block field, devoid of fine matter, as far as can be seen, through which the bare rock peeps in the form of benches, just visible in the photograph, coinciding with joint planes. The ab rupt upward cessation of the lobes must be associated with the absence of fine material at the higher levels. Coarse granitic sand is still being washed out from the lobes as it is often to be seen spread over the slopes below.

A different form of solifluction feature occurs on the $\mathrm{S}$. face of the White Mounth. Three broad continuous terraces run horizontally across gently sloping ground at an altitude of about 3,400 feet. The "tread" of each terrace was about 100 metres wide, the "riser" 1-3 metres high. The former had a slope of only a few degrees, the latter was estimated to have a gradient of 10 to 20 degrees. The "risers" had a gently wavy outline in plan. The inner edge of the treads had a nardus cover, while the outer section bore heather. See figure 37, and photograph 44. At the time when this feature was examined (May 1957) snow patches still lingered at the back of each terrace under the front of the next terrace up the slope. These 
patches were not exercising any appreciable erosive effect -- the vegetation underheath was intact, and even the few stones were lichen covered. The whole form was constructional, not erosional, the snow merely having lingered in a hollow formed by solifluction which had no connection with "snow-patch erosion" (IEWIS 1939). The fronts of the terraces appeared moderately stable, though some motion was continuing as shown by occasional displaced stones and broken turf. The material consisted of granite stones, but with much more interstitial fine material than in the lobes on Lochnagar and Broad Caim.

Block streams were frequent throughout this area, especially on slopes steeper than about 15 degrees. Below about 2,500 feet they disappeared below peat and dense heather.

No slumps were observed at any point in this area -- probably a consequence of the absence of really fine material on steep slopes.

Over the Broad Cairn-Lochnagar hill mass as a whole, mass move:ment today is restricted to the block fields and to the solifluction terraces. The lobes are immobile, seemingly because of the washing out of interstitial fine material. The lobes must have been forming before the development of peat which covers the lower examples, i.e. before the Atlantic period. It seems most logical to correlate the lobes with late glacial conditions, when corrie glaciers existed on the $N$ face of Lochnagar, but the $S$ face would have been swept clear of snow by wind. A more exact dating is not possible on the available evidence.

Two lower hill areas were examined to see what solifluction phenomena existed at intermediate levels in the Eastern Highlands: Meall a' Chaoruinn $(3,0.04$ feet $)$ just to the east of the Pass of 
Drummochter, and Black Hill, West Knock, in the West Water Glen, Angus.

On the former hill, active mass movement was taking place on the glacially oversteepened slopes overlooking the Perth-Inverness road from 1,600 to 2,000 feet. The material consisted of small chunks of gneiss in a matrix consisting largely of weathered peat. Active motion was apparent from the displaced stones and broken vegetation cover. Above 2,000 feet the gradient eases and deep peat covers the hill side. From 2,500 feet to 2,900 feet the peat becomes thinner and a topography of low steps appears. See figure 38 for a profile made along the Inverness/Perth county boundary fence. On the brows of the steps, stones can occasionally be seen. It is apparent that these features are solifluction lobes, buried under peat, and now motionless. Examination of the hillsides around show that similar swellings are widespread, and it is apparent that vast areas, of intermediate gradient, are covered by these fossil solifluction phenomena. A section in a nearby gully, shows that the thickness of material involved is not great, something of the order of 1 to 2 metres is usual. Above about 2,800 feet the gradient eases off still further to less than 5 degrees and heather gives way to rhacomitrium-heath, which in restricted areas shows rings, lobes, and stripings of appearance very similar to those on Ben Wyvis which proved to be underlaid by sorted patterned ground. Time did not permit an excavation to be made. Most of the solifluction features on this mountain pre-date the formation of the peat, but motion is still very active today on slopes greater than about 15 degrees. 
Similar conclusions were reached from an examination of west Knock and Black Hill. Solifluction features, taking the form of low, broad lobes and block fields are common under the hill peat, indeed they are nearly universal on the hillsides of this district. There must have been a period of especially active mass movement before the peat started to form, but stability is far from prevailing even today, as on steeper slopes mass movement is still taking place as evidence by displaced boulders and broken turf.

2) Dating and distribution.

Apart from outcrops of bare rock, screes, and certain level or very gently sloping areas, solifluction deposits cover the entire surface of the Highlands. The greater part of these deposits are of negligible importance, representing merely a slight rearrangement of glacial drift, or the creeping downslope of a very thin and irregular cover of the products of recent frost shattering. In this study only a few examples of the more striking solifluction features have been described, but on almost any hillside it is possible to find boulders aligned down the slope and signs of fossil and contemporary mass movement in the form of lobes, slumps and terraces.

The greatest difficulty in dating these deposits is to distinguish between the roles of former and contemporary conditions. In many cases mass movement continues to take place today in solifluction deposits initially formed under more severe conditions in the past. Those mass movement forms and deposits which are covered by a layer of hill peat, such as the example described from the lower slopes of Broad Cairn, must have formed before the peat developed (possibly in 
Atlantic times), but after the disappearance of the firm fields and ice of the last glaciation. For such deposits a very late glacial to early postglacial age seems most likely. At this time there seems to have been a phase suited to the development of block fields and solifluction all over the Highlands. To the same period one can assign the notable solifluction lobes described from Lochnagar and the stone-fronted, immobile lobes on Ben Wyvis.

Contemporary mass movement takes place in most of the Highlands, except on level areas and under firm peat. Movement is most effective on steep slopes and in fine material with abundant water or individual boulders. However, it is broadly true that the most active soli:fluction, together with the most active cryoturbation, takes place at higher levels.

The lower limit of widespread contemporary solifluction as evidenced by lobes and terraces has already been estimated roughly as 1100 feet in Shetland, 2,000 feet in the $\mathrm{N}$ Highlands, 2,500 feet in the $W$ Highlands and 2,700 feet in the $E$. It was felt that this limit, which represents a significant division in the physical geography of Scotland should, if possible, be fixed more accurately.

One method of approach to this problem would be to map the distribution in altitude of patterned ground. TROLI (1944) used this method on a world-wide scale in his classic paper. He considered the lower limit of periglacial solifluction to coincide with the lower limit of pattermed ground. Such an approach is of value in dealing with entire Continents, but in a more restricted area like scotland the method has severe limitations. Not only is there as yet insuf:ficient data on the distribution of patterned ground, but also the 
lower limit is extremely sensitive to the local variations in site, climate, and vegetation so common in mountain areas. e.g. The pre:sence of a smooth impermeable layer of rock just below the surface is partly responsible for polygons at about 1800 feet in Argyll. (SIMPSON 1932). Overgrazing by destroying the vegetation has helped to induce stone stripes down to 1300 feet on Tinto. (MILLER et al 1954).

The lower limit cannot be defined on a basis of climatic statistics, since data is too scanty and since the critical factors are not fully known.

The region of active periglacial phenomena has also been defined as lying above the tree line, but in a country like scotland with a long history of intense modification of the vegetation by man, the tree line is a cultural, not a natural limit. It may be mentioned that HERMES (1955) fixes the tree line at about 500 metres above the sea in Scotland, except for near the coast where it is much lower. The limit finally chosen was, like the tree line, based on vegetation. The generalised lower limit of contemporary periglaciation was taken as the altitude where vegetation covered less than $50 \%$ of the surface. It cannot be denied that contemporary periglacial con:ditions extend to much lower levels than this in scotland, but it is where the ground is bare that the most active phenomena are to be found. This limit is especially useful since it reflects some of the same climatic and site factors as are believed to affect cryo: turbation and mass movement. It can also be identified on air photographs of good quality the density of the vegetation cover is greatly affected by the nature of the underlying rock. (PEARSAIL 1950, SPENCE 1957). In order to minimise the effect of variations 
in rock type on the altitude of the "50\% vegetation limit" attention was confined to granite areas. As granite generally gives a soil unfavourable to the development of a dense vegetation, the limit is rather lower on hills of this rock than on others of different rock. e.g. The greater part of the Cairngorm plateau on granite rises above the limit, but the SW part, on schists and gneisses is completely covered in vegetation at the same altitude. Even on homogeneous granite areas the altitude was often very variable. e.g. The summit of I o chnagar at around 3,700 feet just barely reaches to the $" 50 \%$ vegetation limit", yet the more steeply sloping Meikle Pap, 500 feet lower, is well above it. Only a rough-and-ready average value could be taken. The altitude of the limit as shown on air photos was estimated by comparison with the I" topographical map, attention being confined to slopes less than about 20 degrees as roughly estimated from the contours. The conclusions were checked by field work and by personal flights in some cases. Although considerable variations existed from one mountain to another within a given locality and even between different parts of the same mountain, a generalised limit could be fixed. The results are plotted on figure 39.

It was found that the "50\% vegetation limit" formed a clear surface rising southwards from 1200 feet in Shetland to 2,600 feet on Nevis, and rising also eastwards to the height of fully 3,000 feet in the Caimgorm and c. 3,500 on Lochnagar area. It passed above the summit of the granite hills in the SW Southern Uplands. This surface is a few hundred feet above the rough-andeready altitudinal limits observed for solifluction lobes and terraces, but they have a similar trend, so the evidence from one supports the evidence from the other. 
Examination of the limit defined in this way throws light on some of the climatic conditions favouring periglaciation on Scottish hills. The chief factors to be considered are temperature, wind and rainfall.

The higher altitude of the limit in the Cairngorms which are distinctly more continental than the mountains of the $W$ and $N$ shows that low winter temperatures are not decisive in the location of the mild type of periglaciation found on scottish hills. Conditions in spring and autumn are probably comparable in $N, W$ and $E$ with a similar frequency of freeze/thaw cycles. Lower summer temperatures would favour a lower limit in the west and north, but the temperature drop is quite inadequate to account for the low altitude of the limit in Shetland. The wetter climate of the $W$ would perhaps help to induce more solifluction, but on the other hand would favour a denser vegetation growth which would inhibit mass movement.

Wind seems to be the dominant factor, operating indirectly through inhibiting the vegetation. (PEARSALI 1950; SPENCE 1957). The latter writer has especially emphasised its role in Shetland in restricting the vegetation to sheltered spots and so leaving the ground bare for mass movement and cryoturbation to take place even at low altitudes. The winds at the summit of Ronas Hill, altitude 1470 feet are comparable in strength to those on the summit of Ben Nevis at 4,400 feet. Winds in the Cairngorms are likely to be rather less than in the $W$ on account of the shelter effect of the surrounding high ground.

Temperature and precipitation can produce periglacial effects down to very low altitudes in scotland -- provided the vegetation 
cover can be inhibited by some cause: overgrazing on the Southern Uplands, (MIIIER et al 1954); poisonous soils in Shetland, (SPENCE 1957 ); wind on really exposed sites.

Hills that project furthest above the altitudinal limit should be expected to have the most markedly periglacial climate. By this standard, Ben Nevis is easily the "most periglacial" of Scottish mountains since it rises some 1700 feet above the limit. Yet on Nevis, as we have seen, large scale periglacial features, notably stone-fronted lobes, are less well developed than on Iochnagar with similar granitic rocks, but rising only a few hundred feet above the limit. This suggests that the summit of Ben Nevis was shrouded with snowfields when the necessary severe climate prevailed and the hill tops in the $E$ were bare. Another possibility is that low winter temperatures, likely to be found in the more continental climate of the $E$, were necessary for the development of these large features, unlike the smaller-scale phenomena of today.

Apart from Nevis, the mountains in Scotland which seem to have the severest periglacial climate today, to judge by the amount by which they rise above the "50\% vegetation limit" are the high summits of $\mathrm{S}$ Ross-shire and Central Inverness. Ben More Assynt and the Cairngorms are other notably high areas.

In the Highlands as a whole post glacial and contemporary peri: glacial mass movement is more widespread than that which can be definitely assigned to the colder conditions of the Pleistocene. This can be ascribed to the shielding influence of snow and ice fields. In the E Highlands, which were less heavily snow covered and consequently bare at an earlier period than the $W$, large-scale solifluction forms 
attributable to the late glacial are to be found, on the summits and under peat at lower levels.

IIIc. The Islands.

1) Description.

FITZPATRICK (1958) has mentioned and illustrated a fine example of the distortion of shattered bedrock by mass movement down a gentle slope. SPENCE (1957) has discussed mass movement of contemporary origin at low levels and on the granitic Ronas Hill.

There is no doubt that the shattering and overlying fossil solifluction deposits mentioned by FITZPATRICK are widespread. The writer has seen similar deposits up to $1 \frac{1}{2}$ metres thick, over shattered rock in the Dingwall area. These deposits, like those in Buchan, are undoubtedly associated with severe periglacial conditions during the ice age. On the other hand, unlike North East scotland, till is widespread at low levels and is unweathered and little disturbed, a feature reminiscent of the Central Iowlands. This suggests that the phase of shattering and solifluction in Shetland was confined to later glacial times, whereas Buchan was ice-free for a much longer period.

The contemporary phenomena discussed by SPENCE are related to the presence of peculiarly unfavourable soil conditions -- serpentine and acid granite -- and to the very severe winds experienced in these areas. The combined effect of these factors is to inhibit vegetation and so permit mass movement and cryoturbation, even though climatic conditions are not severe. 
The block field on the summit of Ronas Hill is illustrated in photograph 45. It consisted of granite boulders generally about 1 metre long half drowned in granitic sand with very scanty vegetation. The boulders had been weathered to a smoothly rounded form, apparent in the photographs. This suggests that they are products of some former period of more intense frost shattering. On the other hand, it is difficult to imagine frost shattering having ever been intense in such an oceanic situation, and perhaps the block fields derives ultimately from deep chemical weathering in interglacial or preglacial times as DAHL (1955) suggests. A solifluction orientation was almost universal. On the brow of the hill, the surface of the block field was cast into terraces of gently wavy plan, with fronts less than a metre high from which water had often washed out an apron of finer material colonisde by grasses. These fronts were in active motion down the slope. It was surprising to see such a "high mountain" landscape at the relatively low altitude of $12-1500$ feet.

Other hill tops examined on Mainland were shrouded in deep peat and no solifluction forms or deposits were visible.

Shetland presents a combination within a limited area of features typical of many parts of the country: fossil solifluction deposits over shattered rock (cf. Buchan); undisturbed till on low ground (cf. Central Scotland); block fields in active motion (cf. Highland summits).

Orkney Islands. Fossil solifluction deposits were found on Mainland and Hoy but not as striking as had been expected in view of the fissile rock, and the possibility that only limited local glaciers existed during much of the last glaciation. WIISON et al (1935) mention 
pockets of solifluction material preserved under till in nooks in the bedrock. They also imply that a good deal of the till originated more or less in situ.

The most impressive solifluction deposit seen was at Rackwick on the $W$ coast of Hoy, just to the south of the outermost extension of the local ice cap in that area. (CHARLESWORTH 1955). The deposit was fully 10 metres thick and consisted of angular chunks of sandstone in a sandy pasty matrix, weathered off the hillside behind. The deposit was being actively cut back by the sea and must at one time have extended much farther to the west. The unusual thickness could be attributed to the position at the foot of a long, steep slope. See photograph 30. Other solifluction deposits, generally a metre or so thick were seen on the east coast of Hoy, On Mainland a drift cover is certainly widespread but the uniform and rather weak nature of the rock, together with few exposures, make it difficult to decide whether this is predominantly of glacial or of periglacial origin. Periglacial solifluction deposits, consisting of typical angular fragments of sandstone were only definitely identified on the sides of rock knolls near Finstown.

On the whole, the evidence obtained in orkney was not of great interest in relation to the role of periglaciation in forming the landforms of Scotland.

The Outer Hebrides. Solifluction deposits of periglacial origin play little part in the landforms of Lewis, dominated by glacial erosion and by a thick peat cover. In Harris, mass wasting, with the development of screes is preceeding space on the steeper hill. The extensive block fields on high ground were probably initiated 
when the hills such as the Clisham rose as nunataks above the ice and/or in late glacial times. Motion of the blocks continues on a reduced scale today. Lower slopes are generally hidden under peat, or consist of bare, ice-scoured rock, but a few minor solifluction deposits were noted. One, visible in a quarry at Tarbert, had alternating layers of coarser and finer stones, rather like a "stratified slope deposit" (DYLIK 1956) suggesting alternative phases of washing and mass movement during the accumulation of the deposit. There was no distinct overlying soil profile, and the whole deposit is of recent origin.

On St. Kilda, WAGER (1953) has mentioned the occurrence of soli:fluction deposits of glacial age outside the limits of the local ice cap. According to photographs in COCKBURN (1929) and to photographs taken recently by Mr. D.R. MACGREGOR mass movement features both fossil and contemporary are widespread, as is to be expected on an island that was never invaded by ice from the Mainland and has today a cool, wet and very windy climate.

The Inner Hebrides. No field work was carried out in these islands, but examination of photographs and the literature (esp. HARKER 190I, and GODARD 1958) indicates that periglacial mass movement took the form chiefly of scree formation in the past and a certain amount of creeping of debris derived from the volcanic escarpments across the fronting lower areas, as on Trotternish. Large scale slumps of basalt underlain by weak Tertiary rock took place in late glacial times, but as a consequence of glacial oversteepening of the slopes rather than periglaciation BAIIEY et al 1924. On the summits, today, mass 
movement continues to be very active although its effects are re:stricted by the prevalence of bare ice-scoured rock surfaces.

2) Dating and distribution.

There is as yet no reliable evidence on which to date the fossil solifluction features on the archipelagoes around scotland. It would seem that they became ice-free fairly early in the last glacial retreat except for local ice caps on the highest areas, and consequently some of the more striking deposits must be fairly old. Mass movement of contemporary age is well developed on high ground.

Fossil solifluction deposits seem widespread in Shetland, although peat conceals much of the evidence. In orkney too, they are widespread but present evidence indicates they are thin. In the Inner and outer Hebrides the occurrence of both fossil and contemporary mass movement is restricted by the wide extent of bare, ice-scoured rock and the resistance of gneiss to frost shattering.

IIId. The Southern Uplands and hill masses of Central Scotland.

\section{1) Description.}

The mass movement phenomena of the Southern Uplands, and of the isolated hill masses in the Central Lowlands resemble those observed in Buchan and in the Highlands, although less intensively developed. There is widespread evidence of fossil solifluction deposits associated closely with shattered bedrock together with evidence of active mass movement today on the hills. At many points differentiation between the share of past and contemporary processes is not easy. 
Since the days of the first geological mapping of the Southern Uplands it has been realised that they were covered by a skin of rubble that was not strictly glacial in origin and appeared to have crept down the slopes. e.g. GEIKIE 1869, and see Appendix A. This rubble has been termed "Earthy angular drift" on many of the $I^{n}$ geological maps. e.g. Sheet 24, Peebles. The angular drift has been distinguished on these maps from the more compact boulder clay of true glacial origin. Until recent years this material has scarcely attracted the attention it deserves in view of its widespread occurrence. MIILER et al (1954) have pointed out how it is actively in motion today on Tinto Hill where the vegetation has been broken, but that it seems to be of older origin since identical deposits lay under peat and vegetation still in situ. TIVY (1955) speculated briefly on the possibility of extensive mass movement of "post glacial times" on the smooth hills NE of Peebles: presumably by "post glacial" she meant after the disappearance of ice in the locality, but not necessarily after the "Official" close of glacial times at the Zone III/Zone IV boundary. A similar cold "post glacial" phase was postulated by GREGORY (in BUCHAN 1925) to account for terrace features seen on slopes at various points in Peeblesshire. e.g. Rommanno, Dunsyre Hill, Purvis Hill near Walkerburn. However, ECKFORD (1928) exploded this idea and showed that the features were man-made although he did mention the existence of true 'soil-creep terraces' on the E slopes of Black Mount, $2 \mathrm{~km}$. SW of Dolphinton. MUIR (1956) has recognised the existence of two types of 'till' in Roxburgh. One is stony and light in texture, and occurs on steep slopes and high ground. The other is less stony and more clayey and is found in valleys and on gentle slopes. 
In fact, a layer of this rubbly drift, composed of angular fragments of the local rock aligned down the slope and in a powdery matrix exists on practically every hillside in Central and Southern Scotland. See photograph 46. The facies changes with the type of underlying rock. The deposit is best developed on the fissile Silurian and Ordovician shales of the Southern Uplands. It is thinner and the fine matrix generally scantier on the old igneous hill masses of the Central Lowlands. That it is predominantly fossil is shown by its occurrence under peat and/or a soil profile at many places. There is little point in multiplying descriptions of such a common deposit, but three examples will be briefly discussed.

In the Lamermuirs, near the junction of the Bothwell water and the Whiteadder Water, at an altitude of about 1,000 feet a steep sided gully some 200 metres long and 4-5 metres deep cuts into a hillside with a gradient of about 12 degrees and exposes the under:lying drift and bedrock. In the sides of the gully 1-2 metres of solifluction deposits can be seen grading into shattered bedrock beneath. A few glacial erratics occur in the upper part of the deposit but it is overwhelmingly composed of sharply angular fragments of the underlying rock. The whole exposure is capped by a semideveloped soil profile. The upper part of the soil profile had been washed away as a consequence of the cultivation of the ground -- it is very common in this district to find the products of this erosion piled up at the foot of the fields against the dykes. The shattering is far too deep to be the work of present day processes of freeze and thaw and must be ascribed to a periglacial origin. The shattering dies out at a depth of a few metres, although the rock is nowhere 
entirely coherent. Very similar exposures of solifluction material overlying and grading into shattered bedrock can be seen in most gullies in the area. The solifluction deposits are never more than a metre or two thick, except quite locally at the foot of long slopes.

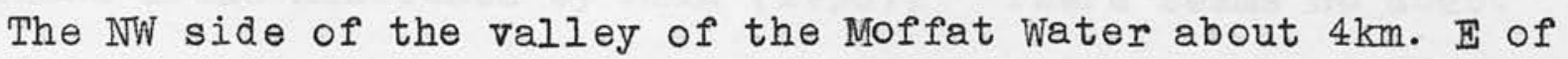
the village of Moffat falls steeply from an altitude of about 900 feet to 500 feet and then grades off into an irregular bench that overlooks the river in a steep bluff 5-15 metres high. See figure 40 . Ex:posures showed that the bench was a denuded terrace or kame terrace. The drift on the slope behind, exposed by the side of a recently-cut Forestry Commission track, consisted of rubbly angular material. The deposit was 2-3 metres thick on the lower half of the slope, but thinned out upwards; it graded here and there into underlying shattered rock. Several indistinct layers could be detected: a loose upper layer with small stones; an intermediate layer with larger stones up to $30 \mathrm{~cm}$ long; and a slightly bluish, more compast lower layer which may have contained a proportion of rehandled till, although no erratics were observed. Stones in all three layers showed a well-developed preferred orientation down the slope.

At this point it was not possible to determine the stratigraphic relationship of the solifluction on the slope to the terrace feature in the bottom of the valley, but a few $\mathrm{km}$. to the $\mathrm{NE}$ it was possible to see that the former overlay the latter and so must be younger, although the possibility that it was partly contemporaneous cannot be excluded. Similar solifluction deposits have been seen overlying glacial till in the upper valley of the Tweed, showing that the mass movement post dated the glaciation. 
The deposits described from the Lammermuirs and the Moffat valley are closely similar to those described above from the phyllite areas of Buchan, and undoubtedly correspond to the looser, stonier till of upland areas mentioned by MUIR (1956)。 There seems no doubt that in greater part they originated under periglacial processes now no longer operative.

The Cleish Hills and Benarty Hill in Central Fife are composed of southward dipping layers of tuff and lavas of Carboniferous age. They form northward-facing escarpments overlooking Loch Leven. This escarpment is fronted by straight slopes with gradients of around 30 degrees overlooked by crags of bare rock. When seen by slanting evening light it is apparent that these slopes are made up of confluent fans. They are in fact screes, now covered in vegetation, to which present day frost splitting on the crags above is making an insignificant contribution. See photograph 47 . It is most logical to correlate their origin with the harsh conditions which formed wedges and involutions in the gravel pit at their foot. See page 34 and page 66 above. In the case of The Cleish Hills, the scree has remained more or less rectilinear since its formation, but the larger example on Benarty Hill bas a softer, curved form. The reason for this can be seen in a small exposure where the rock can be seen to be chemically weathered. This weathering has furnished fine products which have enabled a certain amount of mass movement of the scree as a whole to continue in post-glacial time. Presumably the rock of the Cleish Hills was more resistant to chemical attack.

Similar fossil screes, formed at a period when frost shattering was much more active, are not uncommon in Central scotland. 
can be recognised for instance along the $\mathrm{S}$ face of the Sidlaws. The total thickness of material involved in them is not very great; they usually form a skin over a sloping bedrock surface.

Signs of present day periglacial processes, of a mild type, are not uncommon. Frost shattering is still proceeding at higher altitude in particular as evidenced by fresh spall faces on rock putcrops. Mass movement is also still active, taking the form of lobes, terraces, individual blocks and slower creeping of debris covering entire hillsides.

Lobes occur sporadically in the Southern Uplands and Central Scotland down to levels as low as 1400 feet in the west, and an isolated small example, bare of vegetation, was even found at the bottom of Maurice's Cleugh on the north face of Tinto as low as 1200 feet. (MILLER et al 1954). Most of the examples found were turf-banked with stony upper surfaces. Although the stones on the top of these lobes are covered with lichens as a rule, the upcurled turf bank at their lower edge shows that motion is still actively proceeding. Photographs 48 and 49 illustrate an example from the S. face of White Coomb at an altitude of about 2,200 feet. Others have been observed on Lee Pen near Peebles, on Slaty Law, in the Renfrew hills, and on the higher parts of the Ochils. The dimensions of these forms, particularly the heights of the fronts, are very much smaller than those described from the Highlands. Until many more examples have been examined -- they are doubtless quite frequent -it would be premature to claim that this size contrast is universal and related to less severe climate in the Southern Uplands. The 
contrast may equally well be due to the larger stones in the Highland structures.

Terrace forms are apparent from air photographs on the higher slopes of Merrick and Corserine. They appear to be in active motion, but have not been examined on the ground. Around the summit of Criffel, vague terraces can be made out under the peat and heather, with occasional boulders peeping through. These seem to be large fossil features with fronts about 2 metres high.

Downslope motion of individual blocks is a common phenomenon. Photograph 36 shows an example from an altitude of 1600 feet in the Central Ochils. It shows the characteristic alignment down the slope, buckled-up turf in front and the hollow on the upslope side. In this case the gradient was fairly steep, about 24 degrees, but the same phenomenon has been observed on slopes as gentle as six degrees. Boulders which lie more deeply do not seem to move so readily in this way.

Mass movement of a more general kind affecting large areas is apparent from the number of terracettes to be seen on suitable slopes. When thoroughly sodden peat itself can flow and very actively moving lobes of this kind were seen on White Cairn. See photograph 50.

There is abundant evidence that mass wasting is at work today on quite an active scale in the higher areas. In view of the relatively mild conditions are we justified in terming this activity "periglacial"? The existence of the very active developing stone stripes on Tinto Hill (MILLER et al 1954) proves that the use of the term is justified, 
although it must be emphasised that it is an extremely mild type of periglaciation where the growth of ice in the ground has little effect unless the vegetation cover is broken by other processes, such as overgrazing.

\section{2) Distribution and Dating.}

Solifluction deposits form a nearly universal cover on these hills, except on level areas or on outcrops of bare rock. In the valleys, the solifluction deposits consist merely of relatively small scale rehandling of glacial deposits, but they are extremely widespread on higher areas. e.g. The loose, stony and silty "till" described by MUIR (1956) in the Jedburgh district covers practically all the high ground, and seems to be in fact a fossil solifluction deposit. Contemporary solifluction is also widespread especially on steeper slopes and at higher altitudes. It has already been pointed out on page 152 above why we are justified in terming this contemporary mass movement "periglacial". There is not sufficient information to plot a lower limit of this contemporary solifluction on the lines followed for the Highlands, but by analogy it seems probable that it reaches a lower altitude in the $W$ than in the $E$.

The dating of the fossil deposits can only be done in the broadest of terms. In no case has till in situ been observed overlying these solifluction deposits so that they must all date from a period after the last glaciation; i.e. after the Scottish Readvance. At several points, e.g. NE of Moffat, the solifluction deposits were seen to overlie glacial till and glaci-fluvial deposits. Probably mass 
movement continued after the ice vanished from these hills through late glacial into early post glacial times until the growth of hill peat stabilised the surface and insulated it from the effects of frost.

IV. Conclusions.

1) It has been shown that solifluction deposits are extremely widespread in Scotland, except on bare rock and very gentle slopes. In many areas the deposits represent no more than a minor rehandling of pre-existing deposits, but elsewhere they are an important feature in the landscape and provide the raw material for most soils. Fossil deposits are particularly important in the $\mathrm{NE}$ of Scotland and on the Southern Uplands while contemporary deposits are most important on the slopes and summits of the Highlands.

2) There is a great variety of solifluction deposits in scotland, ranging from fine silty matter overlying Aller $\phi$ d peats to stony material in a fine matrix and to block fields. In many cases the material in the deposits originated as glacial till, or as chemically weathered rock, but the most usual source was frost-shattered debris. 3 ) There is an equally great variety of solifluction forms, including homogeneous sheets, lobes and terraces, block streams and slumps, in:dividual boulders and terracettes. It is scarcely possible to consider these forms apart from the solifluction deposits in which they have developed, and the two have been discussed together here. It may be pointed out that the solifluction deposits of the NE and of much of the Southern Uplands no longer show the minor irregularities induced 
by solifluction, such as terrace fronts, which most probably existed when the deposits formed. In the Highlands and the higher hills of S scotland on the other hand, these forms are well preserved and can reach striking proportions, as on Lochnagar.

4) The nature of the solifluction features depends on climate, the available material, the slope, water content and the vegetation cover. Former periglacial climatic conditions have favoured mass movement by the presence of permafrost, but even the contemporary climate cool and humid, is favourable. The material must contain some fine elements to favour mass movement, but if stones and boulders are common stonefronted lobes and block fields are produced. Solifluction takes place more readily on steeper slopes, until the gradient becomes sufficient (about 30 degrees) to induce gravity sliding and falling. An abundant water content seems to be essential to lubricate the motion. The effect of vegetation depends largely on the strength of the root system: well-developed strong roots bind the ground and inhibit solifluction, or constrain it to adopt a wave-like terraced form. 5) Dating of the solifluction deposits is rendered difficult by the continuance today of mass movement which commenced under earlier harsher conditions. In the NE and in the Southern Uplands the association with shattered rock and sometimes with cryoturbation imply a period of formation during the cold conditions of glacial times. In the Highlands many features can be ascribed to a period between the disappearance of the firn fields at the end of the Ice Age and the commencement of extensive peat formation in the Atlantic period. The cool wet Atlantic phase may itself have been responsible for considerable solifluction. Contemporary mass movement is most 
active on steep slopes and at high altitudes where the vegetation is scanty, but to a limited extent it operates everywhere. It is not justifiable to claim that effective solifluction ceased at the close of the cold conditions of the Pleistocene: in Scotland's cool and humid climate mass movement continues today, although on a reduced scale and often affecting material produced under past harsher climates.

6) The continuance of solifluction today shows that it is not necessarily linked to cold conditions but can take place under cool temperate climates although its effectiveness seems to be much less. For solifluction it is not the period of winter freezing that is important but the period of abundant ground water during spring and summer.

7) While contemporary solifluction is widespread it reaches its greatest intensity on high ground where wind has inhibited the vegetation. It has been possible to map the distribution of these especially favourable conditions, at least approximately, by con:sideration of those granite hill masses where the vegetation covers less than half the surface of the ground. It was found that the most active solifluction reaches to low levels on the outlying islands of the $\mathrm{N}$ and $\mathrm{W}$, but is confined to successively higher levels towards the $E$ and $S$.

8) The volume of material represented in the solifluction deposits of Scotland of all types and ages is very small in relation to the relief as a whole. 


\section{CHAPTER IX}

\section{RUNNING WATER}

\section{Introduction.}

The role of running water in periglaciation is not entirely clear. Some workers have tended to minimise its importance relative to solifluction. e.g. TRICART, 1951; PELTIER, 1950. On the other hand many observers have ascribed great importance to it. e.g. AHLMANN, 1942; DEGE, 1941; JENNESS, 1952. It is generally accepted that stream erosion over permafrost has played a significant role in the development of what are now dry valleys on highly permeable rocks like chalk.

Evidence for the effectiveness of vertical stream incision in the Arctic today has been brought forward by several writers. Rapid run-off and erosion is favoured by the underlying permafrost, the scanty vegetation, the low evaporation, the sudden spring melting in continental periglacial climates, and by the weakening of the rock through frost shattering. JENNESS (1952) and DEGE (1941) have stressed the importance of snow drifts accumulating in gullies and augmenting the water available for erosion in spring. In E Greenland it was apparent that the larger streams were powerful agents of erosion and transport on all but the gentlest of slopes, while smaller streams were effectivel only on steep slopes.

Lateral erosion is also a very effective process during: periglaciation. This is not because the streams are flowing over 
permafrost as DEGE (194I) suggested. (Streams thaw the permafrost beneath them), but because the streams are braided on account of their heavy load. (This is a gross simplification of a very complex hydronamic problem)。The braided streams impinge frequently on the sides of their valleys and so widen them. See photograph 50a. This leads to the typical "box" cross-profile of periglacially formed valleys in Central Europe. e.g. BÛDEL, 1944; POSER \& MDLLER, 1951.

While the presence of abundant water is favourable to solifluction, too much can inhibit mass movement by washing out fine material. This washing was frequently observed in Greenland. If it proceeds far enough in suitable material a block field can be formed with the boulders left behind as a lag concentrate.

As agents of transport, periglacial rivers are very effective. The immense fans typical of Arctic regions today are testimony to the vast amount of material which can be handled by even fairly small streams as the gradient is steep. The larger rivers carry almost as much material as those issuing from glaciers. Despite the great quantity of rock debris furnished by solifluction from the valley sides all but the smallest streams seem capable of evacuating it. The ratio of provision to evacuation of material and consequently the form of the valley varies widely according to the climate, slope, and rock conditions. In rock such as chalk especially suitable to frost shattering and mass movement preexisting valleys become choked rather than deepened. (TRICART, 1949; PELTIER, 1950.) 
So heavily laden are the streams that sometimes they are transformed into veritable mudflows, and build up levees of boulders along their margins. (SHARP, 1942). This levee bullding has been claimed as a specifically periglacial phenomenon (CAILLEUX \& TAYLOR 1954), but in fact it need have no connection with the growth of ice in the ground and can occur just as readily under warm semiarid conditions or on the sides of a Scottish mountain during a summer storm. (BAIRD \& LEWIS 1957).

\section{Description.}

There is but a little scattered evidence on which to base an assessment of the role of erosion by running water in the periglaciation of Scotland. BENNIE (1891) described "washouts" of interstadial age seen in a sandstone quarry near Edinburgh. These were gullies cut in the rock and filled with glacial till or "rubbish" (probably solifluction deposits) and had cross profiles of very narrow Veeshape, of rectangular shape or smoothly rounded. The features seem to be the work of rapid stream incision under cold conditions but it is not known how far they are the work of pre-glacial rather than periglacial streams.

The gullies which commonly gash the steeper slopes in the Southern Uplands are of recent origin, a product of the present climate, but certain softer forms with smoothly rounded cross profiles, transitional to the features known as niches (see Chapter XIV below) may have been the work of stream incision under periglacial conditions, but probf is lacking. More definitive evidence of periglacial stream erosion is to be found in the flat floors of many valleys. 
Figure 32 shows an example from $\mathrm{NE}$ Scotland where the steep sides and flat floor, not the work of glacial meltwaters, have been cut under periglacial conditions. The form closely resembles that of valleys described from Greenland by POSER (1936). Along the upper reaches of many rivers in the eastern part of the Southern Uplands e.g. the Fasenay and Monynut Waters, it is possible to see that a flat floor, being incised by the present stream, has been cut in rock. These rock floors may best be ascribed to rapid erosion under periglacial conditions. They will be further considered in relation to the evolution of slopes in chapter $\underline{\overline{X V}}$ below.

Gullies are frequent on steep rocky hillsides in the Highlands where periglacial conditions may still be said to prevail. These gullies are partly the work of running water but frost shattering along planes of weakness seems to be the main process in their development.

There is less doubt about the importance of running water under periglacial conditions in the more restricted role of the washing out and redeposition of fine material. This washing seems largely re: sponsible for the immobilisation of the great stone-fronted lobes on Lochnagar. On Ben Wyvis washing out of fines has also immobilised the stone-fronted lobes budt has provided suitable material for the development of actively moving vegetation-covered lobes at lower levels. The comparative rarity of patterned ground in scotland despite the suitable climate on the hills must be ascribed in part to this washing process removing the necessary fine fraction. The effectiveness of washing out of fines during the more severe peri: glacial conditions of the past cannot yet be assessed. 
Evidence of the great transporting powers of streams during the former periglaciation of scotland is very apparent. Part of this evidence will be considered more fully in chapter XV below. Fossil alluvial fans, testimony to a former period of more rapid transport heavily laden streams are found in many parts of the country. Examples include the striking fans at the $S$ foot of the 0 chils, and similar features along the foot of the Sidlaws. KENDAII \& BAIIEY (1908) remarked on the large size and seemingly rapid formation of fans laid down on the floor of glacial meltwater channels in East Lothian. The period of formation of these fans seems to have immediately followed the retreat of the ice. Certainly when the fans were deposited there must have been a great amount of loose material available for trans:port and a great volume of water to carry it. When the streams issued from the steeply sloping valleys onto the gentler plains or trough floors below they could no longer carry all their load and dropped much of it to build up a fan. Exactly the same process goes on today very rapidly in the Arctic.

\section{Conclusion.}

As a generalisation of the rather scanty evidence it may be said that under the severe periglacial condition of the past running water played an important part as an agent of transport, but was less important as an agent of erosion, although it did produce steep-sided, flat-floored valleys. In the contemporary periglaciation of hill areas its main function is to impede or favour solifluction by removal or deposition of fine material. 


\section{CHAPTER $\quad \mathrm{X}$}

\section{W I N D}

\section{Introduction.}

Wind can be a very important process under periglacial conditions. Its effectiveness is related to its strength, the scanty vegetation, the low precipitation, and the abundant finely-comminuted rock fragments of sand and silt size produced by the action of frost. Material of this calibre as we have seen is especially favourable for cryoturbation and mass movement. By exporting or importing fine material wind can impede or favour solifluction. In the periglacial regions of Greenland and Spitsbergen its importance is however restricted to limited locali:ties where conditions are specially favourable.

During the Pleistocene periglaciation of Europe wind was very important, producing loess, cover sands, dunes and ventifacts. The loess was deposited in a belt from the $N$ of Brittany to the Ukraine, but to the north of this belt the predominant eolian deposits were sands and ventifacts. Wind action continued to be important as late as Zone III times in The Netherlands and Belgium (MARECHAI \& MAARLEVELD, 1955) and North Germany (SCHULTZ 1956) and in Sweden (HJULSTROM et al, 1955).

\section{Description.}

While sand dunes are a common feature of our coasts, and con:temporary wind erosion has been recorded from the exposed $W$ of Mull, 
(BOSWORTH 1910), there has been no certain identification of wind action during the Pleistocene. SYNGE has been reported in FITZPATRICK (1956a) as having noted a loess-like deposit near Colliestone in Buchan, but re-examination showed that it was a water-laid deposit, probably formed at the same time as the lateglacial clays at Cruden Bay a few $\mathrm{km}$. to the $\mathrm{N}$.

Throughout the course of the field work undertaken in this study a careful search was made for evidence of periglacial eolian action. The only likely instance discovered was in a sand pit $3 \mathrm{~km}$. $\mathrm{S}$ of Kinross. This pit has al ready been mentioned in connection with small ice wedges in chapter IV, and erected pebbles in chapter $V$. The probable eolian deposit was a gritty silt overlying the horizon of erected pebbles. See figure 22. It was of a much finer con: sistency than the underlying glaci-fluvial sands, from which it was probably derived.

It has been shown (chapter VI) that wind plays an important, if indirect, role in contemporary periglaciation. By inhibiting the vegetation in exposed areas it favours solifluction and cryoturbation, but at the same time opposes these processes by removing fine material. Low dunes of wind-blown granitic sand, a few decimetres high, occur occasionally on the windswept granitic plateaux of the Caimgorms and of Ronas Hill, Shetland.

III. Conclusions.

The dearth of Pleistocene eolian deposits in Scotland is not readily explained. It is true that the country lay under ice during 
the glacial maximum when the greater part of the European loess was deposited (BUDEL 1949), but we have seen that there was a prolonged phase of harsh periglacial conditions with a very scanty vegetation cover, during the period from the scottish Readvance to the Highland Readvance stages. The solifluction deposits of the eastern part of the vast glaci-fluvial outwash spreads should have provided abundant raw material for wind to rehandle. Heavy snow fall in winter and wet ground in summer appear may be the inhibiting factors. Scotland's situation between continent and ocean make it unlikely that low wind speeds prevailed in such a potentially stormy situation. 


\section{PART IV.}

\section{LANDFORMS.}

Having shown that periglacial conditions have prevailed in Scotland and reviewed the processes which have been at work in shaping the landscape it is now appropriate to consider the resulting landforms. It is necessary to first consider the pre-existing landscape on which periglaciation operated. Then minor periglacial features will be considered before examining the major forms and attempting to assess the effectiveness of periglaciation in fashioning the landforms of scotland. Finally the modifications suffered since the end of periglacial conditions will be considered. 
CHAPTER XI

\section{THE PRE-PERIGLACIAL LANDSCAPE.}

To appreciate the role of periglaciation in the evolution of the landscape it is necessary to take account of pre-and post-periglacial processes and forms as well. If this line of thought were pursued to its logical conclusion a complete outline of the geomorphic history of the country would be necessary before embarking on a study of the periglaciation. This is of course out of the question and all that can be done is to state some of the salient points which have a bearing on our main topic..

Ideally, one would simply compare directly forms developed before, during and after periglaciation. In practice this cannot be done because of the time-scale involved. In trying to reconstruct a landscape that has been largely destroyed by erosion, one has to make unprovable assumptions: e.g. It is often assumed that an erosion surface, now represented only by accordant summits, was initially a plane. One cannot be sure that one's reconstruction is correct.

A more indirect approach is to "substitute space for time" and compare landforms that have never been periglaciated with those that are now undergoing periglaciation and with forms that have been subject to periglacial influence in the past. This procedure is of great value but natural conditions are so complex and variable that one can never be sure that one is really making valid comparisons 
where all extraneous factors are equal.

A still more indirect, but very useful approach to the problem of guaging the effectivenes of a particular system of erosion can be made through the study of the correlative deposits. If the volume of detritus produced by weathering and erosion from a given area in a given time can be calculated it is possible to deduce something of the rate of erosion. In addition, the nature of the correlative deposits enables one to deduce the nature of the erosive process. e.g. Till is a proof of glaciation, and its volume is an indication of the amount of erosion performed by the ice.

The assessment of the share of periglaciation in shaping the landscape is further complicated by the existence of forms of complex origin, the work of several different processes and climates and by the similarity between forms produced by different agencies. e.g. Minot benches on hillsides can be produced by periglaciation, glacial abrasion, glacial meltwater, or contemporary erosion.

Consideration will be given successively to pre-periglacial forms, periglacial forms and post periglacial modifications. The pre-periglacial forms and deposits were dominated 1) by pre-glacial and inter-glacial warm climates and 2) by glaciation. Strictly speaking these processes alternated with, rather than preceded, periglaciation: there must have been periglacial phases in Scotland before and after each main glaciation. However, we have been overwhelmingly concerned with the last periglacial phase, which succeeded the last glaciation.

1) The phenomena attributable to warm conditions survive best in the eastern Highlands and especially in the North East of the 
country. As LINTON (195I) has pointed out the climatic conditions prevailing in interglacial and preglacial times favoured chemical alteration of the rock to considerable depths. The weathered mantle has been preserved at many points:- It has been reported from the watershed between the Garry and the Feshie-Geldie (BARROW et al 1905; BARROW et al 1913), in E Sutherland (BAILEY 1934, 1949), and, especially, in Aberdeenshire (PHEMISTER \& SIMPSON 1949; SYNGE 1956). In this latter area chemically altered rock is especially frequently encountered. It has often provided suitable material for frost-shattering and for cryoturbation. Pure quartzite has proved more or less immune, but granite and basic igneous rocks have often been deeply rotted. Gneiss and other metamorphic rocks have been moderately affected, schist more so than phyllite or slate. Comparison of topographic with geological maps of the area shows how resistance to chemical weathering has dominated the evolution of the relief: everywhere summits coincide with outcrops of pure quartzite, although it is one of the most sensitive of rocks to periglacial erosion and is seriously affected by glacial erosion. (THOMSON 1950). The weathered mantle has been stripped from some hill tops (SYNGE 1956) but still exists to a depth of at least several metres on others. e.g. Northseat Hill, $10 \mathrm{~km}$. $\mathrm{N}$ of Ellon.

In the W Highlands the weathered material has been almost entirely swept away by the glaciers, though locally remnants survive, pften in positions sheltered from the full erosive powers of the ice. e.g. HARKER (1901) in Skye, PANZER (1928) in Lewis, DAHL (1955) in the Outer Hebrides. In the Southern Uplands there are only occasional traces of deep chemical weathering. There is a brief 
mention in BUCHAN (1925) of rotted rock exposed when excavating the foundations of a reservoir on a high col near Peebles: the rock could be dug out with a spade. The Priestlaw granite in the Lammermuirs is likewise deeply altered but this is probably a post-glacial feature since this rock is extraordinarily sensitive to chemical attack. It is not clear if the scantiness of the weathering mantle in the Southern Uplands (and on the volcanic hill masses of the dentral Lowlands) is a result of its removal subsequent to formation or simply that the rock resembled quartzite in not favouring its development. Little evidence is known of deep rotting of the rock in Lowland areas.

The landforms associated with the deep weathering mantle are not known with sertainty, but it seems that smooth slopes predominated, as these are typical of the areas where the best-preserved remnants of the mantle are found. It is not entirely clear to what extent the surviving fragments of the weathered mantle are of interglacial or of preglacial age. They certainly pre-date the last glaciation since fresh till has been seen to overlie weathered rock (PHEMISTER \& SIMPSON 1949) which at other points is cryoturbated. See page 63 above. If the weathering mantle is preglacial its preservation suggests that Pleistocene degradation was not very effective in Eastern Scotland.

Shortly before the advent of the Pleistocene there was a period of marked stream incision when the land stood higher than today in relation to the sea. This incision cut the buried river channels found under the estuaries of Eastern Scotland. This 
incision doubtless helped to rejuvenate tributary streams and it is possible that a fairly fine network of incised valleys, analogous to those seen today in New Zealand, existed. (COTTON 1958). If such a close network of valleys existed it has largely been lost during the vicissitudes of the Pleistocene.

2) The landscapes produced by glacial processes may be divided into two types. Forms of erosion, with over-steepened slopes, bare rock, and rough topography predominated in the hill areas of the $W$. Forms of deposition, with moderate to gentle slopes built of glacial glacifluvial and glaci-marine material predominated in the Lowlands. The former type of glaciated landscape did not prove amenable to drastic modification by periglaciation, since the rock was too sound and since the ice sheets lingered longest there. The latter type of glaciated landscape provided suitable material for cryoturbation, and probably for mass movement in the case of the finer-grained deposits. The bedrock was more or less insulated from peri:glaciation by the thick drift deposits except where outcrops of resistant volcanics appeared in isolated hill masses.

At this point it is necessary to consider to what extent the forms of "glacial erosion" can be truly ascribed to the work of ice, since it has been/that these forms are themselves essentially related to the effects of periglaciation prevailing before the advent of the ice. Perhaps the strongest advocacy of these views is made by BOYE (1950, 1952). His ideas have been repeated and extended by CAILLEUX (1952), and by TRICARD \& CAILIEUX (no date). BOYE's hypothesis suggests that there was an especially severe 
periglacial climate while the glaciers were advancing, and that the frost shattering which then took place broke up the rock and the advancing ice merely swept away the debris like a bulldozer. If the ice sheet were to advance over coherent rock, unaffected by shattering, it would do little more than smooth and polish it. BOYE suggests that frost shattering, by attack along pre-existing joint planes, can cut vertical-sided, flatfloored valleys in solid rock from which the debris is evacuated by solifluction. These valleys are termed "ravins de gelivation" and have been identified by other workers in Poland (DYLIK, 1956b) and Labrador (TWIDALE 1956). See photograph 51. Landforms in Scotland must be con:sidered in the light of these hypotheses.

The concept of a "periglacial of progression" while the glaciers were growing seems inherently probable. There is a certain amount of evidence for such a phase in Scotland in the wedges and involu:tions under till in central scotland and the shattered rock mentioned under till in Banffshire and Glen Geusachan in the Cairn:gorms and in Orkney (WILSON et al 1935). See chapters IV, V and VII above. Probably the climate was even more severe than during the glacial retreat when most of the periglacial features discussed in this study were formed. This periglacial of progression must have shattered the rock, and so aided the erosive effect of the advancing ice.

BOYE's hypothesis stresses the significance of forms in strong, well-jointed rocks like fresh granite and gneiss. Some landforms in Assynt and the Cairngorms were examined to see if they provided evidence in support of his ideas. 
The western part of Assynt is a low hummocky plateau of Lewisian gneiss with wide stretches of bare, ice-scoured rock. Examination of air photographs (cf. HOBSON 1949) and of the terrain reveals how many of the major and minor features of the relief are related to structural trends, notably joint planes. Rectilinear gullies with steep, joint-bounded walls, are abundant and vary in size from tiny examples measured in $\mathrm{cm}$ and decimetres to troughs tens of metres deep and wide and hundreds of metres long. They trend in many directions, often transverse to that of the ice motion as a whole. According to BOYE's hypothesis they are "ravine de gelivation" formed primarily during a periglacial of progression; the detritus was subsequently swept away by the advancing ice. According to the more usual hypothesis of glacial erosion, they are the work primarily of sub-glacial plucking.

On the $W$ flank of Ben More Assynt several small valleys aligned along dykes run straight down the slope. They have vertical rock walls and flat rock floors. Recent frost shattering has here and there broken down the sides to produce piles of rubble on the floor which the tiny streams are powerless to remove. Like the features on the Lewisian gneiss, they may be "ravins de gelivation" or the work of ice plucking.

The Assynt evidence is not decisively for or against BOYE's ideas. Although many of the gullies are transverse to the direction of ice motion, the lower layers of a glacier are so mobile that plucking can take place in directions very different from that of the glacier as a whole. 
Glem Geusachan in the Cairngorms is a typical U-shaped glacial valley. The debris which plasters the lower slopes is not thick enough to seriously modify this form. Bedrock in the shape of a smooth slab of granite was exposed at the bottom of a 10-metre deep gully cut by the floods of August 1956. (cf. Plate 2a in BAIRD \& LEWIS 1956). The surface of the slab was a joint plane trending more or less parallel to the surface. Such planes are very common in granite terrain. (HARLAND 1957)。A layer of shattered granite still in situ, about 1 metre thick, intervened between the slab and the over-lying glacial till. This shattered granite must have furnished much of the material incorporated in the till. It was evident that if the ice had removed all the loose material, the granite slabs would have been left to form a "boiler-plated" surface after the ice withdrew. Such "boiler-plated" surfaces are abundant on the higher sides of the valley. See figure 4l. In this instance the association of a form of 'glacial erosion' with periglacial shattering before the advent of the ice seems proved, and supports BOYE's hypothesis. However, this is only a form of detail and cannot be claimed as evidence that the entire U-shaped valley, many hundreds of metres deep, has formed in this way.

For a more decisive assessment of the importance of periglaciation of progress in the development of 'glacial' landscapes we must draw efidence from wider areas. The ideal conditions for the exercise of the process envisaged by BOYE are a prolonged phase of exposure to periglaciation followed by invasion by a powerful ice sheet. In Scotland, earliest gathering ground of the snows of the ice age was undoubted high and snowy hills of the $W$ while the $E$ was exposed to 
periglacial conditions for much longer before the advent of the ice, which was however sufficiently powerful to transport vast erratics, such as the Kidlaw limestone mass in East Lothian. In other words it was in the $E$ that the most favourable conditions for the operation of $B O Y E^{\prime} s$ hypothesis existed, but it was in the $W$ and in the high Cairngorms that the typical forms of glacial erosion developed. The conclusion is inescapable that the "periglacial of progression" does not play a significant part in the fashioning of major glacial landforms, although it may help to explain such detailed forms as "boiler plates". Periglaciation only significantly affected glaciated landforms after the disappearance of the ice.

To summarise this discussion of the pre-periglacial landforms of Scotland it can be said that in the NE smooth slopes, possible with some stream incision, and deeply rotted rock prevailed. Similar conditions but with steeper slopes existed in the E Highlands, seriously modified by glaciation in the higher areas, and in the Southern Uplands with the important difference that chemical weathering was less well developed or preserved. In the hill areas of the $W$ forms of glacial erosion predominated. In the lowland districts rolling forms of glacial accumulation predominated, with many lakes. The pre-periglacial landscape thus contained elements of very varied age and origin.

How far have these pre-periglacial forms been modified by periglaciation?

At one time, the smooth slopes so common in the $\mathrm{E} \& \mathrm{~S}$ of Scotland were ascribed to glacial abrasion. e.g. BREMNER (1912) stated with regard to Deeside: "the smooth flowing lines that 
everywhere meet the eye in a distant view are the direct result of the passage of the ice sheet". This view was mistaken and LINTON (1951, 1957) is undoubtedly right in attributing the smooth forms to mass wasting.

There has been a tendency, in line with current geomorphical fashion, to state that this mass wasting took place predominantly under periglacial conditions。 e.g. SYNGE (1956) states: "in'Moraineless Buchan' ... everywhere the hills exhibit the smooth contours typical of a landscape subject to mass wasting under periglacial conditions". FITZPATRICK (1958) is equally emphatic: "Much of eastern and southern Scotland is characterised by smooth undissected slopes while the hill tops are well rounded. These features are attributed to the action of frost removing definite corners while at the same time mass movement filled in any depressions".

In the present state of knowledge such statements are incautious, because we do not yet know to what extent the pre-existing forms have been modified by periglaciation. Modification there certainly has been, but was it more than relatively minor retouches of a landscape already fashioned by mass wasting and stream erosion under warm conditions? It has been shown in the preceding chapter that only the vaguest reconstructions of the pre-periglacial landscapes can be made with certainty in the $E$, although the glacial forms in the $W$ and in the lowlands can be more accurately delineated because they are much younger. To assess the effectiveness of periglaciation we must turn to consider the (assumed) periglacial landforms themselves, together with the associated correlative deposits. The smaller periglacial features (turf benches and niches) will be considered first followed by the larger valley and slope forms. 


\section{CHAPTER XII}

\section{T O R S}

I. Introduction.

The origin and significance of tors has attracted increasing attention in recent years. IINTON in particular has devoted con:siderable thought to these features. (IINTON, 1949, 1950, 1955, 1956). The classic examples in Britain are of course, those found in the SW of England, especially on Dartmoor, but similar features are widespread in other parts of the country. Definitions of tors are as numerous as papers on the subject. They will be defined here as follows: "Tors are rock outcrops surrounded by a surface of mass wasting". This includes features on valley sides as well as on plateaux, but excludes such features as bornhardts or inselbergs which rise from surfaces of sheet or rill wash.

Considerable controversy exists as to the origin of these rocky outcrops. IINTON (1955) makes a strong case for a two-phase origin of differential chemical weathering at depth under a warm humid climate followed by stripping of the weathered mantle to expose the more resistant portions of the rock. He suggests that this stripping/ by periglacial mass wasting, but is not necessarily linked to cold conditions. PULIAN (1954) suggests that both the differential weathering and the removal of the weathered products by mass wasting took place under periglacial conditions in the case of tors in Wharfe:dale. PAIMER (1956) claims that tors in a resistant bed of the Corallian in NE Yorkshire are being actively produced by weathering 
and creep under temperate conditions. His theory cannot apply to tors being destroyed by present day weathering, as is usually the case. NEEF (1955) implies that tors are of periglacial origin since they rise from sloping benches associated with prolonged frost shattering and mass movement.

Tors are also of interest in a study of periglaciation on account of the evidence they supply for unglaciated areas. Many are built of incoherent blocks that would be readily swept away by an ice sheet, and so must post-date the last glaciation if they occur in a glaciated region. (IINTON 1949, PAIMER 1956). Such unglaciated areas could be expected to have experienced severe periglacial conditions. Tors are certainly to be found in present day periglacial regions. EAKIN (1916) illustrated resistant bosses of granite rising abruptly above solifluction slopes. PHLTIER (1950) and FITZPATRICK (1958) believe they are common features of the periglacial evolution of slopes. Tors are certainly due to differential weathering, and removal of the loose weathering products, but there is disagreement on the mode and time relationship of this weathering and removal. This disagreement must be borne in mind when considering these features here.

II. Identification.

Difficulty is sometimes experienced in deciding whether a rocky outcrop is a tor or a feature of glacial erosion. IOUIS (1934) confused tors with roches moutonnes ("Rundhöcker"). As a rule, however the distinction is quite clear. More difficult cases are 
presented by very small, indistinct forms, not uncommon in the Southerm Uplands where small rock knolls hardly deserve the title of tor.

III. Description.

IINTON (1955) has listed 10 different localities, mostly hill tops, in NE and N Scotland where tors occur. In addition he states that the summit of Bencleugh in the ochils has outcrops of basic andesite which "have some of the characteristics of tors". The most impressive examples are those on the summit plateaux of the Cairngorms. See photograph 52 for an example from Beinn Mheadhoin. The Cairngorm tors usually rise abruptly from an undulating surface littered with boulders where periglacial processes of cryoturbation and mass movement are active today. Other fine tors on granite in this part of the country exist on Lochnagar, Clachnaben, Bennachie and Ben Rinnes. IINTON also mentions the tor on toughened schists of The Buck, Cabrach, and other examples at lower levels on the basic igneous intrusion just to the N. See photographs 53 and 54 . In addition to these examples, the tors $2-3 \mathrm{~m}$ high shown in photograph 55 exist on Muckle Long Hill in the same district (G.R. 4536) forming a line coinciding with an outcrop of especially tough, gritty schist. The Craigs of Succoth, $2 \mathrm{~km}$. to the $W$ appear, from a distance, to be of the same nature. Tor-like features seem to be abundant in st. Kilda (COCKBURN 1929, photographs).

Further $\mathrm{N}$, in 'Moraineless Buchan', incipient tors are to be seen around Maud, on basic igneous rocks, and on the NW margin of the Strichen granitic intrusion. These features take the form of low, 
knobbly hillocks, littered with boulders and half drowned in chemically weathered material. Poorly developed tor-like features can also be seen on the outcrop of the Huntly igneous mass.

Speaking of Southerm Scotland IINTON (1955) states: "tors are, as far as I know, unknown except on the Cheviot granite". (COMMON 1954). This is not the case. MIIIER et al (1954) have already suggested that the large caim on the summit of Tinto may have initially been a tor. Tor-like features, rather small, as a rule, exist on the Pentlands (Camethy Hill), the Moorfoots (Makeness Kips, Dunslair Heights, Lee Pen, Clede knowe) and on the andesitic rocks of the Renfrew Hills (Slaty Law, Knockside Hills). Admittedly most of these features are not very distinct and would not classify as tors according to IINTON's genetic definition. Nevertheless they do rise as rock knolls from surfaces of mass wasting. They coincide with more coherent, less shattered outcrops. They have not been noted on the hills of the Western Southern Uplands, but little field work has been done in this area.

IV. Formation, distribution and dating.

These aspects of the interpretation of tors are intimately inter:linked and so must be considered altogether. The tors of the $\mathbb{N}$ Highlands have not been examined in the field and will not be con:sidered here.

It has been pointed out that most of the tors of the NE of the country are found on granite and basic igneous rocks, and it has also been stated in chapter XI that these rocks are those most deeply 
affected by chemical weathering, but when sound are little affected by frost shattering. In these rocks, deep rotting tends to leave zones and core stones of sound rock amid the loose weathering products. See photographs 34 and 54. Tors are absent on the quartzites, slates, and phyllites, which are the rocks most sensitive to frost shattering but not to chemical weathering. Schists and gneisses occupy an intermediate position in respect to resistance to both frost and chemical attack; tors are confined to a locally occurring specially resistant gritty facies of the former.

The tors seem to coincide with locally resistant zones in rocks which in general are sensitive to chemical attack. These zone must also be resistant to frost shattering, otherwise periglaciation will destroy the incipient tor. This is clearly illustrated at Northeast Quarry, $10 \mathrm{~km}$. N of Ellon, and at Windyfield, $12 \mathrm{~km}$. $\mathrm{S}$ of Huntly. In these quarries zones of sound rock can be seen amid deeply weathered loose 'growan'. See photograph 34. As the growan was swept away by mass movement, the sound rock would have formed tors, had it not proved sensitive to frost shattering and so been reduced to fragments which have been removed by solifluction as soon as they were exposed at the surface. Angular chunks, derived from the shattered zone, and representing the wreckage of a tor which never developed, are to be seen in solifluction deposits formed of growan further down the slope.

Periglacial frost shattering thus tends to destroy the tors in NE Scotland rather than create them. This can be confirmed by observation of the tors on the Caimgorms and especially on Lochnagar, where contemporary frost wedging and solifluction are reducing the tors, 
block by block. On the other hand, the role of periglacial soli:fluction seems of great importance in exposing tors by removing the surrounding loose weathered material. Only solifluction could evacuate material across the gentle gradients of the surfaces of mass wasting surrounding many tors.

The evidence supports the hypothesis of origin advocated by BEAUJEU-GARNIER (1953) and other Continental workers and by IINTON (1955).

The tors in the lower hills of NE Scotland are of moderate height less than 5 metres. They cannot have survived glaciation so must be younger than the Greater Highland glaciation.

The occurrence of the best developed tors on the highest summits presents a problem of interpretation, which has already been tackled by IINTON. The abrupt form of the tors as much as 12 metres high and their loose, unconsolidated structure show that they could never have survived the passage of actively moving ice. Their exposure by mass wasting must therefore have taken place at a time when snow and ice were absent from these summits. Their exposure from the surrounding loose weathered material cannot have taken place under the sort of climatic conditions prevailing today -- it has just been pointed out how the present day "mild" periglacial processes are tending to reduce the size of the tors. This leaves only the very early and late glacial periods, and former inter-glacial periods as the time when the exposure took place. As IINTON points out, this exposure may have taken place in several stages, separated either by milder conditions than those of today, or by periods of burial under 
quiescent firn fields of glacial times:- moving ice would have destroyed these fragile features. It is improbable that the summit plateaux were free of firn for long periods while glaciers prevailed in the valleys, fed by snow swept of the neighbouring plateaux by wind, although this may have happened for relatively restricted periods in late glacial times. The records of the Ben Nevis obser:vatory, situated on a wind-swept plateau if ever there ware one, show that snow lies readily on such a site, and if the climate were a little more severe would survive throughout the year.

The existence of the great solifluction lobes on Lochnagar (see photograph 43 and chapter VIII) proves that there was a former phase of much more active mass movement, probably of very late glacial, or possibly Atlantic age. This phase would have helped to expose the tors through removal of surrounding loose material by solifluction, but can hardly have lasted long enough to remove a layer as much as 10 metres thick from gently sloping summit plateaux.

It would seem that the high level tors of the NE are the products of a long and complex evolution commencing with deep chemical weathering in pre-glacial times, and probably in warmer interglacial times. The essential removal of the weathered debris took place by mass wasting during relatively short periods at the close of each glaciation. During glacial times the tors were covered in a protective layer of firm; during cool interglacials they were attacked and partially reduced by periglacial processes such as prevail today.

Turning to the smaller tors which have been mentioned from the Centre and South of Scotland, we find the important difference that here deep chemical rotting of the rock is not apparent. The 
differential weathering, an essential part of all the theories of tor formation, seems to have been mechanical, not chemical. It is apparent that the rate of present day weathering is quite inadequate to account for the features, and its action is to reduce rather than to create tors. This leaves periglacial frost shattering as the most likely weathering agent.

It has been pointed out how the rocks of the Southerm Uplands are generally amenable to frost shattering and how the tors coincide with more coherent, less fissile outcrops. They are surrounded by phenomena attributable to periglacial mass movement, especially smooth even slopes, but also by block fields and possibly altiplanation benches (Lee Pen). It is apparent that periglacial frost shattering and mass wasting has been responsible for the appearance of these forms, in accord with the theories of COMMON (1954) and more particularly of PULIAN (1954). The much smaller size of these features compared to their counterparts in the NE is a consequence of a much shorter period of development and the absence of a phase of chemical deep weathering.

The distribution of erratics shows that the Lammermoors, and probably the Moorfoots, were overridden by ice not very powerful as an erosive agent since U-shaped valleys etc. are absent, but sufficiently effective to shave off tors produced by previous periglacial phases. Thus the tors we see today are the product of the last periglacial phase only, subsequent to the last glaciation. This short evolution, plus not very favourable rock conditions accounts for their relatively poor development. 
$\mathrm{V}$. Conclusions.

1) Tors are of interest in periglacial studies for the evidence they provide of unglaciated areas, and as examples of forms produced in part by periglacial processes.

2) They occur in the $E$ and $N$ of the country generally on high ground but in 'Moraineless Buchan' are found down to low levels.

3) They have formed as a result of a period of weathering followed by removal of the loose material round zones of more resistant rock by mass wasting. In the case of the tors in NE Scotland, where the largest and best developed examples exist, the differential weathering appears to have been a result of warm humid chemical attack on the rock, while the removal of the weathering products was largely the work of periglacial conditions, although it must be admitted that the relatively mild variety of these conditions existing today on the higher hills seems to be reducing the tors themselves as rapidly as it is removing the surrounding unconsolidated material. The deep weathering and mass movement seem to have been going on for a long time and the tors are the products of a long and complex evolution.

The rather poorly developed tors in the Southern Uplands seem to have a different origin and to have developed during periglacial con:ditions after the disappearance of the last ice sheet. In this case both the initial differential weathering and the subsequent removal of the weathered products seem to have been the work of periglacial frost shattering and solifluction respectively.

4) The history of the tors in the $\mathrm{NE}$ is so long and complex that they cannot furnish reliable evidence as to the effectiveness of periglaciation in shaping the landscapes. The tor-like forms on the Southern Uplands suggest that the last periglacial phase of the Pleistocene removed I to 
2 metres of rock from the hills -- a minute amount in relation to the relief as a whole. 


\section{CHAPTER XIII}

\section{BENCHES}

I. Introduction.

The production of sub-horizontal benches on slopes, cut in rock is characteristic of prolonged and severe periglacial erosion. These features are termed "altiplanation terraces or benches". (EAKIN 1916). The outer margin may be built up of solifluction debris, so widening the shelf, but the essential point is that the inner part at least is cut in rock. Polygons, stripes and solifluction features are common on the debris coating the top surface of the bench, and it is by mass movement that material is exported from the inner to the outer margin of the feature. FAKIN suggests that the surface of the bench can be lowered by weathering of the rock surface underlying the "tread" and in this way the higher terraces eventually overtake and incorporate the lower to produce fewer but larger features. Altiplanation features have, however, not been closely studied outside of Russia, and much remains to be learnt about their formation. It is believed that they correspond to periglaciation of a severe type. TRICART (n.d.)

\section{Identification.}

The certain identification of these features in scotland is not easy. Benched features on hill sides can be the product of glacial erosion or the work of glacial meltwaters, or simply represent 
an outcrop of rock especially resistant to present day weathering. Other benches may be purely constructional features due to mass move:ment. The form of benches is often partially obscured by recent erosion or by the growth of peat. None of the features to be described here can be categorically described as altiplanation benches, although this seems the most probable ascription in many cases.

\section{Description.}

Altiplanation features have been described from Southern England, (GUILCHER, 1950; Te PUNGA, 1956), but there is no published record of their occurrence in Scotland, apart from a brief mention of vague benching noted by the writer on the $N$ face of Balloch Hill, Banffshire in FITZPATRICK 1956. BARROW et al (1905) mention a terrace feature on the $W$ side of Beinn $A^{\prime} G h l o$, Perthshire, at a height of just under 3,000 feet. Although they ascribe this feature to the work of glacial meltwater, it is not improbable that it is an altiplanation feature. (The writer has not examined this area).

The best examples of altiplanation features seen in scotland were found on the S slopes of Lochnagar above 3,000 feet. They can be clearly seen in photograph 43 above the belt of solifluction lobes, and in profile on the skyline to the right. They consisted of bare rocky shelves coinciding with joint planes of the granite. One would ascribe them at first to glacial erosion producing "boilerplated" landforms, but the existence of unconsolidated tors on the plateau nearby, and the striking solifluction features on the slope just $\mathrm{b} e \mathrm{l}$ ow suggest rather that the benches are the work of 
periglacial processes. Washing and mass movement have subsequently cleaned off the original layer of periglacial detritus that must have once covered the surface of the bench. Rather similar, but less well. developed features exist near the summit of Broad Cairn, a few $\mathrm{km}$. to the S, likewise associated with large, immobile, solifluction lobes.

At 1700 feet on Whiteside Edge, $5 \mathrm{~km}$. N of Peebles, a welldeveloped bench, some 25 metres wide can be traced for several hundred metees along the $\mathrm{N}$ face of the hill. See figure 42. Bedrock was not exposed, but there seems no doubt that the feature is essentially cut in rock. The bench had a gentle longitudinal slope westwards towards the Eddleston valley, and could well be the work of glacial mett water (indubitable melt water channels cut across the ridge to the NNE at altitudes of about 1550 feet), but periglaciation must have modified the feature to some extent to produce the angular debris observed on the slope at the back of the bench.

A rather similar bench was observed at an altitude of 1300 feet on the $\mathrm{N}$ face of Priestlaw Hill in the Lammermuirs. See photograph 56. The gently-sloping "tread" was about 20 metres wide and extended for several hundred metres along the hillside, falling gently eastwards. On the slope below less well-developed terrace and bench forms could be seen, at lower altitudes, resembling softened slump features and solifluction lobes. The position, and longitudinal slope of this feature once again make a glacial meltwater origin a possibility, but there has certainly been considerable modification by periglacial processes to produce the rough boulders which can occasionally be seen on the surface of the 
bench and onthe slope behind. A totally periglacial origin is not excluded but cannot be proved.

Irregular benching is well developed on the upper part of Lee Pen, $8 \mathrm{~km}$. ESE of Peebles. The benching is found above about 1500 feet and affects the E,S, and SW faces of the hill -- the steeper sides. Bhotograph 57 (taken with the kind assistance of Edinburgh University Air Squadron) gives some idea of the appearance of these benches, although they are more striking when examined on the ground. See photograph 58. From about 1250 feet upwards, the surface of the hill is covered in stones and boulders, visible here and there through openings in the vegetation. Towards the summit the bare stony areas become more frequent and take the form of stone streams. The summit itself consists of a number of low rocky knolls. The benches are irregular in form, their width varying from 2 to 20 metres and the height of the steep slope at the back from 1-10 metres (a rough estimation only). Laterally they extend for a few to several hundred metres, with an irregular gradient. No solid rock was seen on the benches, but rough boulders are frequent. The dyke running up from Innerleithen on the southern ridge of the hill, transects five of the bench features. An origin by glacial meltwater erosion seems improbable in the case of these features, since the longitudinal slope of the benches tends to be up the valley of the Tweed. It is not clear however, if they are solifluction features or true erosional altiplanation benches. These few examples of relatively clear-cut bench features could doubtless be matched from many other hillsides in scotland, but even commoner are vague, ill-defined forms, often best seen 
from a distance and under slanting light. Many thousands of such sub-horizontal shelves are to be seen throughout the hill country in the $\mathrm{E}$ of Scotland. Some, such as those on the flanks of $\mathrm{W}$ and E Knock, (the S side of Glenesk, Angus) have a recognisable bench form; others, like those on the hills around Broughton, Peeblesshire in the Lammermuirs or on the Pentlands are little more than bumps on the slope. These features are often deeply covered in peat and their origin cannot be precisely determined. They are not confined to any particular orientation of slope, but gradients between about 10 and 25 degrees (estimated very roughly) seem to be favourable. COMMON (1954) has mentioned similar features to be seen in the Cheviots. Many must be the work of glacial and glaci-fluvial erosion, while others are certainly buried solifluction forms, but it is not improbable that a considerable number are periglacial altiplanation features. Definitive evidence will only be provided from sections through these features.

IV. Formation, distribution and dating.

The indifference of these features to the direction of orientation of the slope suggests that snow patch erosion has little to do with their development. Much more important is the existence of a suitable gradient. e.g. The benches on Lochnagar face $S$ while that on Priestlaw, in the Lammermuirs, faces $N$, but both lie just below the brow of a slope between 15 and 20 degrees. The rarity of these benches on hills below 1,000 feet is difficult to explain, since the testimony of wedges shows that periglaciation at low levels was severe. 
The examples described above all come from the $E$ of the country, and it would seem at first sight that these features are better developed there than in the more heavily glaciated $W$. There is, however, no real basis for this belief since only sporadic search was made for altiplanation benches in the $W$ of the country. The altiplanation features described can only be dated in the vaguest terms. The close association of the Lochnagar benches with large, immobile, solifluction lobes at high level suggests a fairly late glacial age; The clearcut examples from the Southern Uplands must postdate the last ice sheet in that area (The Scottish Readvance) if they are indeed products of periglaciation. Some of the much vaguer forms might have been initially created during harsh periglacial conditions while the glaciers were developing and were later overridden and abraded by the ice. In the absence of evidence, such a suggestion is pure speculation.

V. Conclusion.

There is considerable evidence of altiplanation having operated on Scottish mountains in the past, implying the existence of severe periglacial conditions there. Unfortunately, none of the evidence collected is entirely unequivocal. The modification of the slope forms as a whole introduced by these features seems to be but slight. Most of the known examples have been found in the $E$ half of the country but it is not known if there is any significance to be attached to this fact. 


\section{NICHES.}

\section{Introduction.}

Niches make up a rather indefinite assemblage of features transitional on the one hand to benches and on the other to valleys. They are hollows on slopes, of smoothly rounded appearance, horseshoe in plan and curved, or flat-floored in cross profile. See figure 43 and photograph 59. In chalk country, large forms are known in English as "coombes", but unfortunately there is no all-embracing term utilisable in all areas, corresponding to the German word "Dell" (plural "Dellen"). COTTON \& Te PUNGA (1955) realise this difficulty and make use of the German word itself. The English equivalent "Dell" has not so clear-cut a connotation. "Nivation hollows" are generally of niche-like form, but not all niches are the work of snow patch erosion. The most suitable term, not in itself implying or excluding any particular genesis seems to be "niche".

Niches can be produced in various ways. In unconsolidated material, one of the commonest is slumping: the scar left by a slump may be termed a "slump niche". Such niches are initially small as a rule, although if the slumped material can be evacuated by washing or by solifluction, repeated slumping can take place at the head of the form, so deepening and extending it. See photograph 60. Slump niches are commonest in very mobile materials with 
plenty of water and especially if the lower part of the slope on which it occurs is being undercut.

Niches can also be produced by infilling of a pre-existing gully by mass movement. NEEF (1955) terms such features "Sammeldellen" because they act as collecting basins for mass wasting products. This type of niche has been described in detail from the Wellington area of New Zealand by COTTON \& Te PUNGA (1955) and COTTON (1958). Here they will be termed "accumulation niches".

It seems that niches can also be carved out by material undergoing mass movement. Such forms are termed "corrasion niches". It is believed that the passage of a solifluction deposit can erode the underlying bedrock, and tends to produce a niche-like form. Te PUNGA (in COTTON \& Te PUNGA 1955) has convincingly demonstrated that such erosion is possible in the case of very weathered rock, but it seems rather more doubtful if it can take place in sound rock, although frost shattering under a slowly moving saturated layer may be effective in this connection. KLATKOWA (1954) has described niches formed by periglacial corrosion in till in Poland.

Niches may form the uppermost part of valleys. (POSER 1936). As a consequence of the large part that solifluction plays in their formation, the stones in the detritus on their floors tend to be oriented down the slope. For slump and corrosion niches it seems that the rate of development depends primarily on the rate of evacuation of material at the mouth. All types of niches may be dissected by gullies if the morphogenetic system should change. In Europe, niches have developed most readily in uncolidated rock, such as terrace gravels and till. The margins of many of 
the Central European river terraces are fretted with niches which can be correlated with cold phases of the Pleistocene. Hard, fresh rock does not lend itself to niche formation. Instead, what have been termed "ravins de gelivation" develop (BOYE 1950. See Chapter XI above). These are gullies, of ten with walls corresponding to dominant joint planes, whidh have developed by frost shattering working along weak zones of the rock; the resulting debris is evacuated by solifluction.

II. Description.

Apart from a brief mention of a'solifluction hollow' noted by the writer at Ardemanoch farm, E of Keith, Banffshire (in FITZPATRICK 1956), there appears to be no record of periglacial niches having been observed in Scotland. This feature was a flatfloored hollow, some 3 metres deep and 20 metres wide that dissected the side of a glacial meltwater channel. Its form was quite different from that of a stream-incised gully. The material from the niche was spread out in a gently sloping fan across the floor of the channel showing that the feature formed after glacial mettwater had abandoned the channel. Investigation has shown that niches are to be seen in various parts of the country, and a few examples will be described.

In the Lammermuirs, near the junction of the Back Burn with the Monynut Water at G.R. 708659 the large niche portrayed in photographs 57 and figure 44 was observed. This feature had a smoothly rounded cross profile and resembled an oblong basin about 200 metres long by 100 metres wide set into the evenly sloping valley 
side. The floor was covered by un unbroken sheet of turf except towards the lower end where a narrow very recent gully entered from the side. The incision of this gully had locally steepened the floor of the niche and this had led to renewed mass movement and slumping in its immediate vicinity. At the mouth of the little gully a fan of debris had been laid down. The floor of the niche as a whole was graded to a level above the rock terrace which floors the main valley at this point. (cf.chapter IX above). The terrace itself has been dissected to a depth of a few metres by the present stream. It is clear that the smooth form of the hollow must be the work of mass movement in the past, and that the debris exported from the niche was readily carried away down the valley since it did not accumulate at the mouth of the niche. When the niche was formed mass movement must have been vigorous and transport of the debris along the main valiey very erfective, i.e., it was Iomed at a time when penglacial conditions prevailed. The sharply cut Litule gully and its associated modern fan are alien features, testimony to the very different agencies of erosion and deposition at work today. It is not clear to what extent the niche is entirely the work of corrasion and to what extent it represents the infilling of a pre-existing streamcut gully. This locality will be considered further when examining the evolution of slopes as a whole in Chapter XV.

Similar but rather longer, steeper and shallower forms are to be seen along the flanks of the Gatehopeknowe valley in Peebles-shire and indeed on the sides of many other valleys of the Moorfoots and Larmermuirs. They have the same gently rounded cross-profile, without a stream and may grade at their lower end to the present valley floor. When/ 
When pernafrost existed running water probably helped to fashion them but their form suggests that corrasion and mass wasting were more important in their development. Much larger features of analagous shape occur at the head of the valleys in the Moorfoots where striking amphitheatres with straight, even slopes are to be found, e.g. in the basin of the Leithen Water - see Photograph61. In many cases the walls of these large amphitheatres are now brutally incised by recent gullies, between which remnants of the smooth pre-existing form survive. These valley heads are much too large to be termed niches but from them there is a complete graduation of forms to true niches on one hand and smooth even slopes on the other.

Forms that may be corrasion niches or nivation hollows occur spor-

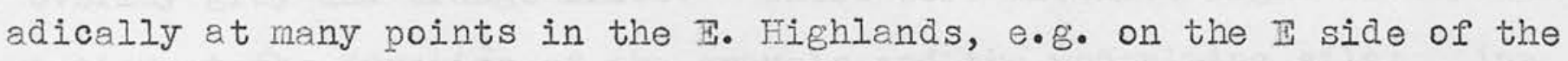
Pass of Drummochter, and on hillsides in the valley of the West Water, Angus, but their shapes are rather indefinite and obscured by the growth of peat and sometimes by recent stream erosion. A large niche or possibly a dry valley can be seen in the Glen of Foudland, S. E. of Huntly. It is a steep straight trough with a rounded bottom in which no stream flows. Niches also exist on slopes at the edge of the great accumulations of sand and gravel derived from the Moray Firth ice sheet to be found along the banks of the North Ugie. See Chapter IV above. They take the form of streamless hollows with rounded crossprofiles grading into dry or nearly dry valleys, that dissect the sand and gravel and debouch onto a low terrace of the Ugie. These niches show ho consistent evidence of asymmetric cross profiles.

Accumulation niches are found in areas of the Southern Uplands and $\mathbb{N}$.. S Scotland where the slopes are less steep than those on which corrosion niches have developed. The infilling of pre-existing valley heads/ 
heads has produced very wide open hollows. Occasionally recent stream incision has revealed sections in which the nature of the infilling can be seen. Thicknesses exceeding 2 to 3 metres are uncommon. The material forming the infilling can include glacial till modified by solifluction, washed silts, sands and gravels, frost shattered rock detritus and peat.

Tavers Cleugh in the Lommermuirs (G.R.6166) provides a good example of an accumulation niche. A recently cut gully in the floor of the upper part showed the section illustrated in Figure 45 . Under fully a metre of peat was a layer of glacial erratics which had moved down from the surrounding slopes by solifluction. These eriratics rested on 2 metres of poorly-rounded gravels in silt which in turn overlay grey and orange silts. There were distinct signs of cryoturbation at the junction of the gravels and the underlying silt; ina neighbouring exposure it could be seen that cryoturbation in the form of erection of peebles, had also affected the gravel itself. This section proves that the accumulation took place a long time ago (since overlain by peat) and under periglacial conditions (cryoturbation). Most of the infilling at this point had taken place by the action of washing water, but in other exposures along the gently sloping sides of the niche it could be seen that solifluction of frost-shattered material had also contributed. Further down the valley the stream had been sufficiently powerful to prevent much accumulation and the rounded profile of the niche is consequently replaced by that of shallow flat-floored trough, cut in (shattered) bedrock. The contemporary stream has continued to fashion this trough form as well as dissect the accumulation on the floor of the niche in the upper reaches of the valley. The head of practically every minor valley in the 
lower and more gently sloping parts of the Southern Uplands is similarly infilled, to form accunulation niches which contrast with the erosional amphitheatric forms found on areas of steeper initial relief and greater depth of dissection.

Niches of accumulation are apparently common also in Moraineless Buchan' although unfortunately no decisive exposures were encountered. Softened hollows on hill slopes, probably coinciding with the infilled head of a pre-periglacial valley can be observed around the headwaters of the Ythan and the Urie and to the $\mathbb{N}$ of Ellon. No cases have been observed remotely approaching the remarkable periglacial infilling of deep gullies reported from New Zealand by COTTON \& Te PUNGA (1955).

\section{Formation.}

It is apparent that, like altiplanation benches, the orientation of the feature is unimportant for its development, but that suitable rock and gradients are necessary. No niches have been observed on very steep or very gentle slopes or on really sound resistent rock: that of the Southern Uplands is not chemically weathered as a rule but is generally frost-shattered. The longitudinal gradient of the Scottish forms is rather steeper than the equivalent features seen (in less coherent material) on the Continent. It is not yet clear how far the niches observed are the work of snow-patch erosion.

\section{(Lewis 1937).}

Slumping does not seem to have played an important part in the developement / 
development of Scottish niches apart from a few small examples in till, such as can be seen on the slopes, behind Kirkton, in the parish of Fettercairn, Angus. In any case there is little reason to regard such features as of specifically periglacial origin. The can form just as well under today's climate.

While solifluction has certainly been responsible for the smoothness of form of niches, it is not so apparent to what extent it has caused the initial hollow. Slump niches, confined to unconsolidated material in wet situations, are entirely the work of mass movement, but accumulation niches in more coherent rock require the presence of some pre-existing valley, almost certainly cut in preperiglacial conditions. twen forms which have been classified here as corrosion niches may in fact be largely the work of initial stream incision with corrosion ading only minor retouches and smoothing off asperities. Only evidence fram sections in the floor of the features will settle this problem. Sections in accumulation niches are not uncormon (e.g. Tavers cleugh) but unfortunately none have yet been observed in the floor of forms taken to be corrosion niches. The recent gully incising the floor of the niche at the junction of the Back Burn and Monynut Water described above is too shallow to furnish significant evidence. A little more evidence is available in the case of the amphitheatre hollows at the head of many valleys in the Moorfoots. Sections show that bedrock lies near the surface, overlain by a thin layer (less than 1 metre thick) of solifluction deposits consisting of angular fragments of the underlying shattered shales. Similar/ 
Similar sections can be seen on most slopes in the area and not only at the valley heads. The shattered bedrock in the amphitheatres is proving very susceptible to gullying under the present climate, but the rate of incision is checked when the streams encounter more coherent rock below the shattered material. The steep sides of the gully are then no longer undercut so rapidly and in turn surfer mass wasting and washing which reduces their steepness until vegetation is once more able to colonise the site and the brutal scar on the slopes is more or less healed. Such healed gullies can be readily recognised in the field by their fresh green vegetation

In this way, the whole surface of the amphitheatre might eventually be eroded back for a distance equivalent to the thickness of the shattered layer, if present conditions continue long enough. Gullying is perhaps particularly prevalent at the present time because of the effects of prolonged sheep grazing, but can probably take place without this artificial stimulus. With the advent of renewed periglacial conditions, the irregularities and concave profile of the slope inauced by the gullying would be smoothed off by solifluction and a little corrosion, and a fresh layer of deeply shattered rock would be prepared for gullying during the next phase of milder climates. Thus the features could be deepened and extended by an alterntion of linear and stream erosion and periglacial mass wasting. COTTON (1958) has recently suggested a similar theory for the development of niches in New Zealand.

An alternative explanation is that the arphitheatres are entirely the result of a combination of shattering and mass movement with some corrasion but no linear stream erosion, and are solely the work of periglacial processes. Bven if this were true one must still postulate stream/ 
stream incision, perhaps in late Tertiary times, to create the necessary initial steep gradient.

It may be that the explanation of the amphitheatric valley heads of the Moorfoots offered here - alternation of stream incision in temperate conditions and frost shattering and solfluction in periglacial conditions - can also apply to the development of corrosion niches. Certainly a theory of origin for these features implying that they were entirely the work of solfluction seems most unlikely as it fails to account for the strict localisation of these forms in areas of homogeneous rock such as the Southern Uplands. If solifluction, acting through corrasion, were the sole agent in their formation there is no reason why the niches should have evolved differently in any way to the surrounding slopes. It is necessary to postulate an initial location by stream incision. Thus it will be seen that corrosion niches are not really so very different from accumulation niches and both mark the site of a pre-periglacial stream head.

More evidence, particularly from sections, is required before these rather speculative conclusions can be confirmed. Whatever process or processes were involved there must have been most effective evacuation of the loose material produced in the making of the niches since no significant quantity of debris survives at the mouth of the features examined. The niche near Keith is the one exception noted and in this case is readily ex lained by the fact that the material was swept out onto the floor of a glaci-fluvial in-and-out channel after the melt waters which cut it had gone, leaving no stream to evacuate the debris. 
Niches continue to be modified today. In some cases con:temporary mass wasting is tending to further infill accumulation niches, but nore usually streams are cutting into the ploors in sharp Vee-gullies very different from the smoothly rounded true niche form. The infilling appears to be very slight, but the gullying is often rapid and leads to renewed mass movement on the oversteepened slopes at the head of the incision.

\section{Distribution.}

Niches are prevalent in the eastern half of the country and in every locality where unconsolidated glacial drift suitable for slumping exists. They reach their finest development in the Southern Uplands and have not been observed on the steep slopes and hard rocks of the intensely glaciated areas of the $w$.

\section{Dating.}

On present information niches cannot be readily dated. The initial strean incision which seems necessary for all niches in consolidated rock must predate at least the last phase of intense mass movement. i.e. The last periglacial phase. In the case of those in glacial deposits a rather more accurate dating is possible. e.g. the niches in sands and gravels near New Pitsligo in Aberdeen: shire must postdate the Moray Firth glacier stage, since they 
occur in deposits of this age. Niche formation must therefore have been possible in fairly late glacial times. Dating of the features not in drift is rendered still more uncertain by the possibility that they have evolved at several different periods.

VI. Concilusions.

(1) Niches have not previously been described in Scotland but they do occur, especially in loose glacial drist and in the South:ern Uplands. They do not occur in Presh solid rock.

(2) Niches caused by slumping, accumulation, and corrasion exist. The first two types are readily explained, but interpretation of corrasion forms is not so easy. Unfortunately little evidence is available, but it appears that they are modifications of a preperiglacial stream-cut valley.

(3) The large amphitheatric valley heads common in the Noorfoots resemble corrasion niches in form and consideration of their development suggests that they are the work of alternations of stream erosion in temperate periods and mass wasting and corrasion in periglacial periods.

(4) The evidence presented is very sketchy and there is great need for further work on niches. 


\section{Introduction.}

The examination of tors, benches, and niches shows that peri: glaciation has affected the landforms of Scotland but gives little idea of the real extent and importance of this modification. These features are only minor retouches. To assess the importance of peri:glaciation in fashioning the relief as a whole we must examine the slopes as it is there that the most effective geomorphological changes take place. The development of the slopes must be considered in association with that of the talwegs since the two are intimately interrelated.

A brief outline of the way in which slopes and talwegs evolve under periglacial conditions has already been given in chapter II but it is necessary to consider this topic more closely.

Broadly spreaking, slopes can evolve by downwasting, becoming ever gentler with time, by backwasting or parallel retreat when the gradient remains more or less constant as the slope retreats, or by a combination of these two. SAVIGEAR (1952) has shown how parallel retreat prevails under today's climate in Devonian rocks of $S$ wales provided the debris arriving at the foot can be evacuated, while downwasting prevails if the detritus accumulates at the slope foot. A slope undergoing parallel retreat generally has a straight profile corresponding to the angle of rest of the weathered material on it, known as "slope deposits". 
Similar considerations govern the evolution of slopes under peri: glacial conditions, although the angle of rest of slope deposits can be very much lower if the material is suitable for solifluction, and consequently the downwasting of pre-existing steep slopes is encouraged.

Downwasting, associated with intense frost shattering, generally prevails on the upper part of the slope giving a rounded, convex form which may be broken locally and temporarily by the rugged form of tors corresponding to more resistant ourcrops.

Backwasting, or parallel slope retreat prevails on the middle section of the slope, giving a straight profile. The inclination of this straight section of the slope depends partly on the rate of evolution of the slope as a whole but more on the proclivity of the slope deposits for solifluction. In material especially favourable for solifluction this inclination can be only a few degrees. In rather less mobile material, such as the solifluction deposits on the Southern Uplands, the gradient is usually over 20 degrees. Slope deposits on this part of the slope are usually thin.

On the lower part of the slope, the evolution is controlled by the rate of arrival of debris from above and its removal from below. If great quantities of solifluction deposits are furnished by the slope above, which cannot be readily removed, they accumulate in a sloping glacis which builds up gradually until it overwhelms the backwasting middle portion of the slope. On the other hand, if the material can be removed from the foot of the slope as fast as it accumulates, back:wasting can prevail right to the talweg, giving straight valley sides that meet the valley floor in a sharp knick. 
The form of the valley floors is the resultant of erosion, longitudinal transport and the supply of material from the adjoining slopes. Erosion can be very effective under periglacial conditions, as many observers have pointed out. (e.g. POSER 1936, DEGE 1941, JENNESS 1952, BUDEI 1948). cf. Chapters II and IX. The initial tendency seems to be to produce narrow gullies which are widened by lateral erosion to form steep-sided flat-floored trought cut in rock. This form can develop only if longitudinal transport is sufficiently effective to remove all material furnished by the adjacent slopes. If not, the cross profile of the valley becomes rounded and there is a possibility of partial infilling. In some valleys the material may be furnished more effectively from one side than from the other leading to the development of asymmetric forms. The rounded cross profile is associated with an abundant supply of debris from the valley sides beyond the capacity of the stream to evacuate and absence of backwasting on the lower portions of the slopes. The steep trough forms are associated with a less abundant supply of solifluction material relative to the transporting power of the stream, and with parallel retreat over all but the uppermost part of the slope. Usually the rounded cross profile prevails in the upper part of valleys passing into the trough form as the volume of the stream increases. e.g. BEAUJEU-GARNIER 1953, POSER \& MULIER 1951.

The correlative deposits corresponding to the erosion of slopes and talwegs consist of the solifluction deposits found on the slopes and accumulate at their foot, and the alluvial material deposited elsewhere by the stream. Under periglacial conditions these alluvial 
deposits can be of immense volume and comprise deltas, fans, gravel spreads and terraces.

II. Identification.

Although it could be claimed that glacial melt water channels are strictly "periglacial", the dominant agent in their formation/water from the melting ice and it is more logical to regard them as glacifluvial rather than periglacial forms. In some cases they can be confused with truly periglacial forms. Melt water channels usually have steep sides and a flat floor cut in rock, a form that it also to be found in periglacially formed valleys. Older examples, or those cut in weak rocks may be partially infilled by mass movement from the sides to give a rounded cross profile reminiscent of the uppermost sections of periglacial valleys. Distinction between glaci-fluvial and periglacial valleys is not always easy, but the former tend to have an abrupt beginning and often run across rather than down the slope, while the latter have a more gradual commencement and do not show anomalous relationships to the gradient.

Iinear stream erosion such as takes place today tends to produce Vee-shaped valleys with interlocking spurs, different from the much straighter troughs produced by periglacial agencies. However in certain cases, it seems that if a present stream inherits a trough shaped valley from periglacial conditions it tends to preserve the form, widening it by lateral corrosion. In such cases it is not easy to decide how far the valley is periglacial in origin. 
III. Description and discussion.

Slope and valley forms of probably periglacial origin are frequently encountered in the hills of the eastern side of Scotland, and in the lowland area of the NE. Only a few outstanding examples will be dis: cussed but it must be remembered that these are not strictly typical, having been chosen as specially clear examples.

Northeast Scotland. The uppermost few $\mathrm{km}$. of the Ythan valley, Aberdeenshire, seem to have escaped invasion by glacial meltwaters at any time since the greater Highland glaciation. (Lower down the valley carried vast quantities of melt water south-eastwards.) The valley begins as a very flat indeterminate hollow on a moorland at wells of Ythan (G.R. 6338), but soon takes the form of an incised trough with flat floor and straight even sides suggestive of parallel retreat and mass wasting. About Glenmellan (G.R. 6538) it is incised as much as 20 metres and the sides are steeper and rougher, but the regular form reasserts itself and is clearly to be seen around Bruckhills (G.R. 6937). Here a section in the side of the valley shows about 1 metre of soli: fluction material overlying shattered rock. See photograph 37 , and figure 32. The form of the valley at this point closely resembles that of fossil periglacial valleys seen in Central Europe and it is logical to assume that it too is of periglacial origin, especially as this valley lies entirely within 'moraineless Buchan'. It may well be, however, that the greater part of the initial fashioning of the valley was interglacial or the work of meltwater of the Greater Highland glaciation. A good deal of the material washed down this 
valley, consisting solely of platy fragments of the local phyllite, has been preserved in terraces around Kirktown of Auchterless.

This is perhaps the best-developed example of this valley form in the area, but many others are to be seen in the Glen of Foudland, for example, or at Hassiewells (G.R. 6540). Straight even slopes, coated with solifluction debris, descending to flat valley floors that do not seem to have carried glacial meltwater, are frequently occurring landforms in this area.

In the valley of the Ness Bogie, lying SW of Huntly, straight slopes descend to a narrow but flat valley floor from rounded hilltops. The slopes are covered with a layer of solifluction deposits, but these are extremely thin, about $\frac{1}{2}$ a metre is the usual figure, and shattered bedrock can often be seen beneath. It may be that glacial meltwater has played some part in the formation of the valley as there are certain indefinite traces of small glacierets at the headwaters. However, the abundant tors nearby, the even slopes and the occurrence of solifluction deposits suggest that it has acquired its present form under periglacial conditions. The cross profile of this valley resembles those figured by DENNY (1951) from near the wisconsin drift border in Pennsylvania, and ascribed by him to periglacial agencies. Ochils. The sides of most of the deep valleys which fret the scarp face of the ochils are strikingly regular, once one penetrates past the rocky outcrops and gorges of the lower part. The straight slopes sweep down from rounded summits or from craggy outcrops of resistant rock to a small trough forming the valley floor. This trough may be partly the work of postglacial incision by the stream, and passes into a gorge downstream while dying out completely at the head of the 
valley where the slopes meet in a Vee or in a rounded hollow with no stream course. The evenness of the slopes is broken by low swellings corresponding to more resistant beds beneath, and by the minor features of present day mass movement: screes, terracettes and individual blocks creeping down the hill. See photograph 62. The entire slopes except for outcrops of bare rock and the sides of the trough at the bottom are covered by a thin layer, about $\frac{1}{2}$ metre thick, of solifluction material composed of angular fragments of the bedrock in a rather scanty matrix of sandy material. See figure 46.

Correlative deposits of the erosion which has proceeded in these valleys comprise the solifluction deposits together with the large fan deposited at the hill foot on which such towns as Dollar, Tillicoultry and Alva now stand. Consideration of the volume of these fans in relation to the extent and available relief of the basins supplies some clues on the rate of erosion under periglacial conditions. See below. Southern Uplands. Mass wasting slopes are well developed in the Moorfoots. Particularly fine examples exist around the headwaters of the Leithen Water where the rounded summits and straight middle and lower valley sides abound. See photograph 61. Similar forms can be seen just to the SW at the head of the Soonhope Burn. See photograph 63. In this region there are local variations of the form of the lower part of the slopes. Where the present stream is powerful, it is meandering and impinging on the valley sides, under: cutting them and oversteepening them to an extent which the slight mass movement occurring today is unable to conceal. Where the stream if not so powerful, the valley bottom may be grassed over, and the lower part of the slopes have been built up a little by contemporary 
mass movement, leading to the beginnings of a rounded cross profile instead of the previous trough form. At the very head of the valleys we encounter amphitheatric forms, frequently dissected by recent gullies, which we have already mentioned in connection with niches. These amphitheatres are themselves comprised, like the valley flanks, of straight slopes plunging down at gradients of around 25 degrees from rounded crests.

Where sections cut down through these slopes it is apparent that the solifluction deposits are not very thick. 1 metre is a typical depth. Locally, in hollows and at the foot of long slopes, the deposits may be considerably thicker, and it is these atypical occurrences which tend to be described in the literature. e.g. GEIKIE 1869.

Similar forms exist in the Lammermuirs. These hills are rather lower and more open than the Moorfoots and consequently the available relief is generally less and the slopes gentler and less strikingly straight. Nevertheless rectilinear slopes below the rounded summits can be repeatedly picked out. e.g. Along the upper Faseney Water and in the valley of the Monynut Water. See figure 47 and photograph 64 . In most cases the present stream is meandering freely across the flat valley floor and has frequently impinged on the valley sides and ex:posed the solid rock that was very near the surface. Sometimes, however, the streams have become incised in the valley floor to a depth of a few metres and it is apparent that the flat floor is not one of alluvial infilling but a truly erosional surface cut in rock. This rock terrace can be seen for example in the Monynut water at the confluence with the Back Burn. (G.R. 708659). See figure 44 
and photograph 59. It can also be seen just above Abbey St. Bathans and along the Faseney Water.

These rock terraces provide valuable evidence of the slow rate of contemporary mass wasting. The incision of the streams into them, doubtless as a result of climatic change, means that there has been no removal of debris from the slope foot for a period certainly to be reckoned in millenia. If mass wasting were effective today on the steep slopes (around 28 degrees, estimated) there would be a softly concave profile of accumulation at the junction with the rock terrace. No such accumulation exists. The slopes with their thin cover of solifluction material plunge straight down to the terrace, and indeed often retain evidence of slight oversteepening at their foot by the last abrasion of the stream before it became fixed in its present rock-bound channel. See figure 44. The last significant fashioning of the slopes cannot be more recent than the period of incision of the stream.

The rock terrace is also evidence of a former phase of active stream erosion when the river was capable of planning off the valley floor very effectively at the same time as it was evacuating any material fumished from the slopes by solifluction. As we have seen, streams under periglacial conditions are capable of these functions of erosion and transport. It seems reasonable to conclude that in fact both streams and valley floors have been fashioned to their present form while periglaciation prevailed. Yet at this point it must not be forgotten that there was a notably damp and cool climatic phase in the Atlantic period, when periglacial con:ditions did not prevail except in the highest hills, but mass 
wasting was active. See page ll6above. DURY (1954) has brought forward impressive evidence for a notable phase of valley erosion about this time.

Forms like those of the Lammermuirs and Moorfoots can be readily matched in the Pentlands (e.g. at Silverburm) and in the western and central Southern Uplands. Indeed, straight slopes with rounded summits are more or less universal throughout the region. The slopes have often been described as if they were entirely rounded, convexity at the summit passing into concavity at the foot. Nevertheless, it is the straightness of the slopes that is their fundamental characteristic.

The evidence presented so far in this chapter shows how frequent in E Scotland are straight slopes descending from rounded summits to flat floored valleys. Although such forms can develop under periglacial conditions their prevalence is not proof that periglaciation has seriously modified the land:forms since the pre-periglacial processes associated with warm humid conditions in this area must have produced essentially similar forms. For less equivocal evidence we must consider the effects of periglaciation on pre-existing landforms of dissimilar shape. i.e. Forms of glacial and glaci-fluvial erosion and deposition. Consideration of the correlative deposits associated with periglaciation will also contribute to an assessment of the role of periglaciation in fashioning the relief. 
(1) On Glacially formed landscapes the rate of modification by periglaciation has naturally been extremely variable. On forms of glacial erosion in hard rocks the eprect has been slight. Frost shattering and mass movement, much of it occurring while the glaciers still occupied the intervening valleys has indeed often obliterated all traces of ice action on high summits and interfluves (PEACH et al 1913) but such traces were probably never very marked. Frost shattering at the very close of the ice age (EARKJR 1901) and continuing fairly actively today (THOMSOIN 1950, GODARD 1958) has commenced to destroy corries and U-shaped valleys by weathering back the headwalls and infilling the floor with scree. Frost shattering has also partially destroyed roche moutonne forms (e.g. by the summit of the road leading from Kishorn to Applecross) though much of this may be due rather to pressure release when the weight of superincumbent ice was removed. (IEWIS 1954, HARLAND 1957). However, this modification of the glacial forms has not proceeded far: the volume of rock debris produced since the end of the ice age is only a minute proportion of the volume of rock removed by the glaciers. It is not just:ifiable to claim (FITZARRICK 1958) that smooth slopes and Veeshaped cross profiles in formerly glaciated valieys indicate extensive periglacial modification of the forms unless one knows the thickness of the drift plastered against the valley sides and what proportion of it is of glacial, not periglacial origin. In fact in most Highland glens the volume of the glacially-derived 
material fas exceeds the volume or pexiglacial material.

Admittedy the severest periglacial conditions were excluded by the ice itself which formed earliest and lasted longest in those areas where forms of glacial erosion predominate, but frost shattering under the present sort of climate has been far from negligible and has been at work for as much as 10,000 years. We must conclude that periglaciation has not seriously modified the forms of glacial erosion in Scotland and that glaciation is a much more effective process in fashioning the landscapes of areas of old hard rock and steep slopes than is periglaciation. This is contrary to some recent opinion which seeks to emphasise the importance of peri: glacial processes compared to glacial ones (BOYE 1950, GODARD 1958), but can be readily confirmed by examining photographs of nunatak areas in Greenland and Antartica: these present jagged forms with steeply undercut slopes because the glacier removes material from their flanks faster than periglaciation can round off the bare summits.

Periglacial modification of forms of glaci-fluvial erosion in hard rock seens likewise to have been but slight. Some of the meltwater channels in the Pentlands, which must have been exposed to periglaciation since a time shortly after the Scottish Readvance are astonishingly fresh. e.g. The deep channel descending from the $W$ to Ioganlee. Modification of the channels in Fast Lothian has likewise been slight, and can be largely ascribed to creep contemporary soil/and soil erosion, except where tributary streams 
have laid down large fans. (KWNDAII \& BAIIEY, 1908). Although in some of the glacially formed landscapes we find forms dominated by glacial or glaci-fluvial erosion which resemble the straight slopes, rounded summits and flat valley floors described above from the Southern Uplands, these forms are not the work of periglacial modification but are the result of glacial and glaci-fluvial processes acting on the preglacial landscape. e.g. The S-facing sides of the great corries on the z side of Ben Wyvis and the slopes or melt water channels in the Pentlands have this form, but do not seen to have been seriously modified by periglaciation. Periglacial modification of foms of glacial deposition is harder to assess. In view of the unconsolidated nature of the material one would expect it to be considerable, although it must be remembered that sands and gravels containing no fine fraction are not very amenable to solifluction. A good deal of the infilling of the late glacial lakes around Bdinburgh such as Corstorphine Ioch took place under periglacial conditions as shown by included remains of Aretic plants. This infilling must correspond to some wasting of the surrounding higher land. DovIJi's (1957) borings in the floors of lochs lying within the probable limits of the Aberdeen-Perth Readvance, on the other hand, show that the thickness of mineral matter which accumulated there during the cold Zone III period'was only a few $\mathrm{cm}$. The amount of erosion must therefore have been very slight. The drumlins, kames and eskers of central Scotland have had some of their asperities sortened since the ice deposited them, but this softening is not at all marked and can be ascribed largely to contemporary processes, aided by the effects of cultivation, rather than to any drastic periglacial erosion and 
deposition.

Periglacial modification of glaci-fluvial deposits has taken the form of the formation of what are now dry or nearly dry valleys in this permeable material. An example about 900 metres long was noted at a point near Muir of Ord, cut in late-glacial outwash and apparently graded to a rather low raised beach. This valley is mentioned in OGILVII 1923, page 393. The feature had a rounded cross profile in its upper part which passed into a flatfloored trough in its lower partion. It now contains no more than a ditch and present processes are tending to infill it by washing from the sides. It is reasonable to attribute the formation of the valley to periglacial strean erosion and mass wasting operating While the gravel was rendered impermeable by permalrost (ice wedges exist in this same gravel a few $\mathrm{km}$. away as mentioned in chapter IV), and when the fall in sea level from the"lo0 foot" level provided the necessary initial gradient.

A more striking feature of the same sort, seen a few $\mathrm{km}$. W of Perth is illustrated in igure 50. It is incised into glacial outwash probably graded to the "100 Poot beach sea". The upper part of the valley, which in all is about $1 \frac{1}{2} \mathrm{~km}$. long, is quite dry; the lower part contains only a trifling ditch. The feature appears to be graded to a raised beach corresponding to the "50 foot sea". It has a maximum depth and width of fully 15 and 300 metres respectively. Its course bears no relationship to the present 
terrain, as can be seen from a glance at figure 50, and it is no longer being deepened in any way by contemporary erosion. Although kettle holes exist in the gravel spread a short distance to the $W$ the valiey cannot be the work of glacial melt waters since it is graded to a sea level which did not exist until the ice had disappeared from this locality. It must have formed during the interval between the cessation of glacial outwash formation (probably at the end of the Ferth Readvance stage) and the fall of sea level from the succeeding "50 foot beach", (probably the end of Zone III times). Stream incision into gravels rendered impermeable by permafrost, with solifluction on the side of the resulting valley have been responsible lor the production of this fom. The rate of erosion must have been rapid as the total period during which the entire valley fomed cannot have been more than a few centuries or at most a milienium.

Signs of similan dry valieys graded to a raised beach level have been briefly noted to the $\mathrm{I}$ of Stranraer. Features of this sort may be quite common in gravelly areas in Scotland. Nany of the winding flat-floored valleys commly found in kane areas may be of periflacial oxigin while the ground was pemanently frozen rather than the work of glacial melt water or the sites of dead ice masses. This is, however, unsupported conjecture at this time.

Thus in outwash material periglacial processes seem capable of a considerable amount of erosion in a short time in restricted 
localities near a considerable gradient such as the cliff induced by marine erosion after a fall in sea level. At first sight this evidence seems to conflict with what has already been indicted as to the relative inefficacity of periglacial erosion in Scotland. However, in the case of the dry valleys we have just discussed, the forms have developed in unconsolidated material, very different from the generally hard old rocks of most of the country. Running water rather than solifluction was primarily responsible for the development of these features, to judge by evidence from the Arctic today. e.g. POSER 1936, JENNES 1952.

Before attempting a final assessment of the importance of periglaciation in shaping Scottish landforms we must consider the evidence of correlative deposits.

2) The periglacial solifluction deposits which we have seen cover much of Scotland can be correlated with fossil or contemporary periglaciation. The volume of the deposits is thus an index of the effectiveness of periglaciation in modifying the relief. These deposits are thin; an average thickness would be something about half a metre. It is unfortunate that interest has been focussed on the exceptionally thick local occurrences infilling hollows and at the foot of long slopes. cf. Concern ing the Ardennes, exposed to periglaciation throughout the Pleistocene, MARECHAL \& MAARLEVELD (1955) state: "L'epaisseur de la couche de solifluction est generalement assez faible (moins de $1 \mathrm{~m}$ ) excepté sur de pentes relativement douces". NEEF (1955) makes the same point with regard to the solifluction deposits on the old massifs 
of the German 'Mittelgebirge': there solifluction deposits are really quite thin.

In Scotland the volume of slope deposits is minute in comparison to the volume of the relief. This may be in part because such slope deposits have been able to accumulate only for a short period since the disappearance of the last ice sheet, but holds true even in 'Moraineless Buchan' where periglaciation prevailed for a longer period and where the deeply rotted rocks are favourable to intense frost shattering and solifluction. According to the thickness of solifluction deposits now preserved, it would seem that the geomor:phological effects of periglaciation have been negligible, in relation to the landforms as a whole.

However, it may be that the present thickness of periglacial slope deposits does not represent the total accumulation, and that mass movement down the slope and evacuation along the val leys was so rapid that the total volume of the deposits was many times that of the surviving remnants observed today. The evidence on this important point is unfortunately confused. On the one hand, there exist many valleys with a partial infilling of bould er clay or glaci-fluvial gravels in the bottom which shows that clearing out by streams was ineffective. This infilling may be overlain by negligible thickness of periglacial solifluction deposits derived from the slopes above, but representing only the minutest modification of their form. Examples of such features can be seen in the Southerm Uplands between St. Mary's Ioch and Moffat, and in side valleys leading off the Glens of Angus. See figure 40. On the other hand, not a few valleys in the $E$ Southern Uplands have, as we have seen, 
a flat floor cut in rock demonstrating that longitudinal stream erosion and transport were very effective. e.g. The Monynut Water.

If there had in fact been rapid evacuation along the talwegs of mass wasting material derived from the valley slopes, this material may have been redeposited elsewhere when the stream was no longer capable of removing it as gravel spreads (now cut into terraces) and as fans and deltas. An example of such gravel spreads may be the extensive accumulations along the Teviot mentioned by MUIR (1956). He states that the gravels are composed of types of stones derived from the adjacent bedrock: solifluction was active on the slopes in this area and so the considerable volume of the gravels may be a result of rapid mass wasting on the slopes and transport along the valleys, for short distances. FITZPATRICK (1958) claims that important gravel spreads along the Dee $W$ of Ballater also represent alluvial accumulations derived from peri:glaciated slopes: this interpretation seems improbable in view of the vast accumulations of glacial outwash along the valley.

Some further evidence of the rate of erosion and deposition under periglacial conditions is provided by a consideration of the fans along the foot of the ochils. These have already been briefly mentioned in chapter IX. See figure 48.

By assuming that each fan had the shape of a half cone with its apex at the point of exit of the stream from the hills it was possible from an examination of the contours on the map, checked by a recon:naissance in the field, to calculate the volume of material which had been derived from a basin of known area. By dividing the volume 
of the fan by the area of the basin, the mean thickness of material eroded to produce the fans could be calculated. The calculations could only be very approximate since the exact shape of the fans was not known, and their lower extremities may have been buried by later alluvium along the Devon valley. Also much of the very finest material must have been carried away entirely from the district, and the fans may incorporate glaci-fluvial deposits such as kames, notably at Tilicoultry. E of Tillicoultry the fans were too ill-defined to be studied in this way.

According to DINHAM \& HALDANE (1932) the fans are in fact deltas laid down in the waters of the "lo0 foot beach" late glacial sea at a time when periglacial conditions certainly prevailed. If these authors are right, the period when the fans were being built cannot have lasted many centuries: a reasonable estimate would be 1,000 years. This period amply covers the Zone III phase with which this high sea level is generally correlated. Under post glacial climatic conditions the fans are being dissected rather than built up. This time estimate enables us to calculate the rate of accumulation and therefore of erosion in the valleys. The results of these calculations of the amount and rate of erosion and deposition in the ochils during periglacial conditions are listed in table 2 .

Comparison between the map (figure 48 ) and table 2 shows that there is an apparent eastward increase in the size of the fans in relation to the area of the stream basins. It is suggested that this is because the westermost fans have been partially buried by more recent alluvium. Superimposed on this are marked variations from one valley to the next. It is apparent that the greatest 
proportional volume of material has been furnished by those valleys having the steepest slopes and the greatest available relief: Tilli:coultry and Alva. The most extensive valley, (Menstrie) has furnished much less material because it is lower and less steep. It is not clear how much of the material in the fans has come from the valley sides by mass wasting and how much has been derived from linear erosion along the streams, but a very rough calculation indicated that the volume of the gorge and trough sections of the valleys was less than half that of the fans, so that fully half of the material was derived from the slopes.

The figures suggest a mean rate of lowering of the surface on the steep sides of the 0 chils of between 0.4 and $3.0 \mathrm{~mm}$ per annum: a high rate of erosion. If the period extending from the scottish Readvance to the end of Zone III times be taken as about 5,000 years (See table I) this would suggest that periglaciation in Southern Scotland removed between 2 and 15 metres of resistant rock steep slopes since the ice disappeared from the area. The total duration of periglacial conditions in the Pleistocene, allowing for phases preceeding as well as succeeding each glaciation must have been around 10 times as long, so the total periglacial remodelling of the forms on steep initial slopes might have been equivalent to a layer of rock between 20 and 150 metres. It must be admitted that these figures are only a guess, and once again the evidence as to the effectiveness of periglaciation is inconclusive. If the lower figure of 20 metres is about correct the periglacial modification has been slight and not sufficient to do more than retouch the pre-existing forms. If the upper estimate of 150 metres 
is nearer the truth, periglaciation in Central and Southern Scotland would have been sufficiently effective to produce in the course of the entire Pleistocene the rounded summits and smooth even slopes we have been considering without being able to seriously modify the major landforms which must owe their origin to the processes at work in the Tertiary.

On gentle slopes the rate of evolution must have been very much slower and consequently the pre-periglacial forms better preserved. This may be one reason for the warm climate weathering mantle being better preserved in $N E$ Scotland where slopes are gentle than in the Southern Uplands where slopes are steeper, quite apart from the possibility of less prolonged and effective glaciation in the former area.

IV. Conclusions.

This review of the forms of slopes and valley floors has been made with a view to assessing the amount of modification induced by periglaciation. The evidence presented is not entirely con:sistent, but on the whole suggests that the modification was slight and amounted to no more than retouches of forms which are mainly the work of pre-periglacial processes. The most effective modification seems to have been the development of what are now dry valleys in glacial outwash. The fissile rocks and rather steep slopes of the Southern Uplands and the chemically weathered rocks of the NE have also suffered some modification of form by periglacial agencies but this has been quite insufficient to seriously modify the work of 
pre-periglacial processes operating under a warm-humid climate. The forms of glacial erosion which predominate in the high areas of the $W$ of the country have suffered little or no periglacial modifi: cation, not only because the presence of ice for long excluded periglacial influences but also because the effectiveness of glacial erosion, especially in hard, fresh rocks, is so much the greater. Periglaciation has not been an important agent in the development of Scottish land forms. 


\section{CHAPTER XVI \\ POST-PERIGIACIAL EROSION}

Since the retreat of periglaciation in scotland from the lowlands to hill areas, non-periglacial processes have been at work, modifying the landscape. This has gone on for some 10,000 years, since the close of zone III times. Periglaciation continues to prevail in high areas, but it is of a different nature and intensity to that of the past. This period of post-periglacial modification has been longer than that of periglaciation in all parts of scotland except perhaps in Buchan. Some writers, e.g. TRICART (1951), have suggested that post-periglacial modification has been very slight. NEEF (1955) has suggested that it may have been rather more marked, but not immediately noticeable since the forms produced by contemporary "temperate" weathering and erosive processes resemble closely those produced under periglaciation.

The predominant differences between contemporary and periglacial processes are the higher temperatures and the much greater abundance of vegetation today. The vegetation inhibits mass movement, shields the ground from temperature changes, and checks the effects of wind and water. The presence of vegetation together with the higher temperatures means that chemical and biochemical processes of weathering are much more active today, while frost shattering is reduced.

The chemical weathering attacks rocks to produce soils with abundant fine particles down to pre-colloid size, and enriches the ground water with material in suspension and solution. If the 
vegetation cover is weakened there can be extensive washing away of fine material, and at all times a certain proportion is removed in solution. The rate of soil formation is not well known and may be faster than some authorities believe, e.g., well-developed soil profiles are to be seen on sand dunes only a few centures old.

Frost weathering is still active today, though not on the scale which prevailed under periglacial conditions. Its effects on hill tops seem to be largely the production of small fragments chipned off larger products of earlier and more intense shattering. The granitic sand which is to be found on many mountain plateaux seems to be the result of contemporary processes, but at these altitudes it is perhaps more accurate to claim that periglaciation still prevails. On rock outcrops, freshly spalled faces show where contemporary frost shattering is still in progress.

Mass movement continues to take place today. There can be no question of claiming that slopes in the damp climates of scotland are completely "fossilised", unless on the very gentlest of gradients. Rarely do we find a completely developed soil profile, proving immobility of the underlying material, except on nearly level ground. At all altitudes, terracettes can be seen, and individual blocks in motion down the slopes are not uncommon. Nevertheless, the total effect of this mass movement seems to be very slight unless the vegetation is destroyed, see photograph 65. It has been shown in chapter XVI how little has been contributed to the valley floors from the slopes in the Southern Uplands for millenia. Furthermore, much of the mass movement taking place today is utilising material 
furnished by earlier more severe periglacial conditions. Locally, on steep damp slopes, and at high altitudes as on Ben Wyvis, mass movement is more active, tending for example to infill gullies in the Southern Uplands. However the elose vegetation cover and the absence of perma-frost has resulted in a very great reduction in the speed and importance of mass movement, which is effectively, if not absolutely, confined to steeper slopes and moister situations than in the past. Contemporary mass movement is more effective at the highest altitudes, but these areas are still experiencing what is essentially a periglacial climate.

Rumning water is one of the most effective agents in the present mophogenetic system. Its main function is the removal of chemical weathering products in solution, and the washing out of fine material. This washing has been one of the main factors in the fixation of solifluction features. On sloping cultivated land, water has proved an effective agent of erosion. Behind any dyke passing across a slope in scotland it is usual to find an accumulation of washed material derived from the field above. Depths of over a metre can occasionally be observed, representing soil erosion since the dykes were built during the agricultural revolution 150 to 200 years ago. In low areas the combination of chemical weathering: with contemporary mass wasting, washing by water and soil erosion has quite erased the minor irregularities such as the steep fronts of lobes which must have developed on the slopes under periglacial conditions. It has already been asserted in the previous chanter that much of the softening of the forms of glacial deposition in 
Lowland scotland must be ascribed to post glacial agencies associated with a temperate climate.

on steep slopes, such as the head and sides of valleys in the Southern Uplands contemporary stream exosion is very rapidy incising the smooth periglacially formed slopes at a few localities. Between the gullies the periglacial form survives intact. contemporary gullying is less apparent on the more coherent rocks of the Highlands and the volcanic hill masses in the Central Lowlands. Nore important streams may in post-glacial times have cut into periglacially-formed gravel spreads to form climatic terraces but this has not yet been demonstrated for certain:- The period of incision may itself have been largely periglacial or the nork of temporary wetter conditions during the Atlantic period. In N.E. Scotland and the less hilly parts of the Southern Uplands the work of contemporary stream erosion has emphasised the periglacially-derived form of the valleys. Lateral widening of flat valley floors continues to take place. Now, however, the widening is the no rk of a meandering stream, impinging occasionally on the valley sides. Under periglacial conditions the same effect was produced by a braided stream. This is a case where contemporary and periglacial processes have operated in the same sense. Another example is mass movement which is continuing the work initiated in periglacial times.

wind action has a significant effect on hill tops by destroying the vegetation and exposting fine material. The climate in these high areas ought to be considered as "periglacial" even today. At lower levels, where the vegetation is unbroken, wind has had no 
effect in modifying the periglacial forms and deposits.

Although there has certainly been some modification of the periglacial features in scotland by the agencies operating in the present temperate climate the total effect has not been great. The quasi-complete preservation of periglacial forms through 10,000 years of mild temperate climate shows that contemporary processes have achieved only minor retouches, just as periglaciation has nowhere been able to seriously modify the pre-existing forms fashioned by glaciers or by warm humid climates far back in the past. 


\section{PART V.}

\section{THE PERIGLACIATION OF SCOTLAND AS A WHOLE}

After considering the nature of the periglacial climate the evidence as a whole will be briefly re-examined with a view to distinguishing types of periglacial landscape in scotland. After an assessment of the place of periglacial studies in scottish geomorphology and Pleistocene investigations the thesis ends with a brief review of some problems requiring further research. 


\section{CHAPTER XVII.}

\section{PERIGLACIAL CLIMATES}

I. Contemporary periglaciation.

It has already been shown that the climate of the greater part of scotland is such as to permit the develonment of shallow and miniature forms of patterned ground, provided that the vegetation can be inhibited. The most usual inhibiting factor apnears to be wind. At some future date it should be possible to analyse more closely the climatic conditions prevailing at the " $50 \%$ vegetation limit" mentioned in chapter VIII, at Fort William/Ben Nevis, at Braemar/Ben Macdhui, and at Lerwick/Ronas Hill. This was not attempted in the present study.

\section{The Zone III climate.}

Many attempts have been made to reconstruct the climate of the ice age. CHARLESWORTH (1957) lists 37 different estimates of the temperature difference from that of today! FAEGRI (1950) and HART (1953 have pointed out some of the inconsistencies and difficulties involved. Perhaps the greatest difficulty is that in seeking to reconstruct the palaeoclimate over a whole area, one must draw evidence from several dif ferent points in space without being sure that they represent exactly the same point in time. As climate is constantly fluctuating strict contemporaneity of evidence is essential, but difficult to ensure. In order to reduce the magnitude of this problem, attention will be confined 
to the short (5-600 years) and well-dated zone III cold phase. Even within this short period the climate was doubtless far from uniform. The zone III cold period coincided with the Highland Readvance-Moor of Dinnet Readvance when most of the W. Highlands were covered in ice but only limited areas in the higher parts of the East were glacierized.

In attempting to reconstruct the temperature and precipitation, evidence can be draw from consideration of cryoturbation, snow lines, and pollen analysis.

The evidence of cryoturbation shows that permafrost existed in scotland during zone III times. It is not entirely certain if the large wedge at Beauly is of this age or dates from zone I, but there is little doubt in the case of the wedge near Aviemore and the Ythan estuary, while the involutions near Spean Bridge may well date from the very early part of the succeeding zone IV. FIMZPATRICK's evidence (1957) for widespread permafrost supports the conclusion. Although WILIETT (1950) and MANLEY (1953) have suggested that short temporary bursts of cold air would be sufficient to cause cryoturbation, this seems quite inadequate to account for wedges in particular, which are forms of slow growth. A permafrost climate must have existed for much if not all of the Zone III period. Furthermore, while permafrost per se requires mean annual temperatures only slightly below $0^{\circ} \mathrm{C}$., in regions of cold cloudy sumers as MANLEY (1951) points out, permafrost with wedges implies very cold winters. Wedges require winter temperatures below $10^{\circ} \mathrm{C}$. (CHARIESWORTH 1957). CAILIEUX \& TAYLOR (1954) 
claim that they imply mean annual temperatures from -5 to $-12^{\circ} \mathrm{c}$. They have been reported from S.W. Spitsbergen (ROZYCKI, 1957) where mean annual temperatures between -6 and $-10^{\circ} \mathrm{c}$. prevail. (BIRKELAND \& FOYNE, 1932).

Palaeoclimatic reconstructions in scotland on the basis of snow lines is hampered by lack of definitive evidence. In view of the vast numbers of corrie glaciers in the country much data remains to be gathered on this question. In a careful reconstruction of the ice age climate in Britain, (MANLEY, 1951) suggests that in the Ben Nevis area during Zone III times the snowline lay about 570 metres rising eastwards markediy. In an earlier naper he gave a generalised figure of 600 metres, compared to an estimated value of 1600 metres today. (MANLEY, 1949). This estimate of 1,000 metres for the rise in the snowline since zone III times is, incidentally, considerably greater than the 400-550 metres estimated by B. G. ANDERSON in Norway, (See DAHL, 1955), and equals BUDEL's (1949) estimate for the rise in Europe as a whole since the maximum of the last glaciation. CHARIESWORTH's reconstruction of the snowline at this period suggested a height of about 450 metres in the Ben Nevis area, rising to 750 metres in the Cairngorms. (CHARLESWORMY, 1955). The height of the snowline varies enormously with the topography, but a generalised value can usually be deduced. This value depends chiefly on the total accumulation of snow, hoar frost and ice, and on the temperature of the ablation season wich around the N. Atlantic extends from June to september. AHIMANN (1948) has worked out the interrelationships of the accumulation and ablation at the firn line (i.e. the snow line on glaciers) in 
a curve for Norwegian values which seems applicable to scotland as well. (MANLIY, 1951). The accumulation at the Zone III snowline can only be guessed. For the Eastern Highlands a figure of around $120 \mathrm{~cm}$. water equivalent seems reasonable. cf. NANLTY adopts an estimate of c. $180 \mathrm{~cm}$. effective accumulation for the $w$. A figure of $120 \mathrm{~cm}$. accords with KLEII's estimate (1953) that the precinitation in scotland in the ice age was about $3 / 4$ of that of today. The temperature lapse rate with altitude must also be considered. IAUTENSACH \& BOGEL (1956) have shown how it varies enormously from one area and season to another, and MORAWETZ (1955) has emphasised how much the reconstruction of temperature of lowlands below the snow line depends on the value adopted. From a consideration of IAUTENSACH's and BOGEI's paper, it wo uld seem that a value of around $0.6^{\circ} \mathrm{C} / 100$ metres is valid.

Pollen analysis cannot provide really accurate evidence on past temperatures (FAEGRI, 1950; but see DAHL, 1955), but can nevertheless give some general guidance. DONNER's (1957) recent work has shown that the vegetation in scotland during zone III times must have been extremely scanty. The mean July temperature must have been well below $10^{\circ} \mathrm{C}$. Which coincides with the tree line. The July $10^{\circ} \mathrm{c}$. isotherm seems to have lain in the s. Midlands auring the Zone III period, (MANIEY, 1951), as tree pollen is found in peats as far north as this area.

According to AHLMANN's curve, for an assumed effective accumulation of $120 \mathrm{~cm}$. at the snowline, the mean June-September temperature must have been of the order of $0-1^{\circ} \mathrm{C}$. The evidence of corrie 
moraines shows that the snowline must have been at an altitude of at least 600 metres in the Eastern Highlands. With our assumed lapse rate of $0.6^{\circ} \mathrm{C} / 1100$ metres this implies a June-september mean of about $4^{\circ} \mathrm{C}$. at sea level. This suggests a July mean of around $7^{\circ} \mathrm{C}$., with $3^{\circ}$ in June, and $4^{\circ}$ and $1^{\circ}$ in August and september. In view of the very scanty vegetation, summer certainly cannot have been any warmer than this, and may well have been colder. This estimate of the surmer temperature agrees closely with that of NaNLEY (1951) which has been worked out on the same basis.

Consideration of the winter temperatures leads to a notable divergence from MANLEY's views. He assumed a mean annual temperature of about $-1^{\circ}$ c., sufficiently cold to account for a weak permafrost in a country of $\operatorname{cool}$ and cloudy summers, but totally inadequate to account for ice wedges. Adopting CAILIMUX \& TAYLOR's minimum estimate of (1954) of $-5^{\circ} \mathrm{C}$., which accords with the evidence in svalbard, although it scarcely allows for the insulating effect of a considerable snow cover in winter in scotland, we can work out the probable winter temperatures. The January mean appears to have been about $-16^{\circ} \mathrm{C}$ : MANLEY's estimate was about $-8^{\circ} \mathrm{C}$. The monthly mean temperatures which probably prevailed are given in table 2 along with the figures (based on only a short period of observations) given by BIRKEIAND \& FOYIV (1932) for Storo at the southern tip of $w$. Svalbard. The svalbard figures are comparable to the suggested scottish values, though generally rather colder in summer and at the end of winter when the absence of sun keeps the temperature down. In view of the evidence of 
very scanty vegetation in summer (DONNER 1957) and the possibility of snow insulation in winter the figures in Scotland may well have been lower and even more similar to the Svalbard values than has been suggested.

The figures for Scotland indicate that the climate was then much more continental than now. The present range of temperature at Aberdeen for instance is about $10^{\circ} \mathrm{C}$., less than half of that postulated here for Zone III times. It is not known for certain if the $W$ of the country experienced comparably low temperatures, but in view of the involutions at Spean Bridge, and at an earlier period, the remarkable assemblage of permafrost structures in Strathaven, it seems probable that there was little amelioration of the climate in the $\mathrm{W}$. In this connection, it is important to bear in mind that KILROE (1908) de:scribed signs of deep freezing in late glacial gravels in the Iondonderry area in Northern Ireland, in a locality which now has a strongly oceanic climate.

The mean rise of temperature since Zone III times implied in these estimates is around $13^{\circ} \mathrm{C}$; - about $7^{\circ}$ in July and $20^{\circ}$ in January. POSER ( 1949 ) suggested $12^{\circ}$ in January and $10^{\circ}$ in July for Central Europe, while FLOHN (1953) suggested a mean annual cooling ranging from $3-5^{\circ} \mathrm{C}$. in oceanic areas to $13^{\circ}$ in the immediate vicinity of the ice sheets in continental climates. POSER, FLOHN, and other writers such as KIUTE (1951) were attempting to reconstruct the temperatures during the glacial maximum, so the Scottish estimate presented here referring to the late glacial Zone III is even more anomalous.

Part of the anomaly is due to the fact that evidence from cryo:turbation tends to give a lower reconstructed temperature than the 
evidence from snowlines or biological data. MORTENSEN (1952 and 1956) claims that this is because intense temperature inversions prevailed during glacial times, making the lowlands much colder than the real lowering of temperature would warrant. While this may have played some part, the writer agrees with FLOHN (1953) that it was not of the overwhelming significance which MORTENSEN attributes to it. e.g. In the Iyngen Peninsula of North Norway, stone polygons were finely developed on plateaux hundreds of metres above the valleys where no patterned ground existed in suitable material although temperatures must have been much lower there during periods of inversion.

There thus seems to have been a very notable lowering of air temperatures in Scotland, especially during winter, in the Zone III phase. Some writers, particularly in Britain (e.g. BONACINA \& HAWKES, 1947) have emphasised the importance of the glaciers themselves in creating a cold climate a round them. CHARLESWORTH (1957) argues in the same sense: the growth of ice sheets greatly reinforces the effect of a primary relatively small cooling. He also mentions, following BROOKS, that the minimum diameter of an ice sheet for it to support a glacial anticyclone with predominantly radial outflowing winds is about 1,000 to $1500 \mathrm{~km}$. -- much bigger than the scottish ice during Zone III times. On the other hand, many writers maintain that the effect of even a large ice sheet on the regional climate is localised and limited. It has been shown that the glacial anticyclone in Greenland has only a limited depth and can be readily invaded by low pressure zones from the Atlantic. (CAIIIEUX 1952). The reconstructions of isotherms and vegetation limits in Europe 
and $N$ America during the last glaciation show little relationship to the course of the ice sheet. (BUDEI 1949; MANLEY 1955). In Europe, it was Westerly winds from the Atlantic which dominated, not North-easterly from the ice sheet, as shown by the disposition of corries and of sand dunes. It has been pointed out in chapter 2 that there is evidence of periglaciation as far south as the SW of the Iberian Peninsula, thousands of kilometres from, and upwind of, the nearest ice sheet.

In scotland, it has been shown that the Zone III climate was very cold, although the extent of the ice sheet was so limited that it could not have had a significant climate effect. Furthermore, a cold fauna was already in existence in the seas around before the glaciers of the Highland Readvance reached the coast. SIMPSON 1933, mentions Arctic shells that must have lived in a fiord now occupied by Ioch Iomond. The limited extent of the glaciation at this time was not the result of a relatively mild climate, but of the shortness of the period during which severe conditions prevailed. The marked Continentality of the climate, despite the existence of a high sea level and prevailing westerly winds, shows that marine influences were much less important than during the preceeding Zone II, Aller $\phi d$ phase, when, as DONNER (1957) points out there was a strong oceanic bias in the vegetation. During Zone III times the $\mathbb{N}$ Atlantic must have been very cold. The Highland Readvance is therefore most unlikely to have been primarily a response to an increase in pre: cipitation: it was the product of a notable decline in temperatures, which must have affected summer (the ablation season) as well as winter, despite the increased continentality. By analogy it seems 
reasonable to claim that the greater ice advances in the past were the result of periods of marked fall in temperature which may have been no more severe than that of the Zone III, but which lasted longer. It was the fall in temperature which constituted the primary mechanism of periglacial phases in scotland, and, incidentally, of the glacial phases. Periglaciation is not a bye-product of glaciation; both are the results of a fall in temperature. Indeed, one could say that it is glaciation which is the bye-product of periglaciation.

The similarity between the suggested climate of zone III in Scotland and that existing in West spitsbergen is not confined to temperatures. AHLMANN (1948) mentions a figure of $920 \mathrm{~mm}$. of snow accumulation at the snowline on the Fourteenth of July Glacier at an altitude of 550-650 metres in 1933-4. This latter figure agrees well with our estimate of $1200 \mathrm{mmm}$. at the snowline of comparable altitude in Scotland during Zone III, when one takes into account the warmer summers postulated for Scotland. Precipitation at lower levels would be considerable less, perhaps, corresponding to the figure of $300 \mathrm{~mm}$. mentioned for west Svalbard by BIRKBIAND \& FOYNE (1932). The rarity of eolian deposits in scotland - a striking contrast with areas further $E$ in Europe - suggests however that the precipitation in lowlands was more than $300 \mathrm{~mm}$. and was sufficient to keep the ground wet and so inhibit wind action throughout the sumer. Of course the analogy is based on very slender evidence, but consideration of temperatures, snowlines, types of cryoturbation, proportion of ice the land surface covered by, and plant cover indicate that Scotland in Zone III times must have resembled SW 
Svalbard today. The periglacial morphology in the latter area however is much more highly developed. This can be explained because suitable climatic conditions have prevailed there for millenia, perhaps since the Boreal period, 7-8,000 years ago, while in Scotland, the greatest period of periglaciation, apart from the $\mathrm{NE}$, cannot have been as long, and in the case of ground immediately outside the Highland Readvance can have lasted less than a millenium. Furthermore, there has been 10,000 years of post-periglacial modification here, which has removed some of the more obvious traces of the work of cold conditions. 


\section{CHAPTIR XVIII.}

THE GENERAI DISTRI BUIION AIND SIGNITICAINCE OF PIRIGIACIATION.

Perusal of the preceeding chapters will have shown that the nature, intensity, duration and effects of periglaciation vary greatly from one part of the country to another. It is possible however to distinguish a certain similarity of conditions over considerable areas which may be termed "Periglaciation regions". These regional entities have already been emphasised in the mar:shalling of the evidence and comprise the following areas: The N. and W. Highlands; the I. Highlands; the Islands; the Iow:lands of Central, S.W. and S.I. Scotland; the volcanic hill masses of Central Scotland; the Southern Uplands. Differences between the regions are not sufficiently sharp for definite boundaries to be drawn, but the evidence of periglaciation in each will be briefly reviewed.

\section{The W. \& N. Highlands.}

The preperiglacial landscape was dominated by forms of glacial erosion giving steep slopes, wide bare areas of hard fresh rock and coarse drift accumulations in the valleys. The ice lingered longest here at the close of the last glaciation, 
and there may have been a small revival of corrie glaciers as late as Atlantic times. Although severe periglacial conditions with permafrost can only have existed at most for a very short time in this area, if at all, the climatic conditions of today, broadly similar to those prevailing for most of the last 10,000 years, favour continued periglaciation of a mild but not ineffective type. Signs of the work of severe periglacial conditions, presumably of late glacial age are not wanting, but cryoturbation (wedges and involutions) are confined to two localities on the $\mathrm{I}$ and. SW margins of the area. Intense frost shattering has affected summits and interfluves which rose above the shrinking ice sheet to give the 'mountain top detritus' characteristic of Highland summits. This detritus, containing many boulders, has furnished the material for the development of stone-fronted lobes which are quite common on summits over 2,000 feet in the $N$ and 2,500 feet in the $S$.

Cryoturbation, Prost shattering and mass movement are associated with the contemporary cool humid climate. The cryoturbation is generally amorphous, and patterned ground is rare because of the lack of sufficient fine material in the rock debris. The frost shattering has sometimes broken up the smooth surface of icemamillated forms and split material off clifes. By working along prominent joints and planes of weakness frost shattering has pro:duced gullies in steep slopes. On granular rocks like granite 
the main effect of frost seems to be the production of fine-grained debris, consisting largely of individual crystals, which contrast with the larger fragments produced by the more intense shattering in the past. Contemporary mass movement is at work on most slopes as evidenced by terracettes, terraces, individual creeping of blocks and occasional lobate features.

These contemporary processes are best developed at altitude where the vegetation has been inhibited, chiefly by wind. Consequently the most active agencies are to be found at lower levels in the $\mathbb{N}$ and $W$ where winds are stronger than in the more sheltered $\mathrm{S}$ and. $\mathrm{F}$.

The total effect of periglaciation on the landscape has been very slight. Frost shattering immediatly preceeding the advent of the ice may have helped to fashion such detail features as "boiler plates"., but the landforms produced by glaciation have been little modified subsequently. Modification of U-shaped valleys and corries by the development of screes and by mass movement has only just commenced. The forms of glacial deposition are preserved practically intact.

\section{The I Highland.S.}

The highest areas of this part of the country resemble the $W$ Highlands in the dominance of glacially-fashioned relief. Tlsewhere 
the geomorphology is very largely that produced under warm humid climates in interglacial, or more probably preglacial, times. Remnants of the weathering mantle produced under these conditions survive.

Although freed from ice at an earlien stage than the $\mathbb{N}$ and $W$ Highlands the geological effects of severe periglacial conditions have been essentially the sane. Cryoturbation in the form of wedges and involutions of late glacial age is generally confined to the margins: lower Deeside, possibly the Tay valley, and near Aviemore, just outside the limit of the Zone III glaciation. Shattering has produced mountain top detritus with coarse blocky material as in the $W$ and $\mathbb{N}$ Highlands, and mass movement has produced really striking examples of stone-fronted lobes and terraces, on the higher slopes.

The effects of conterporary periglaciation also resemble those in the $\mathbb{N}$ and $W$ although the rather less severe climate and the con:sequent closer vegetation cover mean that they reach their best development at greater altitudes.

The effects of periglaciation on the scenery have, however, not been identical to those in the IN and W Highlands. Shattering and mass wasting have led to the formation of altiplanation features in a few localities and more strikingly, to the formation of tors, which almost certainly represent bodies of rock which resisted the pre-glacial warm climate chemical rotting, and were little affected 
by glacial and periglacial erosion while the sumounding loose material was swept away by mass movement.

The extent of modification of the pre-existing slopes fashioned under warm hunid conditions is not easy to guage since periglacial mass wasting produces simjlar forms, not dissimilar ones as is the case in heavily laciated areas. To judge by the thinness of the slope deposits the nodifications induced by periglaciation since the disappearance of the last ice sheet were slight and summit tors represent the cumulative epiect of agencies at work during many different periods of the Pleistocene.

\section{The Islands.}

No cryoturbation associated with intense cold and permafrost has yet been observed in the islands around Scotland with the dubious exception of contortions in blaci-lacustrine deposits in Skye (PFACH et al 1910) and sone vague chuming of waethered sandstone in Orkney. However practically no exposures in suitable material were found. Periglaciation has in the past caused a considerable amount of frost shattering and mass movement.

To judge from photographs, the most intense effects are to be . found on St. Kilda which lay outside the ice sheets of the Pleistocene: snooth straight slopes, block fields and tor-like features are abundant, as well as striking screes, now grassed over for the most part. 
Frost shattering and mass movenent have also been important in Shetland. (c1. Plate $2 a$ in FTTZPATICK 1958). These processes have produced solifluction deposits which accentuate the smoothness of the preglacial relier. Contemporary periglacial phenomena, (mass movement and stone stripes) occur where the vegetation has been severely restricted by wind or by unfavourable soils, practicaliy down to sea level.

In the Orkneys the fissile platy nature of the rock has favoured shattering, but the rather gentle initial slopes seem to have restricted the development of solifluction. On the hillier island of Hoy more impressive solifluction deposits exist outside the limits of the local ice cap. The periglacial effects of the present climate are negligible. Without more field work the modification of the landforms by periglaciation cannot by properly assessed, but on analogy with the rest of the country was probably slight.

The outer Hebrides have a surface omposed largely of either bare ice-scoured rock or of blanket peat and show no signs of periglaciation except for the occasional occurrence of a thin skin of rubble or scree on slopes and extensive block fields, still in motion to-day but probably iormed initially under more severe con:ditions in the past, on the higher hills. The summit of the Clisham may have projected above the last ice sheet as a nunatak.

On the inner Hebrides, as far as they have been examined, periglacial effects mostly consist of screes of late glacial origin 
but still accurnulating today and a certain amount of mass movement of unconsolidated material. Frost shattering and mass movement are restricted by the frequence of bare, ice-scoured rock surfaces. There have been large scale slumps involving millions of tons of material in the basalts overlying Tertiary rocks. These slumps were largely a result of glacial oversteepening of the slopes and so cannot be termed "periglacial" even although many took place just about the close of the ice age. Contemporary climatic conditions on the hills are favourable to the development of patterned ground (e.g. On the Cuillins) if suitable material is available and both stripes and polygons have been observed. In the landscape as a whole forms of glacial origin are predominant and periglaciation has introduced but the very slightest of modifications.

\section{The North East.}

It is in this area that the efuects of periglaciation during the Pleistocene are most apparent. The pre-periglacial forms were largely the work of warm humid conditions and the corresponding deeply weathered regolith is widely preserved. The erosive.effects of glaciation have been very slight and nuch of the area, comprising 'moraineless Buchan' seems to have escaped glaciation entirely during the last glacial period. Forms of glacial deposition are more apparent along the Moray Firth coast and in the valleys around the fringe of the Grampians. 
Wedges and involutions are Prequently encountered, indicating the former existence of severe periglacial conditions with permafrost. In many cases the involutions have developed in the incoherent fine-grained weathering products produced by previous warm humid conditions. Deep frost shattering of the bedrock, often aided by the previous chemical attack, is the rule except in certain resistant rocks like fresh granite. The shattered rock debris and other drift have in the past been extensively transported down slopes by periglacial mass wasting, and a layer of soliliuction deposits covers most hill sides to an averace depth estimated to approach a metre. Practically all the soils, except those on recent alluvium must have developed on periglacially produced material. The frequent occurrence of a soil profile capping periglacial solifluction deposits shows that their formation is no longer proceeding in the present clinate. The absence of any trace of the minor irregular:ities commonly found on a slope evolving under perielacial conditions, such as terrace fronts, indicates that the contemporary processes of soil formation, creep, washing and cultivation are by no means entirely powerless and have modiried the periglacial forms and deposits to a certain extent.

Iandforms produced in part at least by periglaciation include strikingly smooth slopes, tors, niches, and rough-shaped dry or nearly dry valleys. The degree of preservation of the preglacial weathered mantle suggests however that the modification of the landforms, while greater than in other parts of Scotland, has not been of decisive importance in the production of the landscape we 
see today.

V. The Central, SI and SW Iowlands.

The preperiglacial landscape in these areas was predominantly oneof glacial and glaci-fluvial deposition except locally where more resistant material formed hills that rose above the drift-covered lowlands. Signs of pernafrost with wedges and involutions are common in this drift and in the late-glacial marine accumulations which fringe the lower margins. The underlying rock was however shielded by the drift from attack by frost shattering. The dur:ation of severe periglacial conditions since the retreat of the last ice sheet must have amounted to several millenia in these areas, and there is evidence that harsh tundra conditions also existed during the course of an interstadial followed by a readvance of the ice. There is surprisingly little sign of periglacial solipluction, partiy because the sands and gravels in glaci-fluvial devosits are not an ideal medium for the process since they lack sufpicient fine material, and partly because its epfects on till are not readily apparent. To judge by the silty infilling of late glacial lakes some washing of material took place on the nearly bare ground during Zone III times, but contemporary (non-periglacial) processes such as chemical weathering and sheet wash on cultivated land seem to be more effective in modifying the landforms. 
VI. The volcanic hill masses of Central Scotland.

These hills lack the protective cover of glacial drift which shielded the surrounding lowlands and may also have projected for some time as nunatake above the slowly shrinking ice. That is to say they must have been subject to periglaciation that was rather intense and prolonged by Scottish standards. There are no examples or deep shattering or of cryoturbation known from these hilis but the fashioning of the slopes seems to have been fairly extensive. Although the compact rocks proved resistant to frost shattering the process was sufficiently effective to fumish striking screes if the initial slopes were steep enough. These screes are now grass covered and no longer accumulating. On slopes of gradient less than about 30 degrees solifluction deposits are widespread, although thin, and the straight even profiles suggest that mass wasting and parallel retreat have dominated their evolution. How far this wasting was periglacial and how far preglacial cannot be decided on present evidence. Small tors are features which occur on some summits and can more certainly be ascribed to the effects of mass wasting under periglacial conditions. Around the margins of these hill masses, particularly the S side of the Ochils, fans laid down in late glacial times testify to a period of rapid erosion on the slopes and evacuation of the debris by streams which deposited their load on issuing from the hills.

Contemporary periglaciation is evidenced by the signs of con:tinued frost shattering of rock faces, terracettes, downslope creep 
of individual boulders, and the occasional occurrence at high levels of patterned ground and ture banked lobes actively moving down the slope.

\section{The Southern Uplands.}

The same contrast exists in the Southern Uplands as in the Highlands between the more heavily glaciated $W$ and the $\$$ where forms of preglacial origin predominate. In this study attention has been confined to the $\mathbb{E}$. In the case of the Southern Uplands however, there seem to be few survivals of the presumed preglacial weathered mantle, and iresh rock is the rule. As a consequence, the preperiglacial forms cannot be closely derined, but were probably broadiy similar to the present landscape with rounded summits and straight slopes.

On account of the rarity of suitable drift deposits and. exposures, cryoturbation phenomena associated with permafrost are very scanty and have only been observed at one point in the Iamnermuirs. Signs of Irost shattering that must have taken place under a much colder climate in the past are widespread; the pre:dominantly platy, fissile nature of the rock has been a favourable factor. The resulting loose debris has provided the raw material for the solifluction deposits which cover most slopes in the region. These deposits have an average thickness of something less than a metre, and at many points can be seen to be overlain by peat which 
has developed since the Atlantic period is not before. large scale fossil solifluction lobes comparable to those observed on some summits in the Highlands (e.g. Lochnagar) have not been observed by the writer, but block rields do exist.

There is a wide variety of contemporary periglacial features, mainly restricted to areas over 2,000 reet, including amorphous cryoturbation, patterned ground, terracettes, solifluction terraces, lobes of predominanty fine material covered in vegetation, lobes of stones banked with turp, and individual blocks creeping down the slope.

The easily shattered rock, faimly steep initial slopes and relatively long exposure to periglacial conditions have enabled a wide range of periglacial landforms to develop. Small tors, altiplanation benches, niches and trough-like valleys with flat floors cut in rock are of frequent occurrence. The striking straightness of the slopes must also be ascribed in part to peri: glaciation, while the absence of accumulation of debris in the talwegs except at the extreme head of valleys testifies to the effectiveness of stream transport. Nevertheless, here as in the rest of Scotland, periglaciation has only retouched a landscape that is really the product of other processes. Iven some of the most impressive "periglacial" forms - the corrasion niches - seem to be in great part the work of stream erosion during intervals of mild climate. 


\section{Conclu.sions.}

From this review of the distribution of periglaciation in Scotland it is apparent that it is necessary to take account of the pre-existing landscape in the broad sense of landforms, weathering and structure, as well as the nature, duration and intensity of the periglacial climate. The evidence of cryoturbation, pollen analysis and deep shattering shows that severe conditions, very favourable to periglacial erosion and deposition prevailed in ice free areas right to the end of the Pleistocene, and less severe but by no means ineffective conditions have continued to prevail on high fround ever since. Yet the geomorphological agencies associated with these conditions hare at the most been able to but slightly modify the pre-existing forms. The slightness of the modification compared to what has been claimed for unglaciated areas of $W$ Furope can in part be ascribed to the shortness of the period during which severe periglaciation prevailed, probably no more than 5,000 years from the retreat after the Scottish Readvance to the end of Zone III times, but even in 'moraineless Buchan' where ice free conditions seem to have existed throughout the last glaciation and the bedrock was usually weakened by chemical rotting the modification has not gone very far, as shown by the extensive pre:servation of the weathering mantle ard the thinness of the solifluction deposits. It must be concluded that in areas of old hard rock such as Scotland periglaciation is not the extraordinarily effective 
agent of land sculpture it is sometimes claimed to be. Many socalled periglacial forms are in lact the heritage of earlier, very different, clinates and have been merely retouched by periflaciation. For the geomorphologist periglaciation has but introduced some minor, if interesting modifications to a landscape that owes its origin to other morphogenetic systems.

On the other hand, periglaciation is of great importance in the study of climatology, botany, and above all pedology and Pleistocene geology.

From a consideration of cryoturbation much can be learnt of the nature of clinates during the ice age and the conditions pre:vailing today on Scottish hills. The growth and melting of ice in the ground and solifluction are two of the most important factors in the habitat of vegetation on mountain tops today, contributing much to the instability of the plant's environment. Periglaciation was of course the dominant feature of the environment of the flora of the cold phases of the Pleistocene.

Periglaciation in Scotland is of the greatest significance to the pedologist. Not only has permasrost lert an indurated horizon in the soil over wide areas (PITZPATRICK 1958), seriously affecting its drainage and suitability for cropping and forestry, but periglacial solifluction has affected most of the unconsolidated. drift deposits on which a large proportion of our soils have developed, and frost shattering has provided the raw material in many cases. 
An understanding of the composition, origin, texture and age of periglacial solipluction deposits is as necessary when studying Scottish soils as a knowledge of the corresponding data for till. It is through the medium of the soil which profoundly afpects vegetation and agriculture, rather than the landforms, that peri: glaciation is of significance in the landscape of Scotland.

Although Scotland is a heavily glaciated country, the evidence of widespread periglaciation shows that future studies of the Pleistocene must take cognizance of periglacial, as well as glacial, interglacial, and postglacial, periods. The volume or periglacial deposits is not great, and the stratigraphically particularly userul loess and coversands are not represented, but the main value of periglacial phenomena in Pleistocene geology is perhaps the light they can throw on the climatic conditions prevailing when some other deposit was fomed or during a period when there was no deposition and the stratigraphic record is consequently blank. Cryoturbation and solifluction horizons will be of increasing value in dating and correlations, especially in scotland where biotic evidence is scanty. The possibility of the disturbance of the normal strat:igraphic sequence of glacial deposits by cryoturbation and especially by mass movement on slopes will have to be constantly borne in mind. by the Pleistocene geologist.

Whoever studies periglacial phenomena in Scotland must agree with the Edinburgh geologist, Janes BZnII, when he wrote, some 
I

70 years ago,: "The glacial period was not simple and uniform

in its course, or short in its duration, but was varied and even diverse in its circumstances".

I

BENII:, (1891), p. 393. 


\section{CHAPTER XIX.}

\section{SOME PROBIIMS FOR FURTHTR STUDY.}

The primary problem in Scottish periglacial studies is simply the acquisition of more information. Fundreds more examples of fossil cryoturbation features undoubtedly await discovery in sand:pits and stream banks across the countryside, while only a start has been made in the location of contemporary patterned ground. Tens of thousands of lobes and other soljeluction features on hill slopes and sumnits have never been examined. Some of this work can be done from air photographs, but detailed studies are required not only of the occurrence of these features but also of their nature, origin, dimensions, age and formation. There is a part:icular dearth of information from the Islands, Caithness, the Central Iighlands and the Iowlands of the SI and the SW.

There is equally great scope for the identification, mapping and explanation of periglacial landforms, from tors and niches to the major slopes and valley ploors. It will be necessary to consider the rate of formation of these features and this will require a more detailed knowledge of the pre-existing forms. Study of correlative deposits, particularly alluvial fans at the foot of hills and on the floors of glacial and glaci-fluvial trenches, in sites where the period of formation of the fans can be closely dated, should be of value in this connection. A 
particular geomorphological problem which has not yet been even superficially examined is the evolution of the shore line of the late glacial sea(s).

The chronology of periglaciation deserves more attention. It will probably never be possible to work out a Scottish sequence on the basis of periglacial deposits alone, but nevertheless con:sideration of periglacial phenomena should help in deducing the glacial history of the country, and in particular the nature of interstadial periods for which the biotic/stratigtaphic evidence is slight and not unequivocal.

A better understanding of the role of periglaciation in the development of Scotland's soils is required and will involve perhaps laboratory studies of the effect of frost shattering on Scottish rocks.

The climatic and biotic significance of fossil periglacial phenomena requires to be investigated in greater detail, not only in relation to Scotland but also in the wider context of Turope as a whole. In this connection Scotland occupies a very interesting position right on the NW margin oi the Continent. For this it will be necessary to have a better knowledge of the climatic con:ditions implied by various types of cryoturbation.

Consideration of contemporary periglacial phenomena especially on high ground should lead to a betten understanding of the nature of our hill climates, so little known from instrumental records, and the ecological problems associated with an instable soil. 
While the logical and most fmiterul method of considering the phenomena associated with a severe climate is first to examine them in areas of the world where they are currently developing and then to compare the evidence so gained with the evidence of fossil features in other areas, it does seem that there is scope for some reversal of the process, particularly in the case of cryoturbation which is usually seen in sections in Scotland, but only rarely so in the Arctic. Consideration of these sections should help tp solve some of the vexed questions of the mechanisms involved in the for:mation of patterned ground today in cold regions. 
Table 1.

Glacial Sequence

Limits shown in figure 2.
Glacial Sequence N. Britain N.E. Scotland
Pollen Sequence Dating in years B.P.

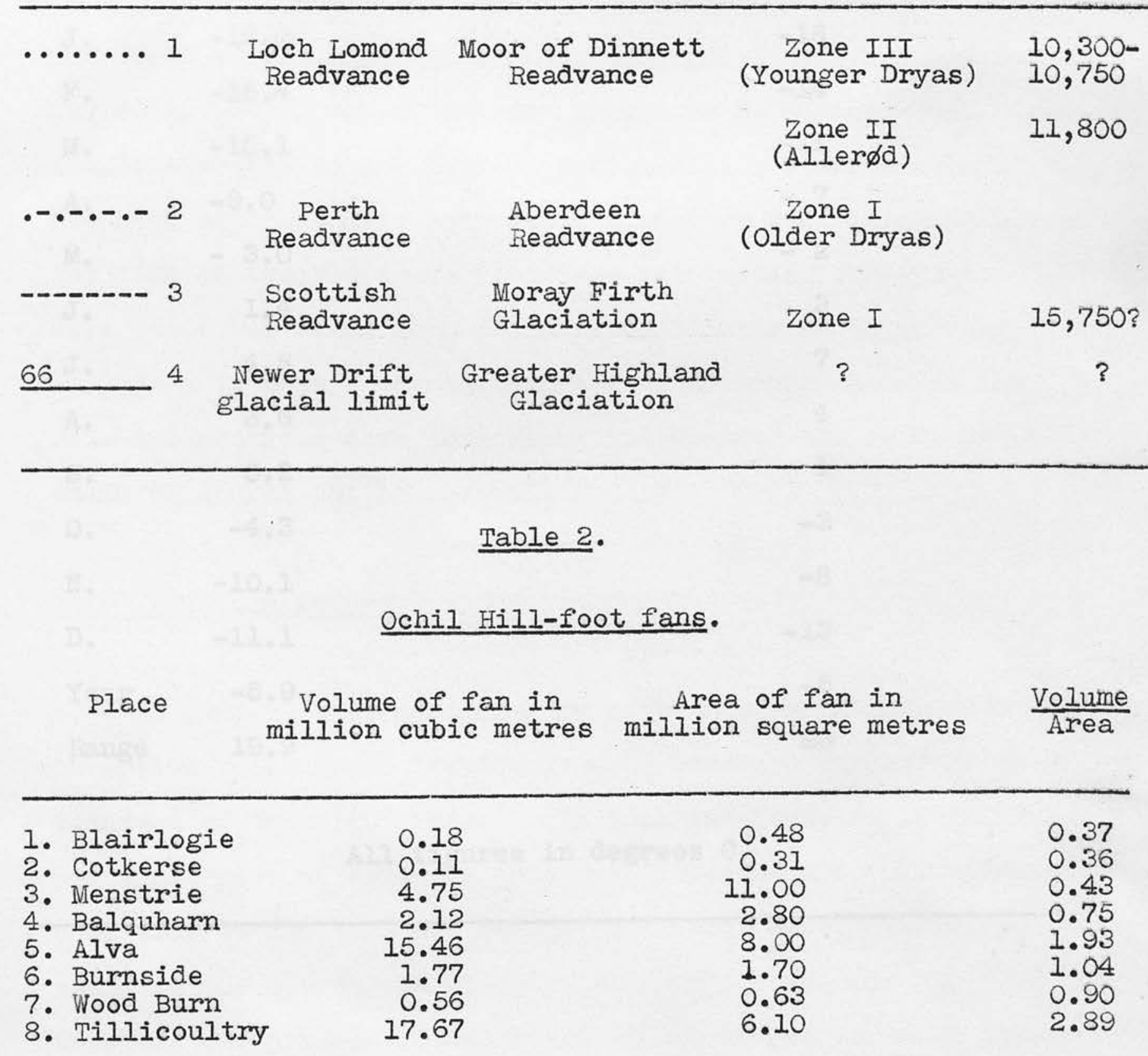


Table 3.

Mean Monthly Temperatures.

Story, SW Svalbard

Sea level

1912-1926

J.

$-12.0$

F. $\quad-15.4$

M. $\quad-15.1$

A. $\quad-9.0$

M.

J.

J.

A.

S.

o.

N.

D.

Year

Range
$-3.0$

1.4

4.5

3.6

0.2

$-4.3$

$-10.1$

$-11.1$

$-5.9$

19.9

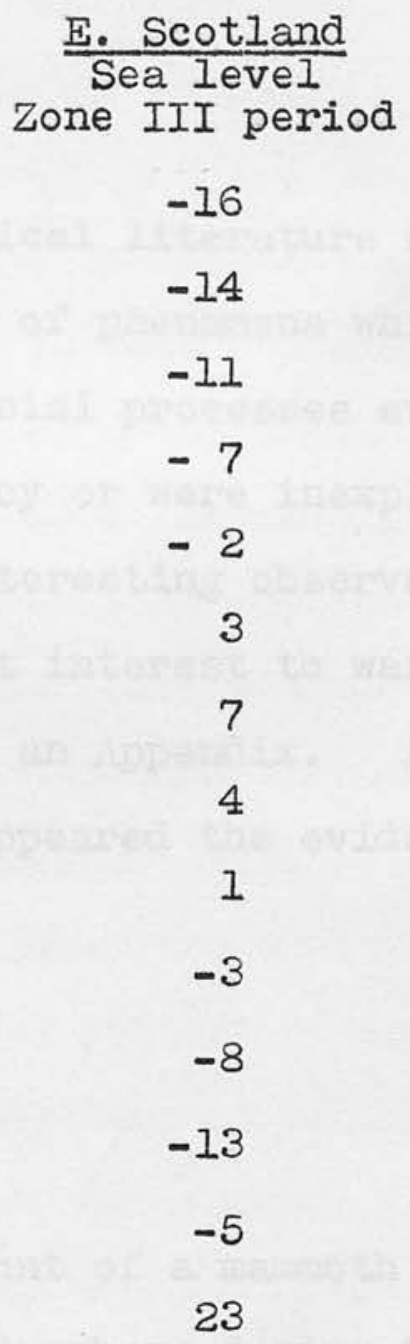

$\frac{\text { E. Scotland }}{\text { Sea level }}$

Zone III period

$-16$

$-14$

$-11$

$-7$

$-2$

23

All figures in degrees $C$. 
APPENDIX A.

SOME EARLY OBSERVATIONS OF PERIGLACIAL PHENONENA.

I. Introduction.

Some of the older scottish geological literature was consulted to see if there were any record of phenomena which might now be ascribed to the work of periglacial processes even if they had been attributed to some other agency or were inexplicable at the time of their discovery. Some interesting observations were unearthed which seem of sufficient intersst to warrant inclusion in this study in the form of an Appendix. As the relevant sections have long since disappeared the evidence could of course not be checked.

II. Possible wedges.

In 1823 R. BALD published an account of a mammoth tusk unearthed three years previously near Broxburn during the excavation of theUnion Canal. The tusk was found in till, in the upper part of which he observed "fissures about five inches wide at the top, and ending in a wedge below, formed by rents in the clays, and filled with sand". (p.60). If these fissures were indeed fossil frost or ice wedges as seems likeIy, this must be the earliest published record of their occurrence. 
BLACKADDER (1824) described and illustrated in the same journal what appear to be a wedge and some involutions in sand pits near Falkirk. See figure 51. These may well be the earliest published illustrations of these phenomena. On page 433 he described a section further up the Forth Valley where fine gravel could be seen penetrating "into the subjacent sand betweixt two travessing veins, the section presenting the trumpet form, mouth upwards". This sounds a graphic description of a fissil wedge with material downslumped on the margins. Minute "shifts" (i.e. faults) were common at traversing veins: this is characteristic of formerly deeply frozen sands. BLACKADDER seems to have made many other observations in the drift around Edinburgh, but only a second-hand account of some of his observations was found. See TAYLOR 1874, below.

In $1839 \mathrm{~J}$. SMITH described and illustrated a section in a sandhill at Warriston, Edinburgh. The pattern of faults in the sand (figure 52) suggests to us now that it was a kame of the crevasse fizling type, or an esker, but one of the faults forms a fissure filled with some of the overlying gravel. This fissure may be a wedge structure.

In FLEVING's "Lithology of Edinburgh", published in 1859, narrow tongues of gravel are illustrated descending into underlying till for several feet or yards. Possibly these tongues were fossil ice wedges.

Three papers in Volume 2 of the Trans. Edin. Geol. Soc., 1874, recorded wedge-like features in Edinburgh. TAYLOR described unpublished sections examined many years before by 
BLACKADDER. Firstly, at Fettes Fow, vertical seams of coal grains occurred in clayey-sandy material. Secondly, near Bellevue, many crooked openings in stratified sand could be seen, filled with foreign matter and a few inches to ten feet deep. The deep ones extended many yards horizontally with a crooked course. Both these records seem to refer it either to dessication phenomena or to periglacial features. RICHARDSON described a vertical fissure about eleven feet deep at Tynecastle cutting sand and gravels and infilled with some of the overlying till. Downslumping of adjacent material occurred at the margins. The feature was regarded as an inexplicable oddity at the time, but there can be little doubt that it was a fossil wedge, very similar to some in Midlothian found in recent years. HENDERSON dealt with a similar feature, also at Tynecastle. Perhaps he was describing the same thing as RICHARDSON.

BENNIE (1891) discussed a "washout" of interglacial/interstadial age seen in New Redhall quarry. A striking feature of the lithograph illustrating his paper is a vertical fissure some 4 metres deep, traversing till and the underlying shale. In his account BENNIE made no reference to this phenomenon which looks like a remarkably fine example of a wedge!

In a paper on Ayrshire drift published in 1898 SMITH discussed with sketches, 10 near-vertical "sand dykes" a few inches wide and at least 7 feet deep penetrating till. (pp. 38,44). He attributed them to ice drag, but they could be wedges. It is interesting to note that while many of the features 
described by these early writers were in stratified drift, like all the wedges known in scotland today, not a few were in till. (BAID, 1823; FLEMING, 1859; BENNIE, 1891).

\section{Possible involutions.}

The contortions described in 1824 by BLACKADDER in a sand pit near Carron have already been mentioned and illustrated in figure 51. They are probably periglacial involutiens.

In 1869 A. \& J. GEKIE mentioned and illustrated diturbances of fine clay and sand in the South Medwin Valley. They ascribed the contortions to the impact of grounding icebergs in a glacial lake, but they might be of periglacial origin, or simply slump structures such as often occut in such material.

MILLER in 1870 stated that brick clays of Portobello were often curiously disturbed and contorted in the upper six feet. These contortions might be the work of groundinf ice bergs, but their occurrence near the top of deposits consisting of clay with sand partings -- ideal material for cryoturbation-- strongly suggests a periglacial origin in response to cold conditions afetr emergence from the sea.

An origin by iceberg drag seems more liekly in the case of crumpled laminated clay, sand and gravel illustrated byCROLL (1875) from near Musselburgh. See figure 53. There is a definite overfolding of the strata to the right as if driven by some force from the left. Nevertheless, even in this case a periglacial origin is by no means excluded: the disturbance could be an involutions structure displaced in its upper layers by solifluction. 
The Geological Survey Memoir, Explanation of sheet 31, Ist. Edition, 1879, (A. GEIKIE, Ed.), refers to disturbances of "100 foot raised beach deposits" near Larbert. On page 53 it is stated that "several of the clay seams are crumpled up in a wonderful manner, great sheets of them being rolled over and over and invovling the associated sands for considerable horizontal distances". This crumpling could well be of periglacial origin.

MORRIS (1892) mentions crumpling of raised beach deposits seen in a section near Stirling, while J. GEIKIE in the $3 d$. Edition of "The Great Ice Age" illustrated three other examples of contorted raised beach material at Portobello and Leith.

In 1898 SNITH illustrated (p. 34) gently contorted sands and silts overlain by flat-lying sands and silts. The contortions resemble a mild form of cryoturbation.

\section{Possible periglacial solifluction deposits.}

BLACK published a paper in the Edinburgh New Philosophical Journal for 1841 on shattered sandstone with angular fragments in a sandy matrix observed beneath till in Lancashire. He ascribed the shattering to "antediluvian congelation of the interstitial water" -- i.e. in effect, to periglacial shattering before the advent of a glacier which deposited the overlying till -- but erred in attributing the slight displacement of the fratgments to currents of water. A somewhat similar occurrence in the Edinburgh area was described and illustrated by FLEMING in 1859. His sketch showed till overlying and incorporating "shivers" of the underlying shale which appears to have suffered 
frost shattering previous to the deposition of the till.

A fuller description of what are probably periglacial solifluction deposits on the plateaux of the Eastern Lammermuirs is given by GEIKIE (1863), and quoted by KEINALL \& BAILEY (1908). His remarks are worth quoting.

"Between the heath and the rock there intervenes, on the higher parts of the Lammermuir range, a mass of rudely stratified rubbish, to which, in the progress of the survey, the provisional name of Surface Wash has been given till its true history is better understood. It lies along the ridge between the head of the Hopes Water and the Kilpallet Heigts. It is usually a sandy clay or earth more or less distinctly stratified, and containing pieces of greywacke and shale, often well striated. Though frequently different in character from the rocks immediatly adjacent, these stones cannot have come from any great distance. The deposit is only a few feet in thickness. Perhaps it is to be regarded as the remanie of the boulder clay, washed down and reassorted by rain, though the comparativly small number of the striated stones and the irregularity of the striation have sometimes suggested that this accumulation may be as old as the snowfields of the glacial period".

Although KENDALI \& BAILEY took these deposits to be evidence of local glaiers on the Lammermuirs, the deposits so well described by GEIKIE is in fact a solifluction deposit of periglacial origin showing the typical properties of angular fragments of the local rock, weakly striated, and with a crude bedding. 
GEIKIE also observed similar surficial deposits on Peeblesshire hills and stated that they occasionally exceeded 25 feet in thickness. (GEIKIE, 1869). It is apparent that the tendency to mention only the thickest occurrences of solifluction deposits instead of their average depth, has not been confined to recent workers! GEIKIE fully realised that this type of drift was not strictly glacial in origin and that it was widely distributed in the Southern Uplands although he never made the final step of correlating it with the well-known "head deposits" of Devon and Cornwall.

Other writers also occasionally noted drift deposits with a crude bedding parallel to the slope. e.8g. SMITH in 1898 described a section of such material in Ayrshire from " a side gill of the App Water". Most likely these deposits are the product of periglacial processes.

\section{Conclusion.}

The not infrequent mention in the older literature of what can now be recognised as periglacial features is a tribute to the acute powers of observation of the workers in the field of Pleistocene geology during the 19th Century. Their observations reiforce the conclusion that fossil periglacial phenomena are widespread in scotland. 


\section{APPENDIX B.}

POLIEN ANALYSIS OF PEAT OVERLAIN BY EARTHY RUBBLE AT BRIDGEND, HUNTLY, ABERDEENSHIRE.

In a stream-cut section on the $\mathbb{N}$ bank of the Ness Bogie, S of Huntly, Aberdeenshire, (G.R. 518359) the section sketched in figure 54 was observed. Grey silty peat was overlain by 1 to 2 metres of stony, earthy matter. The slope behind the section had a gradient of about 20 degrees. A pollen analysis of the peat was kindly undertaken by Dr. S.E. Durno of the Macauley Institute of Soil Research. His investigations showed that the peat was of early Atlantic, (Zone VIIa) age. The pollen counts were as follows:-

Arboreal Pollen.

Pinus

Betula

Alnus

Ulmus

Quercus

Also recorded

Non-Arboreal Pollen.

Gramineae

Cyperaceae

Corylus $\ldots 6 \%$

$\ldots 18 \%$

$\ldots 73 \%$

$\ldots . .1 \%$

$\ldots 2 \%$

...Tillia and Fraxinus. (percentage of tree pollen).

$$
\text { ..14\% }
$$$$
\ldots 2 \%
$$

$\ldots 13 \%$

Various other dicotoledenous herbs ....5\% 
Dr. Durno states in a personal communication:"The pollen analysis suggests a date in the early Atlantic period (Zone VIIa). The alder pollen is very high with birch value low for that species. Pine is also low, but this is usual all through the Atlantic to the sub-Atlantic - at least in Eastern Scotland. It is common for alder to reach its highest values in the Atlantic or sub- Boreal but birch in the latter period is generally somewhat higher than in the Bridgend material. The deciduous mixed oakwood group tell nothing except for one grain of Tillia (lime); it is not advisable to deduce too much from a single identification, but Tillia is rarely found in any period other than the Atlantic or sub-Boreal in Scottish deposits. The final significant point is the very low non-arboreal pollen count, in particular the complete absence of Ericaceous pollen which I interpret as an indication of forest dominance in the area. Again, a period of maximum forest influence with alder as the dominant tree most probably occurrs in the Atlantic of sub-Boreal but I feel inclined to favour the Atlantic in view of the low birch count".

The existence of a considerable thickness of slumped material over this peat shows that mass movement has locally been not insignificant at low altitudes even after the end of the ice age and before the advent of cultivation.

Two sections of Allerød peat discovered in the course of the field work have been analysed by DONNER (1957). These are the two most northerly occurrences so far known in Britain. 


\section{BIBLIOGRAPHY.}

AHLIVANN, H.W: son, 1941.

The main morphological features of North East Greenland. Studies in North East Greenland, 1939-1940. Part I. Geog. Ann., 23, pp. 148182.

1948. Glaciological research on the North Atlantic coasts. R.G.S. Research Series: No.l. Royal Geographical Society, London.

AINDERSON, J.G.C., 1940. Glacial drifts near Roslin, Midlothian. Geol. Nag., 77, pp. 470-473.

ANDERSSON, J.G., 1906.

Solifluction, a component of subaerial denudation. Journ. of Geol., 14, $\mathrm{pp}$. 91-112.

ARKELL, W,J., 1947.

The geology of Oxford. Clarendon Press, Oxford.

BAILEY, E.B., 1927. in: Summary of Progress of the Geol. Surv. for 1926 . H.M.S.O., London.

, 1931.

in: Summary of Progress of the Geol. Surv. for 1930. H.M.S.0., London.

, 1934.

in: Pre-Cambrian Association. B. Second excursion, Scotland, 18th Aug.-2nd Sep. Geol. Mag., 7I, p.553.

, 1949.

Pleistocene deep weathering. 164 , p. 1130 .

Nature,

H.B., 1916. The geology of Ben Nevis and Glencoe. Mem. Geol. Surv. Scotland. Explanation of sheet $5 \overline{3}$.

, et al.,

Tertiary and post-Tertiary geology of Mull, Loch Aline and Oban. Mem. Geol. Surv. Scotland. Explanation of sheets $43,44,51,52$.

BAIRD, P.D., \& LEWIS, W.V., 1957. The Cairngorm folods, 1956. Scott. Geog. Mag.s 73, pp. 91-100.

BALD, R., 1823.

Notices regarding the fossil elephants of Scotland. Mem. Wern. Nat. Hist. Soc., 4 , pp. 58-66. 
BARROW, G., HINXIMAN, $\mathbb{1}$. W., \& CUNNINGHAM CRAIG, E.H., 1913. The geology of Upper Strathspey, Gaick, and the Forest of Atholl. Mem. Geol. Surv. Scotland. Explianation of sheet 64 .

BARROW, G., WILSON, J.S.G., \& CUNNINGHAI CRAIG, E.H., 1905. The geology of Blair Atholl, Pitlochry and Aberfeldy. Mem. Geol. Surv. Scotland. Explanation of sheet 55.

BEAUJEU - GARNIER, J., 1953. Modele periglaciaire dans le Massif Central francais. Rev. Geomorph. Dyn., 44, pp. 251-281.

, 1956. Massif Central francais. Commission of Periglacial Morphology. Proc. 8th Gen. Ass. \& 17 th Int. Cong., I.G.J. Washington 1952. $\frac{1}{\mathrm{pp}}$. 209-212.

BENNIE, J., 1891.

Note on a recent exposure of a "washout" of strata in New Redhall Quarry, Edinburgh. Proc. Roy. Phys. Soc. Edin., 10, pp. 392-296.

BIRKELAND \& FOYNE, N.J., 1932. Klima von Nordwesteuropa. Handbuch der Klimatologie. Band III, Teill. Koppen, W., \& Geiger, R., Ed... Berlin.

BIROT, P., 1956.

Nord-ouest de la Peninsule Iberique. Commission of Periglacial Morphology. Proc. $\frac{8 \text { th }}{\text { I.G.U. }}$ Washing'ton $\frac{\text { Ass }}{1952 .} \frac{17 \text { th }}{\text { p. }} \cdot \frac{\text { Cong. }}{212 .}$

BLACK, J., 1841.

On some appearances inferred to have been connected with the Antediluvial congelation of the interstitial water of rocks. Hoin. New Phil. Journ., 31, pp. 38-50.

BLACK, R.F., 1952.

Polygonal patterns and ground conditions from aerial photographs. Photogramm. Engin., 17, pp. 123-234.

BLACK, R.F., 1953. Permafrost - a review. Trans. NEW YOrk Acad. Sci., Ser. II, 15, pp. 126-131.

BLACKADDER, A., 1824. On the superficial strata of the Forth district. Mem. Wern. Nat. Hist. Soc., $\underline{5}, \mathrm{pp} .424-4 \overline{36}$.

BONACINA, L.C.W., \& HAWKES, L., 1947. Climatic change and the retreat of glaciers. Quart. Journ. Roy. Met. Soc., 73, pp. 85-95. 
BOSWORTH, T.O., 1910.

BOYE, If., 1950.

1952.

\section{$-1952$ \\ BREIVNER, A., 1912. , 1934.}

BREUII, H., 1934.

BRYAN, K., 1946.
Wind erosion on the coast of Mull. Geo1. Miag., New Ser., Dec. 5, 2, pp.

Glaciaire et periglaciaiare de l'Ata sund nord-orientale (Groenland). Act. Scient. Indus., No. IIII. Hermann, Paris.

Gelivation et cryoturbation dans le massif du Mont-Perdu, Pyrenees Centrales. Pirineos, 8, pp. 5-29.

The physical geology of the Dee Valley. University studies (Aberdeen) No. 56.

The glaciation of Moray and ice movements in the North of Scotland. Trans. Edin. Geol. Soc., 13, pp. 17-56.

De l'importance de la solifluxion dans I' etude des terrasses. Rev. Geog. phys. et Geol. Dyn., 42, pp. $\overline{269-331 .}$

Cryopedology - the study of frozen ground and intensive frost-action with suggestions on nomenclature. Amer. Journ. Sci., 244, pp. 622-642.

BUCHAN, J.W. (ed.), 1925. History of Peebleshire. Vol. I. Glasgow.

BUEL, J., 1944.

Die morphologischen Wirkungen des Eiszeitklimas in gletscherfreien Gebiet. Geol. Rundscahu, pp. 482-519.

Die klima-morphologischen Zonene der Polarlander. Erdkunde, 2, pp. 22-53. , 1949 .

Die rlumliche und zeitliche Gliederung des Eiszeitklimas. Naturwiss., 39, pp. 105-112, \& 133-139.

CAILLEUX, A., 1943. Fissuration de la craie par le gel. Bul1. Soc. Geol. France, Ser. 5, 13, pp. 511-520.

CAILLEUX, A., 1952.

Polissage et surcreusement dans le hypothese de Boye. Rev. Geomorph. Dyn., 3, pp. 247-257.

, \& TAYLOR, G., 1954. Cryopedologie. Act. Scient. Indus., No. 1203 . Hermann, Paris. 
CARRUTHERS, R.G., 1941, 1942. Glacial drifts. Geol. Mag., 78, pp. 317-318; 79, pp. 153- $\overline{154}$.

CHARLESWORTH, J.K., 1926. The marginal kame-moraine of the south of scotland and some later stages of retreat. $25-50$. Trans. Roy. Soc., Edin., 55,

, 1955. The late-glacial history of the Highlands and Islands of Scotland. Irans. Roy. Socc. ㅍiㄹ.

, 1957. The Quaternary Era. 2 Vols. London.

CLOUGH, et al., 1925. The geology of the Glasgow area. Mem. Geol. Surv. Scotland. Explanation of the Glasgow District map.

COCKBURN, A.M., 1929.

The geology of St. Kilda. MS of Ph.D. Thesis, University of Edinburgh,

COMION, R., 1954.

The geomorphology of the east Cheviot area. Scott. Geog. Mas., 70, pp. 124-138.

, \& GALLOWAY, R.W., 1958. Ice wedges in Midlothian: a note. Scott. Geog. Nag., pp. 44-46, 74.

COTTON, C.A., 1958.

Alternating Pleistocene morphogenetic systems. Geol. Miag., 95, pp. 125-136. , \& Te PUNGA, M.T., 1955. Solifluxion and periglacially modified landforms at Wellington, New Zealand. Trans. Roy. Soc. New Zeal., 82, pp. 1001-1031.

CRAMPTON, C.B., CARRUTHERS, R.G., et al., 1914. The geology of Caithness. Miem. Geol. Surv. Scotland. Explanation of sheets $110,115,116$.

CROLL, J., 1875.

DAHL, E., 1955.

DEGE, W., 1941.

DENNY, C.S., 1936.
Climate and rime. London.

Biogeographic and geologic indications of unglaciated areas in scandinavia.during the glacial ages. Geol. Soc. Am. Bull., 66, pp. 1499-1519.

Landformende Vorgunge im eisnahen Gebiet Spitzbergens. Pett. Geog. Mitt., 87, pp. 81-97, \& 113-122.

Periglacial phenomena in Southern Connecticut. Amer. Journ. Sci., 232, pp. 322342 . 
1951.

DIMBLEBY, G.W., 1952.
Pleistocene frost action near the border of the Wisconsin drift in Pennsylvania. Ohio Journ. Sci., 51, pp. 116-125.

Pleistocene ice wedges in North Last Yorkshire. Journ. Soil Sci., 3, pp. 1-19.

DINES, H.G., HOLLINGWORTH, S.E., EDWARDS, W., BUCHAN, S., WEICH, F.B.A., 1940. The mapping of head deposits. Geol. Mag., 77, pp. 198-226.

DINHAMI, C.H., 1927.

The geology of the district around idinburgh. Proc. Geol. Assoc., 38, pp. 405-510.

, \& Haldane, D., 1932. The economic geology of the Stirling and Clackmannan Coalfield. Mem. Geol. Surv., Scotland.

DONNER, JJ., 1957. The geology and vegetation of late-glacial retreat stages in Scotland. Trans. Roy. Soc. Edin., 63, pp. 221-264.

DUCKER, A., 1954. Die periglazial-Erscheinungen im holsteinischen Pleistoz\&n. G\&tting. Geograph. Abhand., Heft 16, pp. 5-54.

DURY, G.H., 1954. Contribution to a general theofy of meandering valleys. Amer. Journ. Sci., 252, pp. 193-224.

DYLIK, J., 1956 a. Esquisse des problemes periglaciares en Pologne. Biul. Periglac., 4, pp. 57-71.

DYLIK, J., 1956b.

EAKIN, H.M., 1916. Coup d'oeil sur la Pologne periglaciaire. Biul. Periglac., 4, pp. 195-238.

Yukon-Koyuskuk region, Alaska. U.S. Ged1. Surv. Bu11. No. 631, pp. 67-82.

ECKFORD, R., 1928.

On certain terrace formations in the south of Scotland and on the English side of the Border. Proc. Soc. Ant. Scot., 62, pp. 107-120.

EDELMAN, C.H., FLORSCHUTZ, F., \& JESWIET, J., 1936. Uber spatpleistoztne und frithholoz ane kryoturbate Ablagerungen in den Ostlichen Nederlanden. Verh. Geol. Minb. Genoot. V. Neder. en Kolon., Geol. Ser. II, pp. $30 \overline{1-336}$.

FAEGRI, K., 1950. On the value of palaeoclimatological evidence. Roy. Met. Soc., Centenary Proceedings. $\frac{\mathrm{pp}}{\mathrm{p}} \overline{188}-1 \overline{95}$. 
FERMOR, L.L., 1939. On coal veins in Malaya. Geol. Mag., 76 , pp. $465-472$.

FITZPATRICK, E.A., 1956a. Progress report on the observation of periglacial phenomena in the British Isles. Biul. Periglac., 4 , pp. 99115.

1956b. An indurated soil horizon formed by permafrost. Journ. SoiI Sci., 7, pp. $248-254$.

1958. An introduction to the periglacial geomorphology of Scotland. Scott. Geog. Mag., 74, pp. 28-36.

FLEMING, J., 1859. Lithology of Edinburgh. Edinburgh. FLETT, J.S., \& READ, H.H., 1921. Tertiary gravels of the Buchan district of Aberdeenshire. Geol. Mag., 58, pp. 215-225.

FLETT, W.R., 1927. Description of the sand deposits at Hungryside, Torrance. Trans. Gals. Geo1. Soc., 17, pp. 396-397.

FLINT, R.F., 1957.

FLOHN, H., 1953.

GALLWITZ, H., 1949.

GEIKIE, A., 1863.
Glacial and Pleistocene Geology. John Wiley \& Sons, New York.

Studien tber die atmospharische Zirkulation in der letzten Eiszeit. Erdkunde, I, pp. 266-275.

Eiskeile und glaziale sedimentation. Geologica, 2, pp. 5-24.

The geology of East Mem. Geol. Surv. Scotland. Explanation of sheet 34 . Ist Ed.

, (Ed.), 1879. The geology of the country round Falkirk. Mem. Geol. Surv. Scotland. Explanation of sheet 31 .

, 1902 .

The geology of Eastern Fife. Nem. Geol. Surv., Scotland, Explanation of sheet 41 and parts of sheets $40,48,49$.

, \& GEIKIE, J.S., 1869. The geology of Mem. Geol. Surv. Scot. Explanation of sheet 24.

GEIKIE, J.S., 1894. The Great Ice Age. 3d Edn. London. 
\& RAMSAY, A.C., 1878. On the geology of Gibraltar. Quart. Journ. Geol. Soc. London, 24, pp. 505-54I.

GODARD, A., 1958.

GODWIN, H., 1956.

GOLAB, J., 1956.

GREGORY, J.W., 1927.

, 1930.

GUILCHER, A., 1949.

1950.
Quelques observations sur le modele des regions volcaniques du norouest de $I^{\prime}$ E'cosse. Scott. Geog. Mag., 74, pp. $37-43$.

The History of the British Flora. Cambridge.

Ice- dges as ground-water conductors. Biul. Periglac., 3, pp. 135-137.

The moraines, boulder clay and glacial sequence of south-western scotland. Trans. Glas. Geol. Soc., 17, pp. 354-376.

Stone polygons beside Loch Lomond. Geog. Journ. 96, pp. 415-418.

Sur les vallons cotiers suspendus des environs de Lisbonne et leurs analogies avec ceux du littoral breton. Comptes Rendu de I'Acad. d. Sciences, 228, 1512-1514.

Nivation, cryoplanation et solifluction quaternaire dans les collines de Bretagne Occidentale et du Nord du Devonshire. Rev. Geomorph. Dyn., I, pp. 53-78.

HAIVIEN, Th. van der., 1951. Late-glacial flora and periglacial phenomena in the ivetherlands. Leid. Geol. Meded., 17, pp. 71-183.

, 1952. Dating and correlation of periglacial deposits in Middle and Western Europe. Geol. en Mijnb., 14, pp. 328-336.

HARE, F.K., 1953.

HARKER, A., 1901.

HARLAND, W.B., 1957. Two pictures of the recent past. Arctic, 6, pp. 58-60.

Ice erosion in the Cuillin Hills, skye. Trans. Roy. Soc. Edin., 40, pp. 221-252. Exfoliation joints and ice action. Journ. Glaciol. 2, pp. 8z-10.

HENDERSON, J., 1874.

On glacial phenomena in the Pentland Hills and at Tynecastle, near Edinburgh. Trans. Edin. Geol. Soc, 2, pp. 360-367. 
HERNES, K., 1955.

Die Lage der oberen Waldgrenze in den Gebirgen der Erde und ihr Abstand zur Schneegrenze. Kolner Geograph. Arb., Heft 5, 277p.

HINXMANN, L.W., 1904. in: Summary of Progress of the Geol. Surv. for 1903. p. 88 .

HJULSTRON, F., SUNDBORG, A., \& FALK, A., 1955. Problems concerning the deposits of windblown silt in sweden. Geog. Ann., 37, pp. 86-117.

HOBSON, P.M., 1949.

HOGBOM, B., 1914.

HOLNES, C.D., 1941.

IVES, R.L., 1940.

JAHN, A., 1956.

JENESS, J.I., 1952.
Assynt Parish. Scott. Geog. Mag., 65, pp. $25-43$.

Wber die geologische Bedeutung des Frostes. BuI1. Geol. Inst. Upsalla, 12, pp. 257-389. Till fabric. Geol. Soc. Am. Bu11., $\underline{52}$, pp. 1299-1354.

Tundra ponds. Journ. Geomorph., 生, pp. 285-296.

Some periglacial problems in Poland. Biul. Periglac., 4, pp. 164-182.

Erosite forces in the physiography of Weste ern Arctic Canada today. Geog. Rev., ", 42, pp. 238-252.

KENDALL, P.F., BAILEY, E.B., 19091 The glaciation of East Lothian south of the Garleton Hills. Prans. Roy. Soc. Edin., 46, pp. 1-31.

KLATKOWA, H., 1954. KLEIN, A., 1953.

KLUTE, F., 195la. , 1951b.

LANG, W.B., 1943.
Niches de corrasion aux environs de Lodz. Biul. Periglac., I, pp. 150-152.

Die Niederschlage in Europa im Maximum der letzten Eisziet. Pett. Geog. Mitt., 97, pp. 98-104.

Wie kann das Klima der letzten Eiszeit in Mittleeuropa bestimmt werden? Scientia, 86, pp. 48-55.

Das Klima Europas whhrend des Maximums der Weichse1-Wurmeisziet und die Anderung bis zur Jetztzeit. Erdkunde, 5, pp. 257-283.

Gigantic drying cracks in Animus Valley, New Mexico. Science, 98, pp. 583-584. 
LAUTENSACH, H., \& BOGEL; R., 1956. Der Jahresgang des mittleren Lufttemperatur in den verschiedenen Klimagebieten der Erde. Erdkunde, 10, pp. 270-282.

LEFFINGWELL，K., 1915.

Ground-ice wedges the dominant form of ground-ice on the North coast of Alaska. Journ. of Geol., 23, pp. 635-654.

LEHMANN, H., 1948.

LEIGHLY, J., 1949.

LENBKE, H., 1954.

LEWIS, W.V., 1939.

1954.

LINTON, D.L., 1949.

, 1950.

1951.

1955.

1956.

LOUIS, H., 1934.

LUNDqUIST, G., 1949 .
Periglaziale Erscheinungen in der Umgebung von Bonn. Erdkunde, 2, pp. 186-190.

On Continentality and glaciation. Geog. Ann., 31, pp. 133-145.

Die periglazial Erscheinungen im Jungmorunengebiet westlich des Oder-Bruchs bei Freienwalds. Gott. Geograph. Abhand., Heft 16, pp. 55-93.

Snowpatch erosion in Iceland. Geog. Journ., 94, pp. 153-161.

Pressure release and glacial erosion. Journ. Glaciol, 2, pp. 417-422.

Unglaciated areas in Scandinavia and Great Britain. Irish Geog., 2, pp. 25-33.

Unglaciated enclaves in glaciated regions. Journ. Glaciol., 1, pp. 45l-452.

Problems of scottish scenery. Scott. Geog. liag., 67, pp. 65-85.

The problem of tors. Geog. Journ., 121, pp. $470-487$.

The significance of tors in glaciated lands.

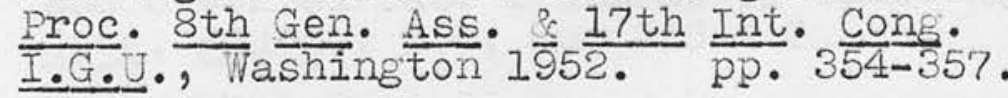

Glazialmorphologische Studien in den Gebirgen der Britischen Inseln. Berlin. Geograph. Arbeiten, Heft 6 .

The orientation of block material in certain species of flow earth. Geos. Ann., 31, pp. 335-34\%. 
MAARLEVELD, G.C., 1956. Sur les sediments periglaciaires en Hollande: formes et phenomenes. Biul. Periglac., 4, pp. 73-82.

MANLEY, G., 1949.

The snowline in Britain. Geog. Ann. 31, pp. 179-193.

, 1951.

The range of variation of the British

Climate. Geos. Journ., 117, pp. 43-68.

, 1953.

Climatic variation. Roy. Met. Soc. Quart. Journ., 79, pp. $185-\overline{209}$.

MARECHAL, R., \& MAARLEVELD? G.C., 1955. L'extension des phenomenes periglaciaires en Belgique et aux Pays-Bas. Meded. v. d. Geol. Sticht., No. 8, pp. 77-86.

MCBURNEY, C.B.M., \& HEY, R.W., 1955. Prehistory and Pleistocene geology in Cyrenaican Libya. Cambridge.

MicCALL, J., \& GOODLET, G.A., 1952. Indicator stones from the drift of South Midlothian and Peebles. Trans. Edin. Geol. Soc., 14, pp. 401-408.

INEINARDUS, W. , 1912.

Beobachtung uber Detritussortierung und Strukturbsden auf spitzbergen. Gese11. f. Erdkunde $z \cdot$ Berlin, Zeitsch. №.4, pp. $250-259$.

METCALFE, E.G., 1950.

The ecology of the Cairngorms. Part 2. The mountain callunetum. Rourn. Ecol., 38 , pp. 46-74.

NILLER, H., 1870. Edinburgh and its neighbourhood, geological and historical. Edinburgh.

MILLER, R., COMION, R., \& GAIIOWAY, R.W., 1954. Stone stripes and other surface features of Tinto Hill. Geog. Journ., 120, pp. 216-219.

MORAWETZ, S., 1955. Zur Frage der eiszeitlichen Temperaturniederung. Mitt. d. Geograph. Gesell. Wien, 97, pp. 192-201.

MORRIS, D.B., 1892. The raised beaches of the Forth Valley. Trans. Stirling Field Ulub \& Nat. Hist. Soc., 15, pp. 18-48.

MORTENSEN, H., 1952.

Heutige Firnrickgang und Eiszeitklima. Erdkunde, 6 , pp. 145-160. 
, 1956. Die horizontale Temperaturschichtung in der Wurmeiszeit. Proc. 8th Gen. Ass. \& 17th Int. Cong., I.G.U., Washington I952 pp. $363-365$.

MUIR, J.W., 1956.

NEEF, E., 1955.

OGILVIE, A.G., 1923.

PAIMER, J., 1956.
The soils of the country round Jedburgh and Morebattle. Mem. Soil Surv. Great Britain. Sheets $\overline{17}$ and 18 .

Zur Genese des Formenbildes der Rumpfgebirge. Pett. Geog. Mitt., 99, pp. $183-192$.

The physiography of the Moray Firth Coast. Trans. Roy. Soc., Edin., 53, pp. $377-404$.

Tor formation at the bridestones in northeast Yorkshire and its significance to problems of valley-side development and regional glaciation. Prans. \& Papers of Inst. of British Geographers, №. 22,

BANZER, W., 1928. riden. Zeit. f. Geomorph., 3, pp. 169 203.

PARIZEK, E.J., \& WOODRUFF, J.F., 1957. Mass wasting and the deformation of trees. Amer. Journ. Sci., 255, pp. 63-70.

PATERSON, T.T., 1940. The effects of frost action and solifluxion around Baffin Bay and in the Cambrige district. Quart. Journ. Geol. Soc. London, 96, pp. 99-130.

PEACH, B.N., HORNE, J., WOODWARD, H.B., CLOUGH, C.T., HARKER, A., \& WEDD, C.B., 1910. The geology of Glenelg, Lochalsh and South-East part of Skye. Mem. Geol. Surv. Scotland, Explanation of sheet 71.

PEACH, B.N., HORNE, J., GUNN, W., CLOUGH, C.T., GREGNLY, E., HINXMANN, L.W., CRAMPTON, C.B., \& ANDERSON, E.M., 1912. The geology of Ben Wyvis, Cairn Chuinneag, Inchbae, and the surrounding country. Mem. Geol. Surv. Scotland. Explanation of sheet 93.

PEACH, B.N., HORNE, J., HINXIMAN, L.W., CRAMPTON, C.B., ANDERSON, E.N., \& CARRUTHERS, R.G., 1913a. The geology of Central Ross-shire. Mem. Geol. Surv. Scotland. Explanation of sheet 82 . 
PEACH, B.N., HORVE, J., GUNN, W., CLOUGH, C.T., \& GREEVLY, E., with contributions by HINXMAN, I.W., BOCOCK, T.I., \& CRAMPTON, C.B., 1913b. The geology of the Fannich Nountains and the country around Upper Loch Maree and Strath Broom. Mem. Geol. Surv. Scotland. Explanation of sheet92.

PEARSALI, W.H., 1950. Mountains and Moorlands. Collins, London.

PELTIER, L.C., 1950.

The geographic cutle in periglacial regions as it is related to climatic geomorphology. Ann. Ass. Am. Geog. 牛, pp. $214-236$.

PHEMISTER, J.C., \& SIMPSON, S., 1949. Pleistocene deep weathering in North-East Scotland. Nature, 164, pp. 318-319.

PIERZCHALKO, L., 1956. Periglacial phenomena in Northern Poland. Biul Periglac., 4, pp. 415-427.

POSER, H., 1936.

Talstudien aus Westspitzbergen und Ostgronland. Zeit. f. Gletscherk., 24, pp. 43-98.

1948

Boden und Klimaverhaltnisse im Mittelund Westeuropa whrend der Wurmeiszeit. Erdkunde, 2 , pp. 53-68.

, \& HOVERMANN, J., 1951. Untersuchnung zur Pleistozanen Harz Vergletscherung. Abh. Braunsch. Wiss. Gese11., 3 , pp. 61-115.

, \& MULLER, T., 1951. Studien an den assymetrischen THlern des Niederbayerischen Hitgelandes. Nachr. Akad. Wiss. Gott. Matth. Phys. KI.,

PULILAN, R.A., 1954.

The geomorphology of Mid-Wharfedale with special reference to periglaciation. M.Sc. Thesis, University of Birmingham. (Unpublished).

READ, H.H., 1923.

The geology of the country round Banff, Huntly and Turriff. Mem. Geol. Surv. Scotland. Explanation of sheets 86 and 96.

RICHARDSON, R., 1874.

Notice of a section in the building excavations at Tynecastle, West End, Edinburgh. Trans. Edin. Geol. Soc., 2, pp. 358-36ф. 
RICHEY, J.E., ANDERSON, E.M., MacGREGOR, A.G., with contributions from BAILEY, E.B., WILSON, G.V., BURNETT, G.A., \& EYLES, V.A., 1930 . The geology of North Ayrshire. Mem. Geol: Surv. Scotland. Explanation of

ROBERTSON, T.D., \& HALDANE, D., 1937. The economic geology of the Central Coalfield. Area I. Kilsyth and Kirkintilloch. Mem. Geol. Surv. Scotland.

ROZYCKI, S.Z., 1957. Zones du modele et phenomenes periglaciaires de lat Terre de Torell (Spitsbergen). Biul. Periglc., 5, pp. 187-222.

SAVIGEAR, R.A.G., 1952. Some observations on slope development in South Wales. Inst. Brit. Geog., Trans. \& Papers, No. 18, pp. 31-5i.

SCHMID, J., 1955.

Der Bodenfrost als morphologischer Faktor. Huthig Verlag, Heideloerg.

SCHULTZ, H., 1956.

Der Geschiebedecksand als spHtglaziale Wanderschuttdecke im Brandenburgischen Alt- und Jungmorlnengebiet. Pet. Geog. Mitt., 100, pp. 16-28.

SHARP, R.P., 1942.

Wudflow levees. Journ. Geomorph., $\underline{5}$, pp. 222-227.

SHARPE, C.F.S., 1938.

Landslides and related phenomena. Columbia Geomorphic Studies, No. 2. Colurnbia University Press, New York.

SIBRAVA, V., \& KROUTILIK, V., 1957 Periglacial phenomena in the region of Hlucin and Opava. Biul. Periglac., $5, \mathrm{pp} .241-252$.

SIMPSON, J.B., 1932.

1933.

SIMPSON, S., 1948.

SMITH, J., 1839.
Stone-polygons on Scottish mountains. Scott. Geog. Mag., 48, pp. 37-38.

The late-glacial Readvance moraines of the Highland border, west of the River Tay. Trans. Roy. Soc. Edin., 57, pp. 633-646.

The glacial deposits of Tullos and the Bay of Nigg, Aberdeen. Trans. Roy. Soc. Edin., 61, pp. 687-698.

On the last changes in the relative levels of the land and sea in the British Isles. Mem. Wern. Nat. Hist. Soc., 8, pp. 49-113. 
SMITH, J., 1898.

SPENCE, D.H.N., 1957.

STEEGER, W., 1944.

SYNGE, F.M., 1953.

, 1956.

, 1957.

TABER, S., 1930.

, 1943.

TAYLOR, A., 1874.

Te PUNGA, M.T., 1956.

THOMPSON, H.R., 1950.

THORNBURY, W.D., 1954.

TIVY, J., 1955.

TRICART, J., 1949.
The drift or glacial deposits of Ayrshire. Trans. Glas. Geol. Soc, ll, Supplement.

Studies on the vegetation of Shetland. I. The serpentine debris vegetation.in Unst. Journ. Ecol., 45, pp. 917-945.

Diluviale Bodenfrosterscheinungen am Niederrhein. Geol. Rund., 34, pp. 520-538.

Retreat stages of the last ice-sheet in the British Isles. Irish Geog., 2, pp. 168-171.

The glaciation of North-East Scotland. Scott. Geog. Mag., 72, pp. 129-143.

Personal communication.

The mechanics of forst heaving. Journ. of Geol., 38, pp. 303-317.

Pernennially frozen ground in Alaska, its origin and history. Geol. Soc. Am., Bull., 54, pp. 1433-3548.

On unpublished sections illustrating the superificial geology of the Northern district of Edinburgh. Trans. Edin. Geol. Soc., 2, pp. 77-78.

Altiplanation terraces in southern England. Biul. Periglac. 4, pp. 331-333.

Some corries of North West Scotland. Proc. Geol. Assoc., 62, pp. 145-155.

Principles of Geomorphology. Wiley \& Sons, New York.

A study of the vegetation of hill grazings in .. selected areas of S. Scotland. Ph.D. Thesis, University of Edinburgh.

La partie orientale du Bassin de Paris. Etude Morphologique. S.E.D.E.S., 3 vol., Paris.

TRICART, J., n.d. (probably 1949). Cours de Geomorphologie. Deuxieme Partie. Geomorphologie Climatique. Fasgicule 1. Le modele des pays froids. 1 Le modele periglaciaire. 
1951. Le systeme d'erosion periglaciaire.

I'Information Geographique, 5, pp. 1-7.

, 1956. Etude experimentale du probleme de la gelivation. Biul. Periglac., 4, pp. 285-318.

, \&C CAILLeUX, A., n.d. Cours de Geomorphologie. Modele glaciaire et nival. C.D.J., Paris.

TROLL, C., 1944.

1947.

1948.

TWIDALE, C.R., 1956.

WAGER, L.R., 1953.

WASHBURN, A.L., 1947.

, 1956.
Strukturbdden un solifluktion. Geol. Rundschau, 34, pp. 545-694.

Die Formen der Solifluktion und die periglaziale Bodenabtragung. Erdkunde, I, pp. 4-6.

Der subnivale und periglaziale Zyklus der Denudation. Erdkunde, $\underline{2}$, pp. 1-21.

Vallons de gelivation dans le centre du Labrador. Rev. Geomorph. Dyn., 7, pp. 18-23.

The extent of glaciation in the Island of St. Kilda. Geol. Mag., pp. 177-181.

Recconnaissance geology of portions of Victoria Island and adjacent regions of Canada. Mem. AM. Geol. Soc., No. 22.

Classification of patterned ground and review of suggested origins. Geol. Soc. AM. Bul1., 67, pp. 823-865

WATT, A.S., \& JONES, E.W., 1948. The ecology of the Cairngorms. Part 1. The environment and the altitudinal zonation of the vegetation. Journ. Ecol., 36, pp. 283-304.

WEINBERGER, L., 1944. Frostspalten bei Leipzig. Geol. Rundschau, 34, pp. 539-544.

WILKINSON, S.B., et al., 1908. The geology of the country round Londonderry. Mem. Geol. Surv. Ireland.

WILIETI, H.C., 1950.

The general circulation at the last (WHrm) glacial maximum. Geog. ANN., 32, pp. 179189.

WILSON, G.V., et al., 1935. The geology of the Orkneys. Mem. Geol. Surv. Scotland. 
WRIGHT, H.E., 1957.

The late-glacial chronology of Europe - a discussion. Amer. Journ. Sci., 255, $\mathrm{pp} .447-460$.

ZEUNER, F.E., 1944. The Pleistocene Period. Its climate, chronology and faunal succession. The Ray Society, London. 
FIGURES. 


\section{Figure 1.}

Distribution of periglacial studies in the Brisish Isles.

(Based on FITZPATRICK, 1956a)

a- published up to 1955. b- in progress in 1955

1- Limit of Newer Drift.

2- Studies of fossil periglacial phenomena

3- Studies of contemporary periglacial phenomena. 


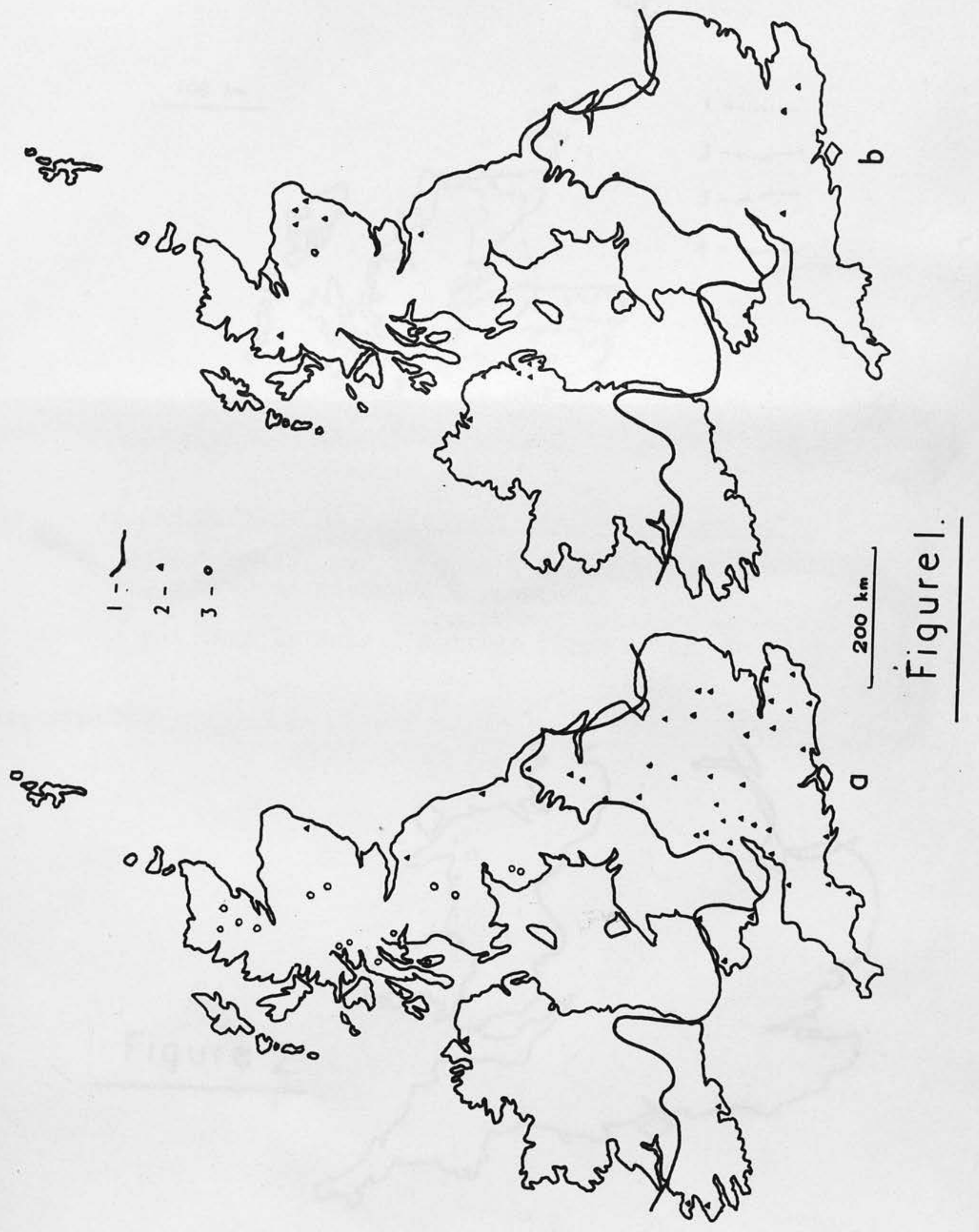




\section{Figure 2.}

Phases of the last glaciation in Great Britain.

1- Loch Lomond / Moor of Dinnett Readvance.

2- Perth Readvance / Aberdeen Readvance.

3- Scottish Readvance.

4- Newer Drift maximum extent of last ice sheet. 


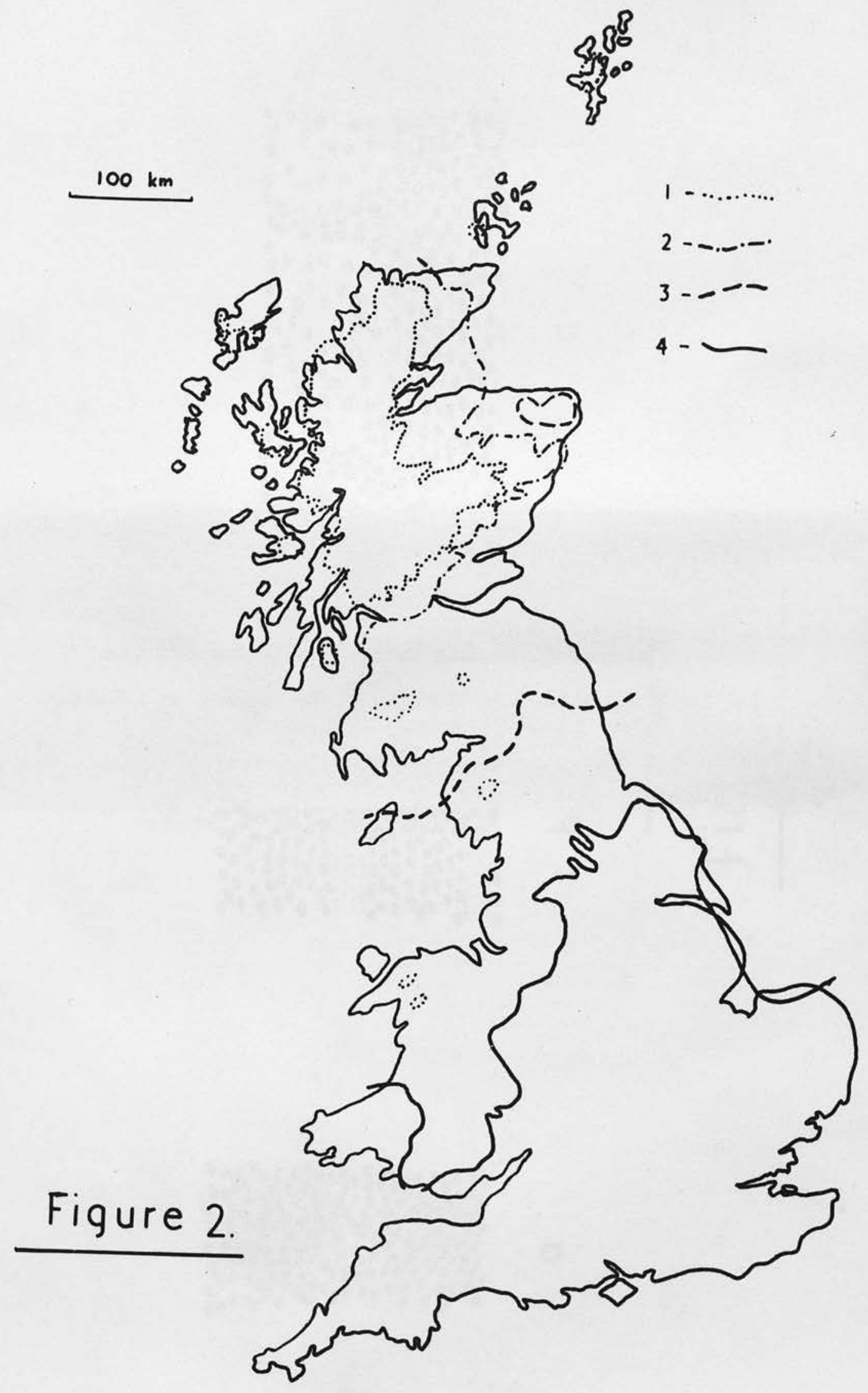




\section{Figure 3.}

Columns of erected stones in gravel.

a- in a fossil ice wedge. b- along a fault.

c- in free involutions. 

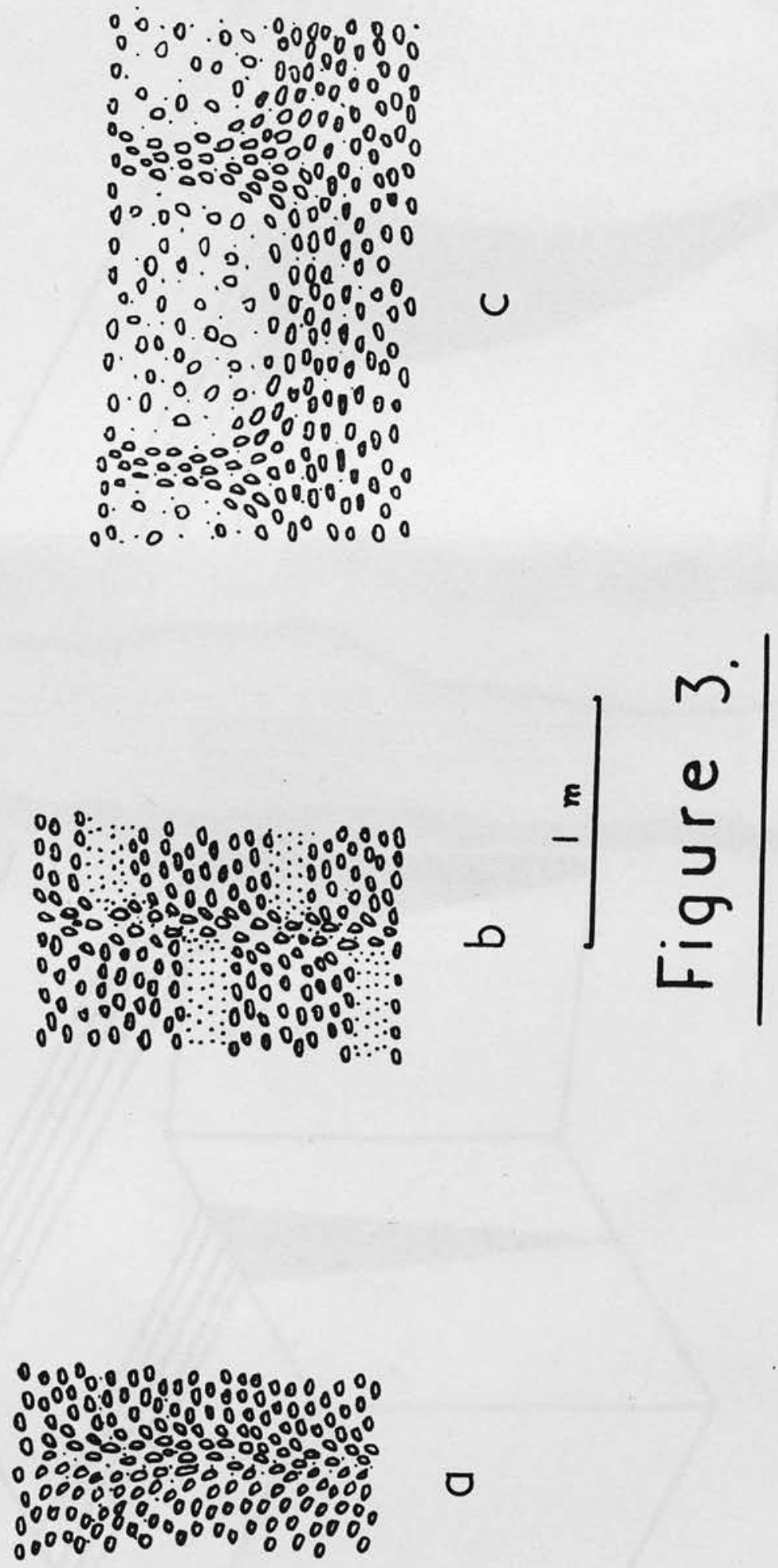
Figure 4.

Change in apparent form of wedge with variations in the angle of intersection by the face. 


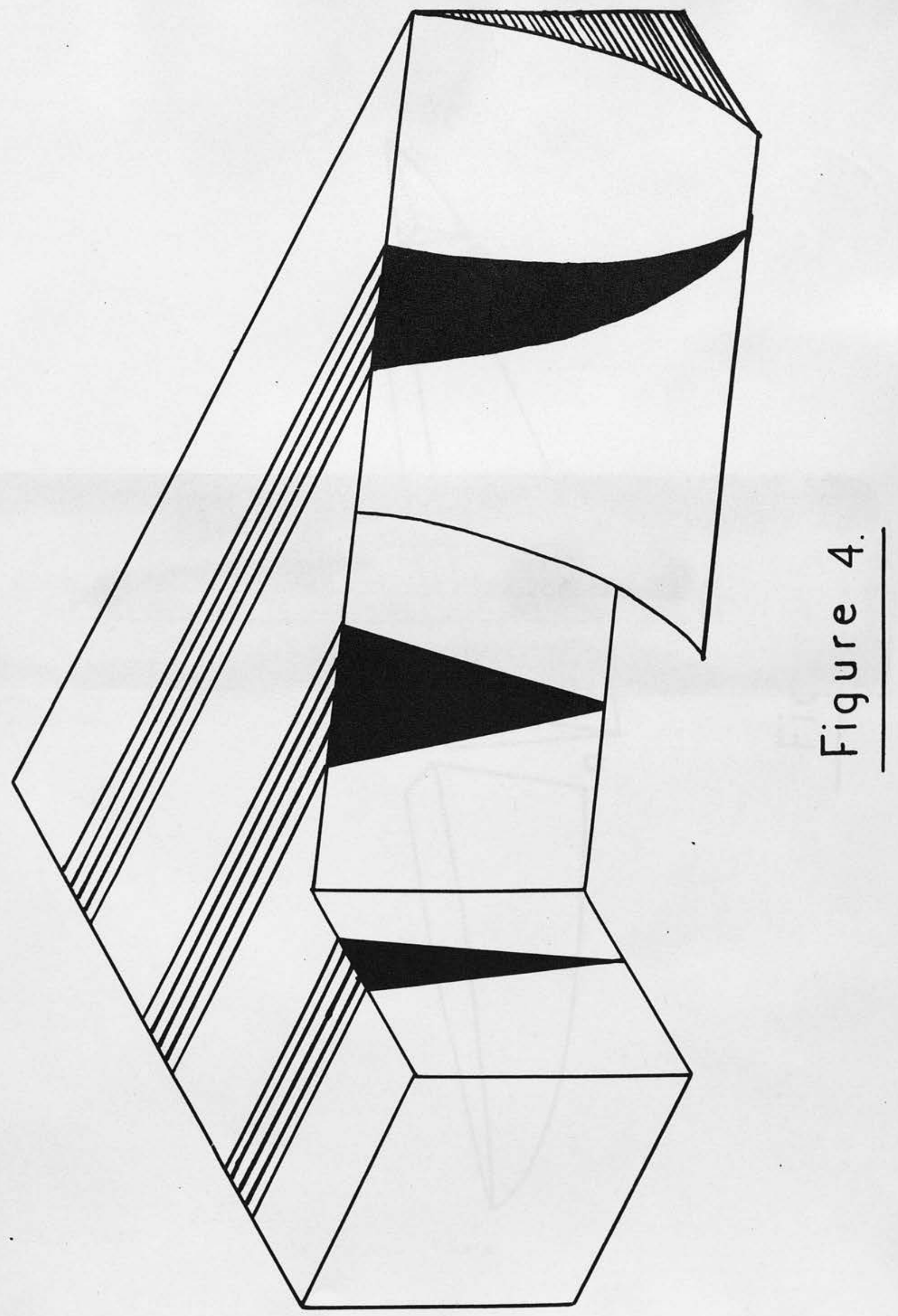




\section{Figure 5.}

Change in wedge form exposed with variation in point of section along the long-axis of the structure. 


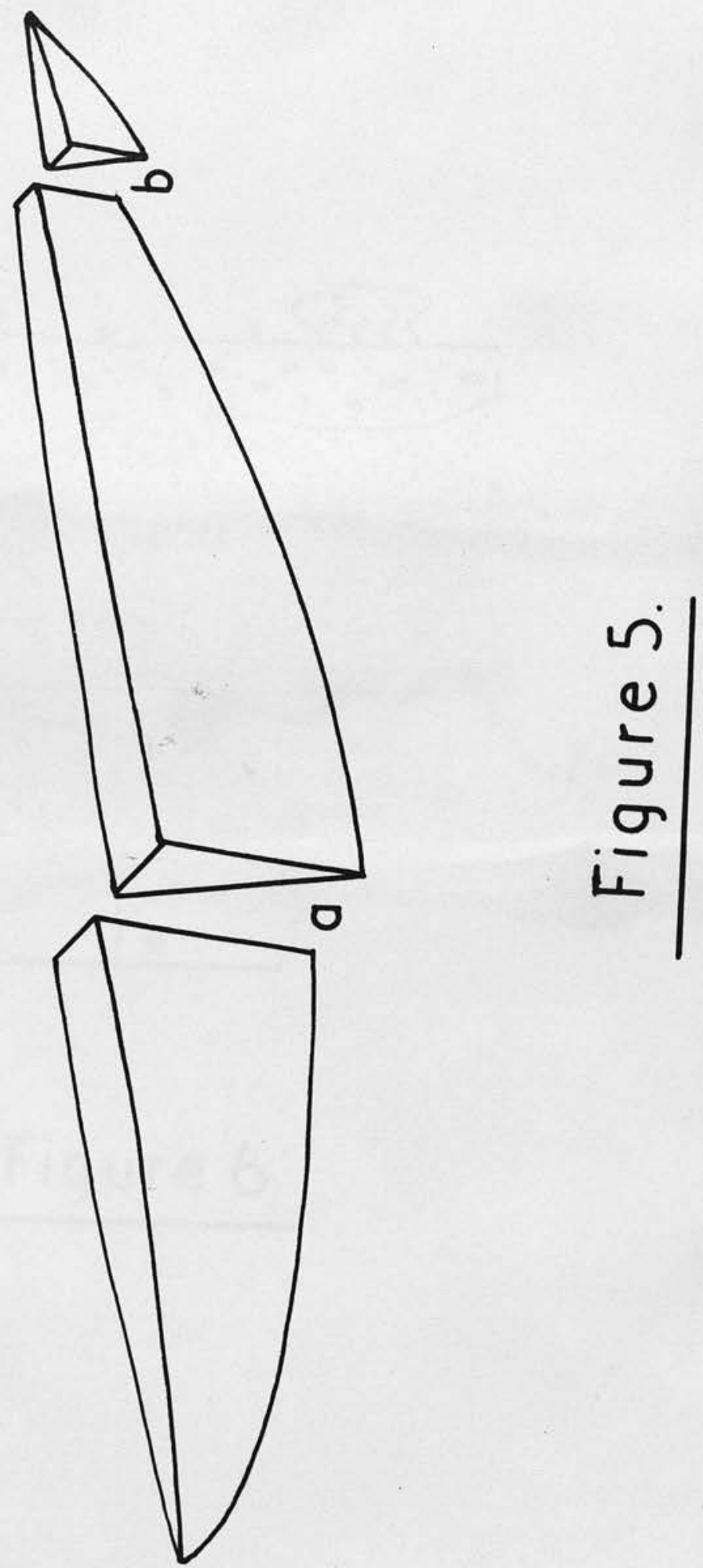




\section{Figure 6.}

Wedge in kame between Aviemore and Carrbirige.

1- modern soil profile in sand with stones.

2- current bêdded sand.

3- gravel.

4- sand with clay layers. 


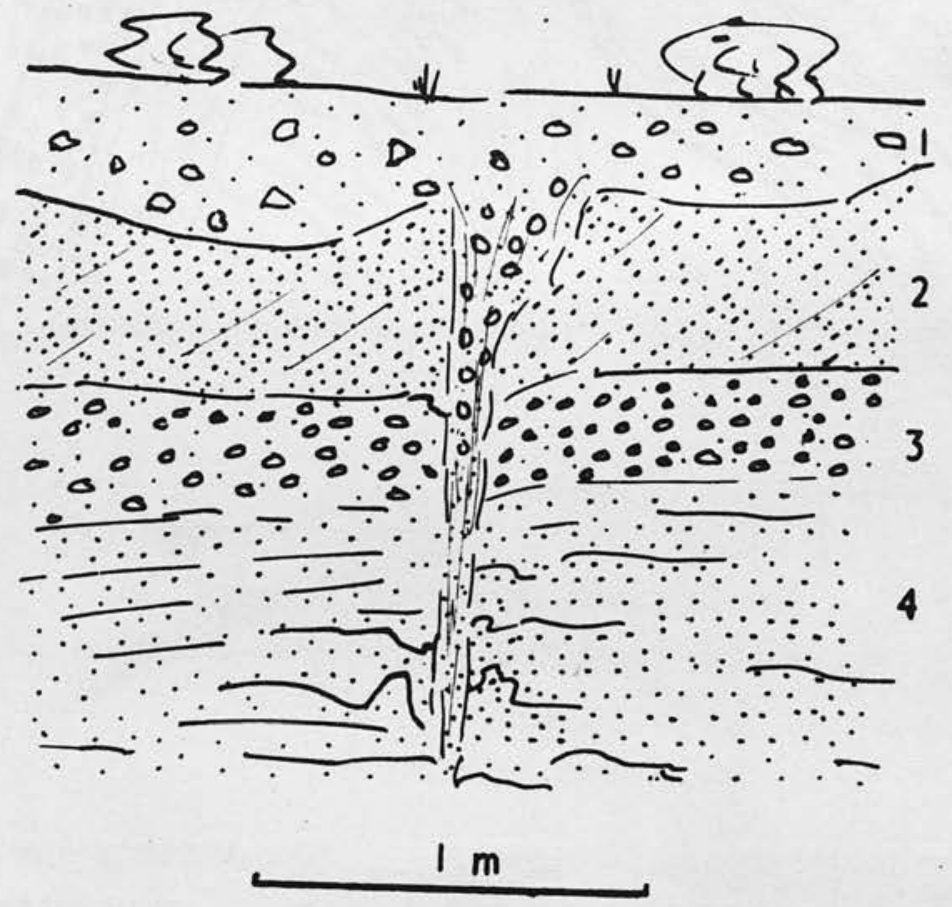

Figure 6. 


\section{Figure ?.}

Wedge in sandpit in river terrace just $E$ of Ellon, Aberdeenshire.

P.O.- preferred orientation of the longest horizontal axes of stones in the wedge.

1- well-bedded gravel.

2- well-bedded sand. 


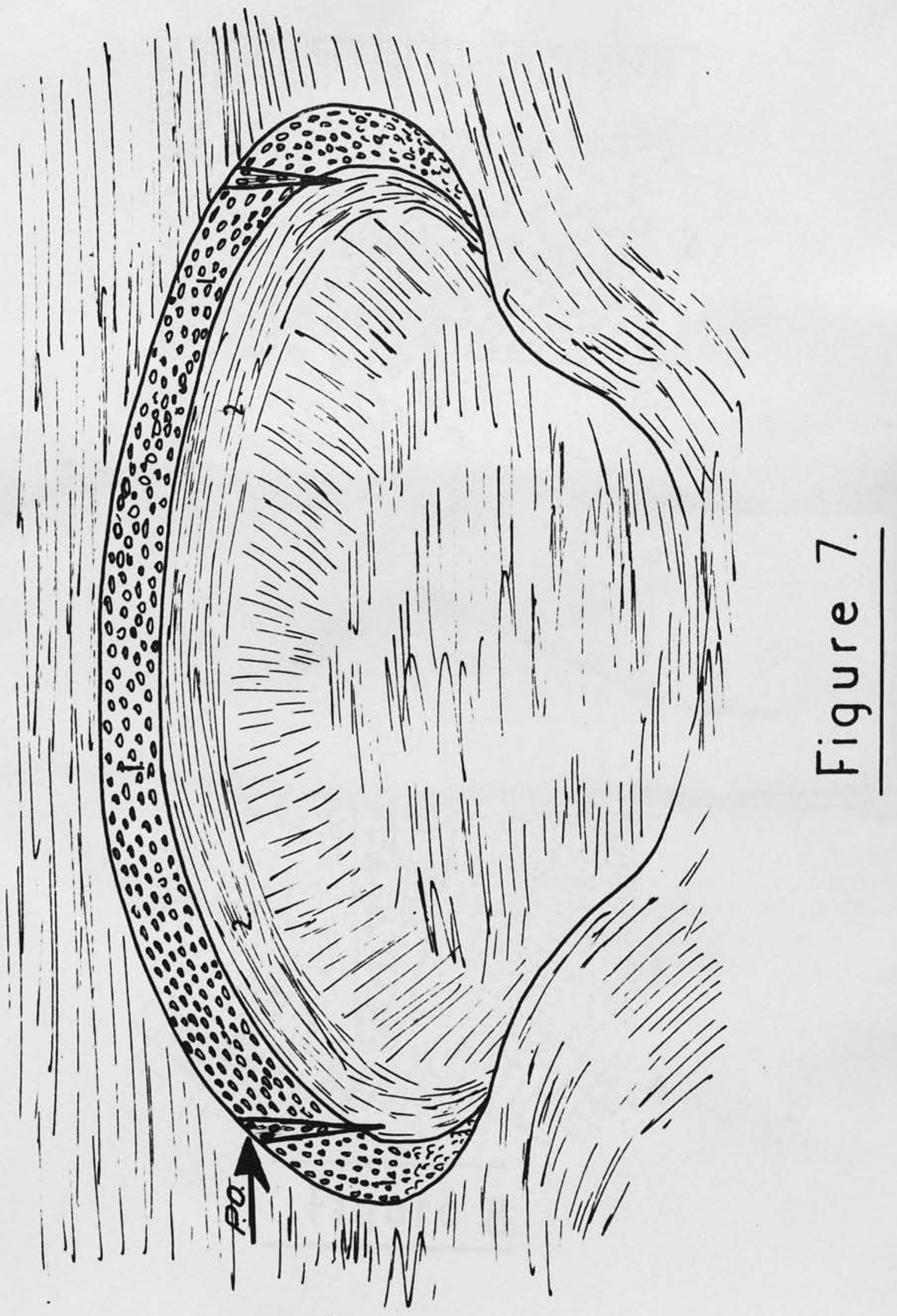


Figure 8.

Wedge at Edzell Golf Course.

1- present soil.

2- gravel.

3- sand with clay bands.

4- slumped amterial. 


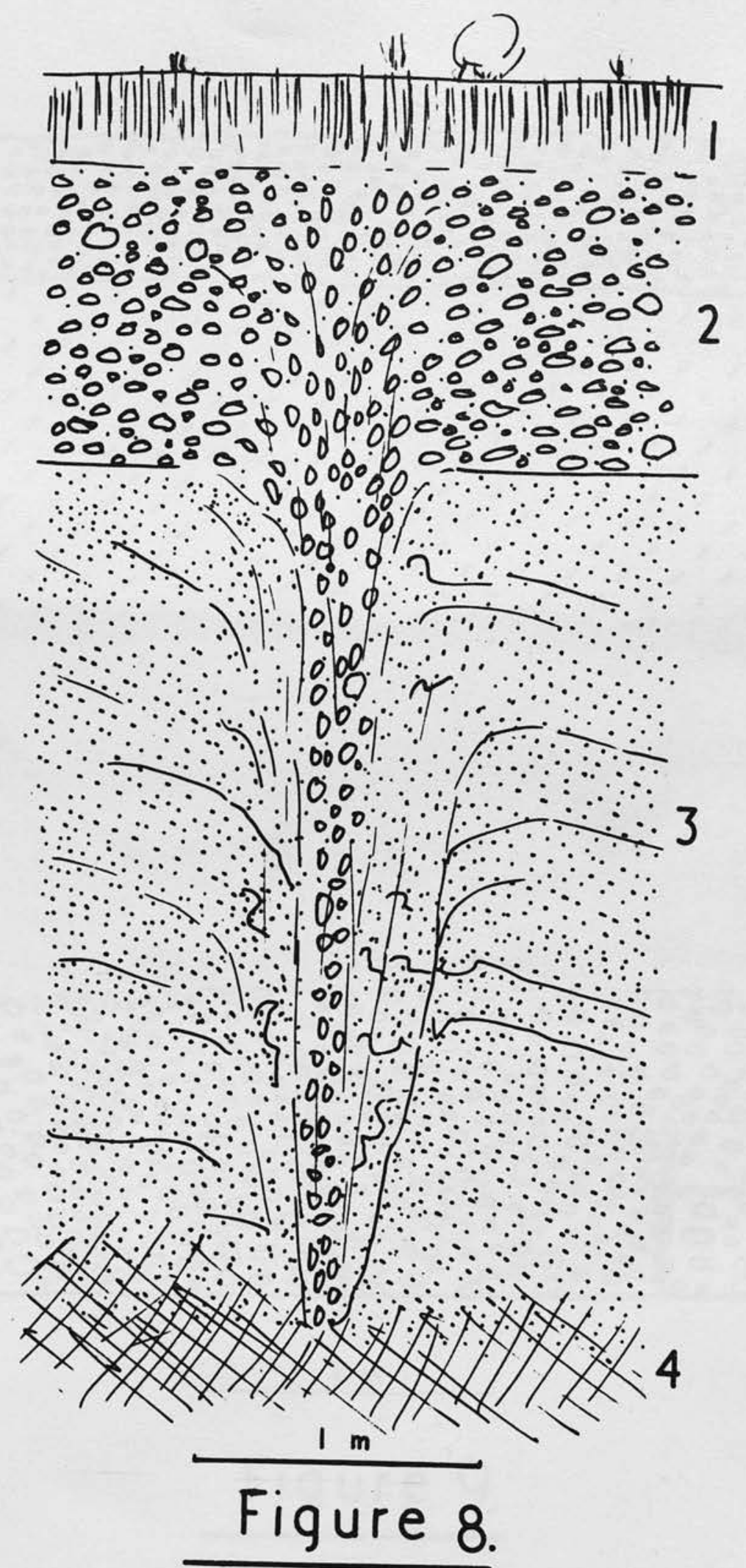




\section{Figure 9.}

Section exposing two wedges in gravel under till at Reston, Berwickshire.

1- coarse gravel.

2- till.

3- fine gravel. 


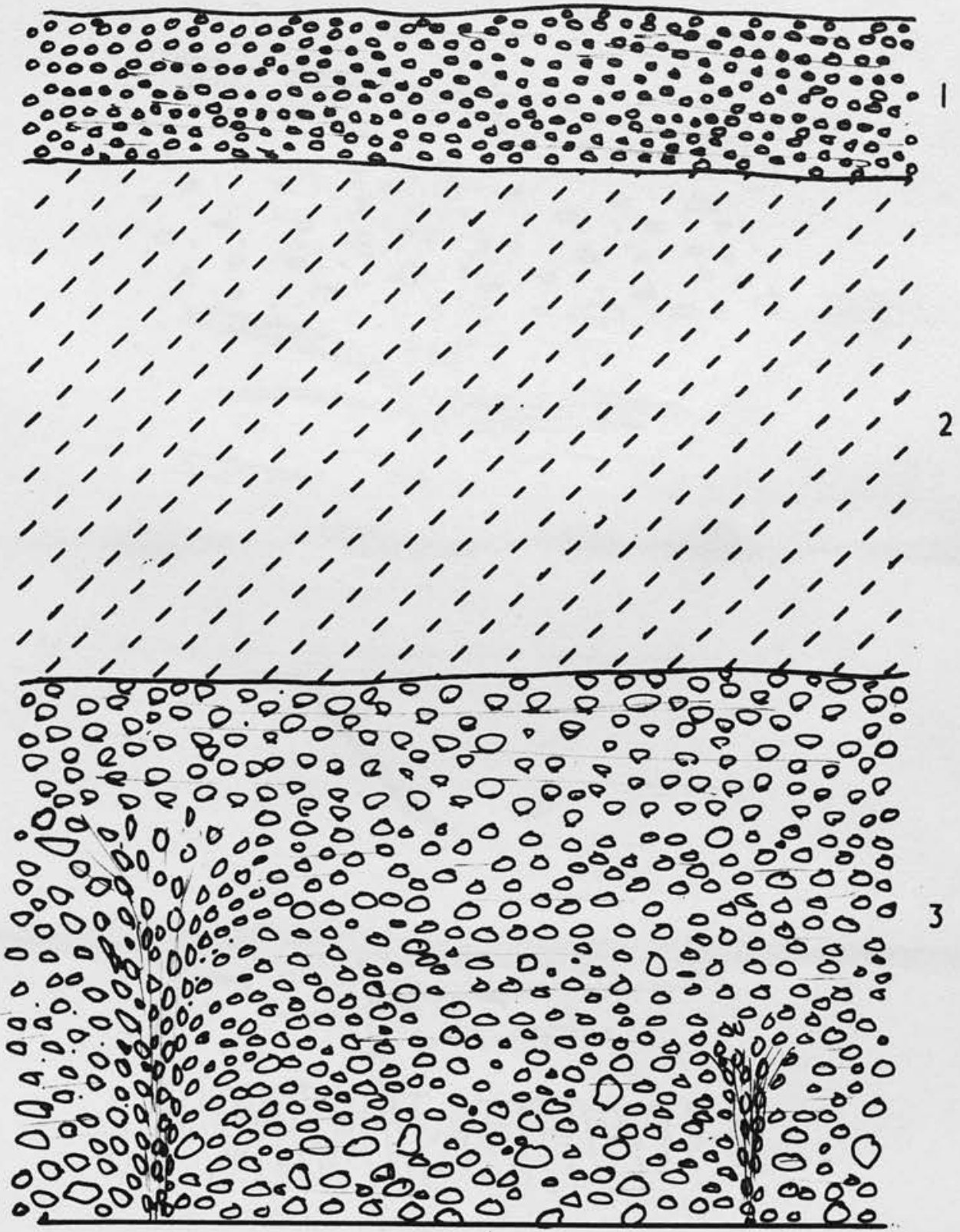

$2 m$

Figure 9. 


\section{Figure 10.}

Wedge in old sandpit at Bathgate.

1- present soil.

2- stony sand.

3- sand.

4- silty sand.

5- sand with chimy bands.

6- slumped material. 


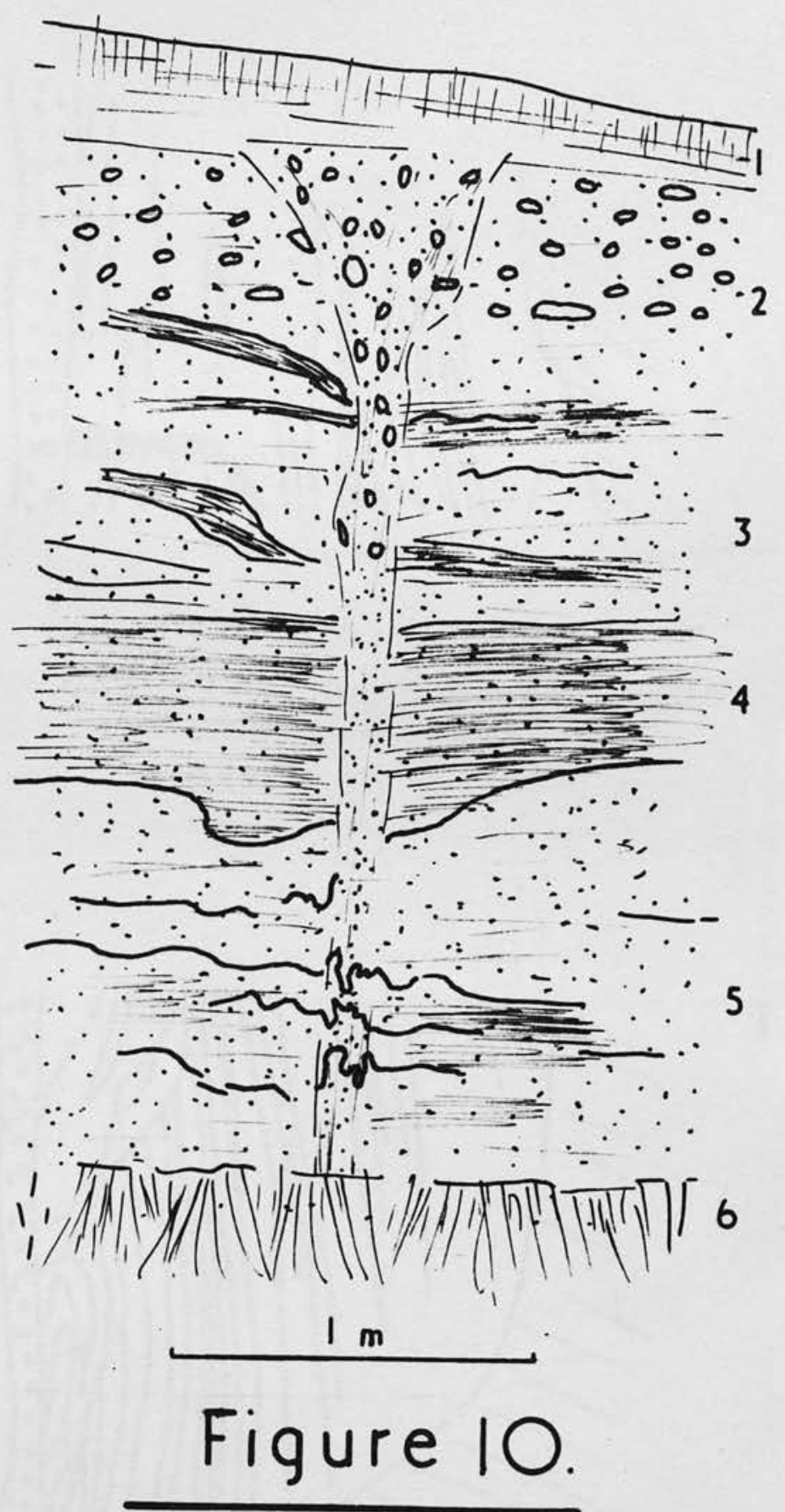


Figure 11.

"Washout" (?) in sands in Keir \& Cawdor No. 3 Pit, $1 \frac{1}{2} \mathrm{~km}$. $\mathrm{S}$ of Balmore, Kelvin Valley. $X-X$ - fossil ice vein. 


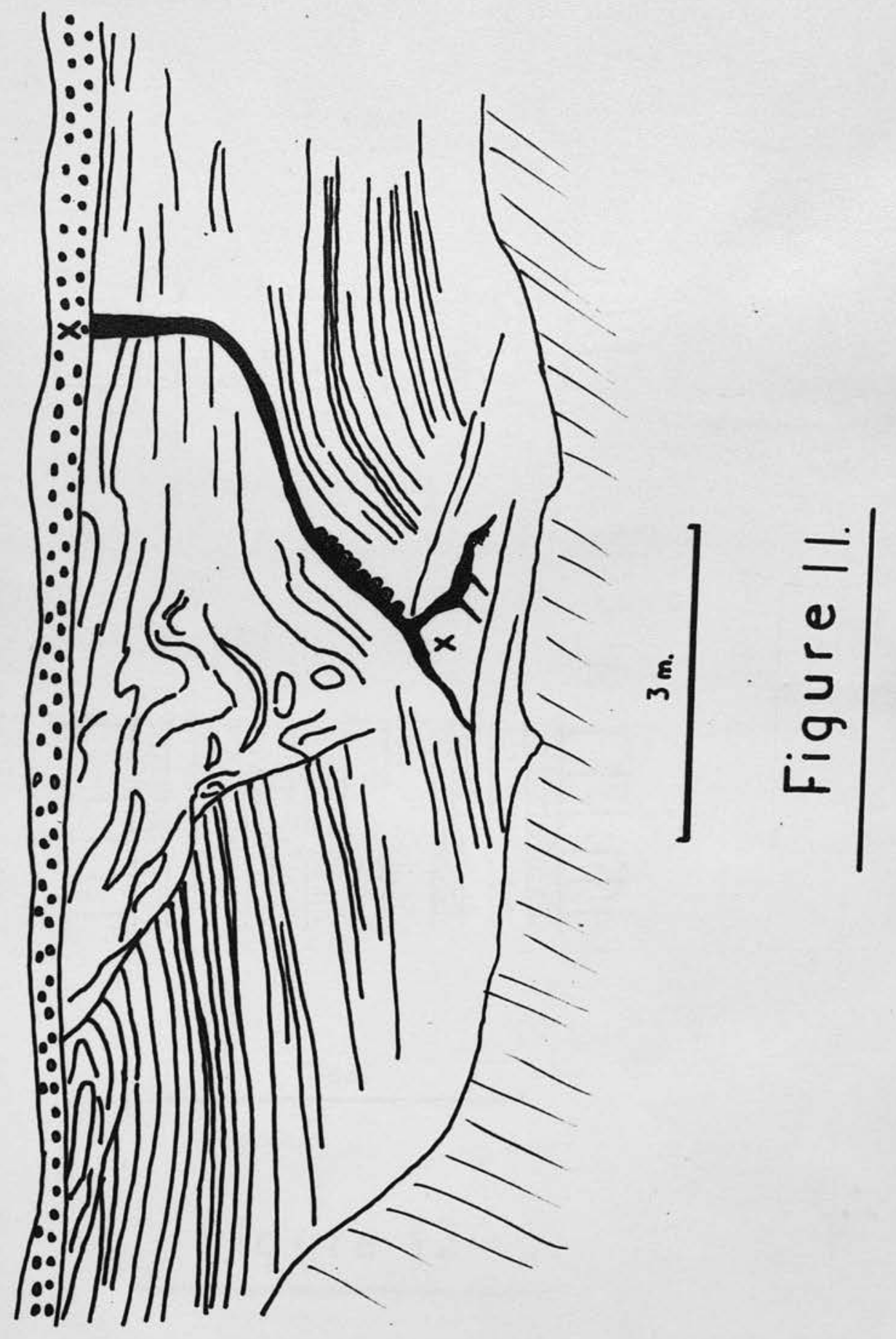


APP

Figure 12.

Section in fossil ice vein at Drumclog, Strathavon.

Coarse dotting - sand. Medium dotting - silt. Fine dotting - clay. 


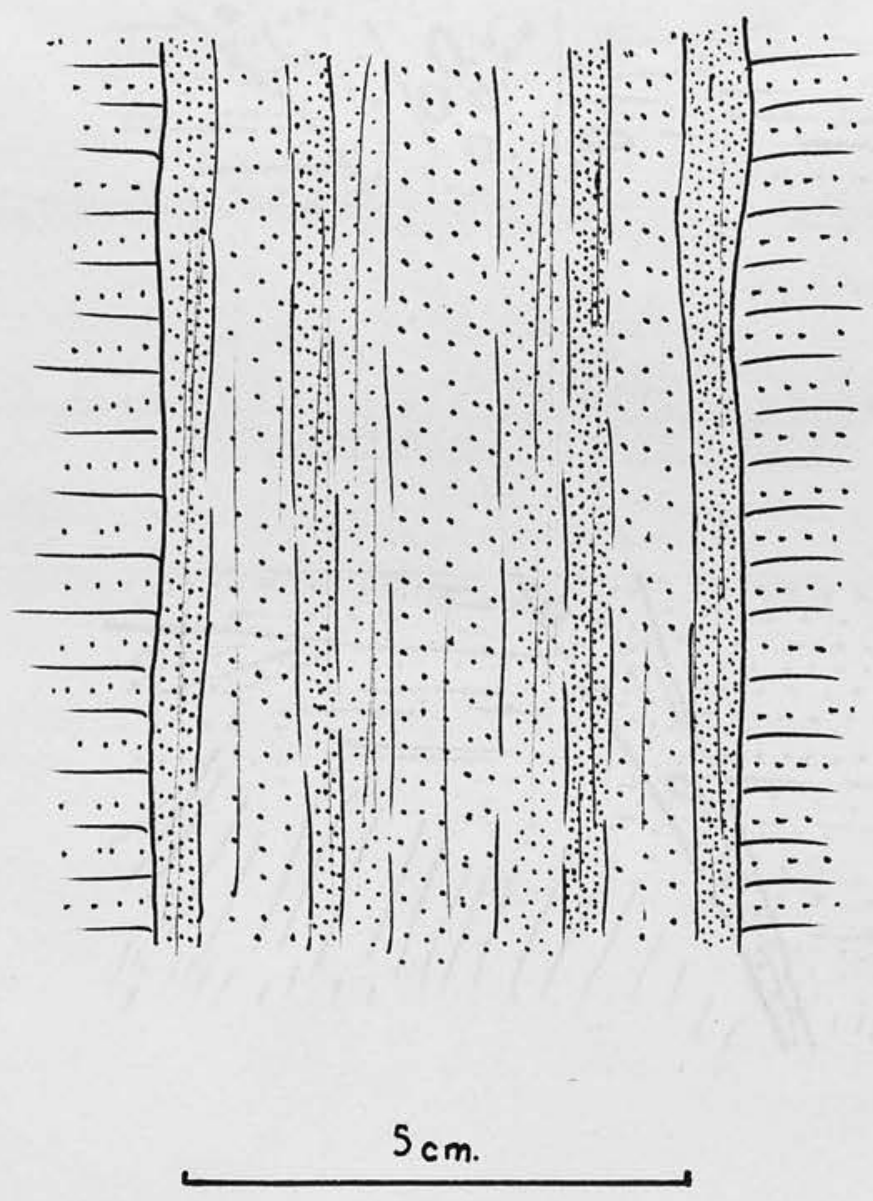

Figure 12. 
Figure 13.

Fossil ice wedge developed along a fault, I km. SW of Cadder, Lanarkshire. 


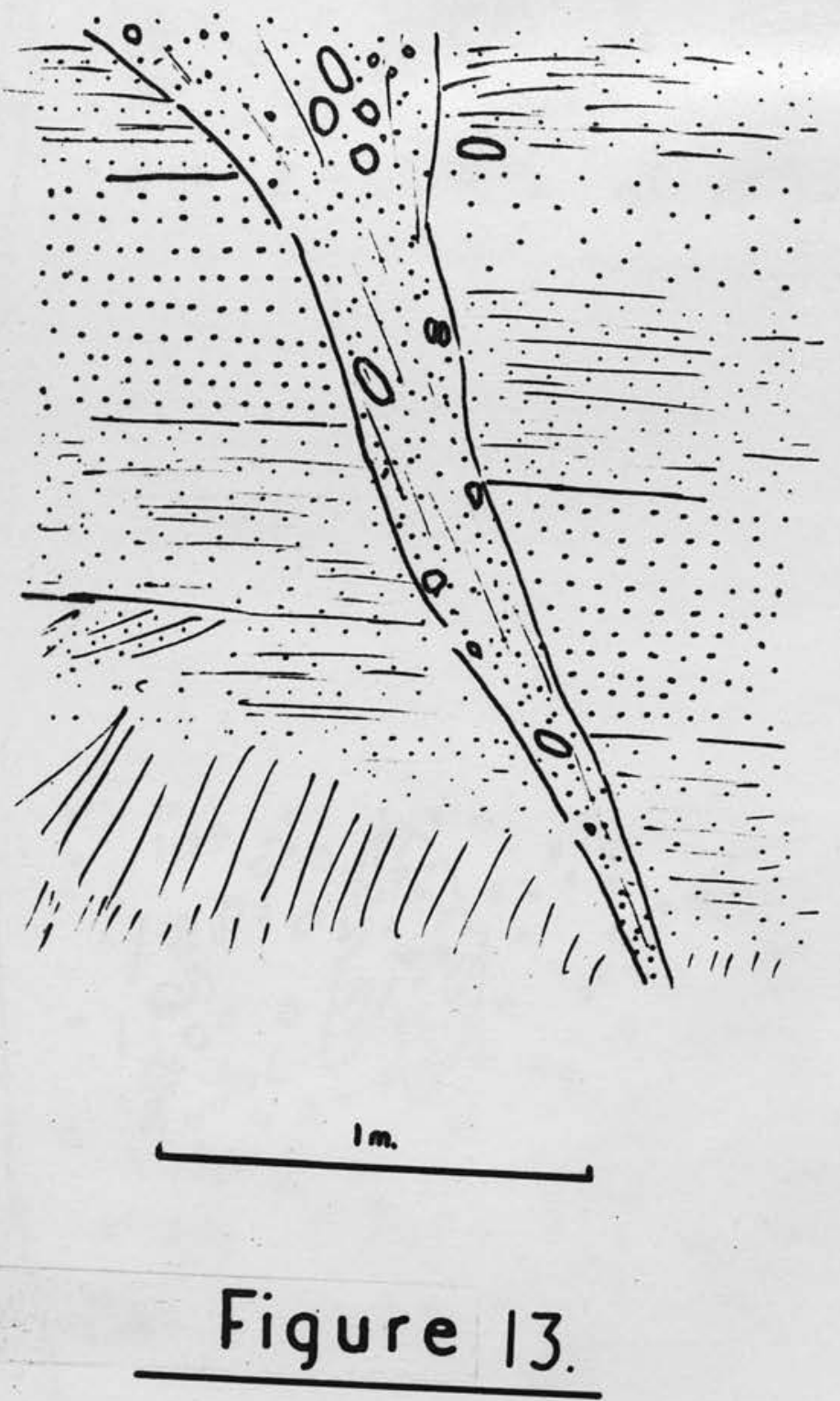




\section{Figure 14.}

Sketch of exposure in raised beach of kame terrace, $10 \mathrm{~km}$. SE of Newton Stewart.

1- sandy / silty material with some stones. 2- layer of very shattered and disturbed gravel.

3- gravel.

4- patches of contorted sands.

5- columns of erected stones.

6- slumped material. 

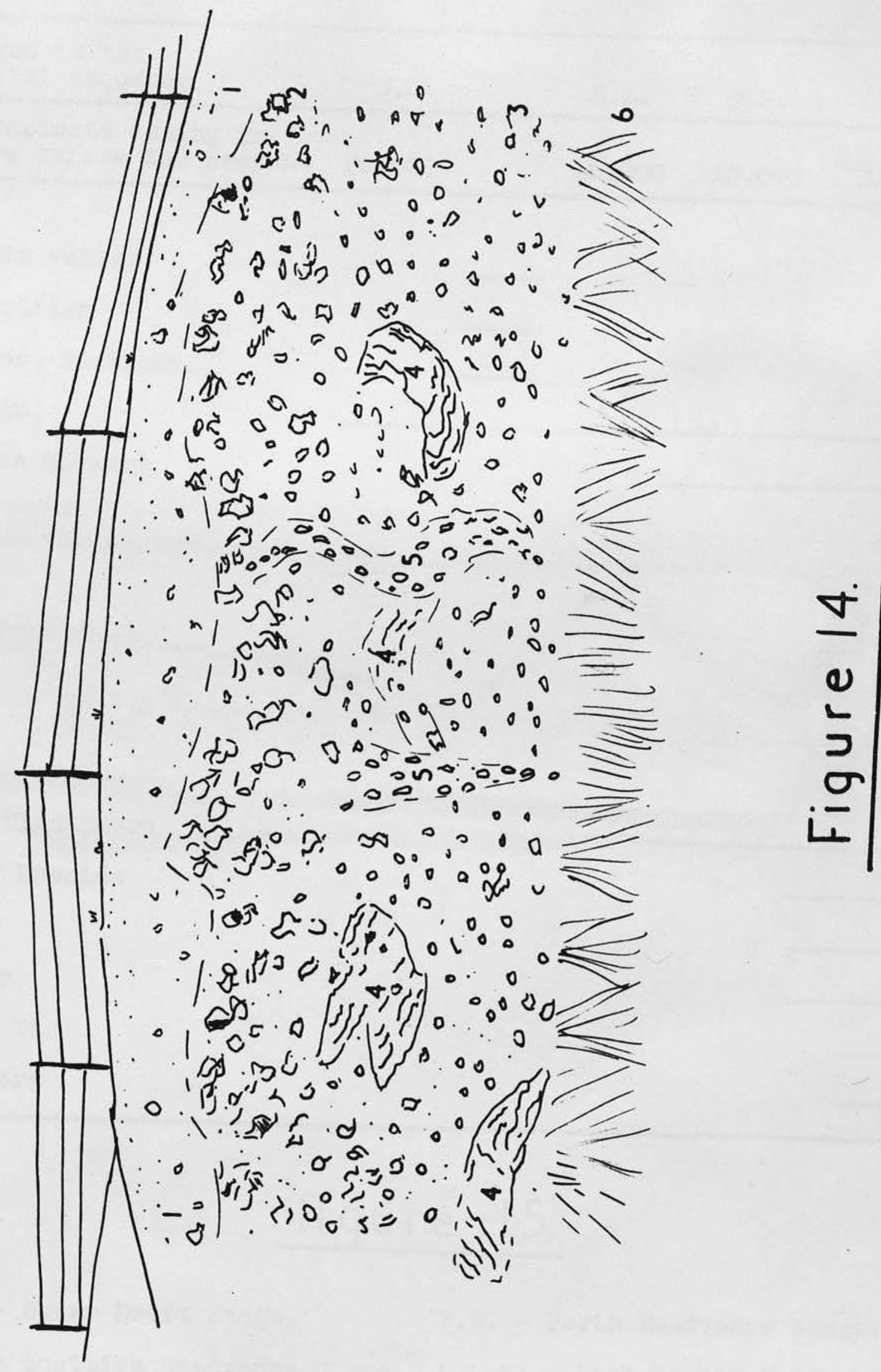
Figure 15.

Suggested dating of Scottish wedges.

N.B. The horizontal lines represent the period during which the wedges could have pormed. 
Stages in the

Glacial sequence

N.D.

S.R.

P.R.

L.L.R.

Approximate dating in

years before the present 20,000

$15,000 \quad 13,000$

103000

Kelvin Valley

Midlothian

Reston, Berwicks.

Buchan

Newton Stewart

Strathavon

Bathgate

Carstairs

Kincardine-on-Forth

Kinross

C, Starthmore

N.E. Strathmore

Lower Deeside

Elgin

Beauly

Ythan $Y$ th

Aviemore

\section{Figure 15.}

N.D. - Newer Drift Stage.

P.R. - Perth Readvance Stage.

S.R. - Scottish Readvance Stage. L.L.R. - Loch Lomond Readvance Stage. 
Figure 16.

Distribution of wedges in Scotland.

1- limits of Zone III readvance.

2- largest wedge exposed less than 2 metres deep.

3- largest wedge between 2 and 4 metres deep.

4- largest wedge over 4 metres deep.

5- wedges overlian by till. 


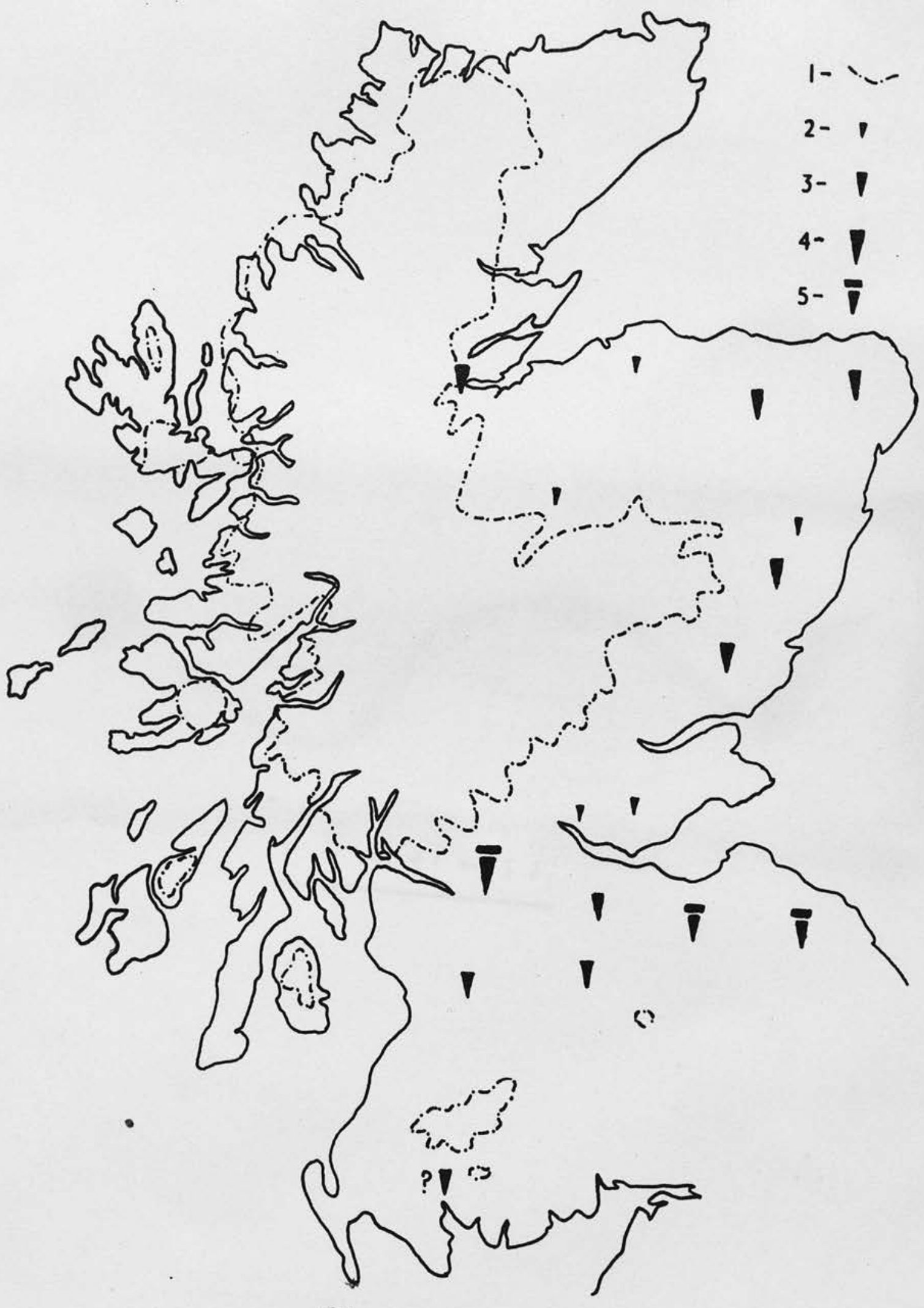

Figure 16. 


\section{Figure 17.}

Bound "pillar" involution in kame at Ladysbridge,

$3 \mathrm{~km}$. W of Banff, 2 metres

below the surface.

1- silt.

2- sand

3- czlay. 


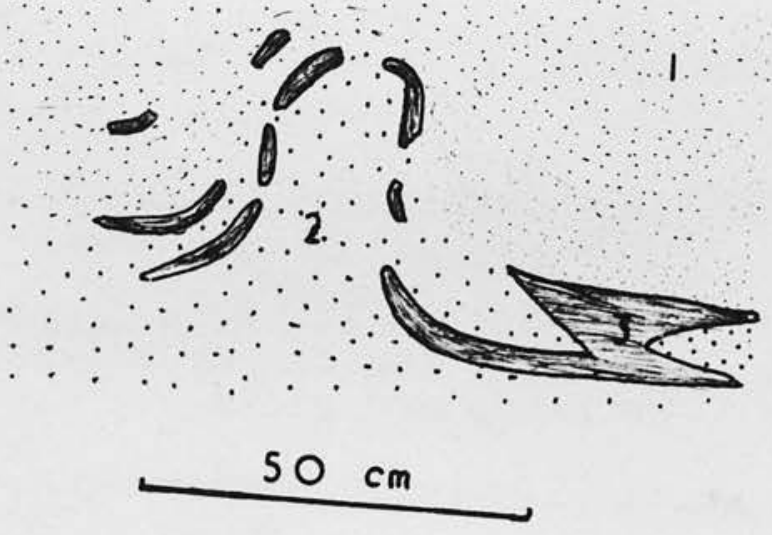

Figure 17. 


\section{Figure 18.}

Bound solifluction structures at Roehill, Aultmore, Banffshire.

1- stony solifluction deposit.

2- silty and clayey material.

3- sands and silts. 


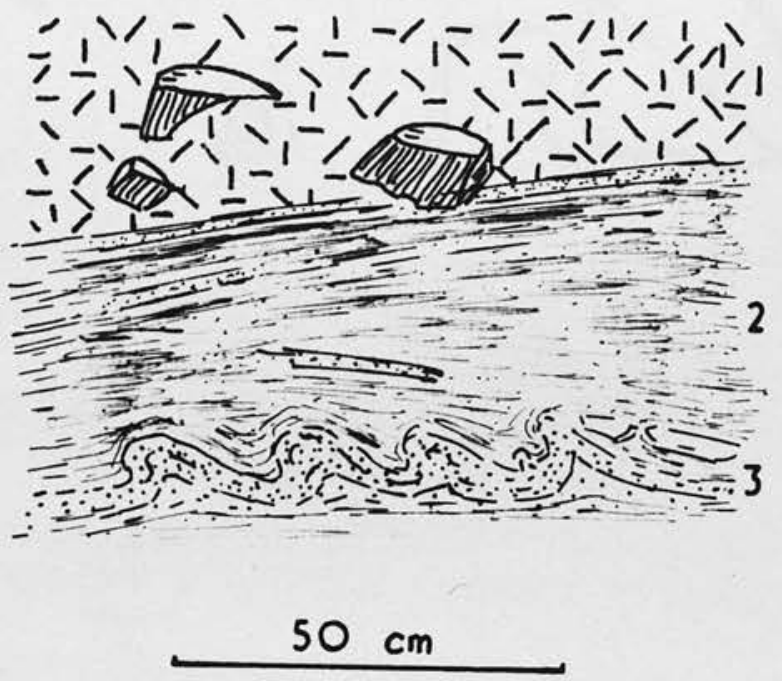

Figure 18. 


\section{Figure 19.}

Cryoturbation and solifluction at Braehead, New Pitsligo, Buchan, Aberdeenshire.

I- weathered and shattered rock still in situ.

2- displaced rock fragments forming a solifluction deposit.

3- quartz vein, broken and contorted.

4- small patches of contorted fine material.

N.B. cf. photograph 22 . 


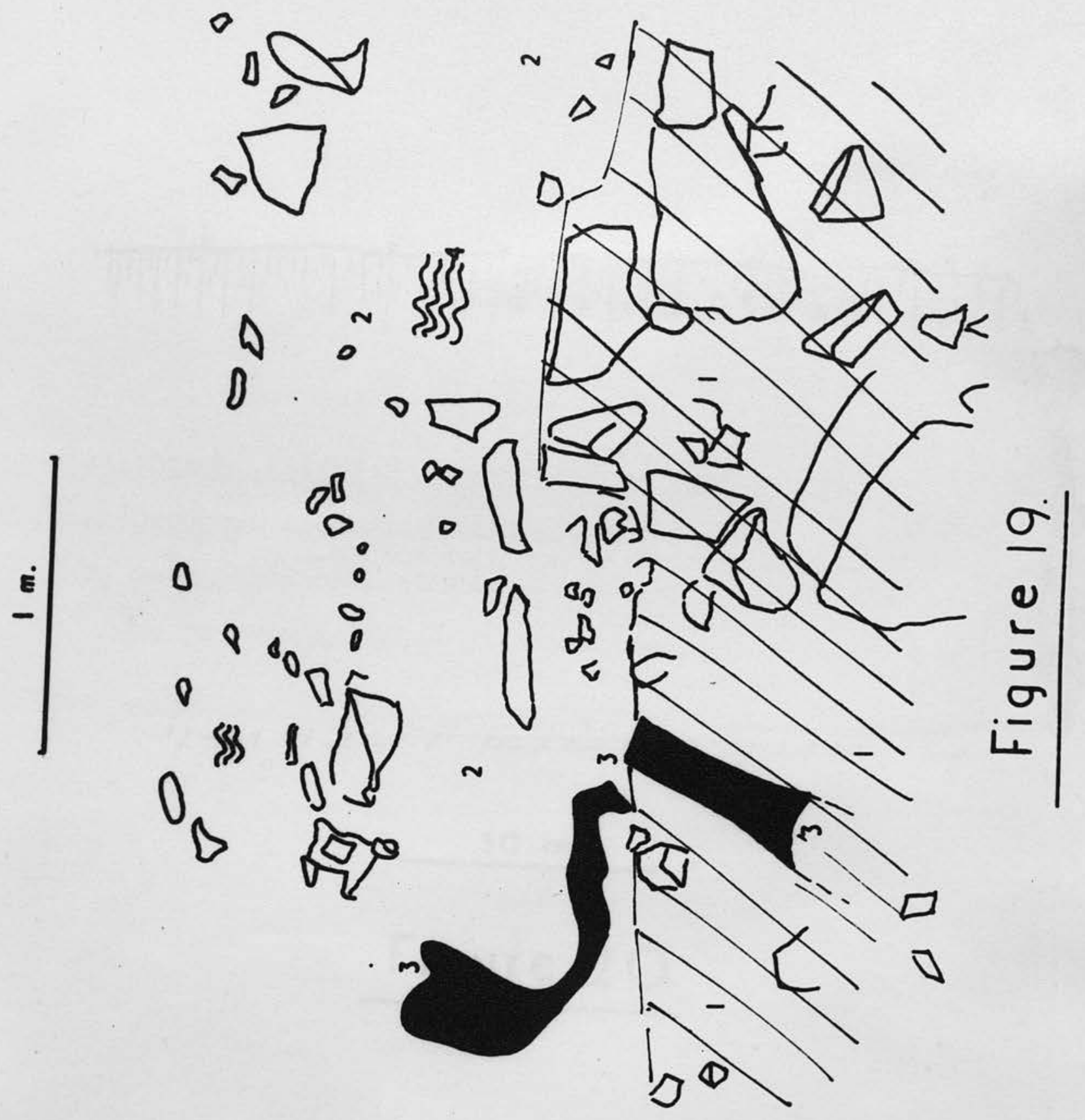




\section{Figure 20.}

Involutions at Gurgedykes, Methlick, Aberdeen.

I- soil and recently disturbed overburden.

2- pocket of angular stones.

3- fine sand derived from decomposition of the rock below.

4- coarse sand with a few angular stones.

5- weathered bedrock. 


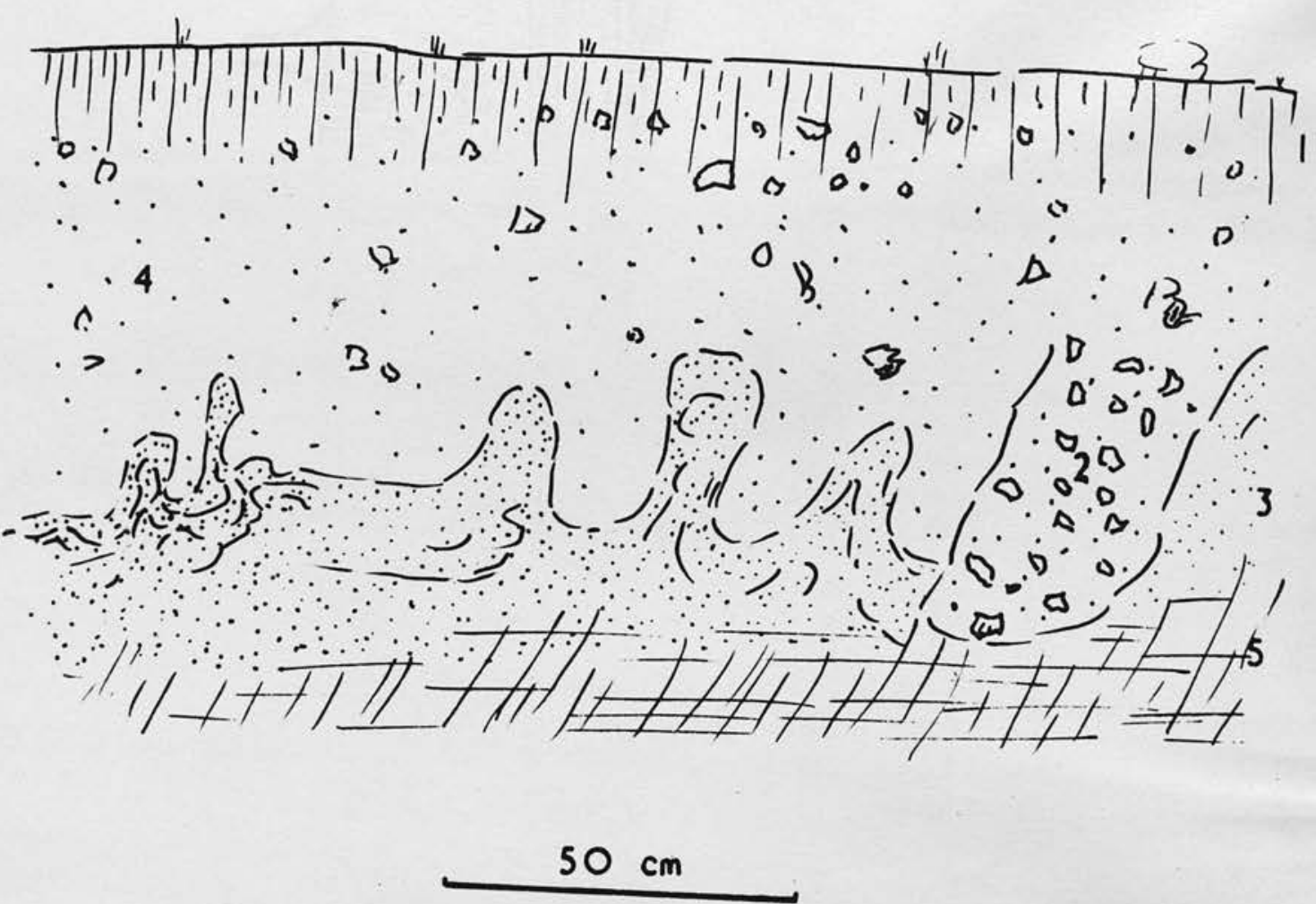

Figure 20. 


\section{Figure 21.}

Involutions on S bank of River North Esk at Gallery House, Northwaterbridge, Angus.

a- stone-filled pocket. b- contorted wisp of peat.

c- free involutions, sectioned stone rings or stone polygons.

1- soil.

2- fine gravel and coarse sand.

3- very fine, slippery clay:

4- till, some 10 metres thick, resting on Old Red Sandstone. 


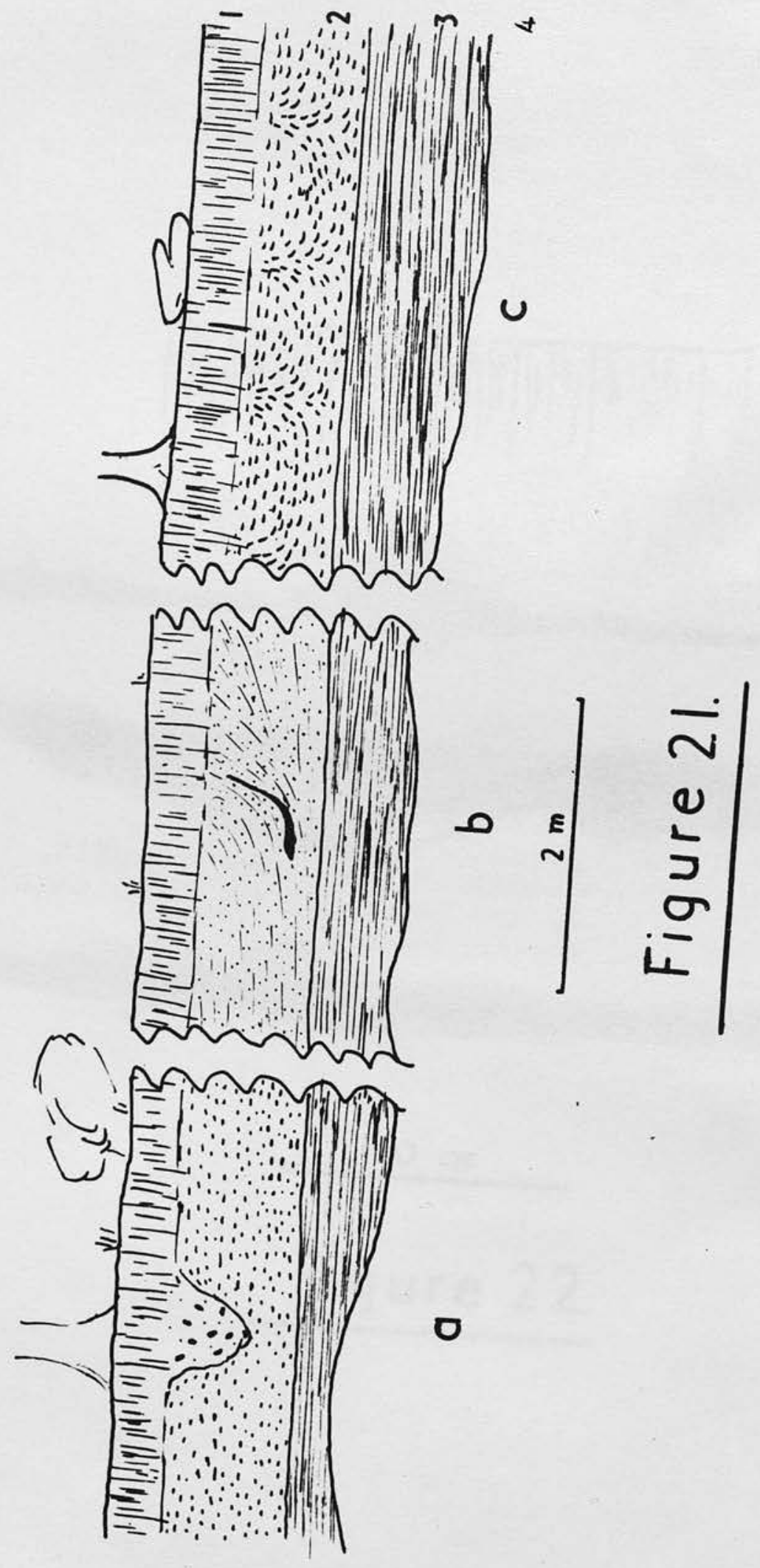




\section{Figure 22.}

Erected pobbles and wind-blown matexial (?) in a sandoit $3 \mathrm{~km}$. 5 of kinross.

1- soil.

2- gritty fine sand and silt.

3- erected layer of small pebbles.

4- pebbles in situ. 

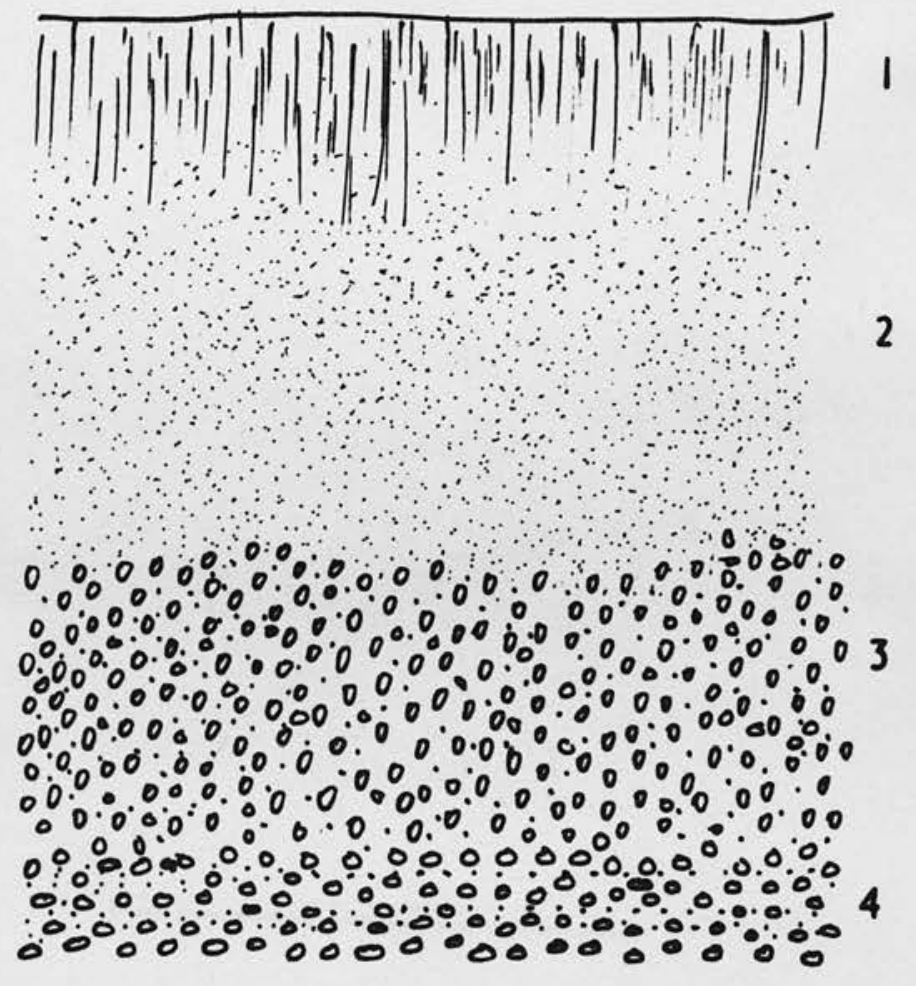

$50 \mathrm{~cm}$

Figure 22. 
Figure 23.

Bound fold and pillar involutions in glaci-fluvial deposits near Bonnyrigg, Nidlothian.

$$
\begin{aligned}
& \text { 1- sand. } \\
& \text { 2- silt. } \\
& \text { 3- clay. }
\end{aligned}
$$




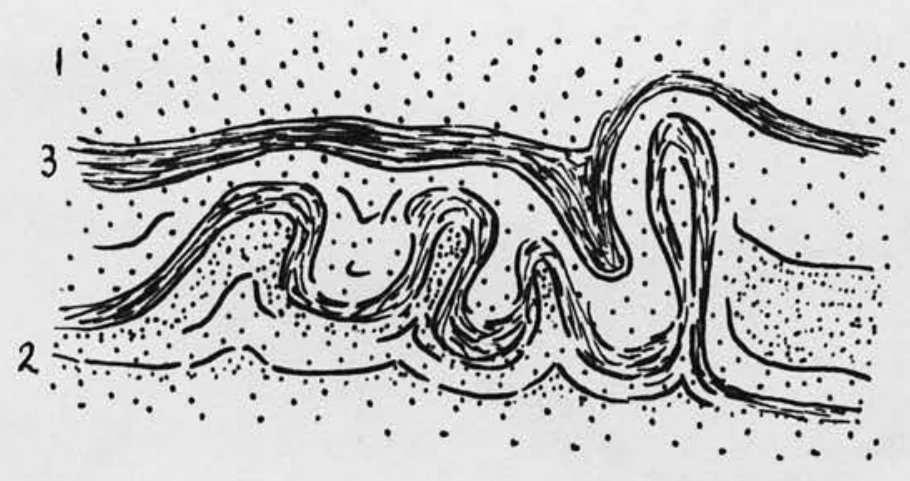

$50 \mathrm{~cm}$

Figure 23. 


\section{Figure 24.}

Possible stone stripes in solifluction deposits $3 \mathrm{~km}$. s of Cockburnspath.

1- slope, about 20 degrees.

2- silty material with a few stones.

3- wavy line of stones, possibly sectioned stone stripes.

4- stones in powdery matrix.

5- larger stones in less abundant matrix

6- shattered bedrock. 

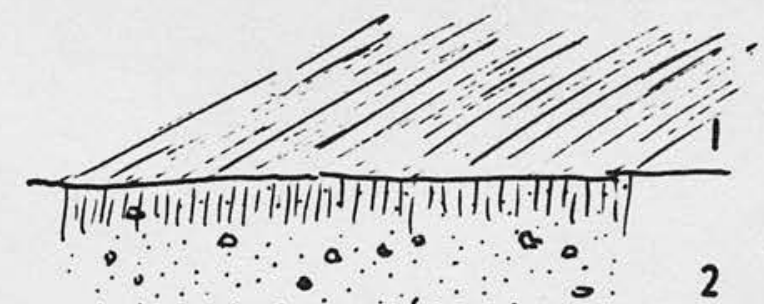

s $-\infty \therefore \cdots \cdots$

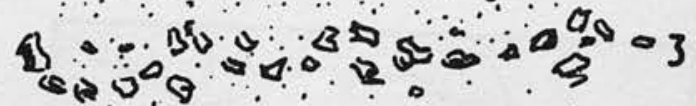

$\therefore \therefore \circ: \therefore \circ:$

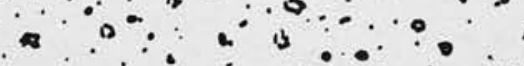

$\therefore \therefore$ a $\because \cdots$

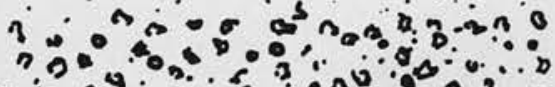

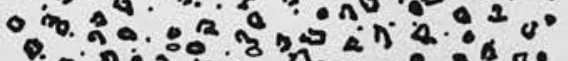

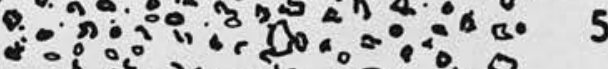

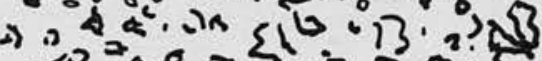

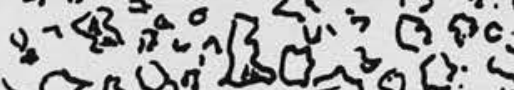

年,

$1 \mathrm{~m}$

Figure 24. 
Figure 25.

Plan view of contortions in "100 foot" raised beach material at Bonnybridge, Stirlingshire.

$$
\begin{aligned}
& \text { l- silt. } \\
& \text { 2- sand. } \\
& \text { 3- clay. }
\end{aligned}
$$

(N.B. cf. photograph 25.) 


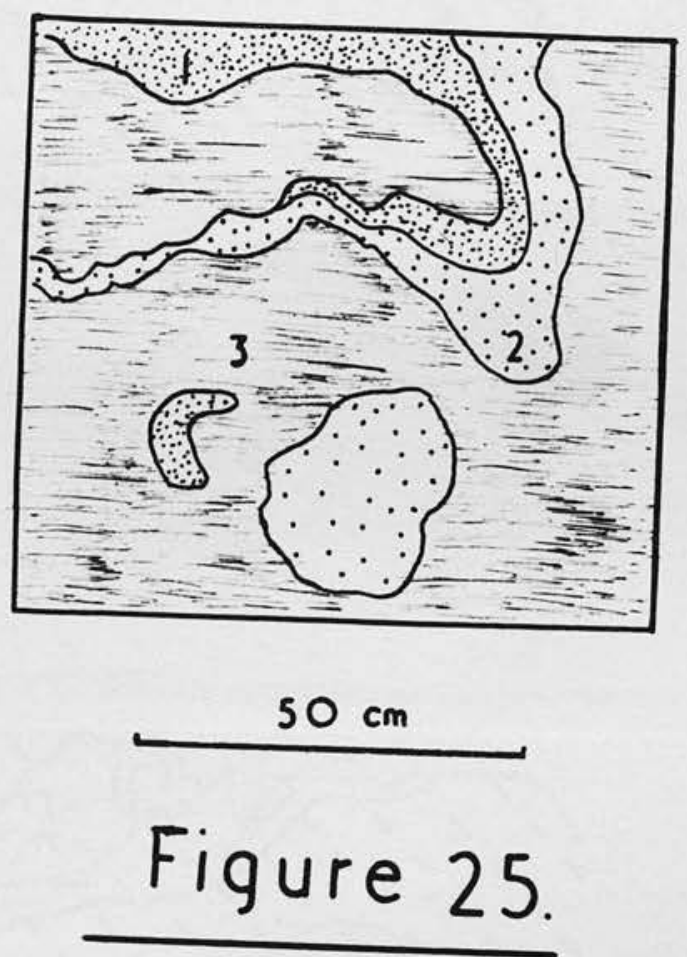




\section{Figure 26.}

Contorted sands and silts overlain by till at Keir \& Cawdor No. 3 Pit, Kelvin Valley.

1- glacial till.

2- sands, silts and occasional clay

3- erratic boulder. 


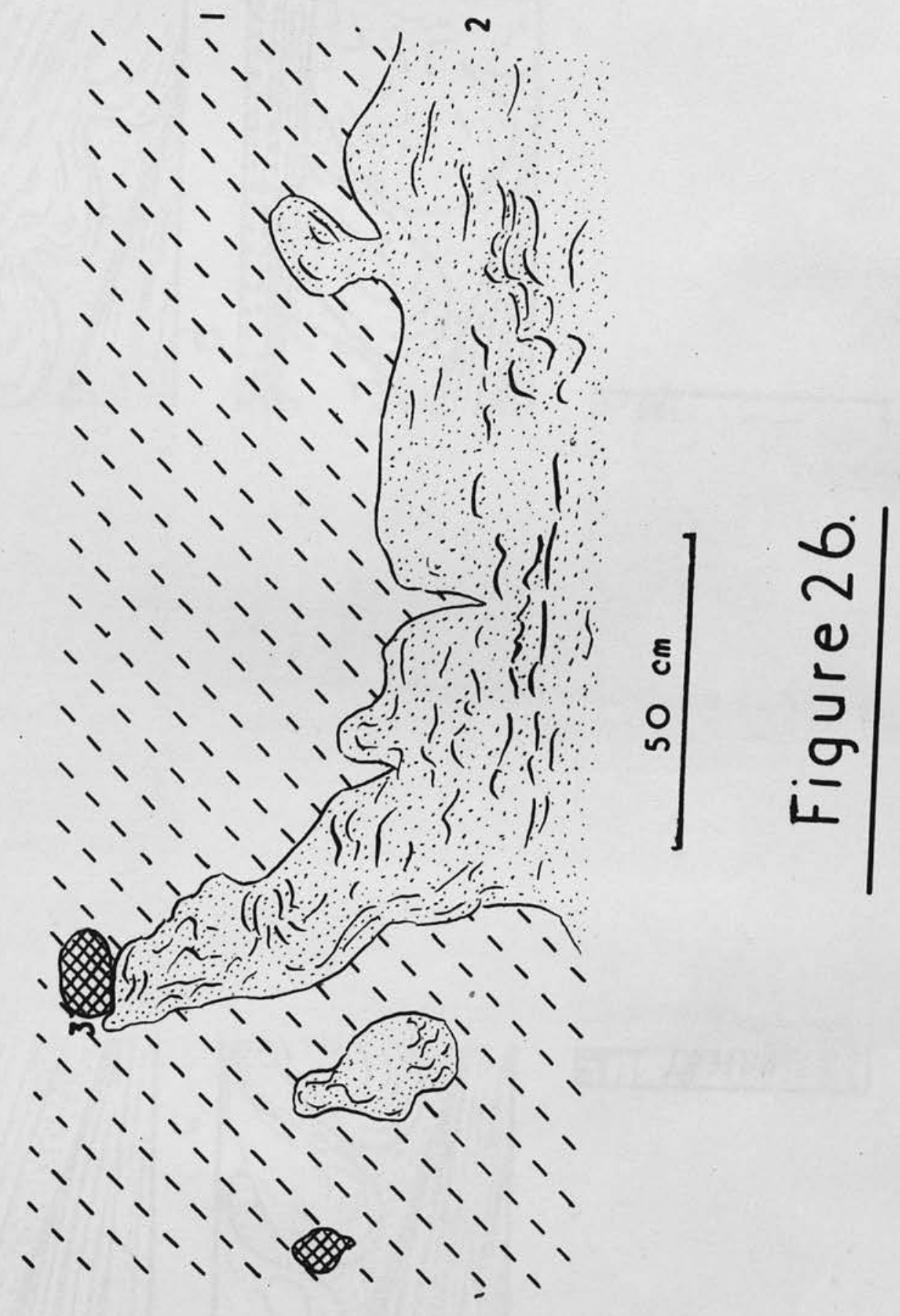




\section{Figure 27.}

Sequence of development of involutions at Drumclog, Strathavon, Lanarkshire.

a- initial deposition of current-bedded sand with a silt or clay layer.

b- commencement of development of the involutions by expansion in this finer material.

c- completion of the involution.

d- erosion of the upper layers and renewed deposition.

e- development of a wedge through the whole sequence.

N.B. cf. photograph 26. The wedge does not in fact occurr at the exact point shown in the sketch. 

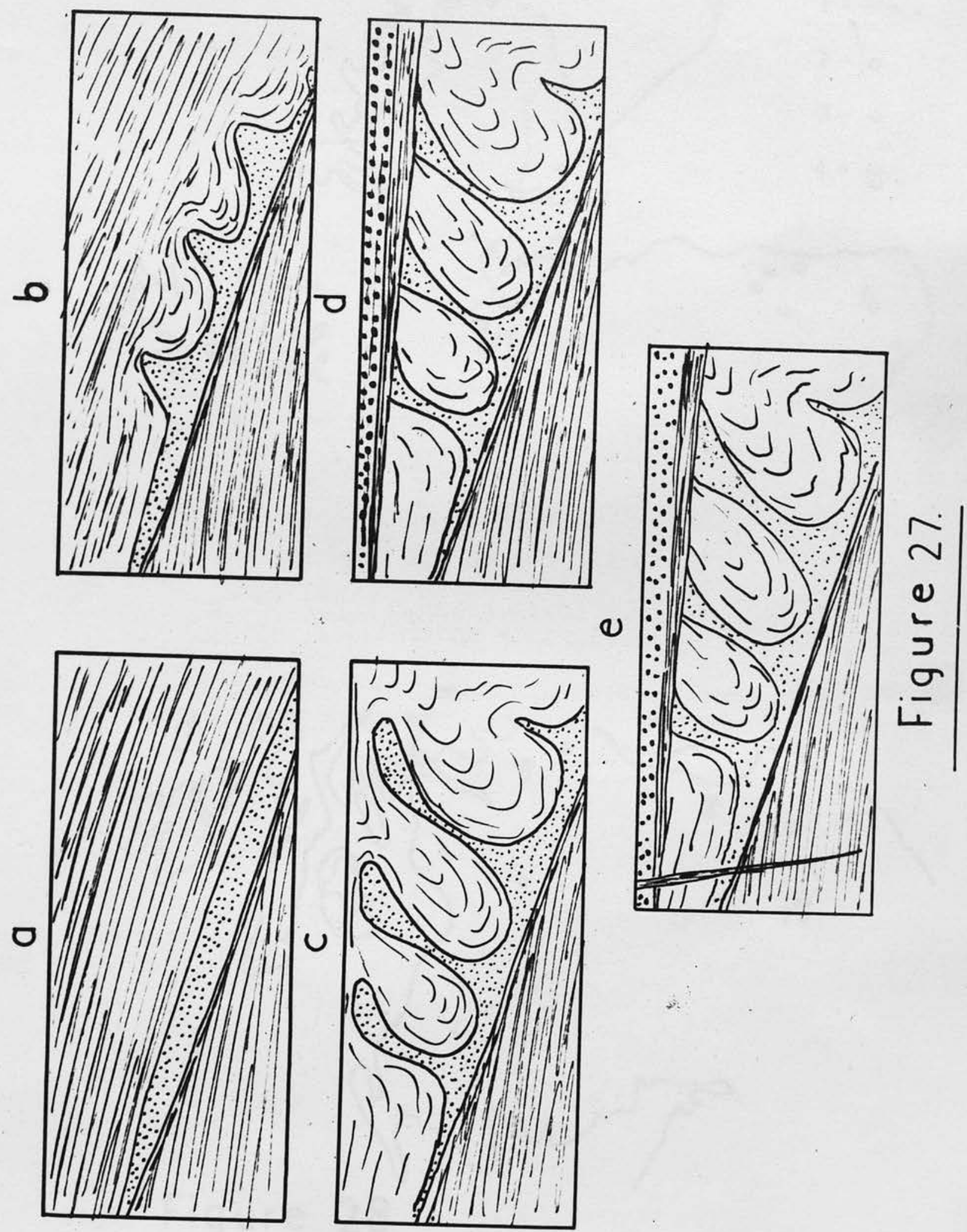


\section{Figure 28.}

Distribution of involutions in scotland.

1- limit of Zine III readvance.

2- bound involutions.

3- free involutions.

4- involutions under till. 


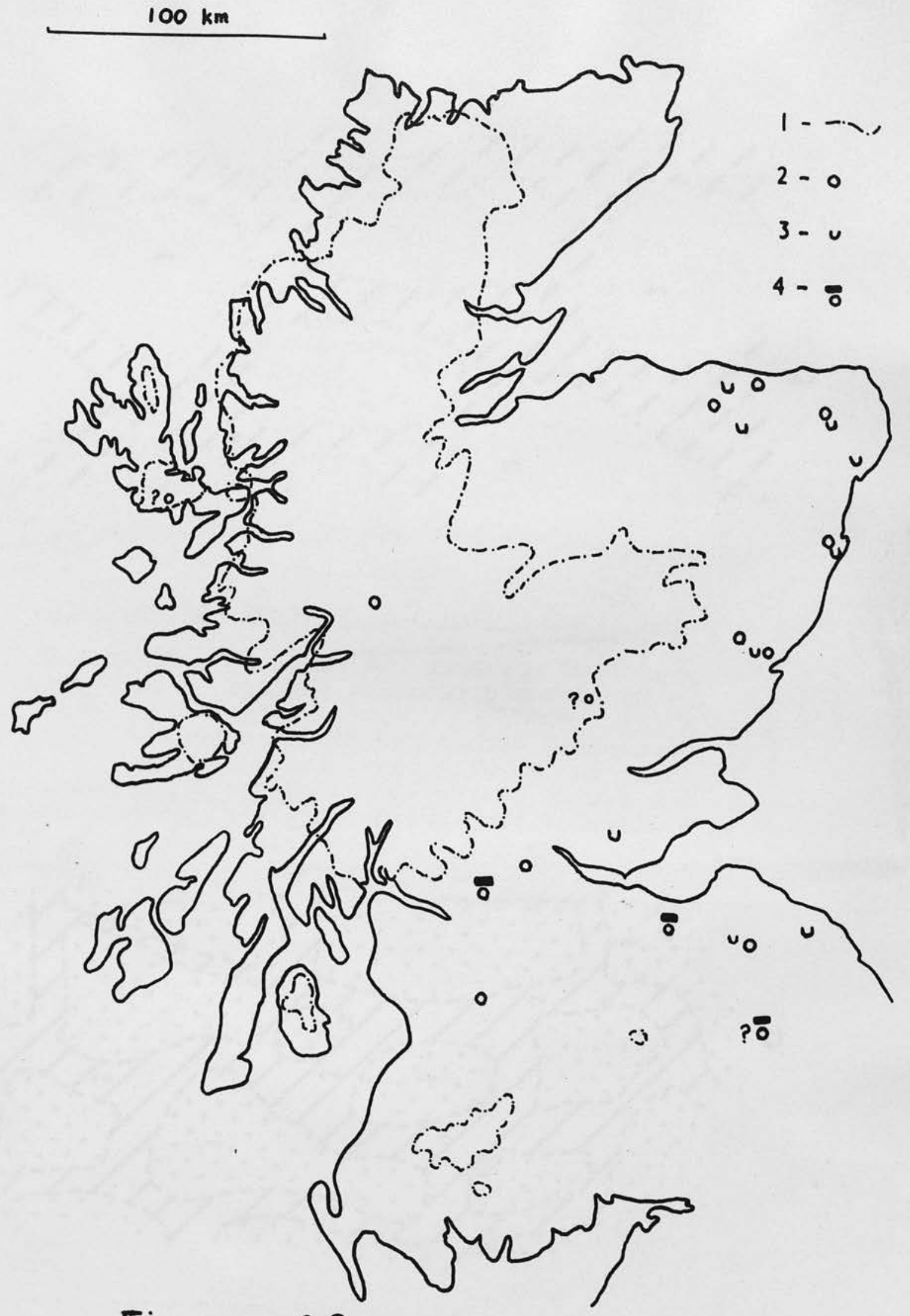

Figure 28. 
Figure 29.

Patterned ground in Greenland and Scotland.

a- sorted polygons and rings in $\mathrm{E}$ Greenland.

b- nonsorted vegetation pattern on Ben Wyvis.

1- bare earth with a few small stones.

2- stony border with many stones on edge.

3- low mounds of grey-brown rhacomitrium moss.

4- hollows of grey-green rhacomitrium moss, underlain by large stones lying flat. 


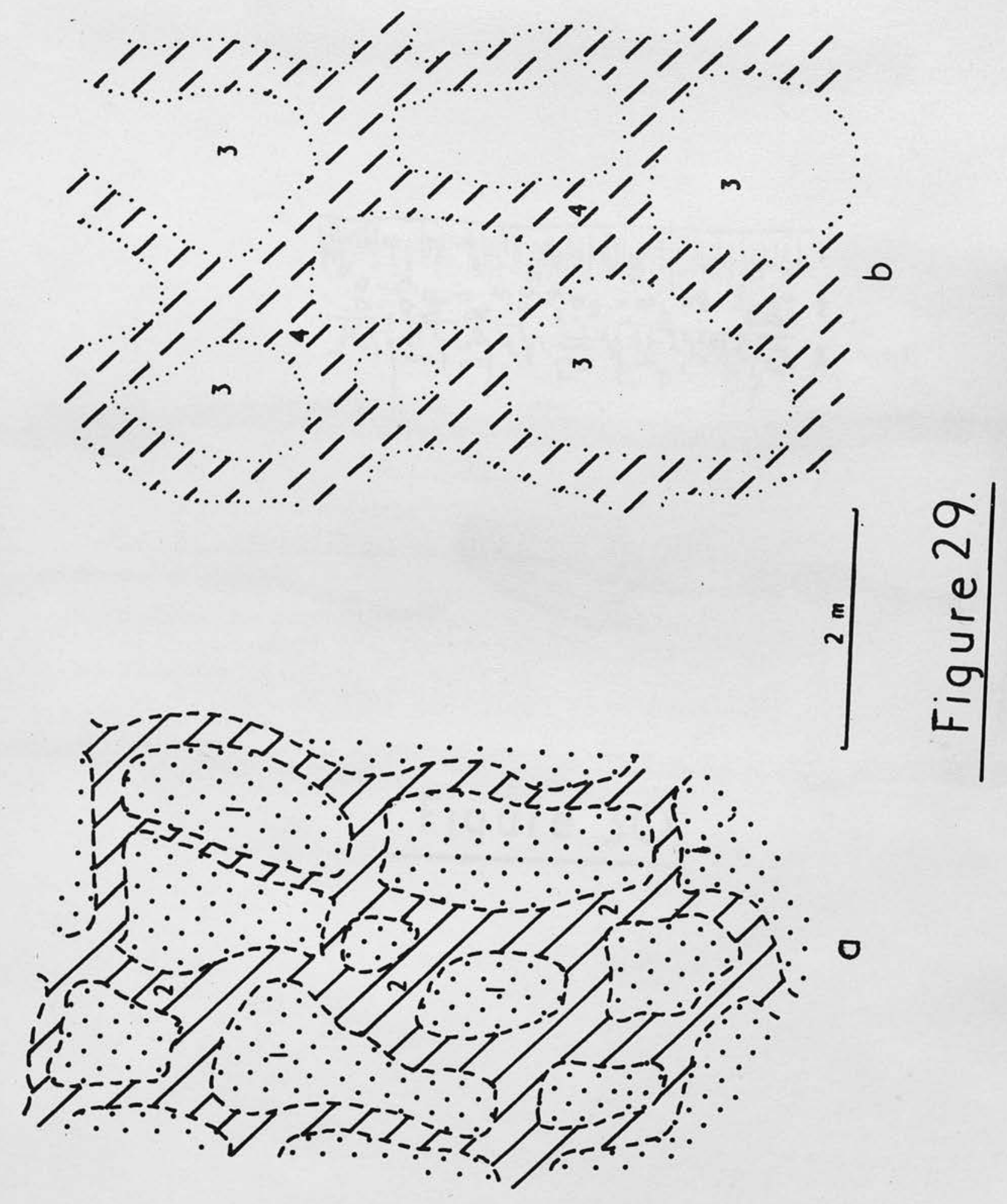




\section{Figure 30.}

Shattering of sandstone near Finstown, Orkney.

1- soil.

2- solifluction layer with fragments os sandstone.

3- superficial shattering of the rock.

4- resistant beds scarcely affected by shattering.

5- shattered less resistant layers.

N.B. Figure 31 was not necessary to the development of the argument and has been ommitted. 


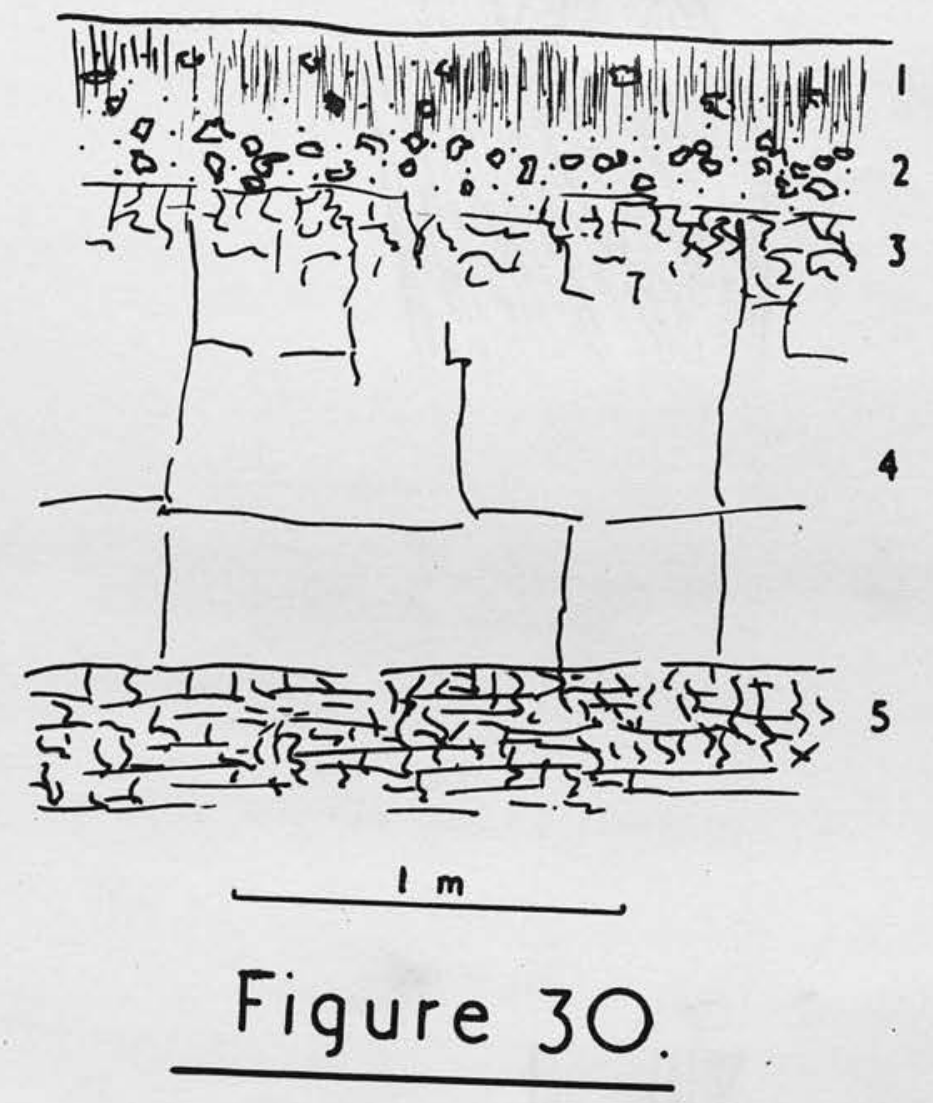




\section{Figure 32.}

Diagramrnatic sketeh of the upper Ythan valley, at Bruckhills, Aberdeenshire.

1- solifluction deposit unde smooth slope.

2- shattered phyllite.

3- artifically cut present stream course in flat floor of the valley.

N.B. cf. photogaphrs 33, 37, and 50a. 


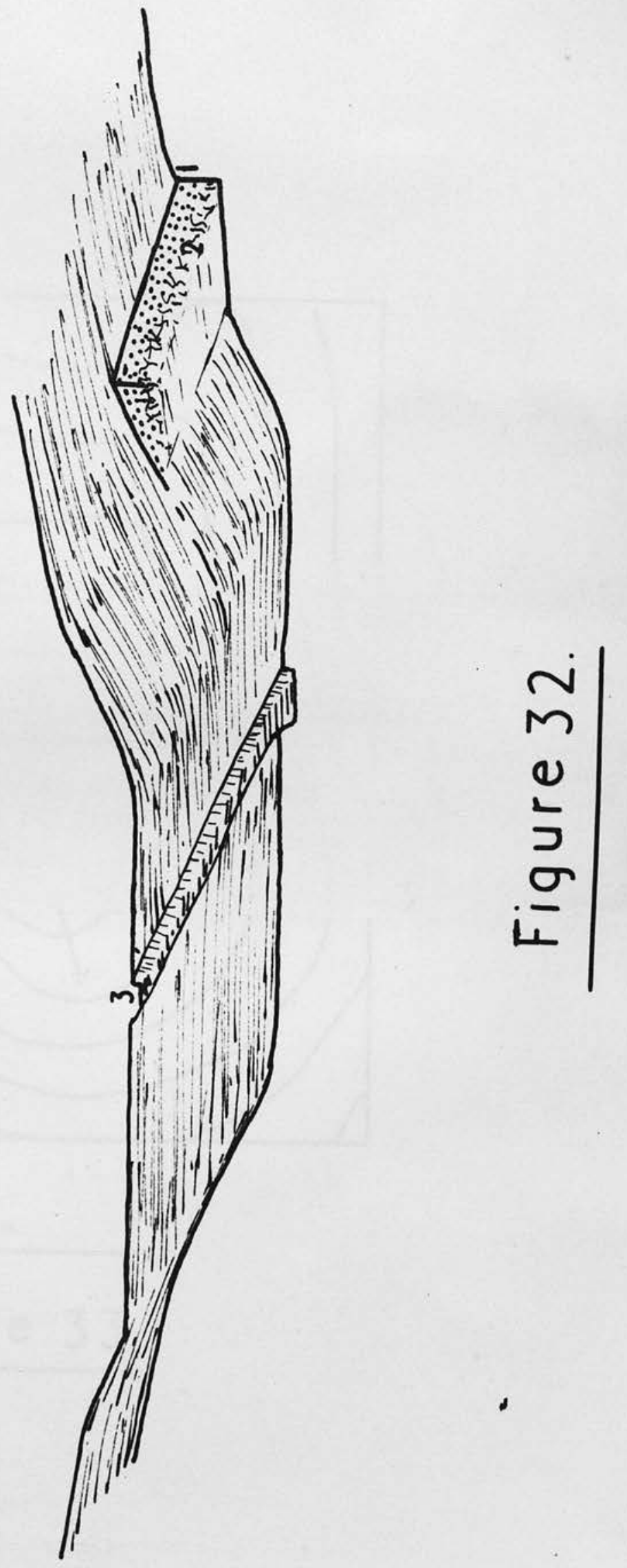


Figure 33.

Preferred orientation of glacial erratic boulders on the summit of The Knock, Banfishire.

N.B. Each arrow represents the mean orientation of about 50 boulders. 


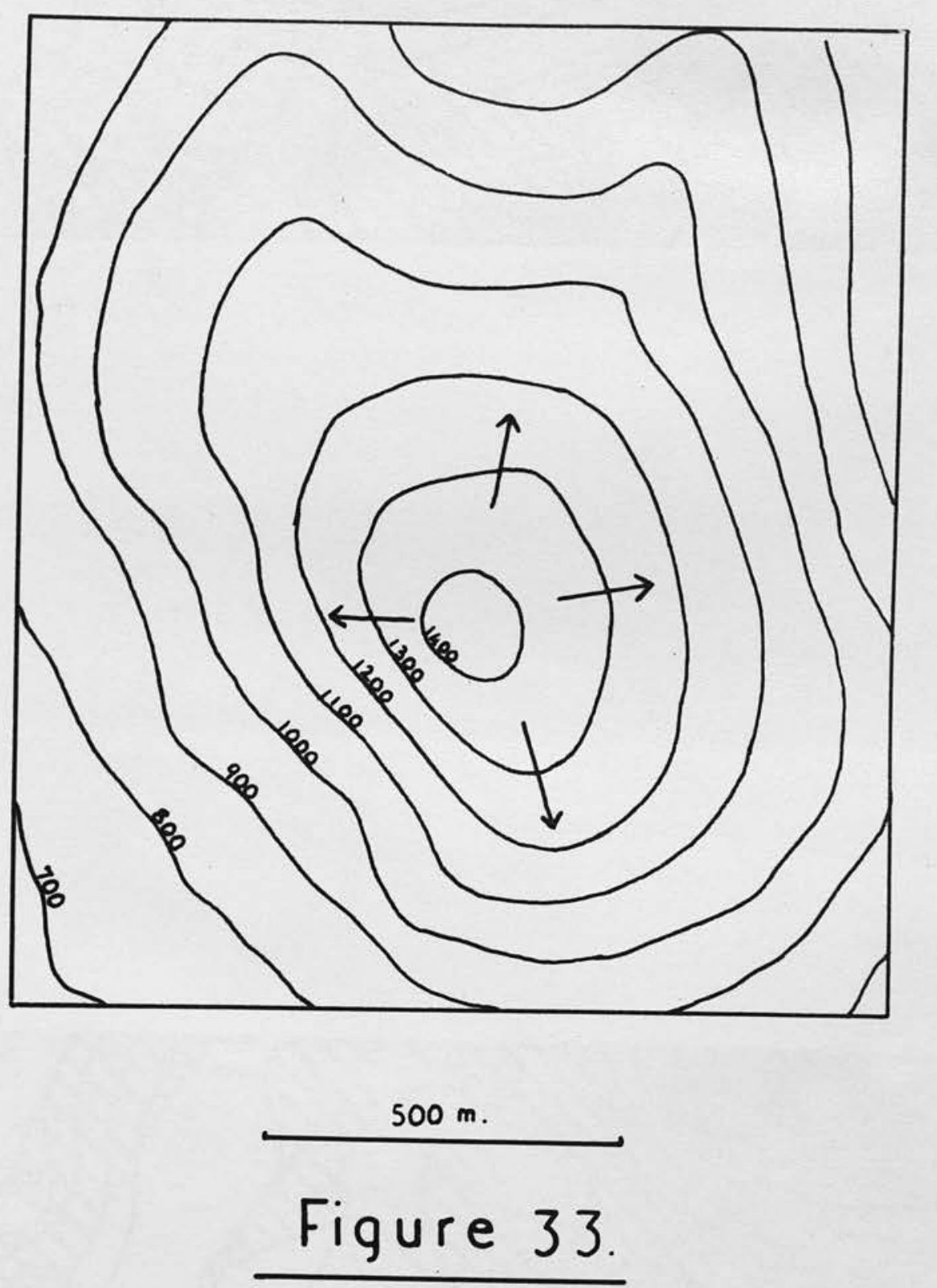




\section{Figure 34.}

Reconnaissance map of solifluction features on Ben Wyvis, Ross-shire.

1- areas occupied by stone fronted and vegetation covered lobes.

2- solifluction terraces.

3- rhacomitrium stripes developed on buried stone stripes.

4- slumps.

5- long continuos front at lower edge of a solifluction sheet.

6- block fields.

7- notable stone streams, some formed by disintegration of stone fronted lobes.

8- small ponds dammed behind solifluction features.

9- snow patches on 13th June 1958. 


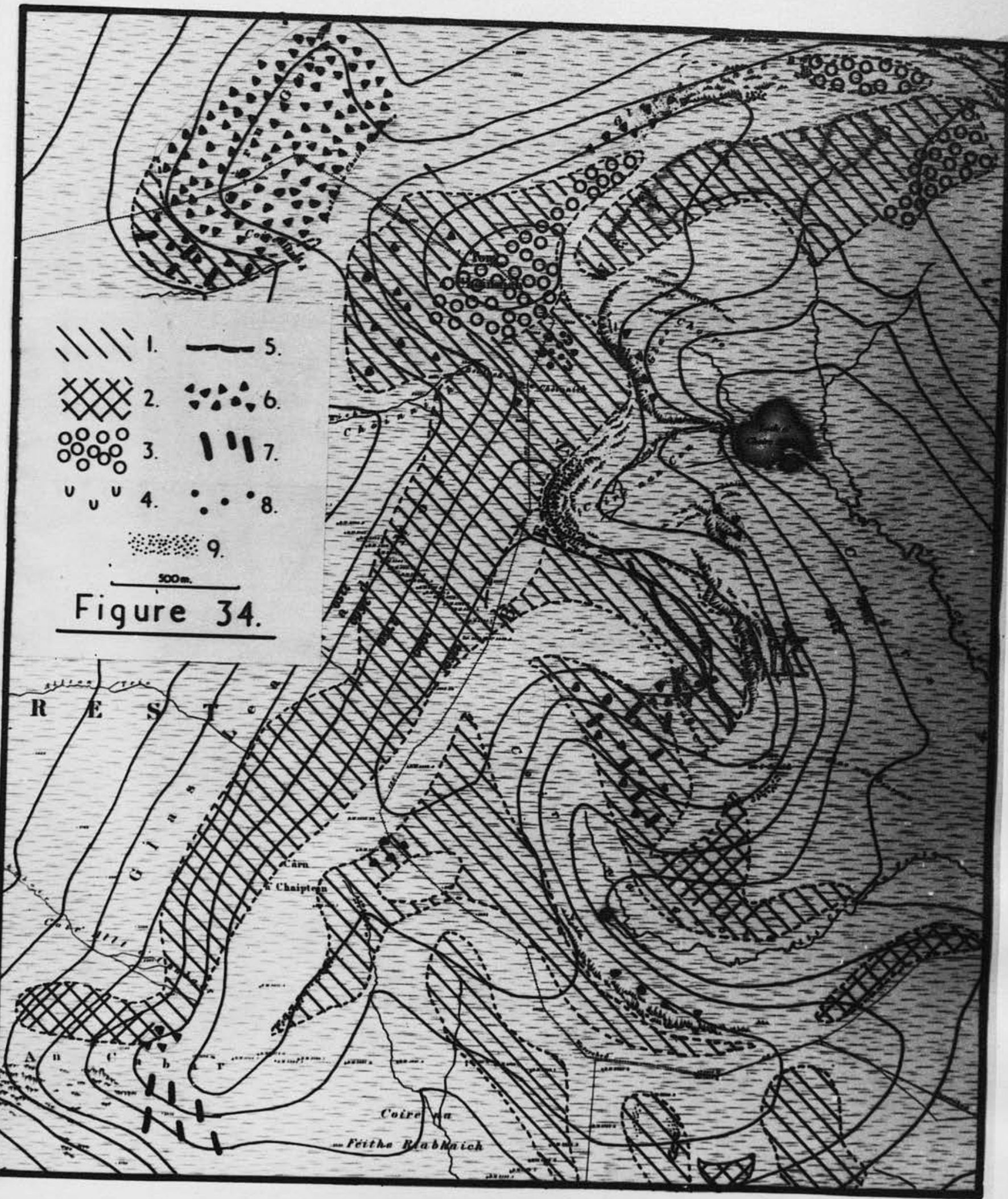


Figure 35.

Sketch of typical stone fronted lobes on Ben Writ. 


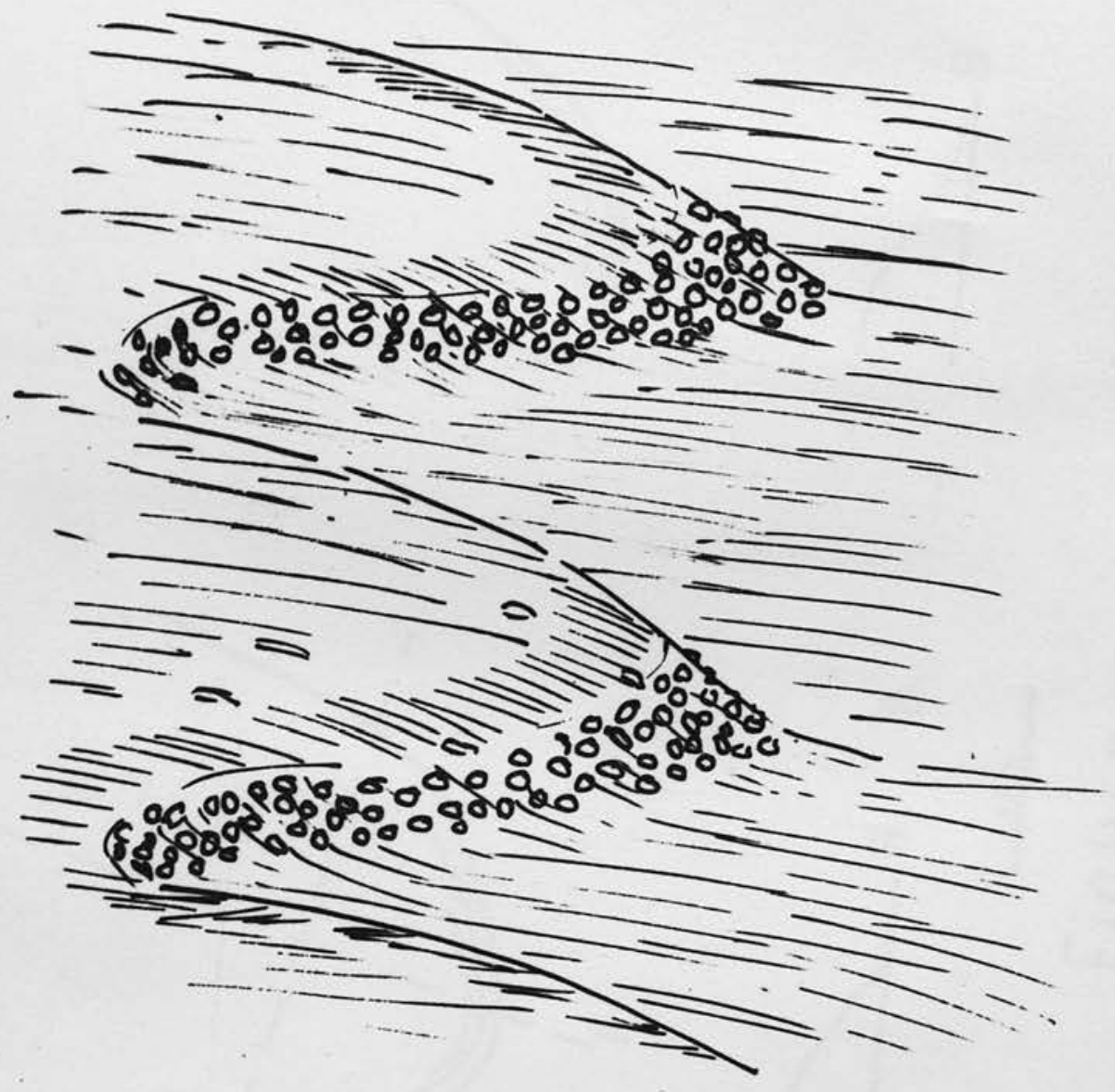

Figure 35. 
Figure 36.

Dimensions of typical lobes on SE face of Lochnagar. 

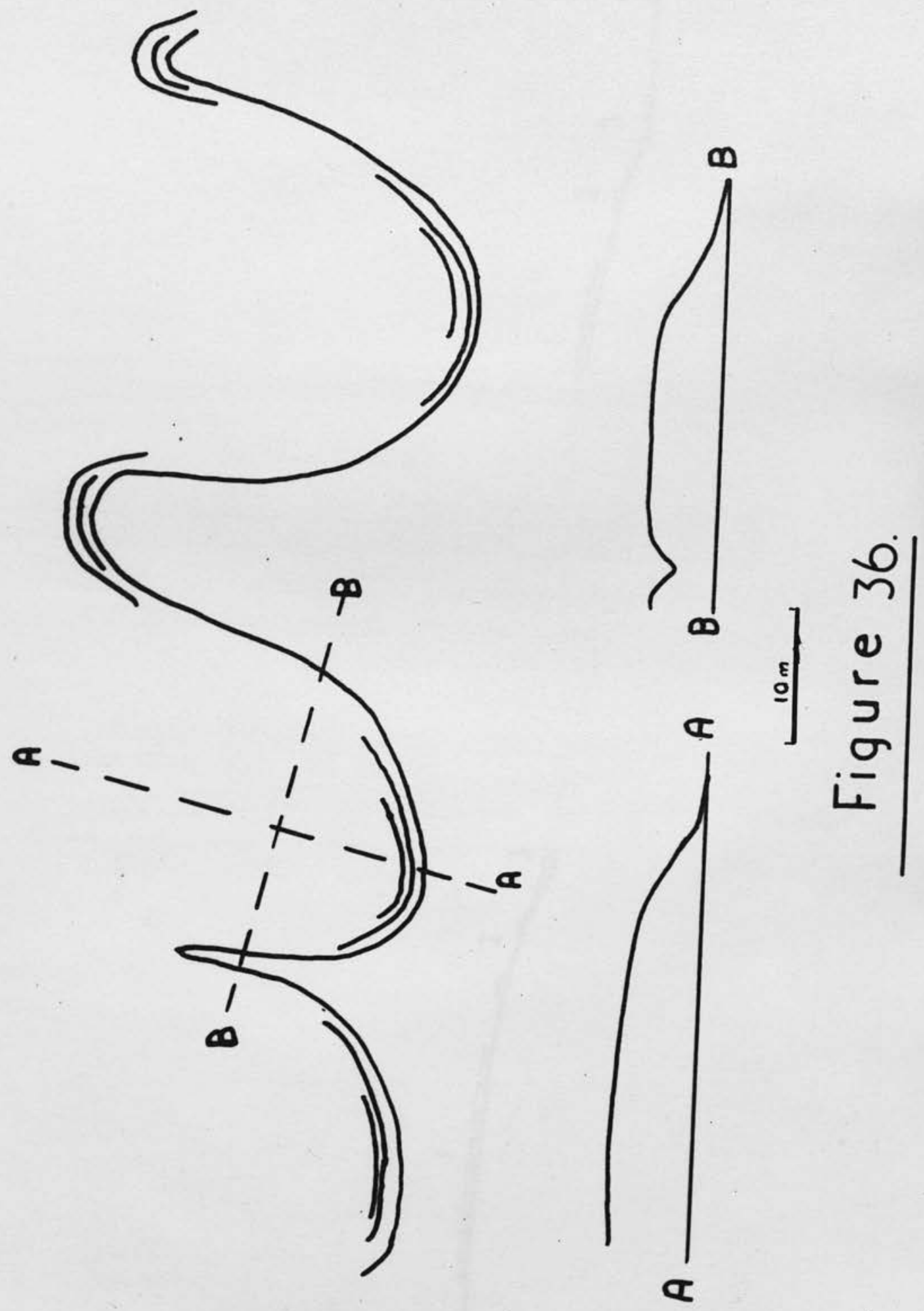


\section{Figure 37.}

Sketch profile of large solifluction terrace on the wite bounth, Aberdeenshire. Altitude, c. 3,200ft.

1- heather.

2- boulders exposed at surface.

3- snow patch.

4- nardus.

Horizontal scale 1:1,000 approx. Vertical scale 1: 500 approx. 

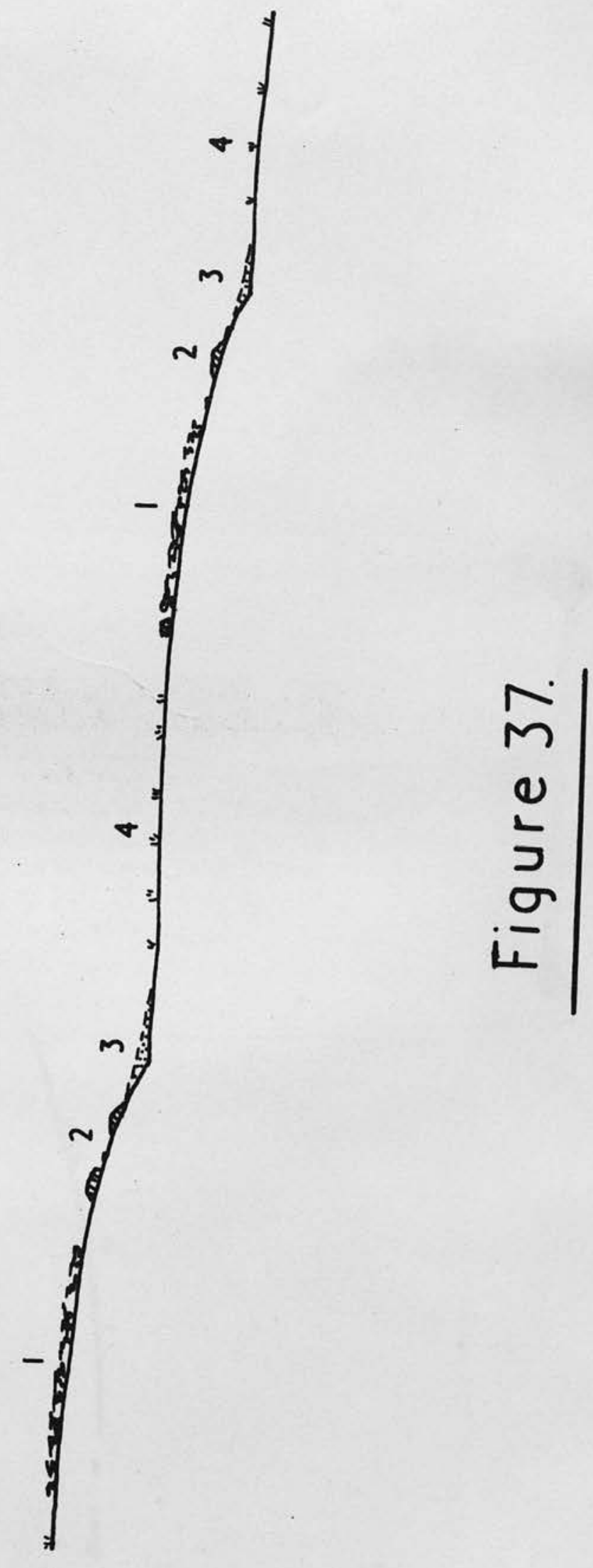
Figure 38.

Profile along the Perth / Inverness County Boundary, E of the Pass of Drummochter.

1- active solifluction on steep slope.

2- deep hill peat.

3- thin peat over fossil lobes.

4- rhacomitrium stripes. 


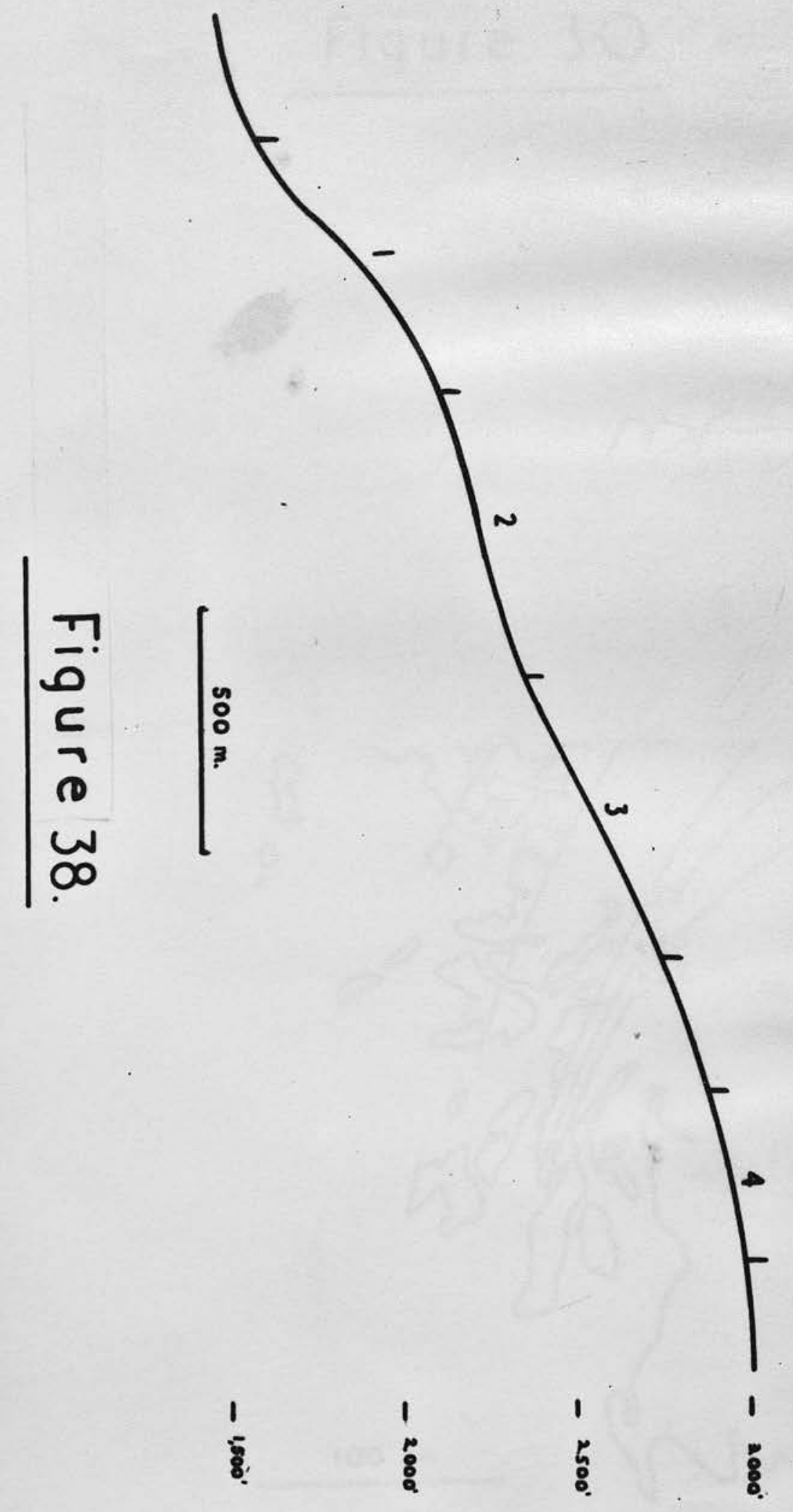


Figure 39.

Altitudes on granite hills above which vegetation covers less than half the ground. 


\section{Figure 39.}
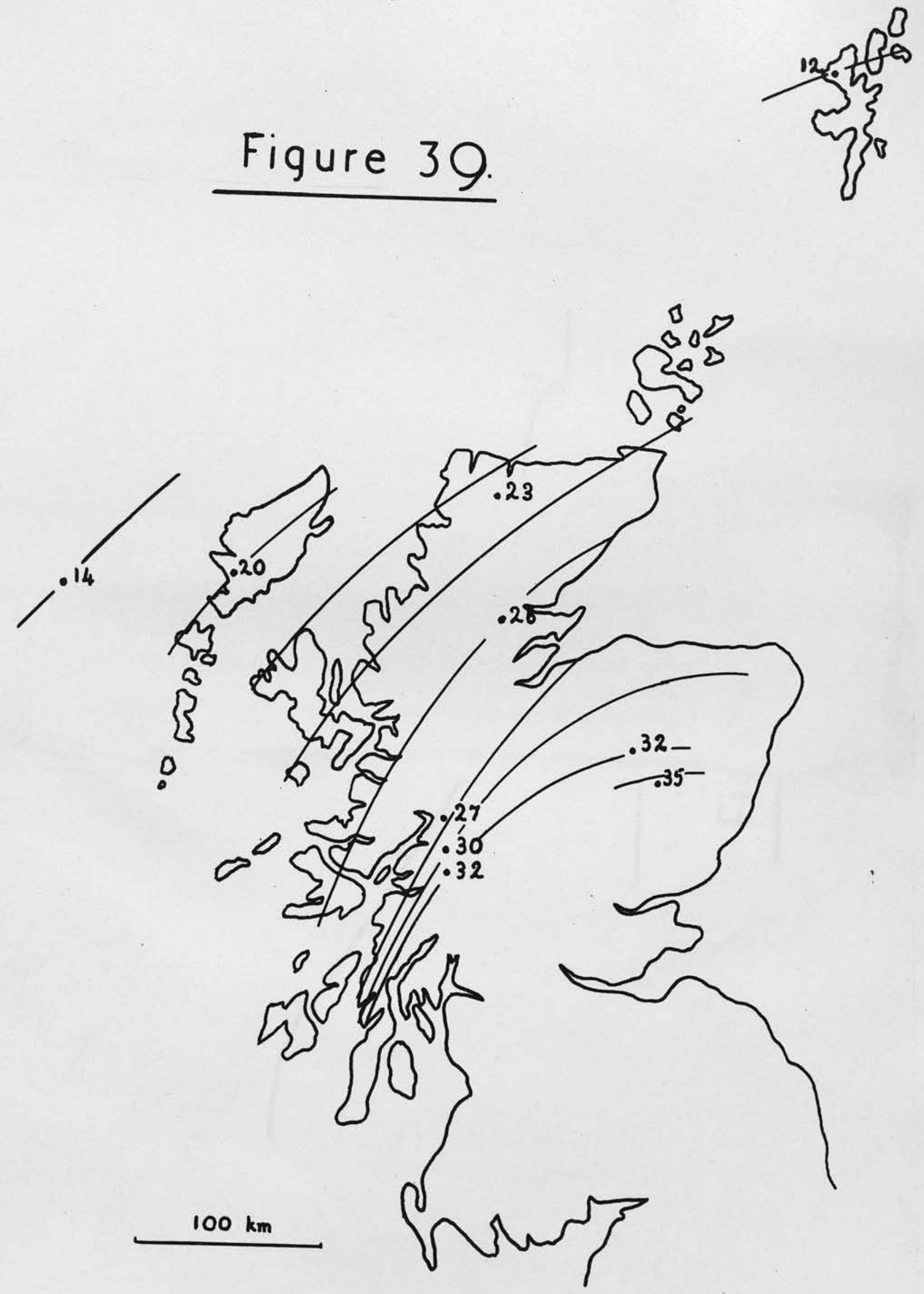
Figure 40.

Sketch profile of $\mathrm{N}$ side of valley of Moffat Water.

I- rock outcrop.

2- even slope covered in solifluction deposits, drawn to correct thickness.

3- Glaci-fluvial gravels exposed by the river. 


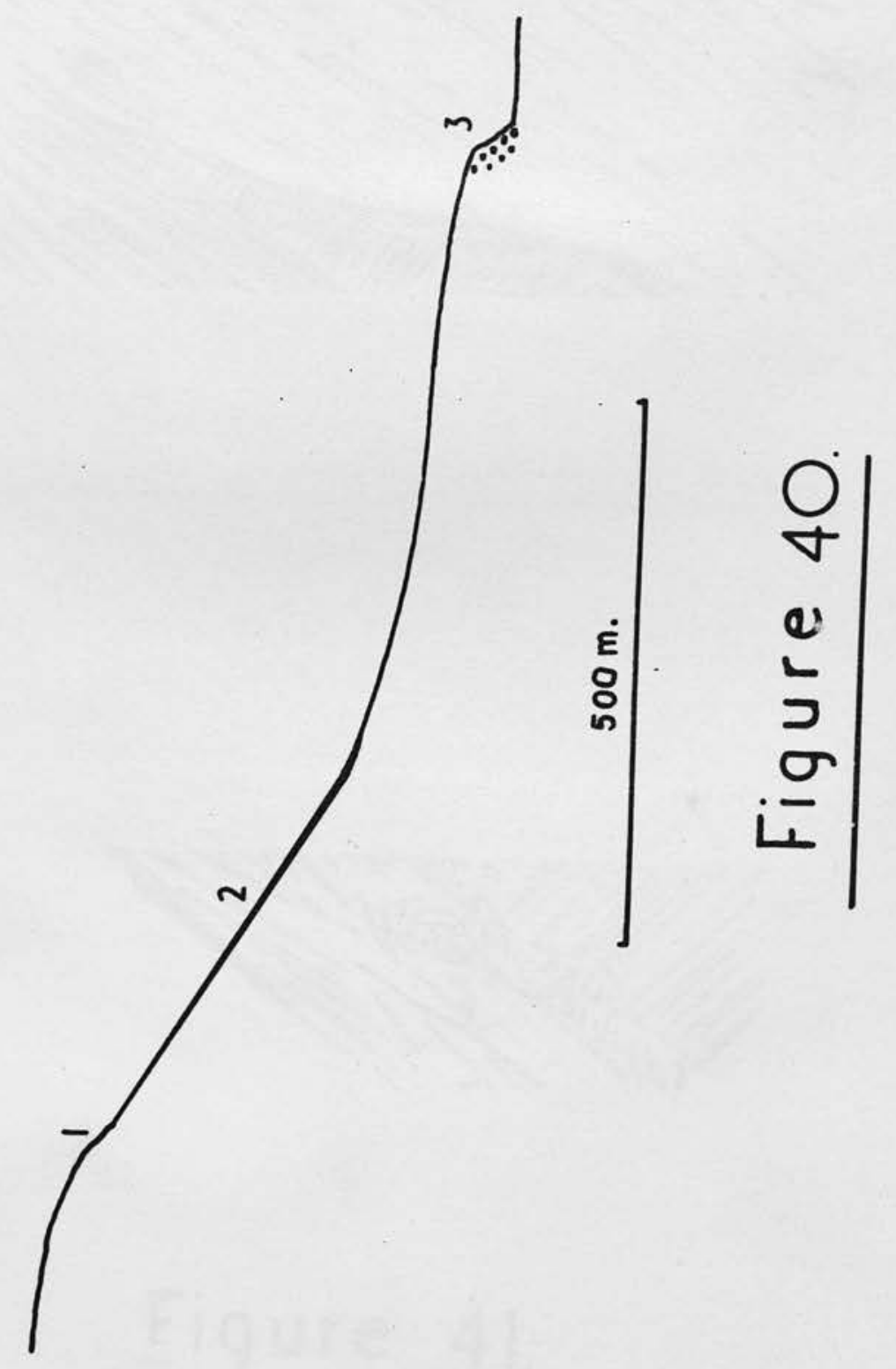




\section{Figure 41.}

Sketch of gully on S side of Glen Geusachan, Cairngorms.

1- shattered granite.

2- glacial till

3- smooth slab corresponding to a sheet joint plane in the granite.

4- another smooth slab, corresponding to the subjacent joint plane. 


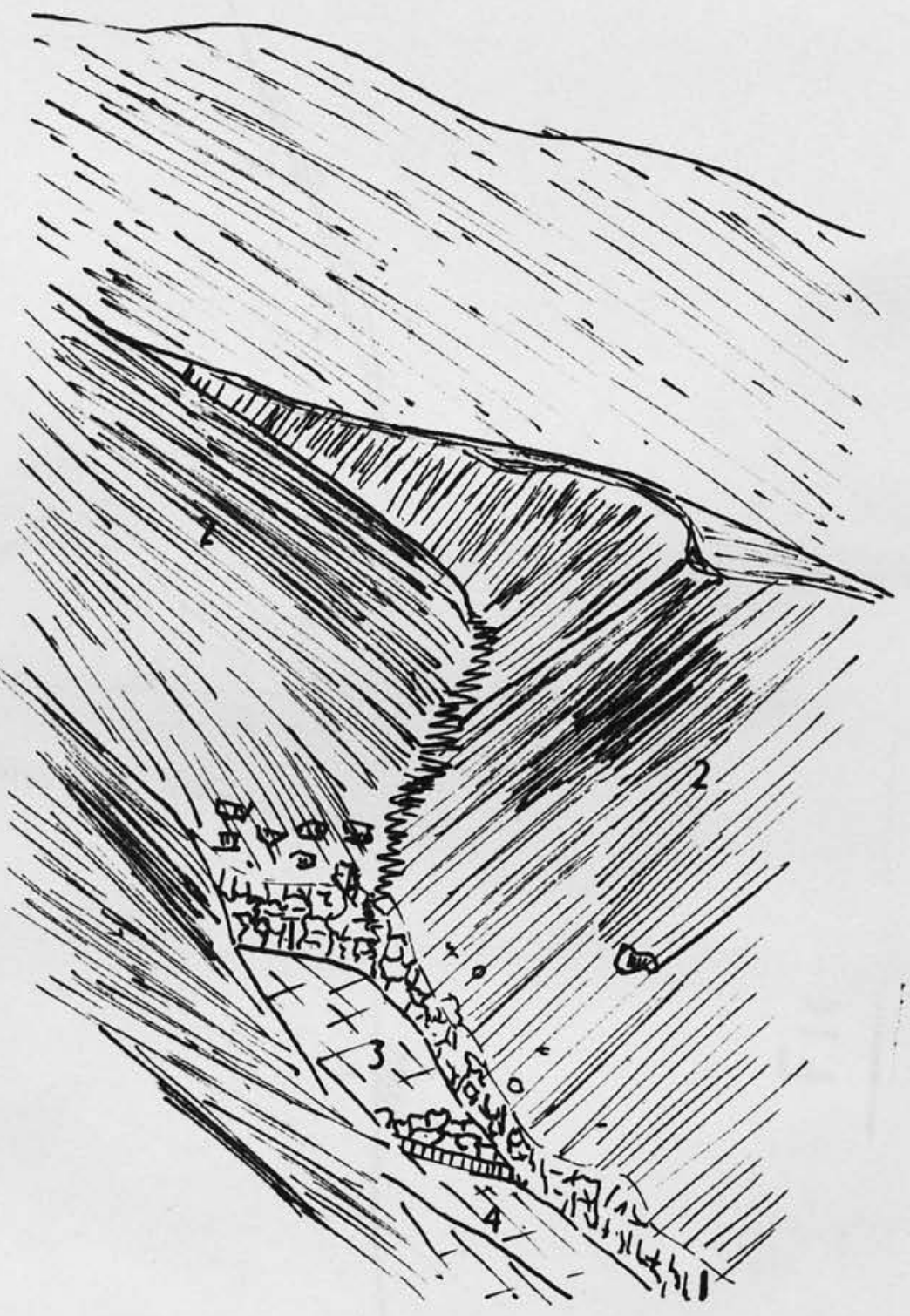

Figure 41. 
Figure 42.

Sketch profile of a bench on the $\mathbb{N}$ face of Whiteside Hill, Peebles.

1- possible rock outcrop.

2- recent hill wash.

3- boulders and rabble. 


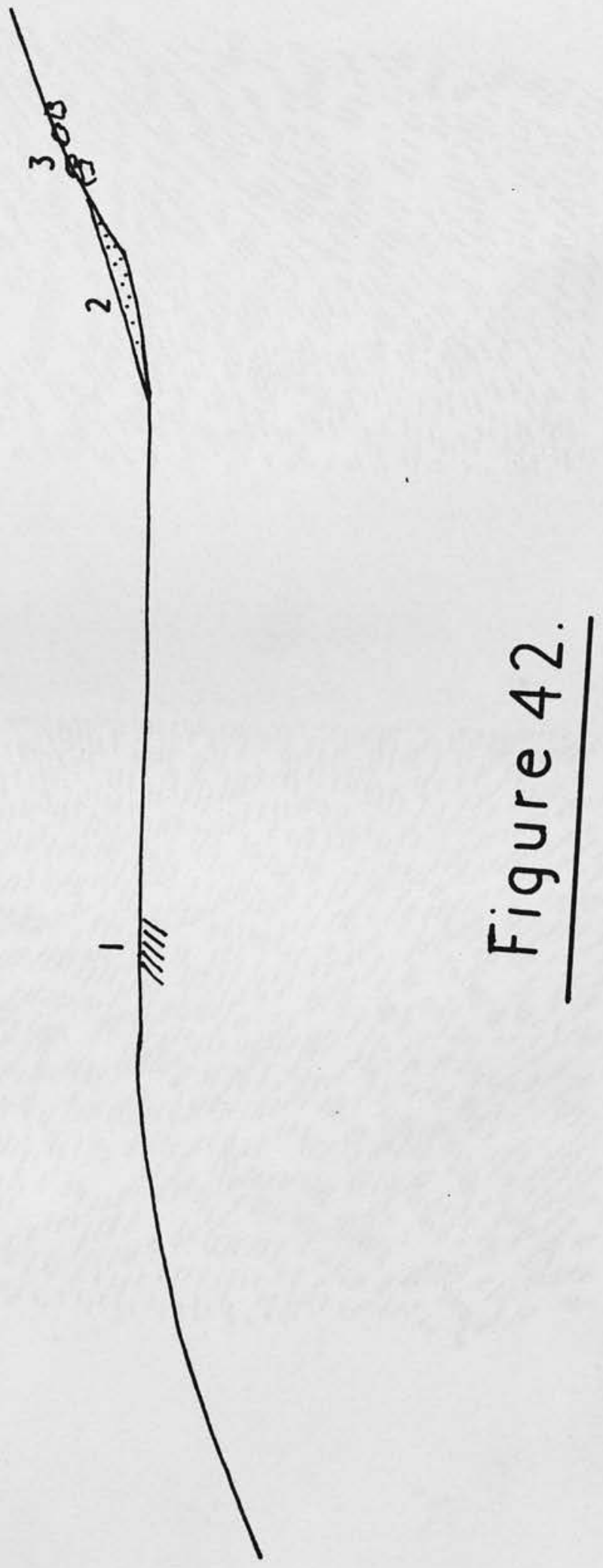


Figure 43.

Sketch to illustrate typical niche form. 


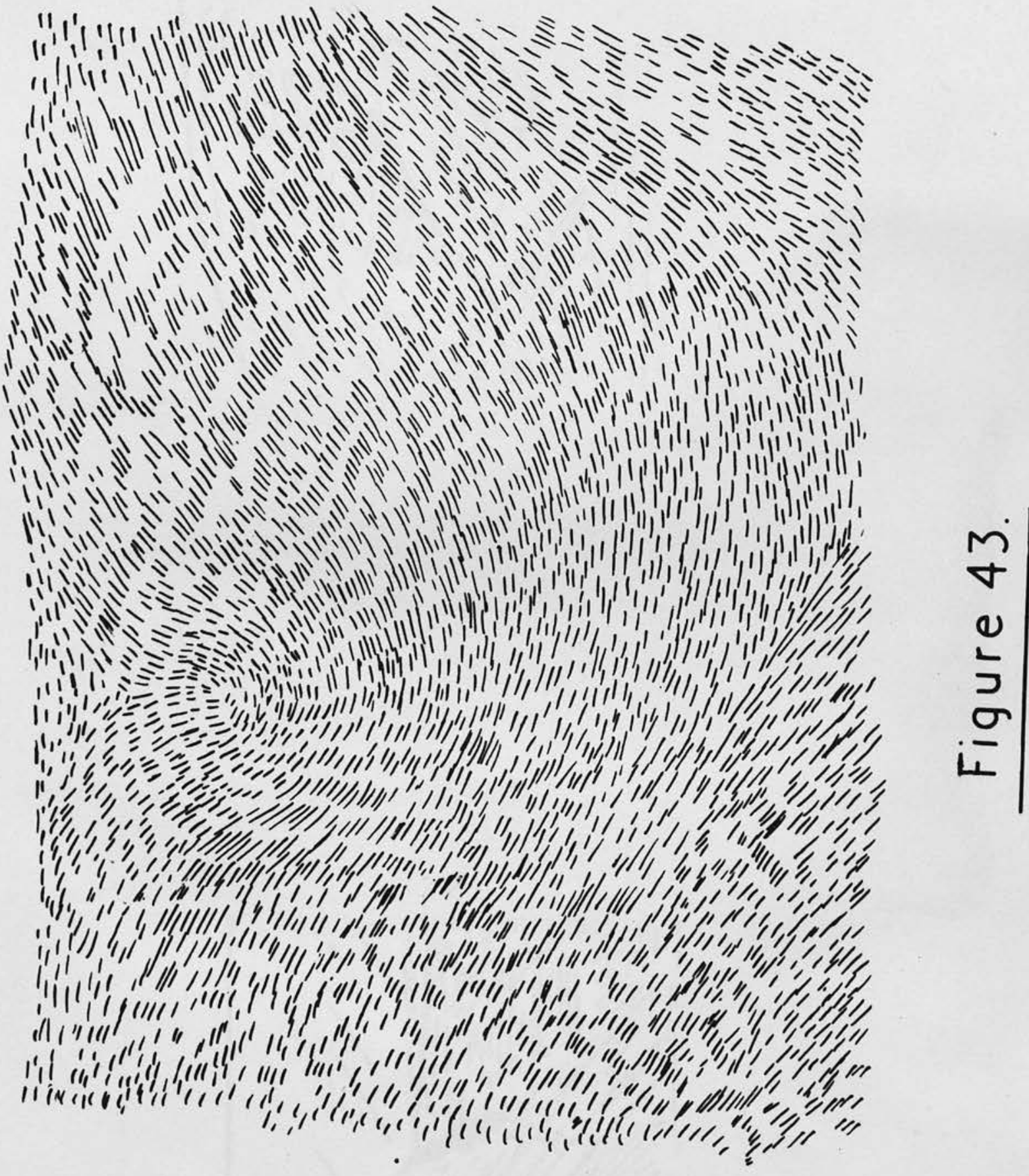


Figure 44.

Sketch of landforms around the junction of the Back Burn with the Monynut Water, Lammermuirs.

1- niche. cf. photograph 59.

2- straight slopes of mass wasting.

3- slightly steeper lower parts with terracettes.

4- recent fan of gully dissecting the niche.

5- terrace cut in bedrock.

6- present course of the Back Bum incised into 5.

N.B. True proportions in this sketch have been modified to bring out the points being discussed. 


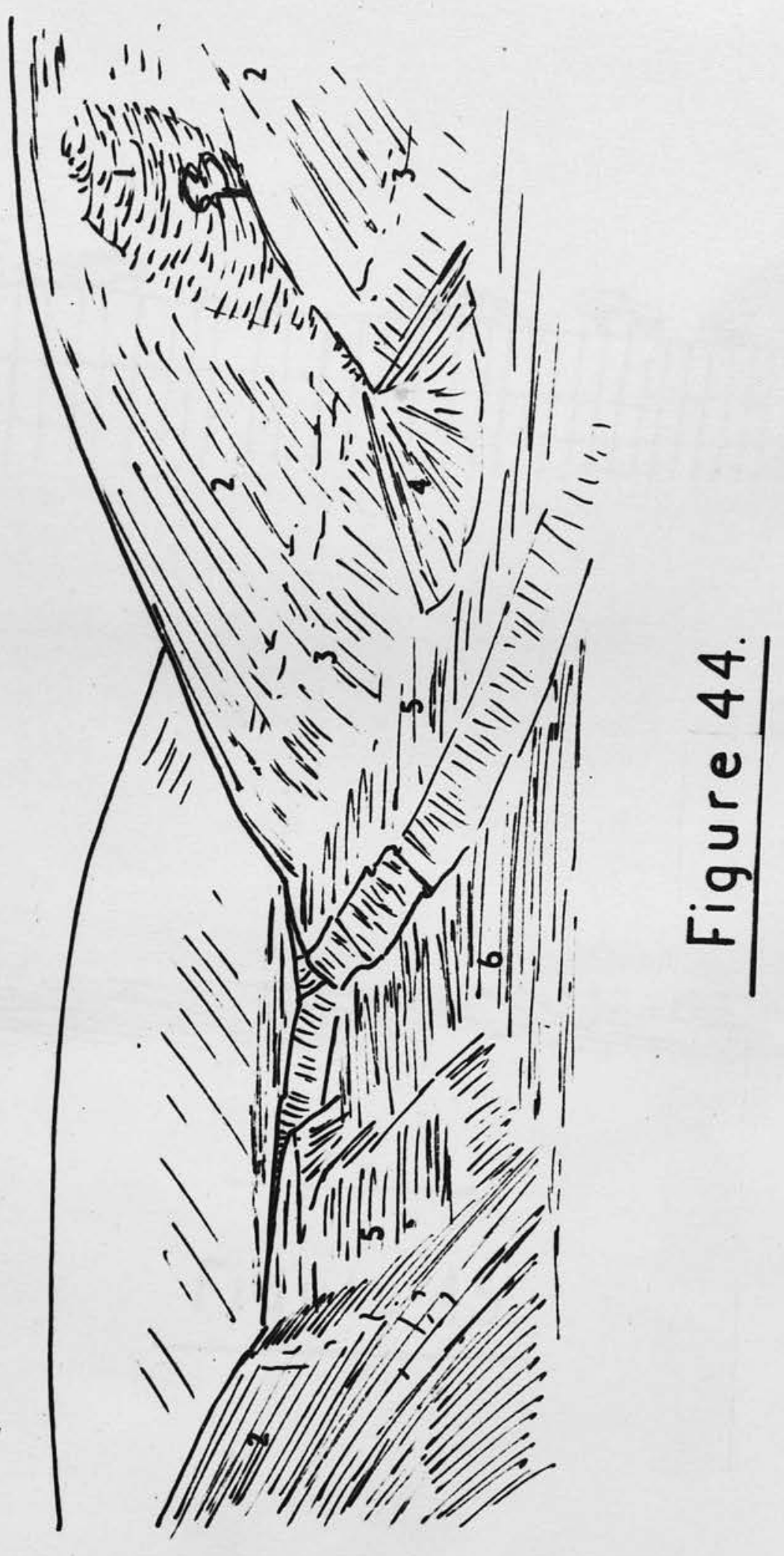


Figure 45.

Section of infilling at 1 fead of Tavers Cleugh, Lammermuirs.

1- peat.

2- Stony washed and solifluction material with a few old glacial erratics in the upper part.

3- reddish sandy silt.

4- greenish silty clay, with involutions at junction with layer 3 . 


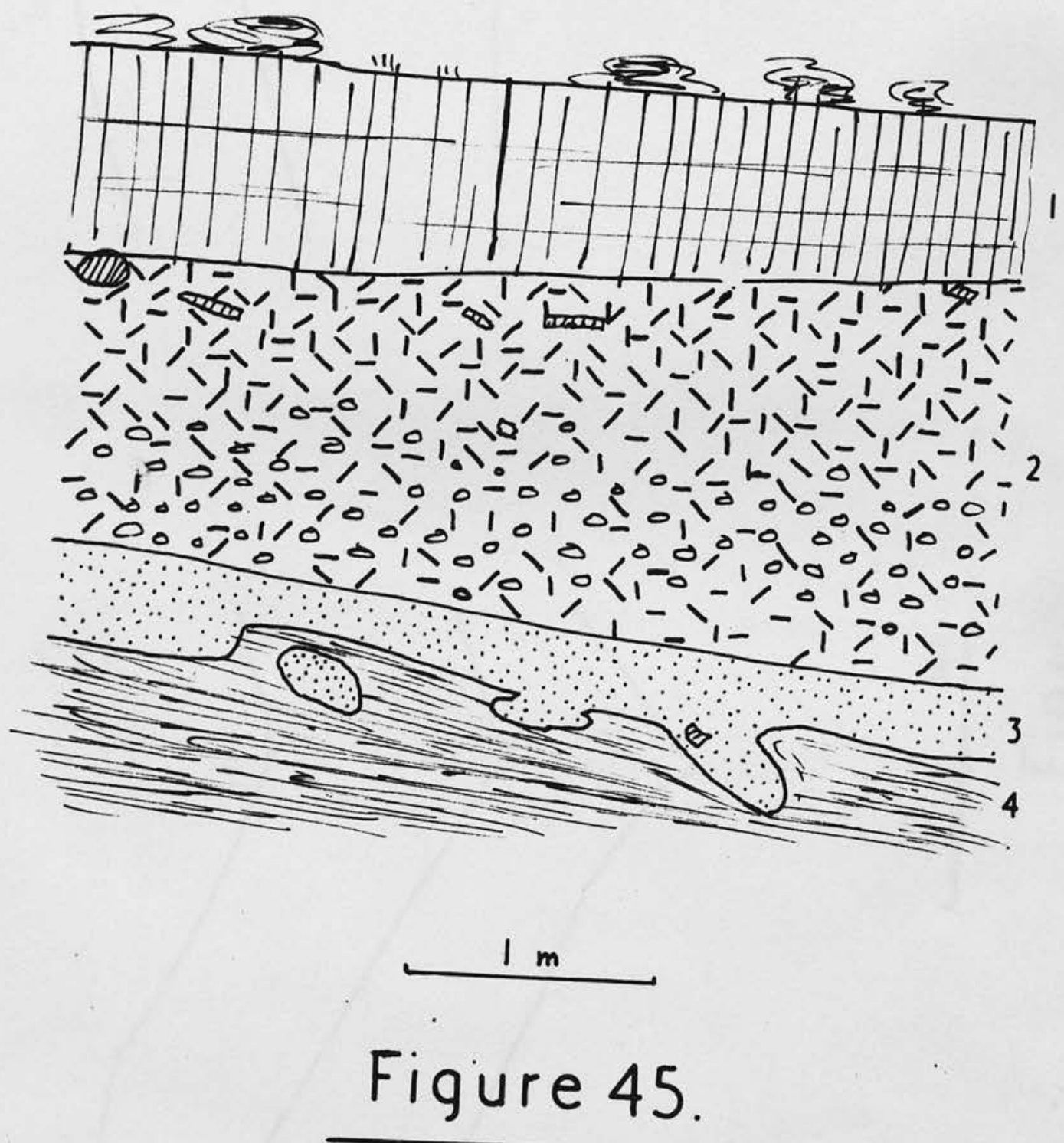


Figure 46.

Profiles to show slope form along the Tillycoultry Burn.

N.B. No vertical exagerration. 


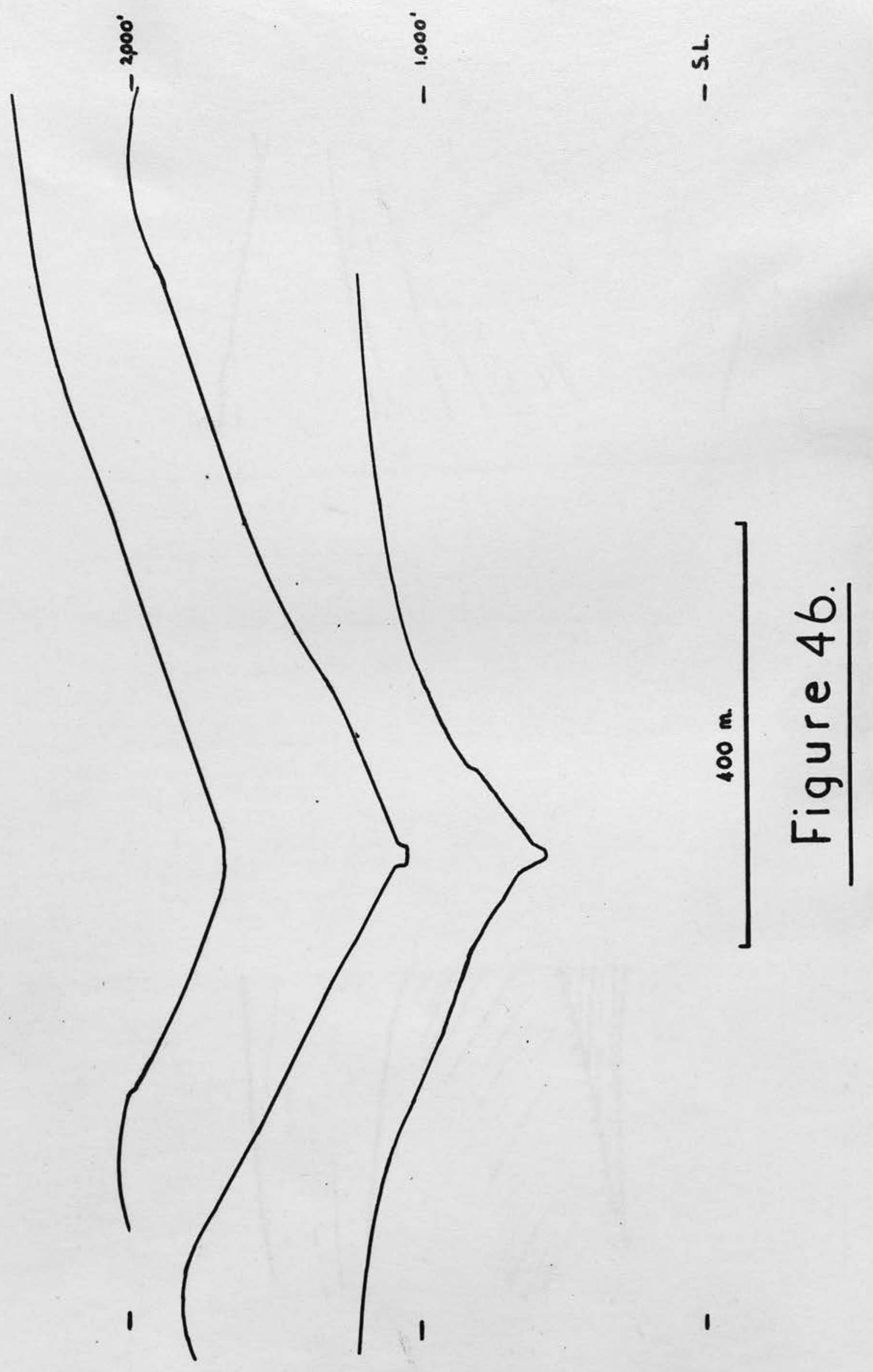


Figure 47.

Priestlaw area, Lammermuirs. (Key to photograph 64)

1- altiplanation benches (?) on $\mathrm{N}$ face of Priestlaw.

2- straight slopes of mass wasting.

3- recent gullies dissecting the slope deposits and underlying shattered rock.

4- bench cut in deeply weathered Priestlaw granite, with litte or no solifluction deposits on top derived from the long slope behind.

5- flat valley floor across which present streams meander; probably periglacial stream was briaded. 


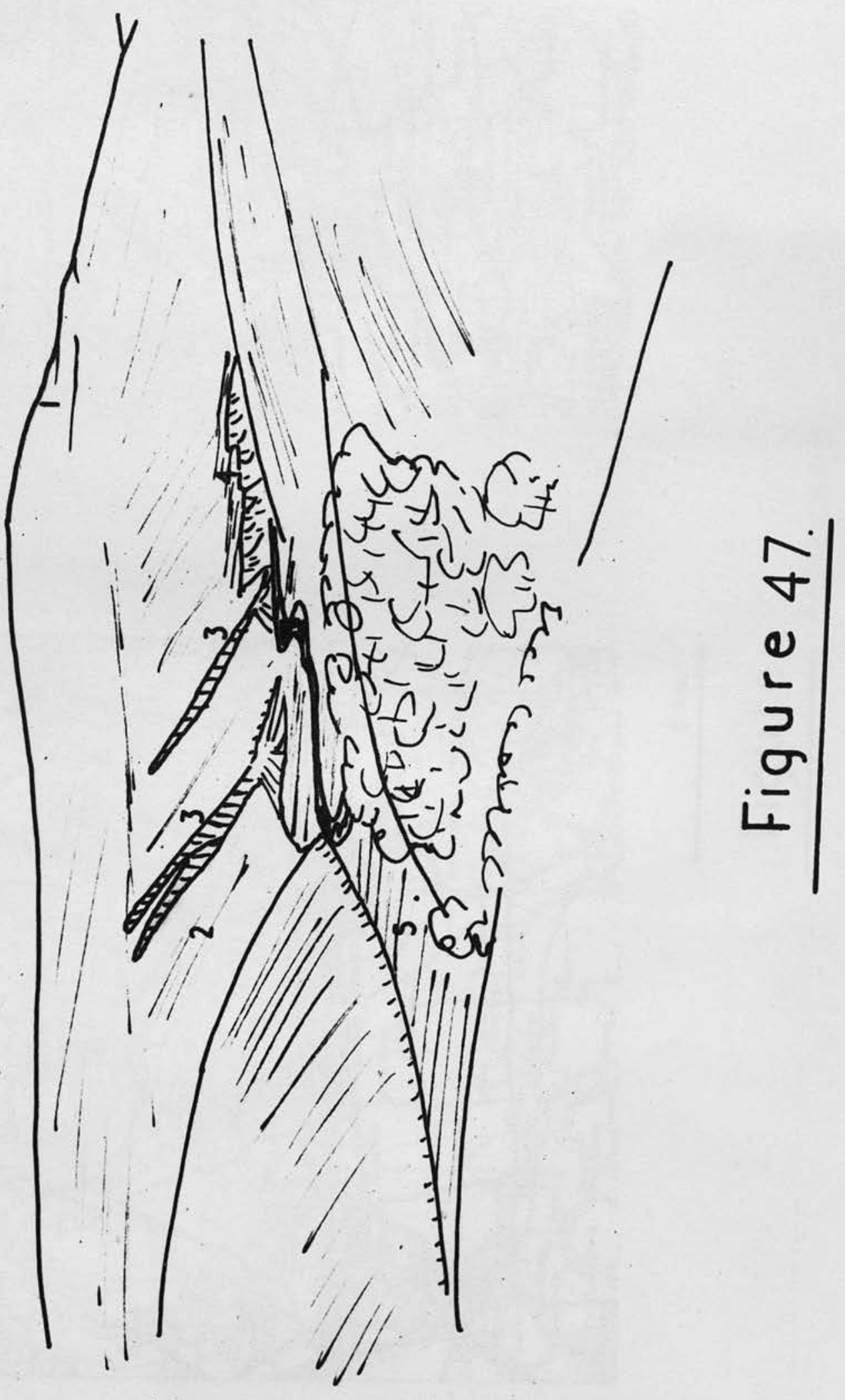


Figure 48 .

The Ochil hill-foot fans. 


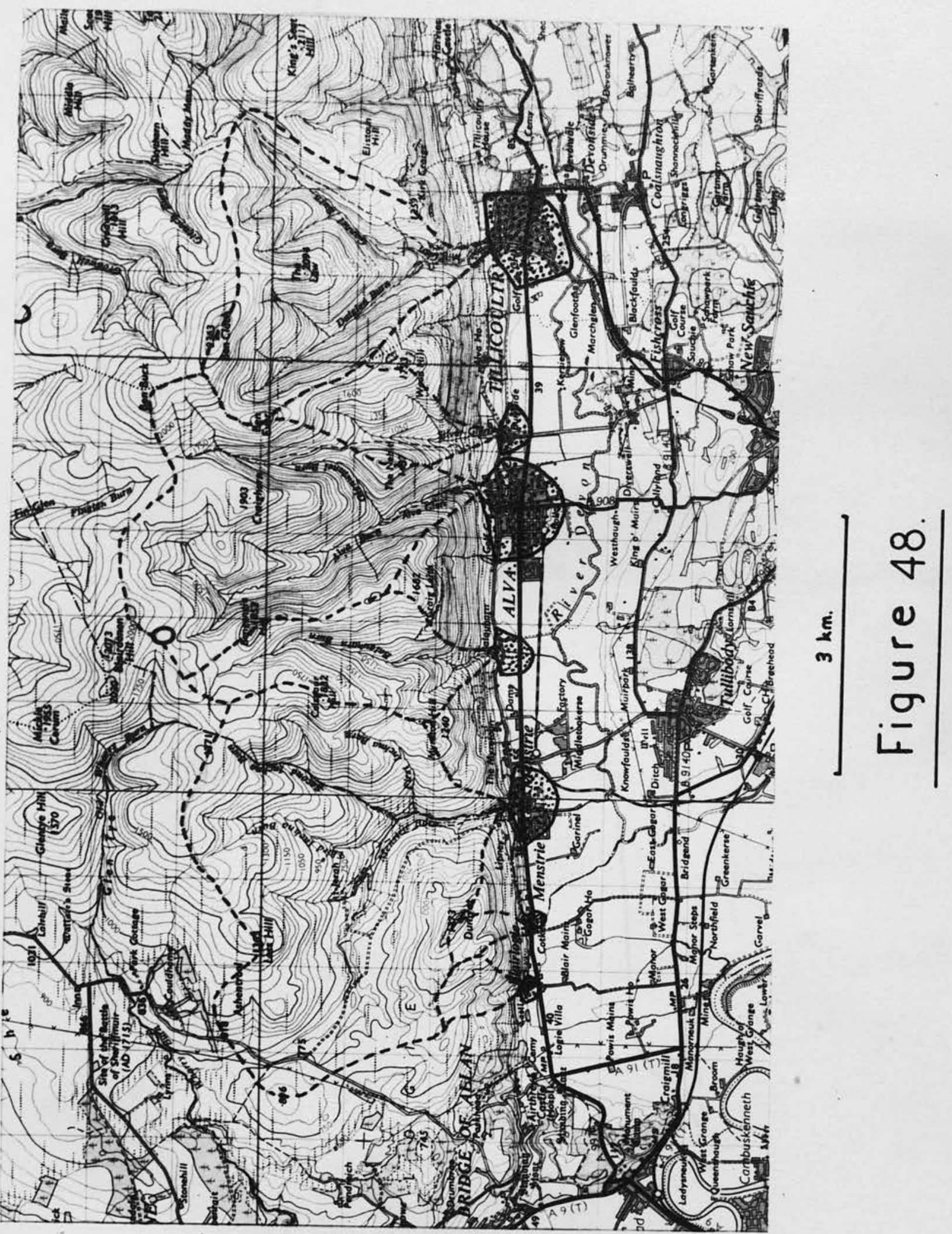




\section{Figure 49.}

Sketch profile across valley of Burn of Corfinnoch, $7 \mathrm{~km}$. N of Edzell.

1- bench of glacial till.

2- straight mass-wasting slope with terracettes and thin slope deposits which have not appreciably encroached on the till bench. 


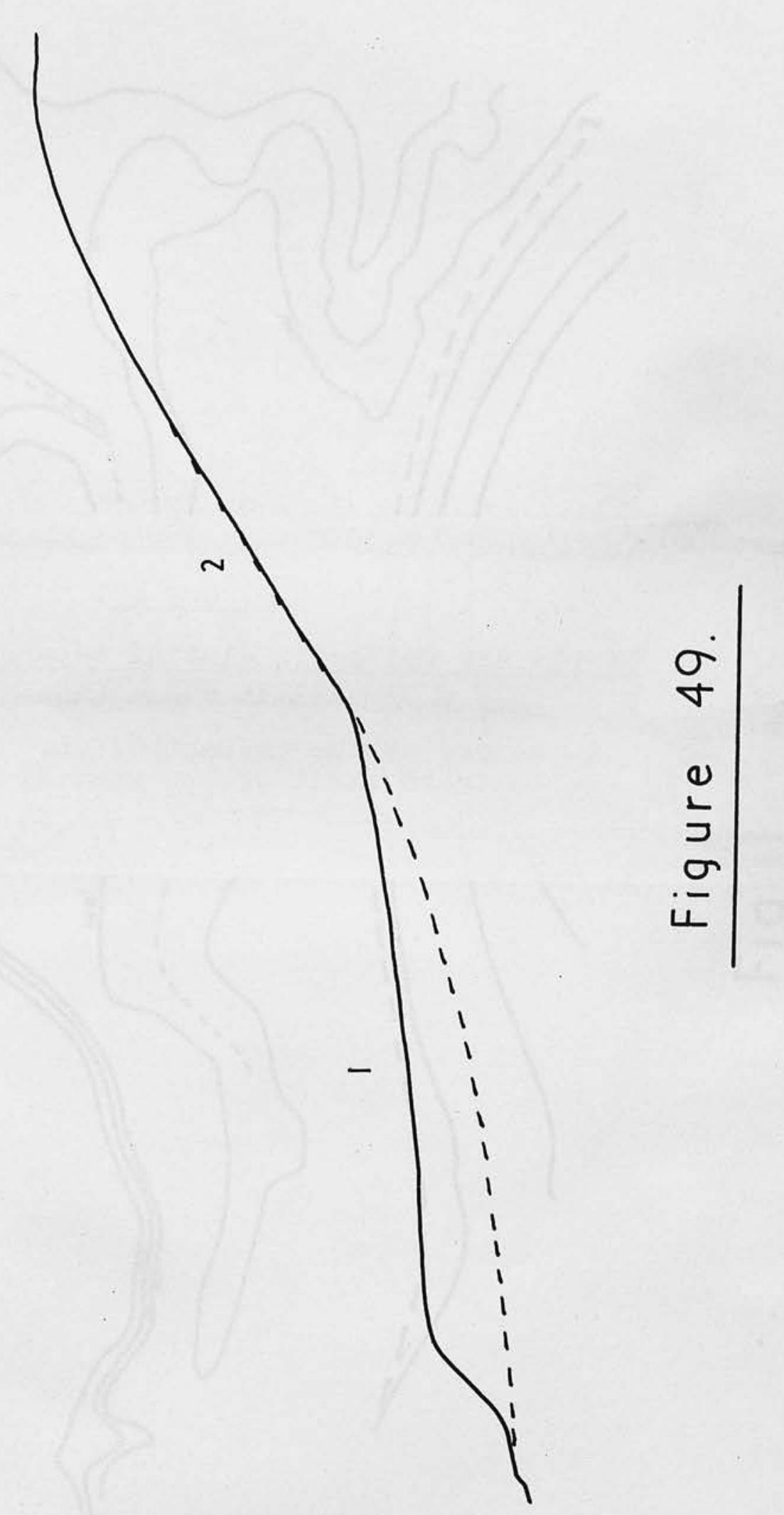




\section{Figure 50.}

Nearly dry valley in glacial outwash between Hunting-

$$
\text { tower and Perth. }
$$

1- course of the present ditch.

2- southern limit of the glacial outwash gravels. 


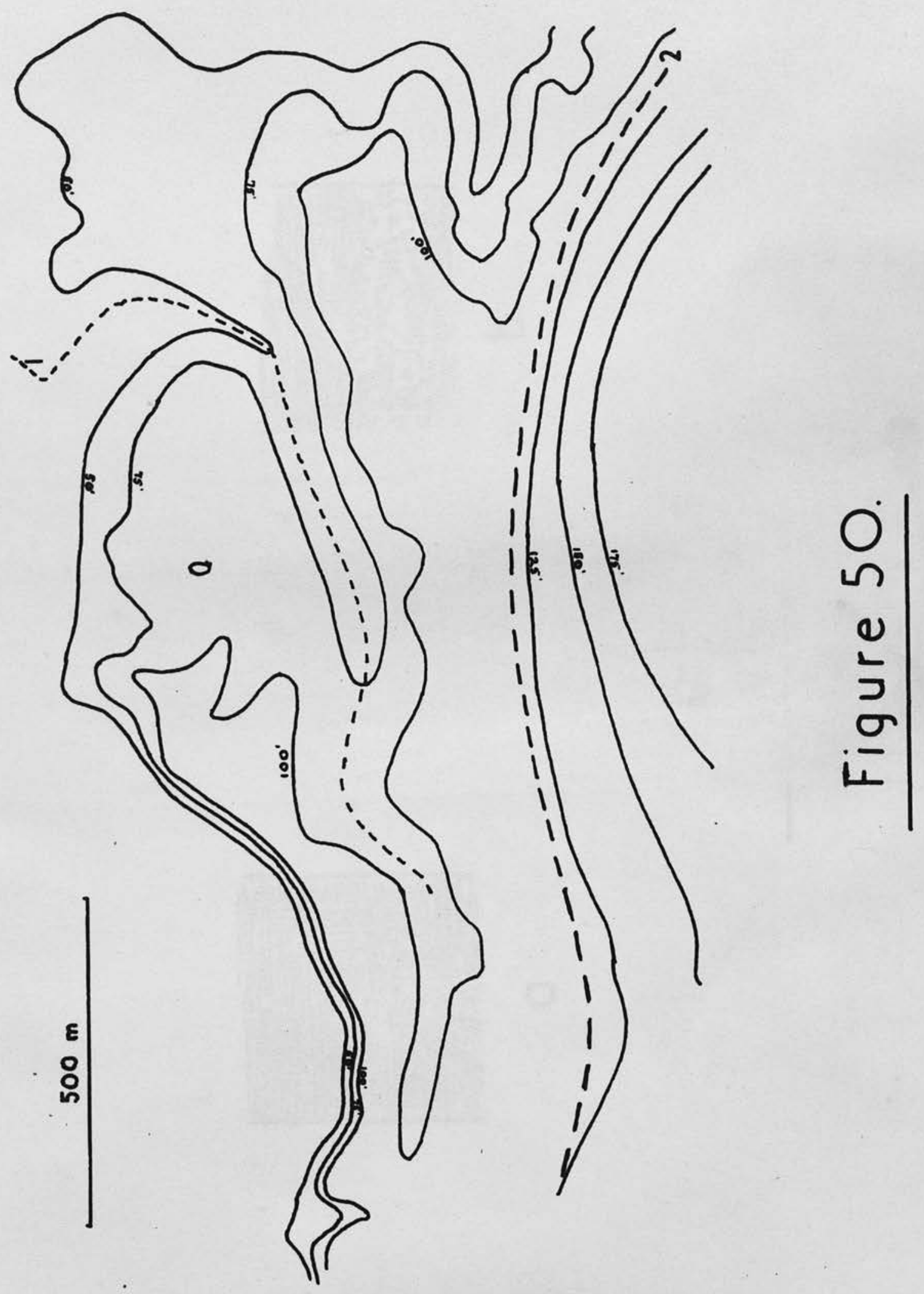




\section{Figure 51.}

Probable cryoturbation phenomena figuredby BLACKADDER, in 1824 .

a- probable wedge in sands and fine gravel. No scale.

$\mathrm{b}$ - probable involutions in sands and clays of the late glacial raised beach. Depth of section about 10 feet. 

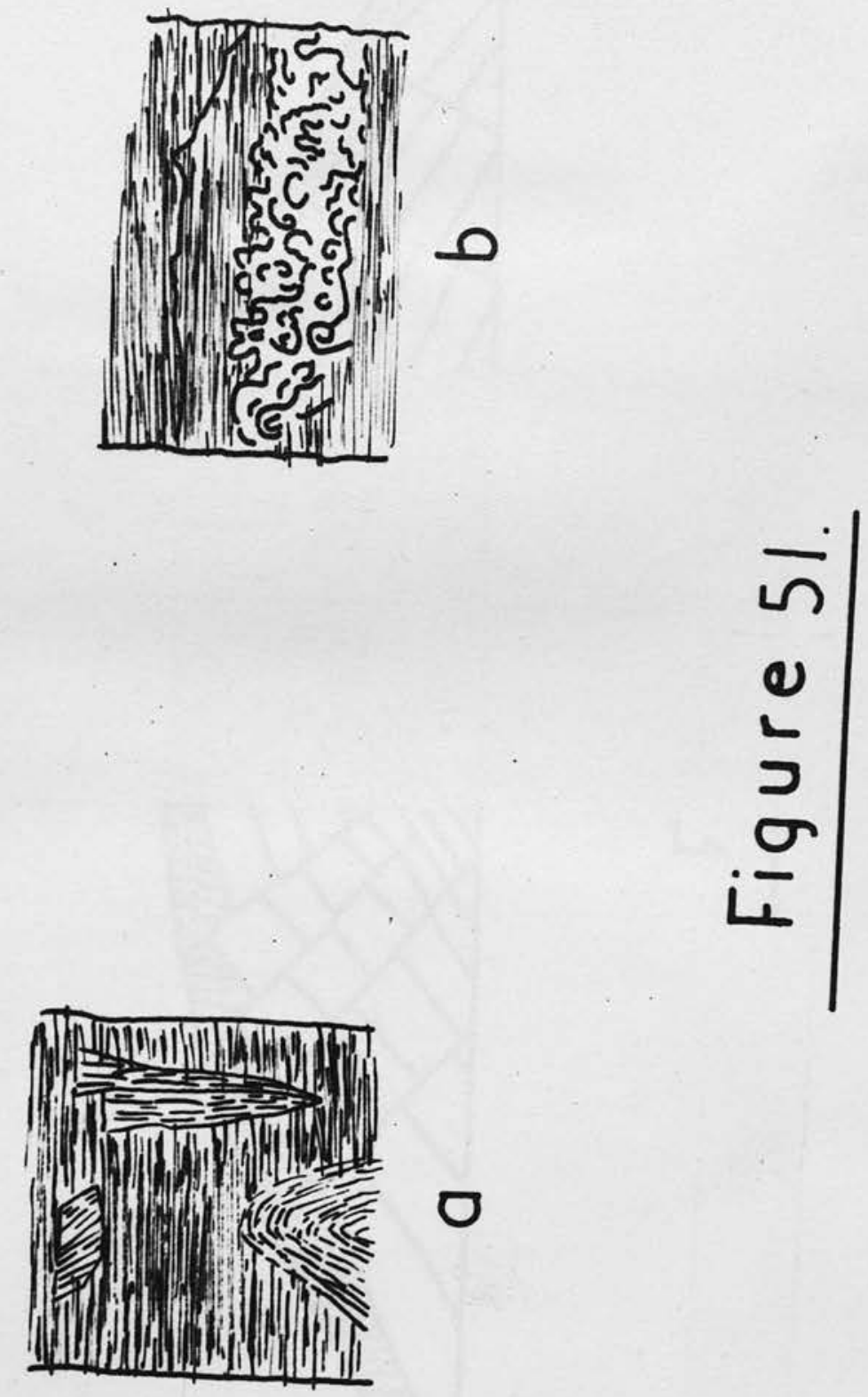
Figure 52.

Section in mound of sand capped by gravel as il1ustrated in SIITH, 1839.

1- gravel.

2- sand. 


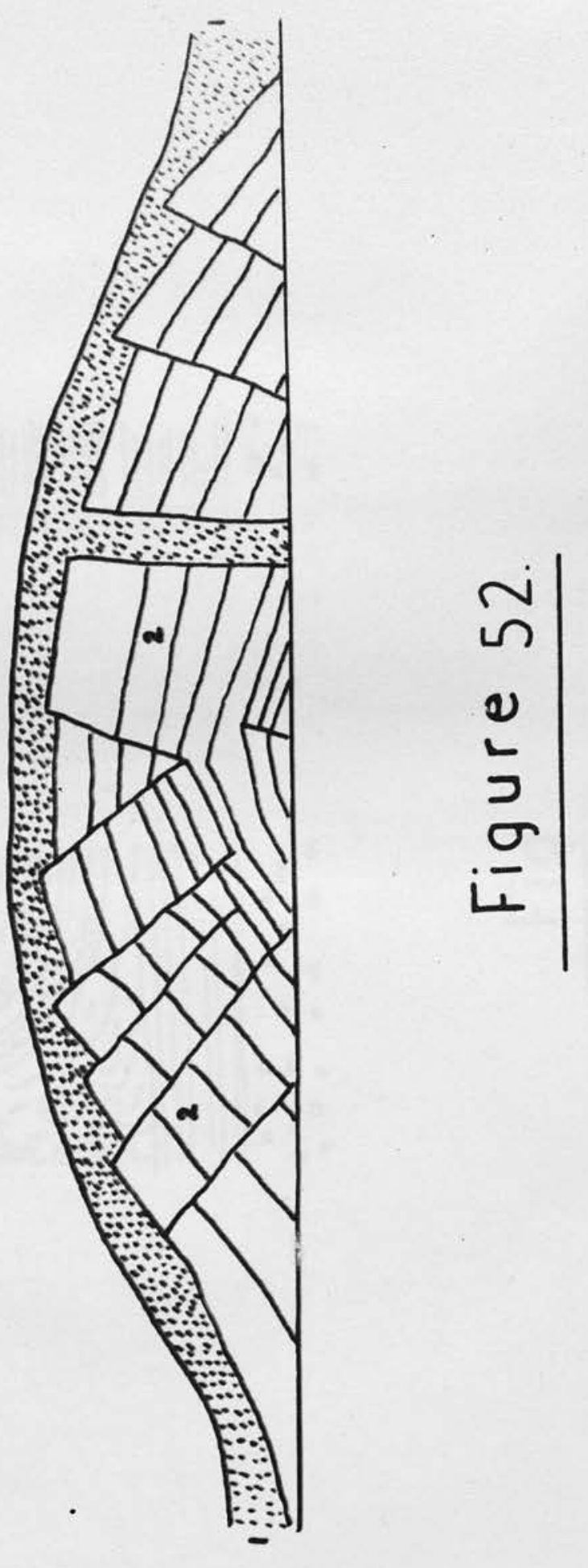




\section{Figure 54.}

Section on $N$ bank of Iless Bogie, at Bridgend, $4 \mathrm{~km}$. S of Huntly, Aberdeenshire.

1- earthy, stony slumped material.

2- peat layer. 

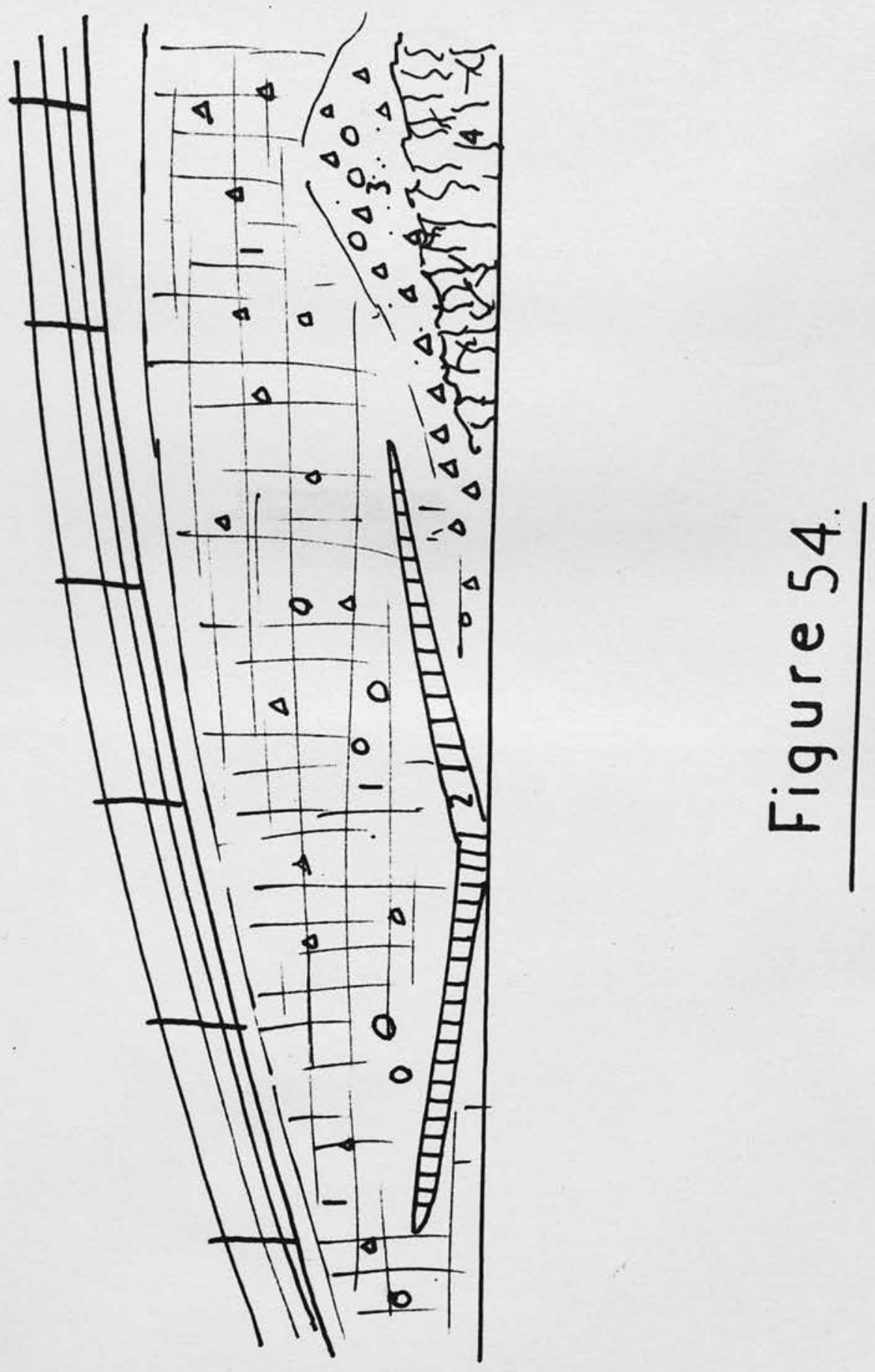
PHOTOGRAPHS 

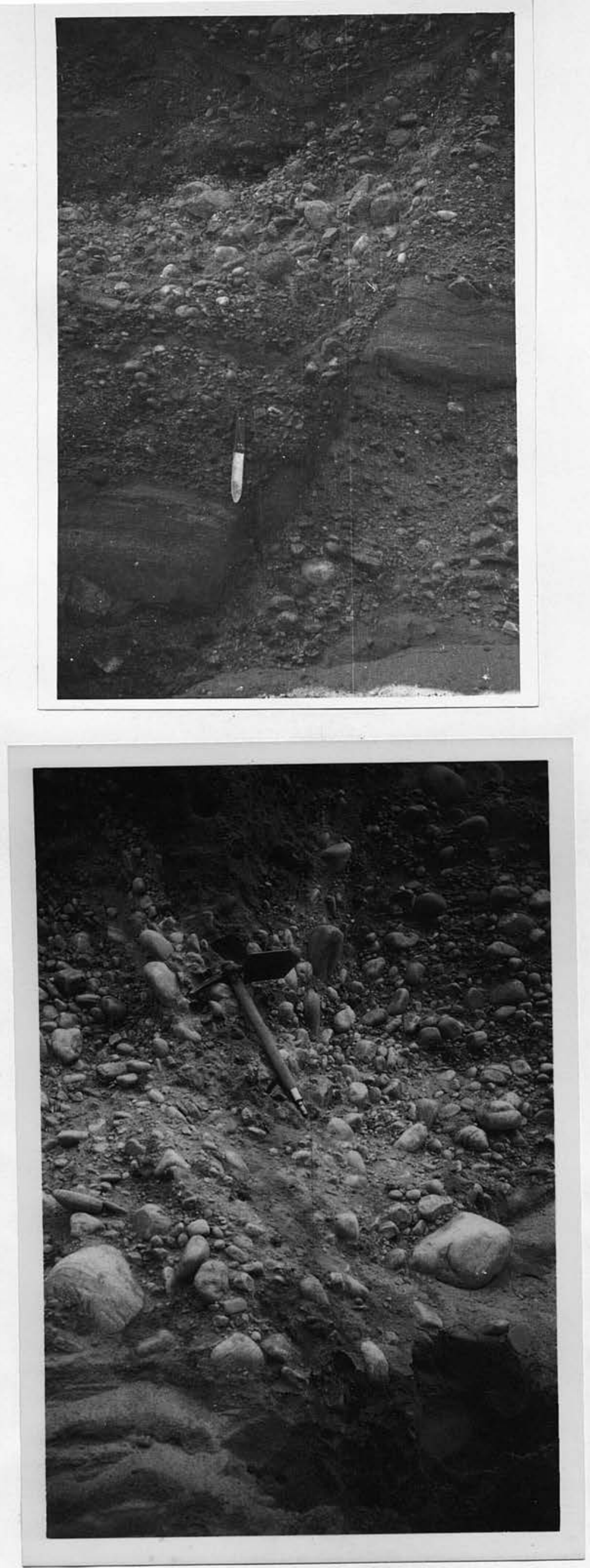


\section{Photograph 1.}

Fault in glaci-fluvial gravels at Hill of Auchleuchries, Buchan, Aberdeenshire. (G.R. 006366).

\section{Photograph 2.}

Fossil ice wedge in late glacial outwash gravels exposed in a pit $2 \mathrm{~km}$. SW of Beauly. (G.R.511449). 

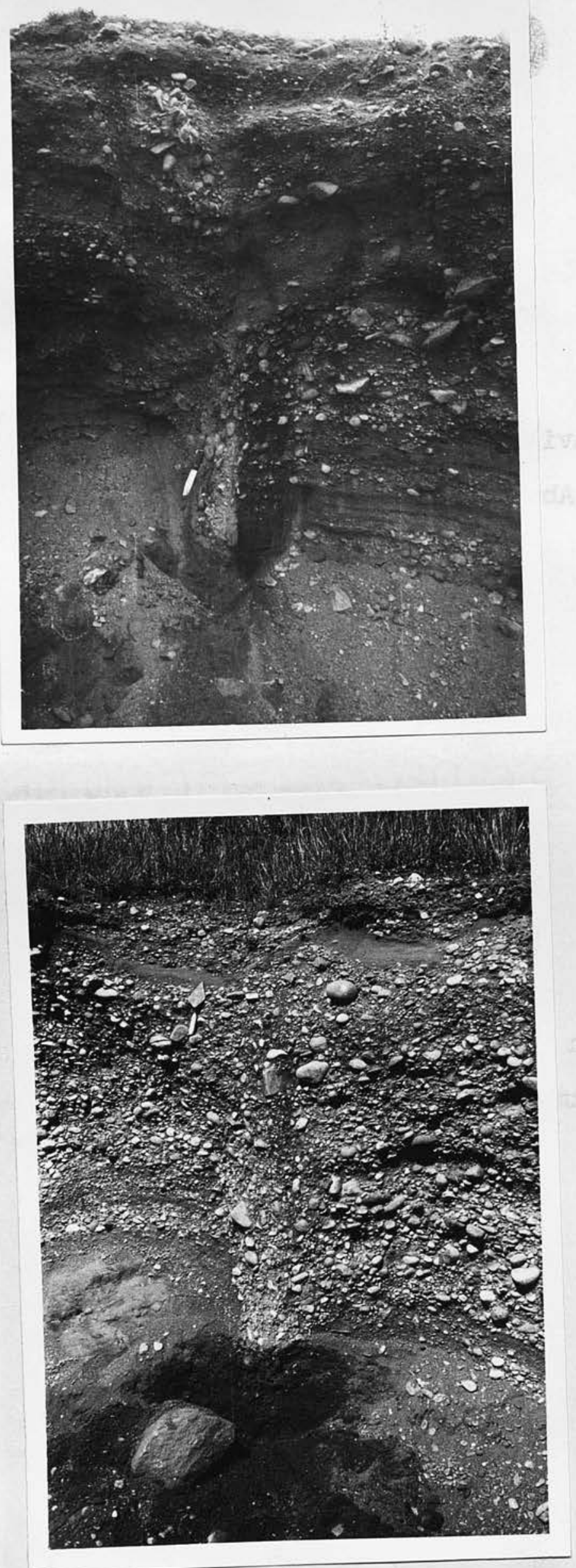


\section{Photograph 3.}

Wedge in gravel pit at Denhead, $6 \mathrm{~km}$. SE of Strichen, Buchan, Aberdeenshire. (G.R. 995522).

Photograph 4.

Wedge in a kame, c. $6 \mathrm{~km}$. E of Forfar.

(G.R. 5252). 

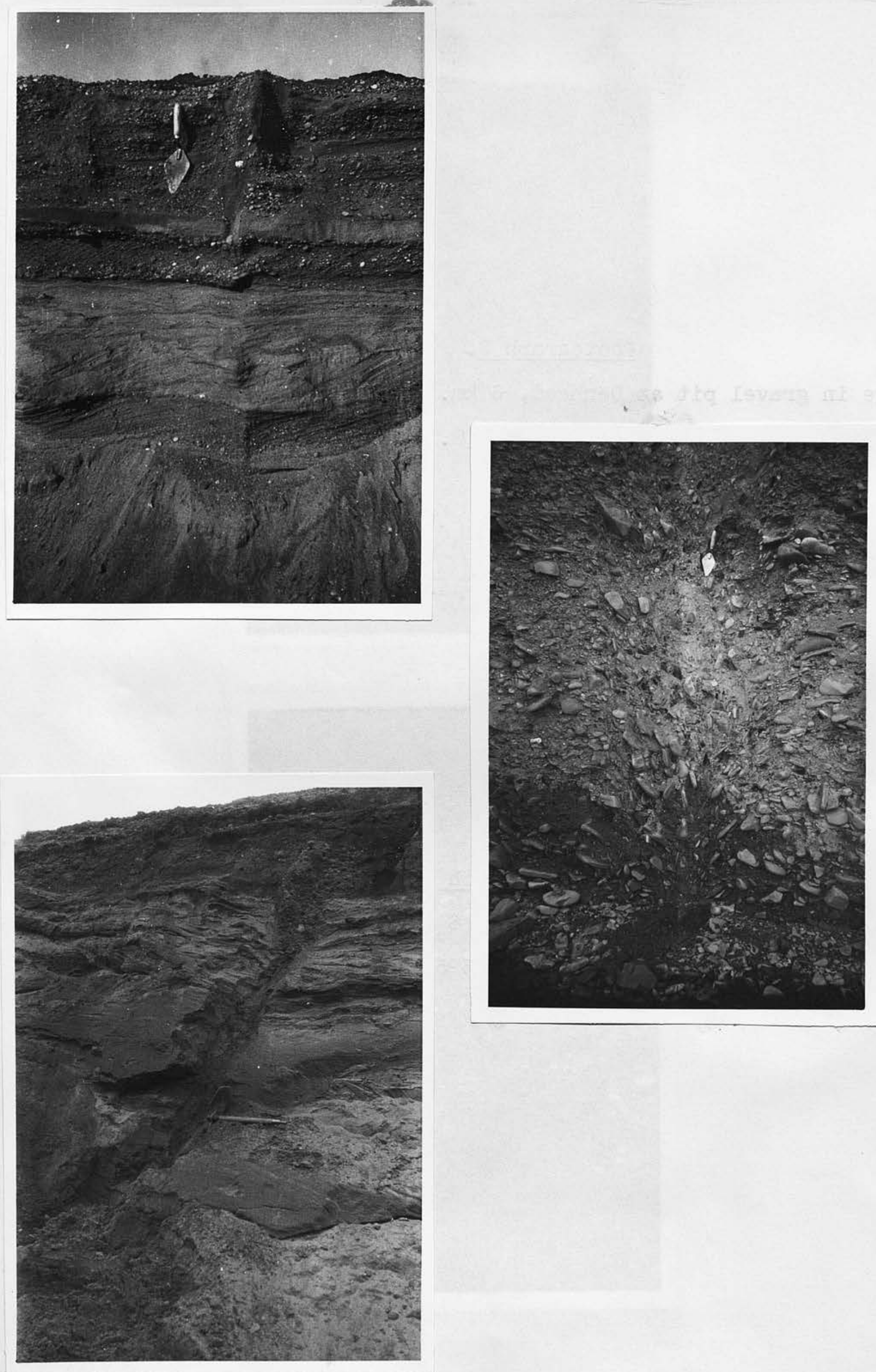


\section{Photograph 5.}

Small wedge in sandpit $3 \mathrm{~km}$. S of Kinross. (G.R.129990).

\section{Photograph 6.}

Wedge in glaci-fluvial (?) gravel at Reston, Berwickshire. (G.R. 877622).

(cf. figure 9)

\section{Photograph ?.}

Wedge in kame at Bathgate. (G.R. 985678).

N.B. Taken oblique to the axis of the structure. cf. figure 10, taken at right angles to the axis. 

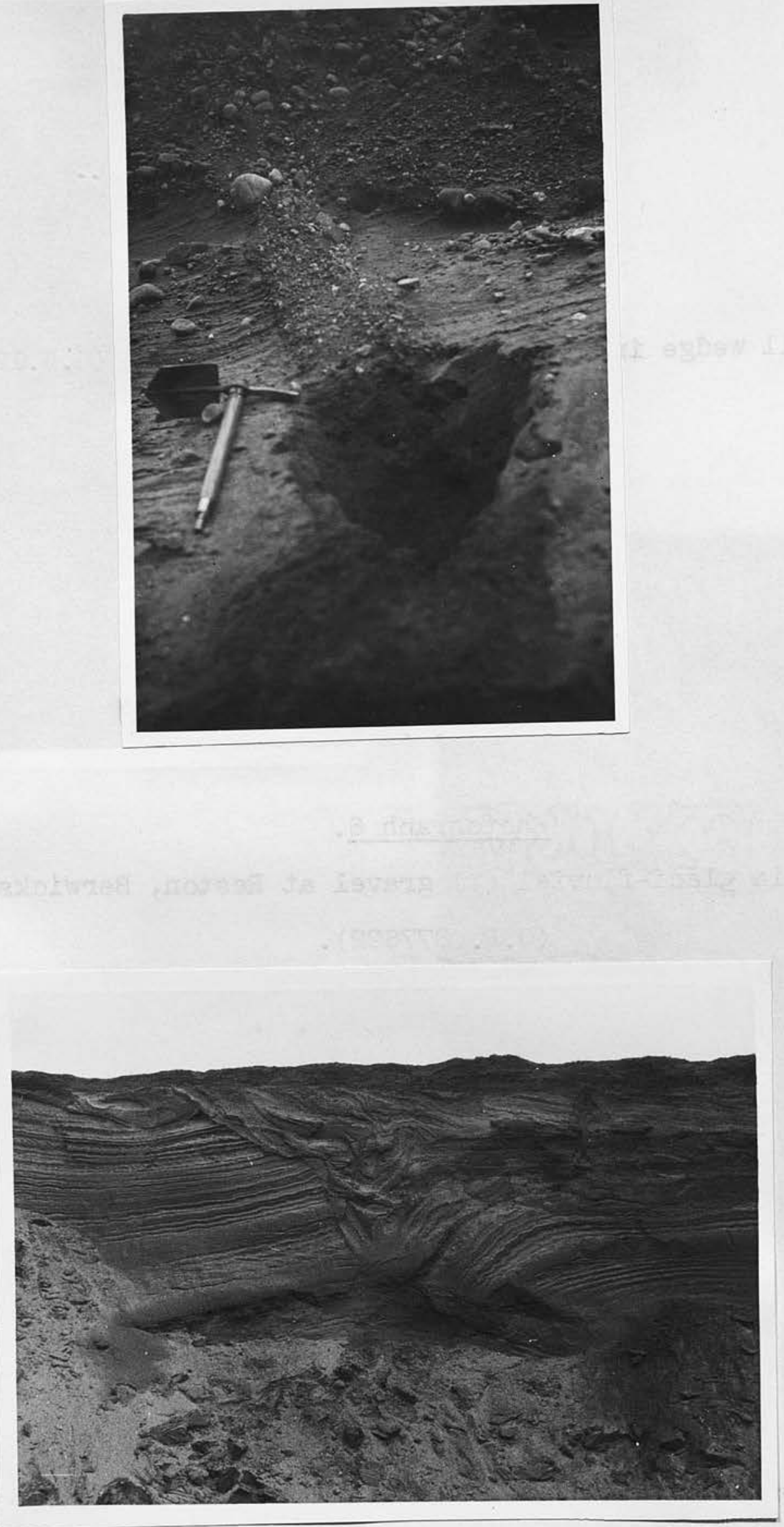


\section{Photograph 8 .}

Upper part of a wedge in Auchenlea sandpit, $1 \mathrm{~km} . N$ of Carstairs. (G.R. 94146ף) .

(N.B. One of the few wedges in Scotland showing upcurling of the bedding at the margins.)

Photograph 9.

"Washout" structure in Keir \& Cawdor No. 3 pit, $1 \frac{1}{2} \mathrm{~km}$. S of Balmore. (G.R. 598725).

cf. figure 11. 

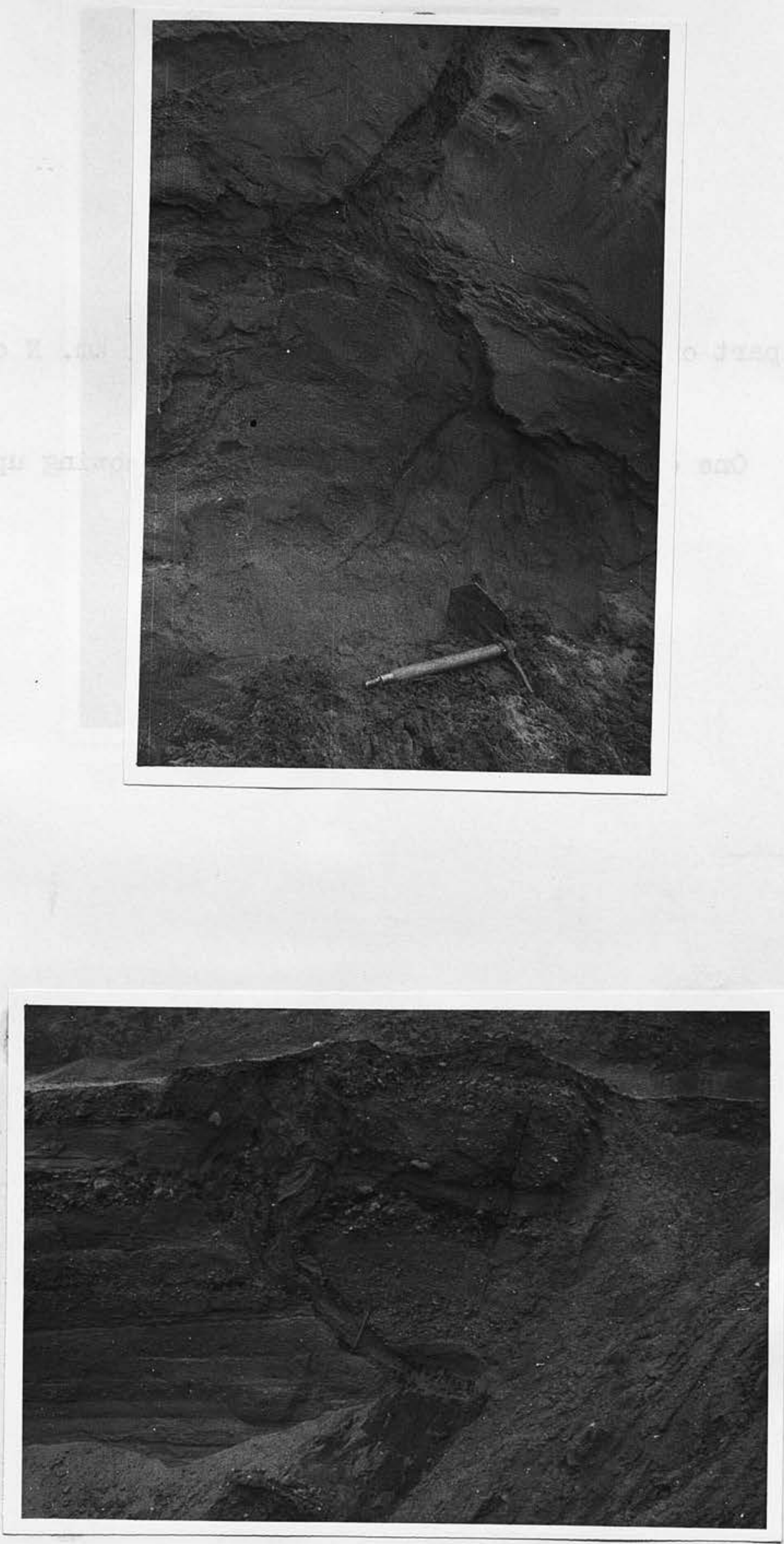
Photograph 10.

Lower end of the clay seam $X-X$ shown in figure 11 , and in photograph 9.

Photograph 11.

Large wedge (?) in abandoned sand pit on the $N$ side of the Forth and Clyde canal, Balmore area. (G.R.611721). 

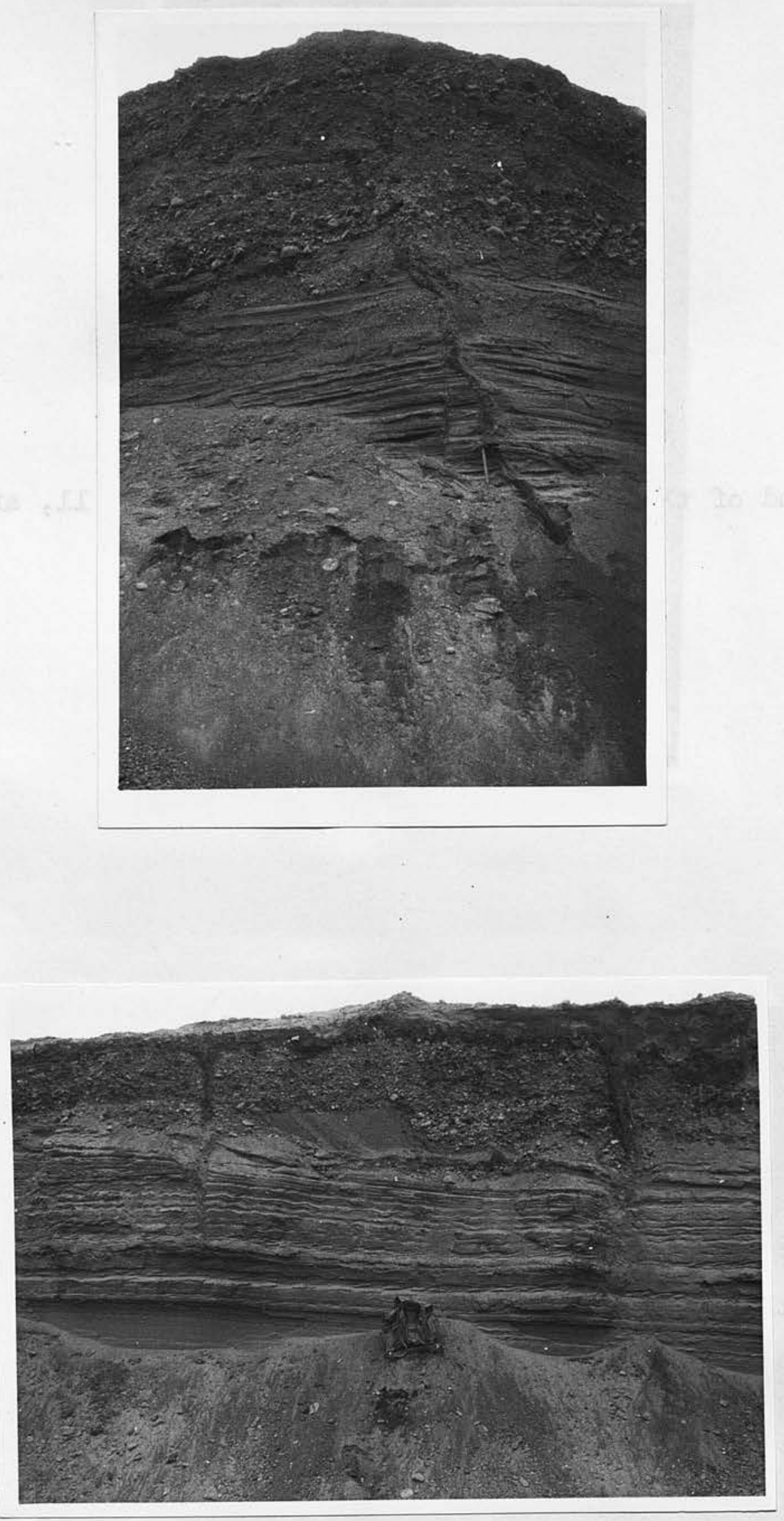


\section{Photograph 12 .}

Frost crack in abandoned sand pit on the $N$ side of the Forth and Clyde canal. (G.R. 611721).

Photograph 13.

Two narrow dges in a sandpit at Dmumclog, Strathavon. (G.R.645387). 

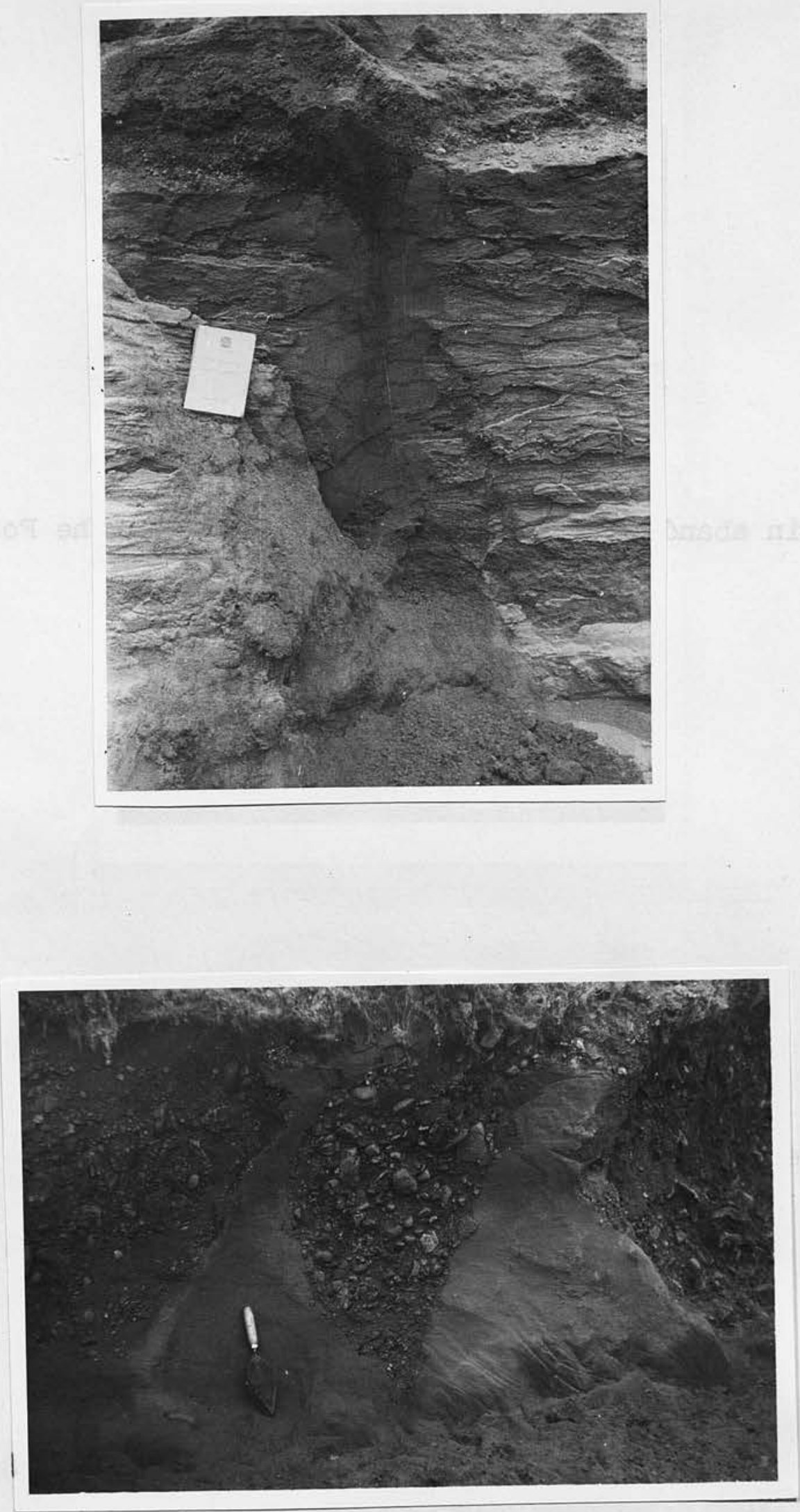


\section{Photograph 14.}

Small wedge with rounded bottom in sandpit at Stomehouse, Lanark. (G.R. 7547).

Photograph 15.

'Tropfenboden' at Dalbog, Angus. (G.R. 592717). 

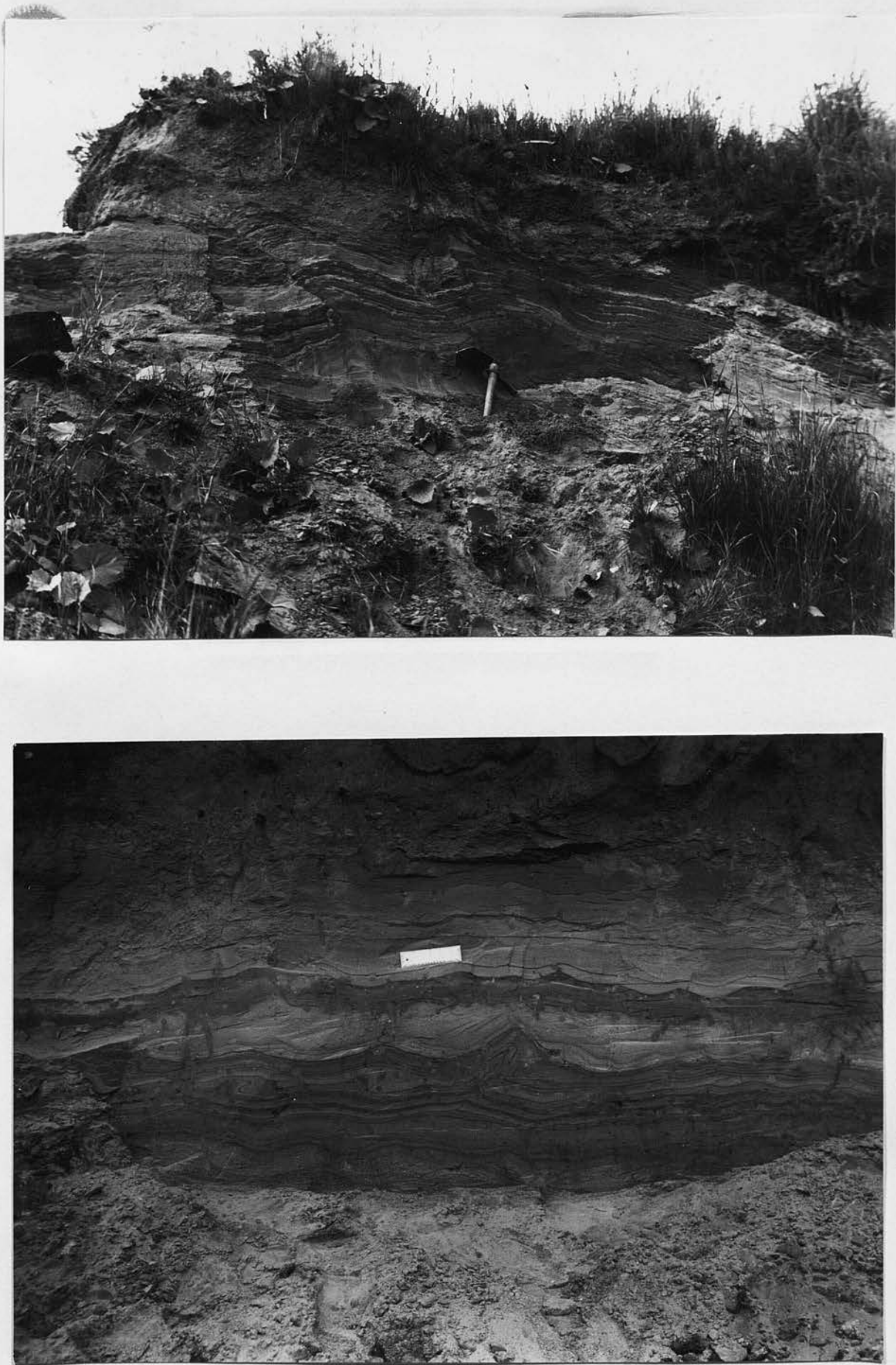


\section{Photograph 16.}

Cryoturbation in Foxley sanpit, Lanark.

(Geological Survey photograph C4232)

Photograph 17.

Bound involutions in Brackletter sandpit, $3 \mathrm{~km} . \mathrm{N}$ of spean Bridge. (Geological Survey photograph C4092) 

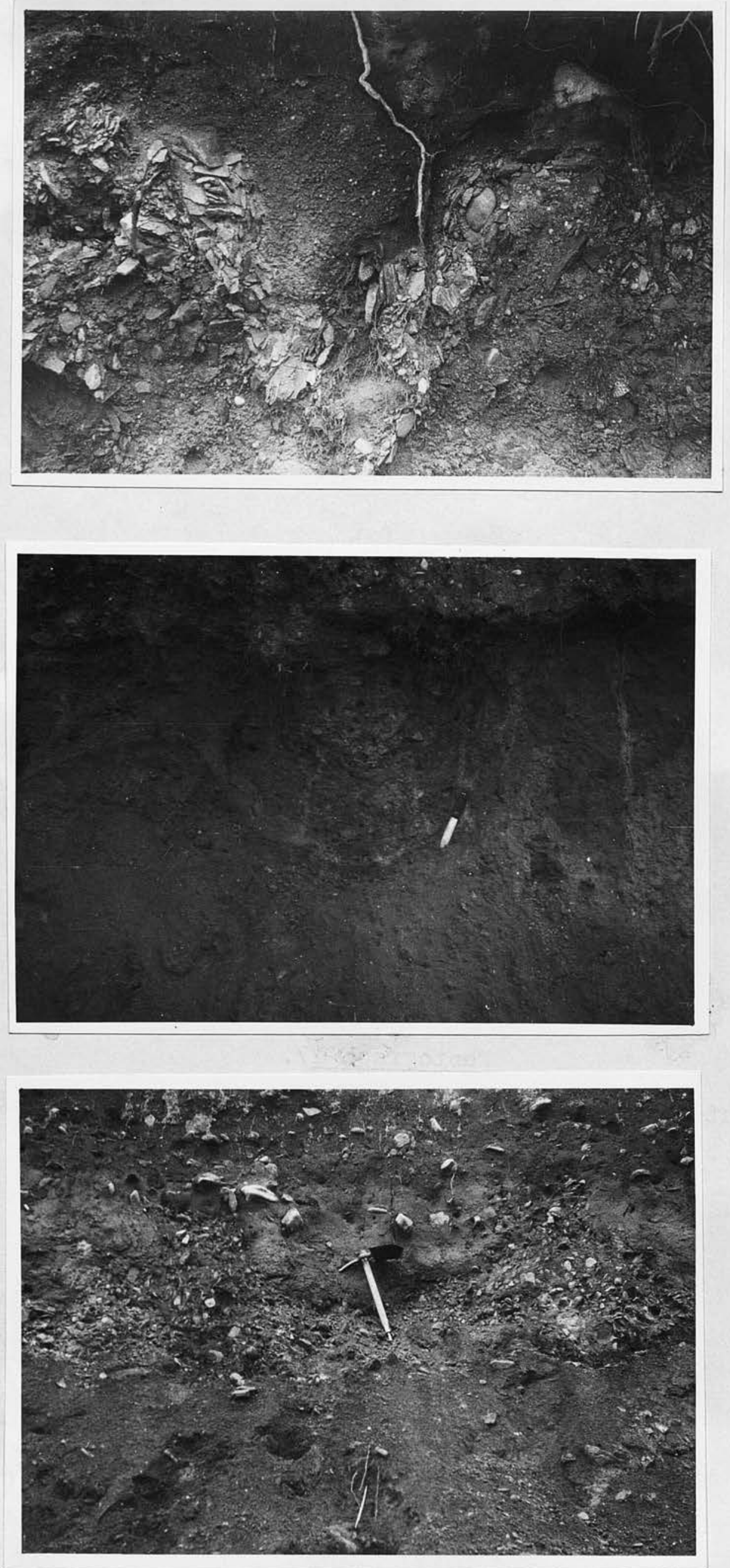
Photograph 18.

Free involutions at Nigg Bay, Aberdeen. (G.R. 9604). (Sectioned stone polygon)

\section{Photograph 19.}

Free (?) involutions at Tochineal quarry $2 \mathrm{~km}$. SSE of Cullen. (G.R. 5265).

Photograph 20.

Free involutions in a gravel pit at Ruthven, Strathbogie, Aberdeen. (Sectioned stone polygons) 

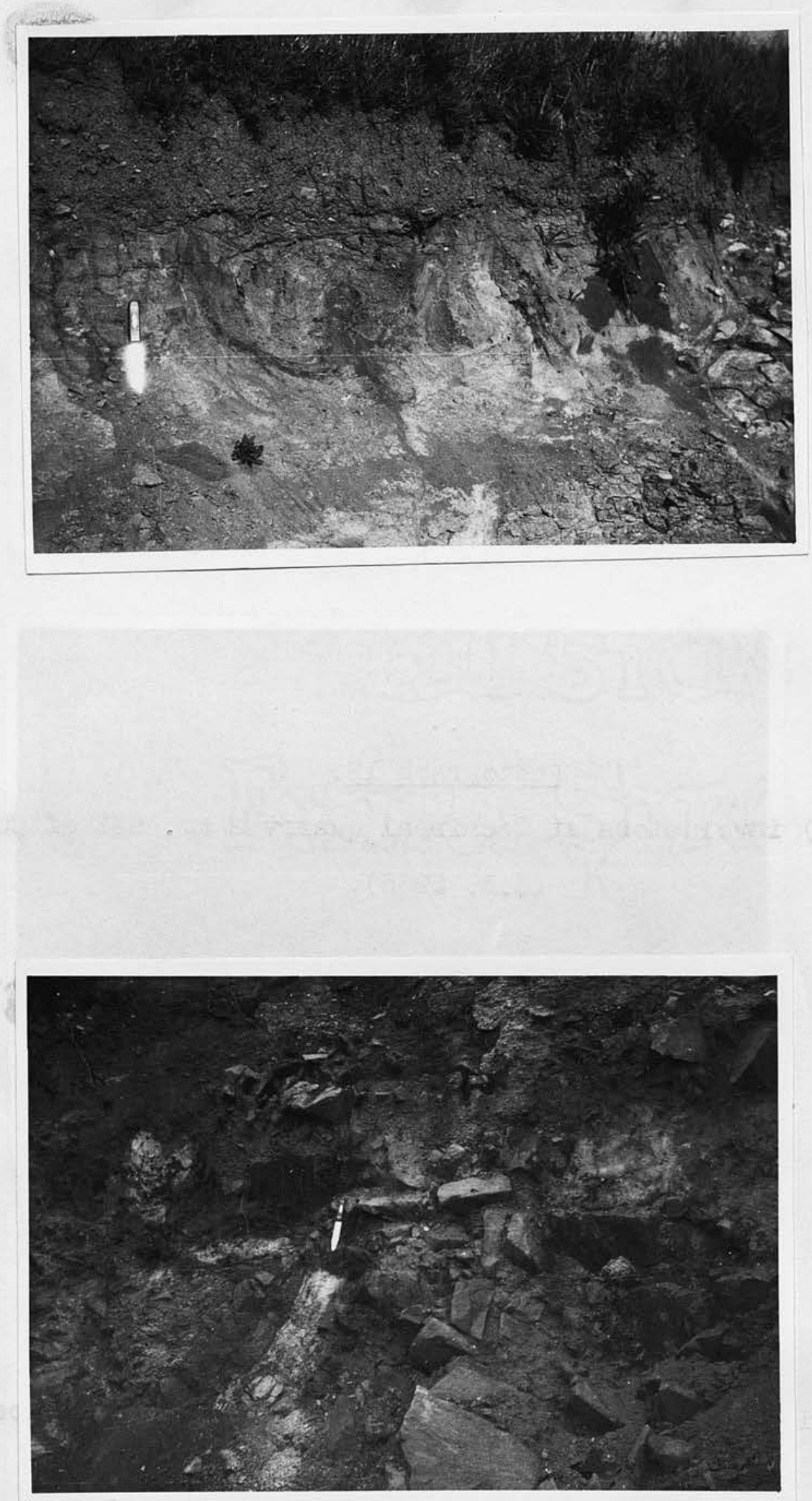


\section{Photograph 21.}

Free (?) involutions at Mains of Birness, Buchan, Aberdeenshire. (G.R. 991340).

The cryoturbated material is weathered gneiss.

\section{Photograph 22.}

Distortion of a quartz vein in chemically weathered and frost shattered schist at Braehead farm, $3 \mathrm{~km}$. NW of New Pitsligo, Aberdeenshire. (G.R. 869584).

(cf. figure 14) 

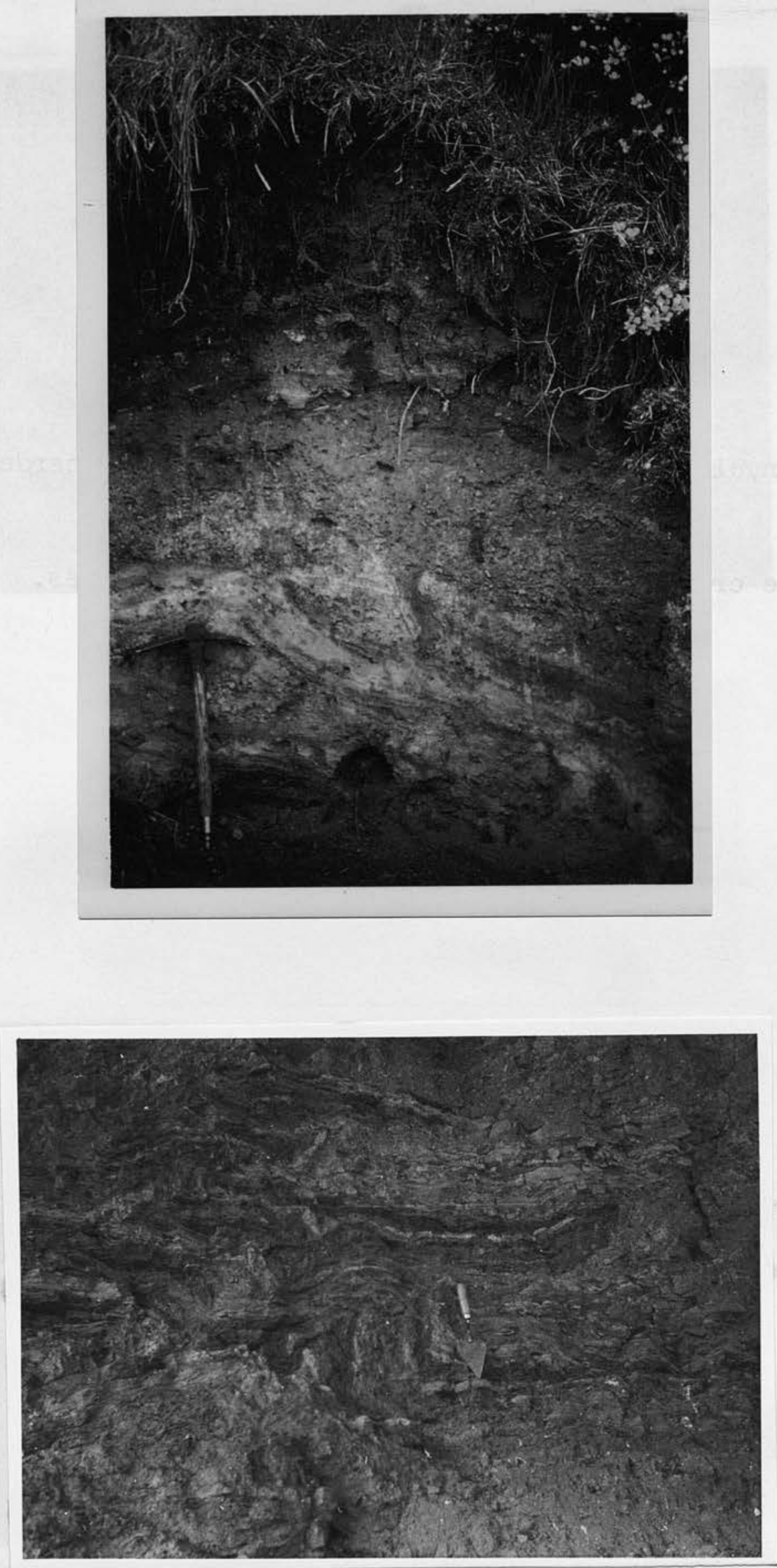
Photograph 23.

Cryoturbation of chemically weathered schist $2 \mathrm{~km}$. SW of New Pitsligo, Aberdeenshire. (G.R. 868544).

Photograph 22 .

Bound involutions or ice-drag structure on $\mathrm{N}$ bank of Teviot, $2 \mathrm{~km}$. SW of Ancrum. (G.R. 620234). 

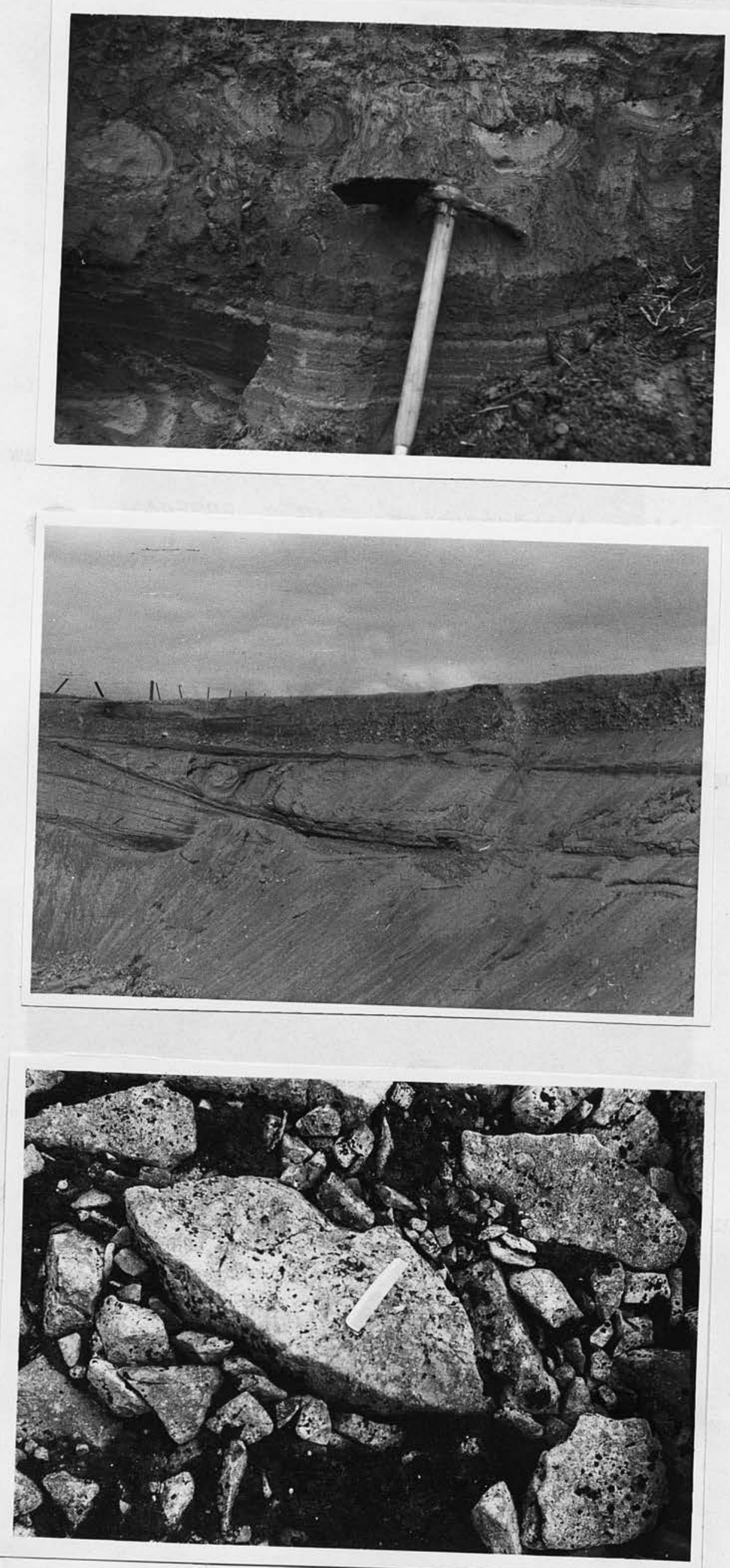
Photograph 25.

Bound involutions (?) in silts and clays of the "100 foot" raised beach at Bonnybridge, Stirling. (G.R. 827806).

Photograph 26.

Bound involutions in glaci-lacustrine material at Drumclog, Strathavon, Lanarkshire. (G.R. 645387).

Photograph 27.

Packing of small stones round a boulder on the summit of Ben Nevis. 

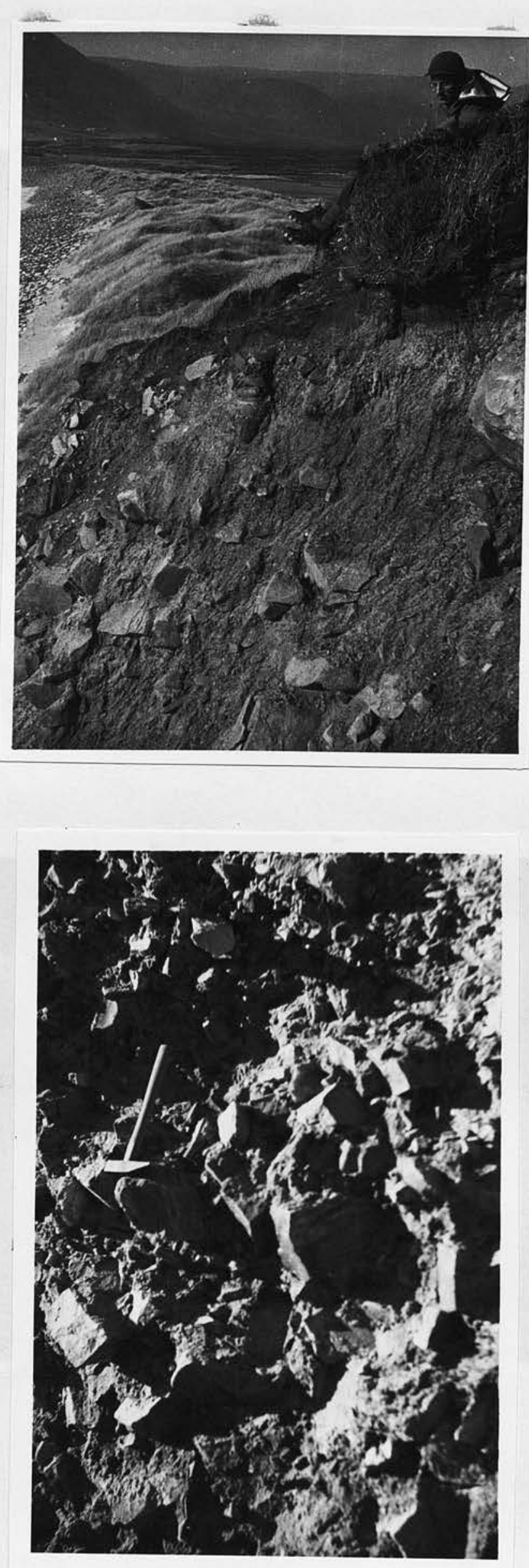
Photograph 30.

Solifluction deposit at the S end of Rackwick Bay, Hoy, Orkney. Frostshattered chunks of sandstone in sandy matrix.

Photograph 31.

Frostshattered quartzite at Sillyearn Hill, near Keith, Banffshire. (G.R. 507514). 

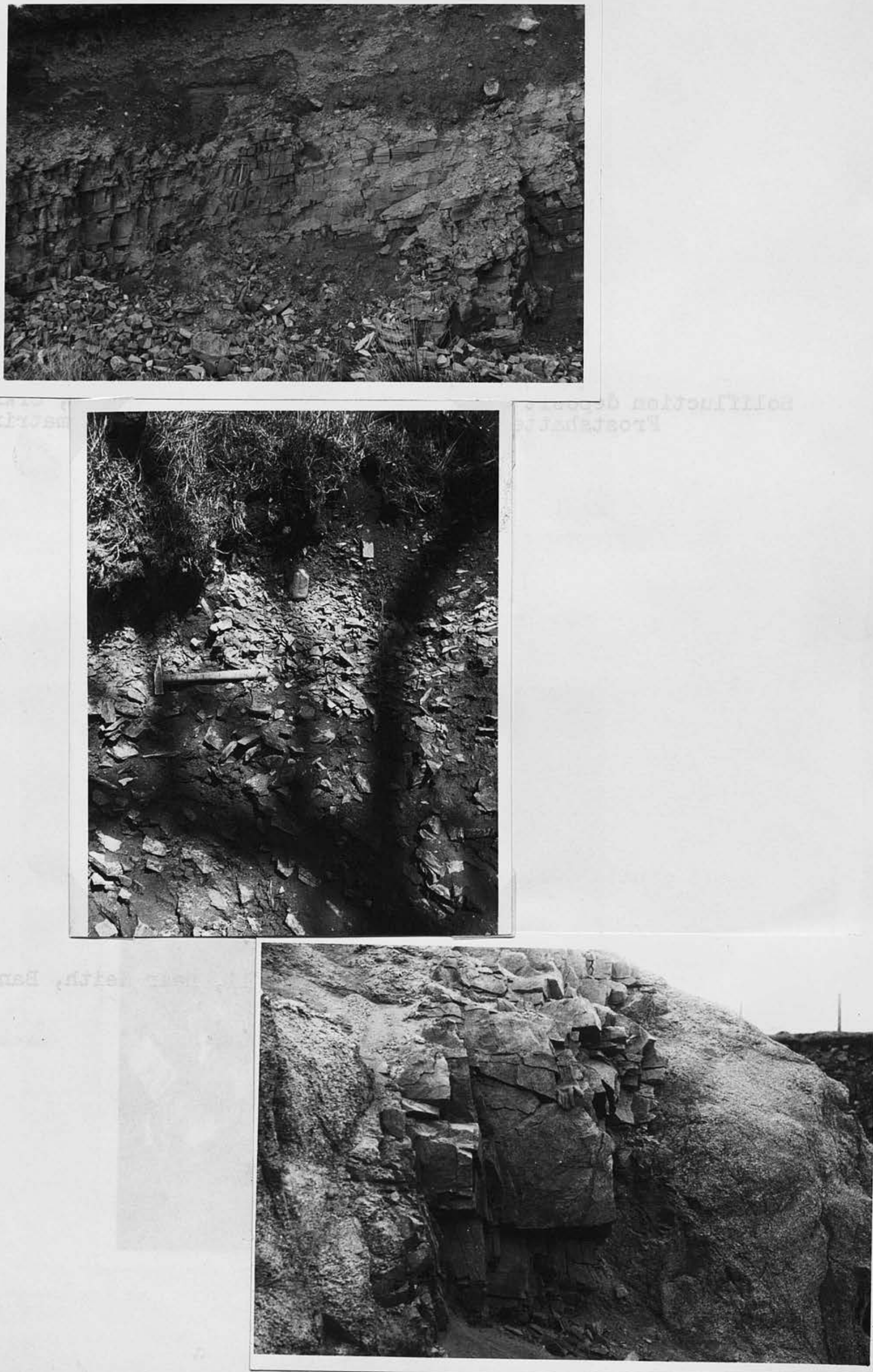
Photograph 32.

Frost shattered quartzite overlain by till at Newbiggin farm, Fordyce, Banffshire. (G.R. 527591).

Photograph 33.

Frost shattered phyllite at Bruckhills farm, Auchterless, Aberdeenshire. (G.R. 692379).

(cf. photograph 37)

Photograph 34.

Chemically weathered granite surrounding a belt of chemically sound but frost shattered rock in a quarry at Windyfield, Strathbogie, Aberdeenshire. (G.R. 4927). 

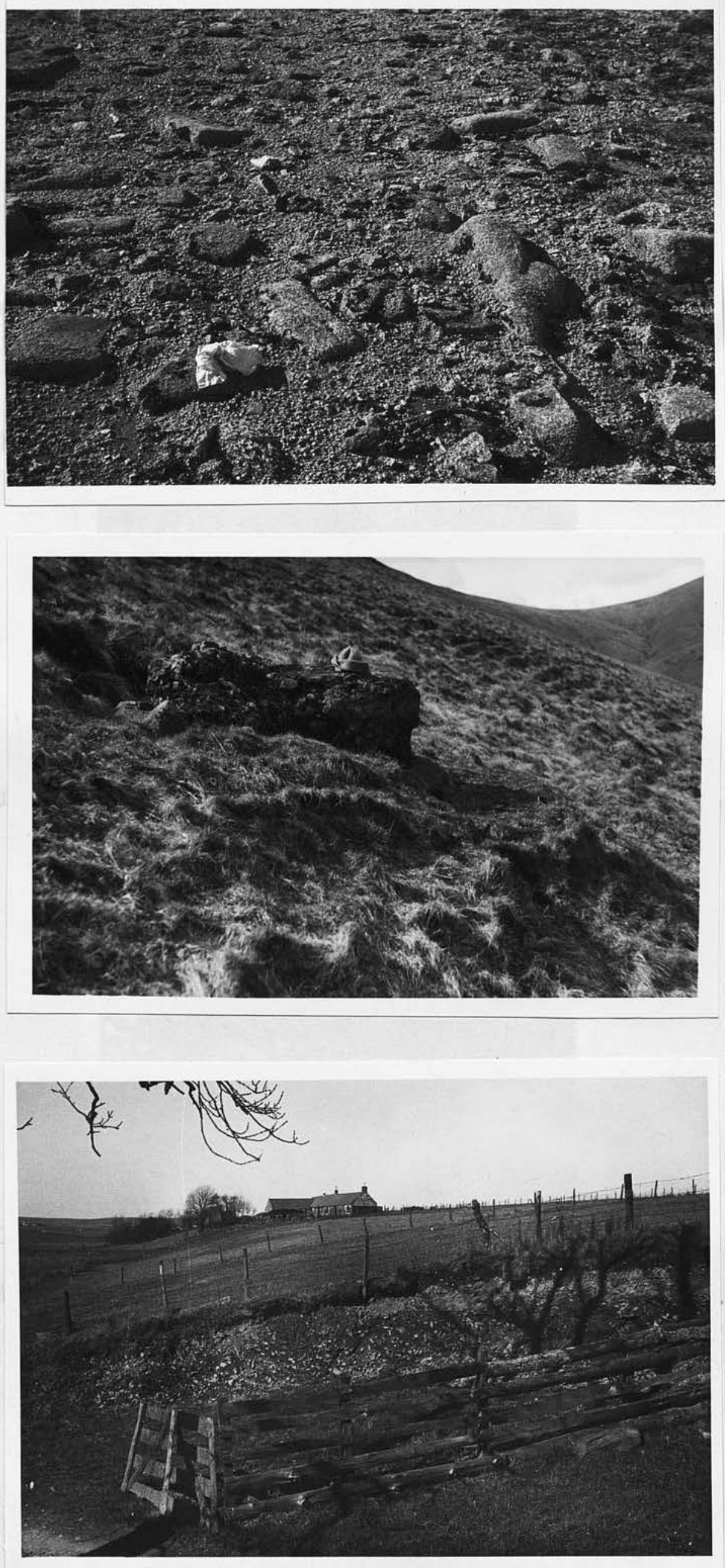
Photograph 35.

Block field on the summit of Ben Macdhui, composed of granite blocks.

\section{Photograph 36.}

Boulder creeping down the slope at an altmitude of c. $1800 \mathrm{ft}$. in the Ochils.

Photograph 37.

Smooth slope of periglacial mass wasting descending to flat floored upper Ythan valley. Bruckhill, Auchterless, Aberdeenshire. (G.R.692379). cf. photograph 33 and figure 32 . 

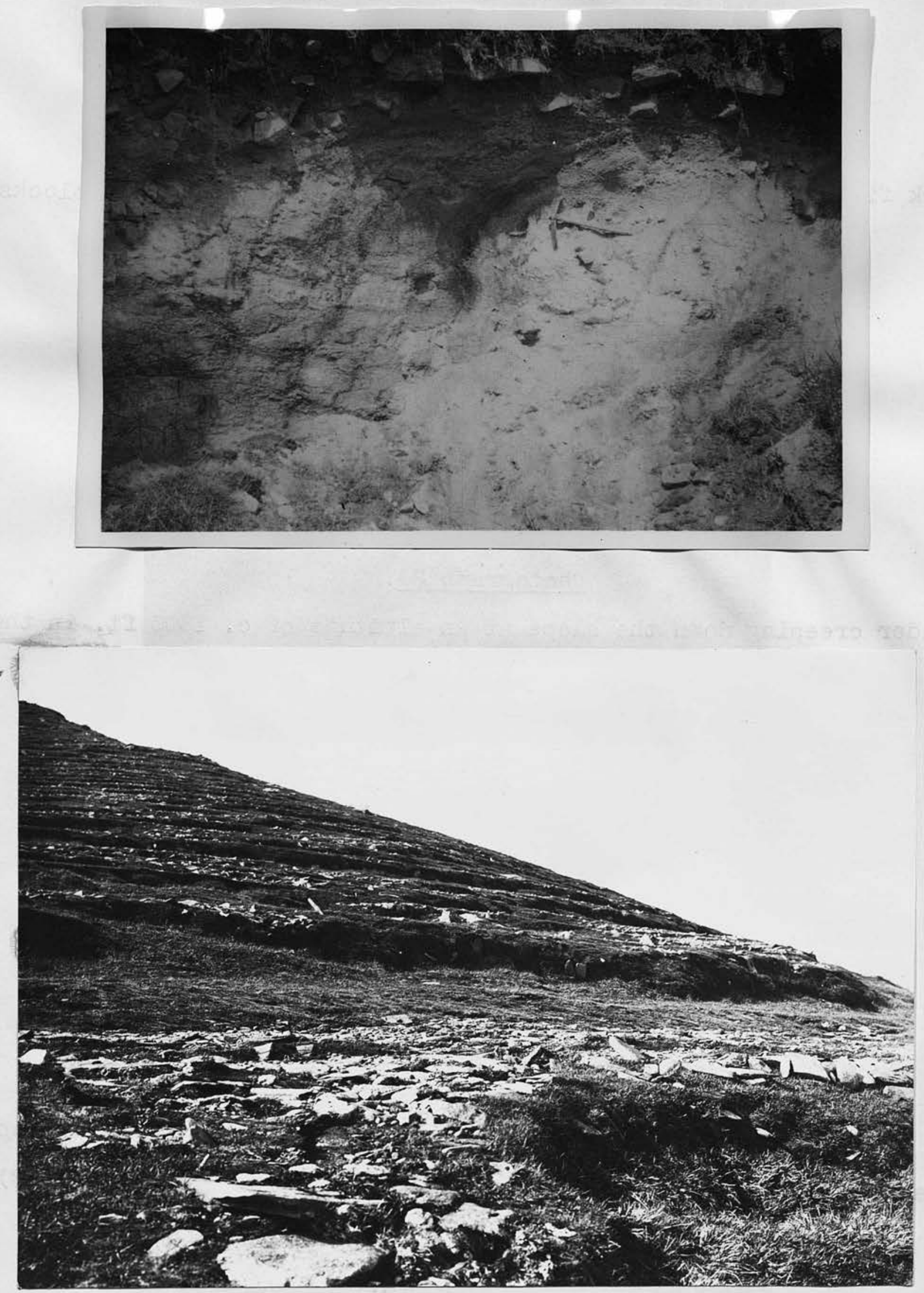


\section{Photograph 38.}

Periglacial solifluction in chemically weathered granite exposed by the roadside, $3 \frac{1}{2} \mathrm{~km}$. $\mathrm{S}$ of Strichen, Aberdeen.

(G.R. 957517).

Photograph 39.

Terraces formed by contemporary solifluction on the S slope of Sgurr Mior, Fannich Forest. Geological Survey photograph C 1333. 

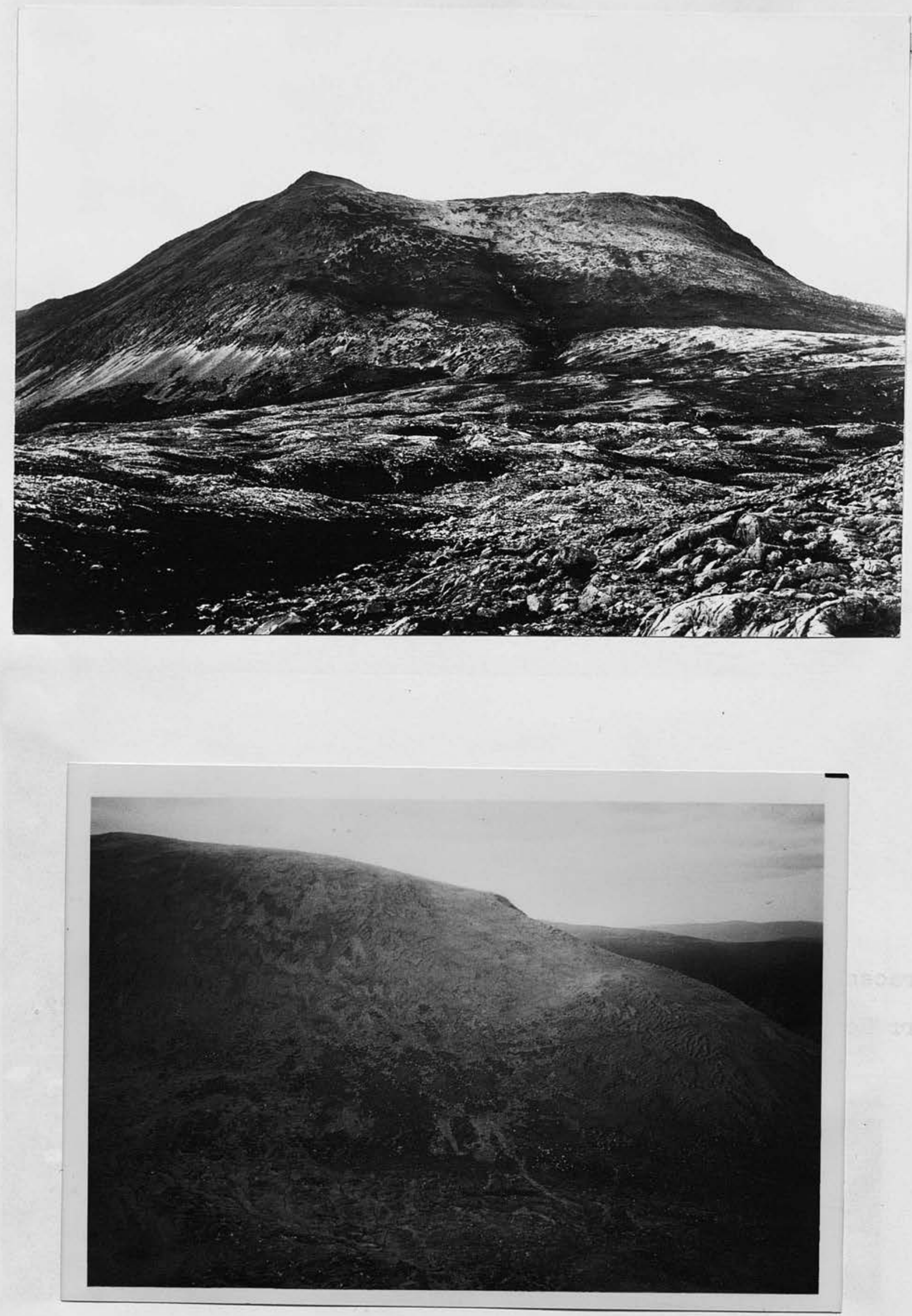


\section{Photograph 40.}

Stone fronted lobes and screes on Meall a Ghiubhais, Bein Eighe, Loch Maree. Geological Survey photograph B77.

Photograph 41.

Mass wasting on the S flank of Ant-Socah ridge, Ben Wyvis, Ross-shire. Fossil stone-fronted lobes being destroyed by individual block creep on the left; contemporary solifluction terraces on the right. 

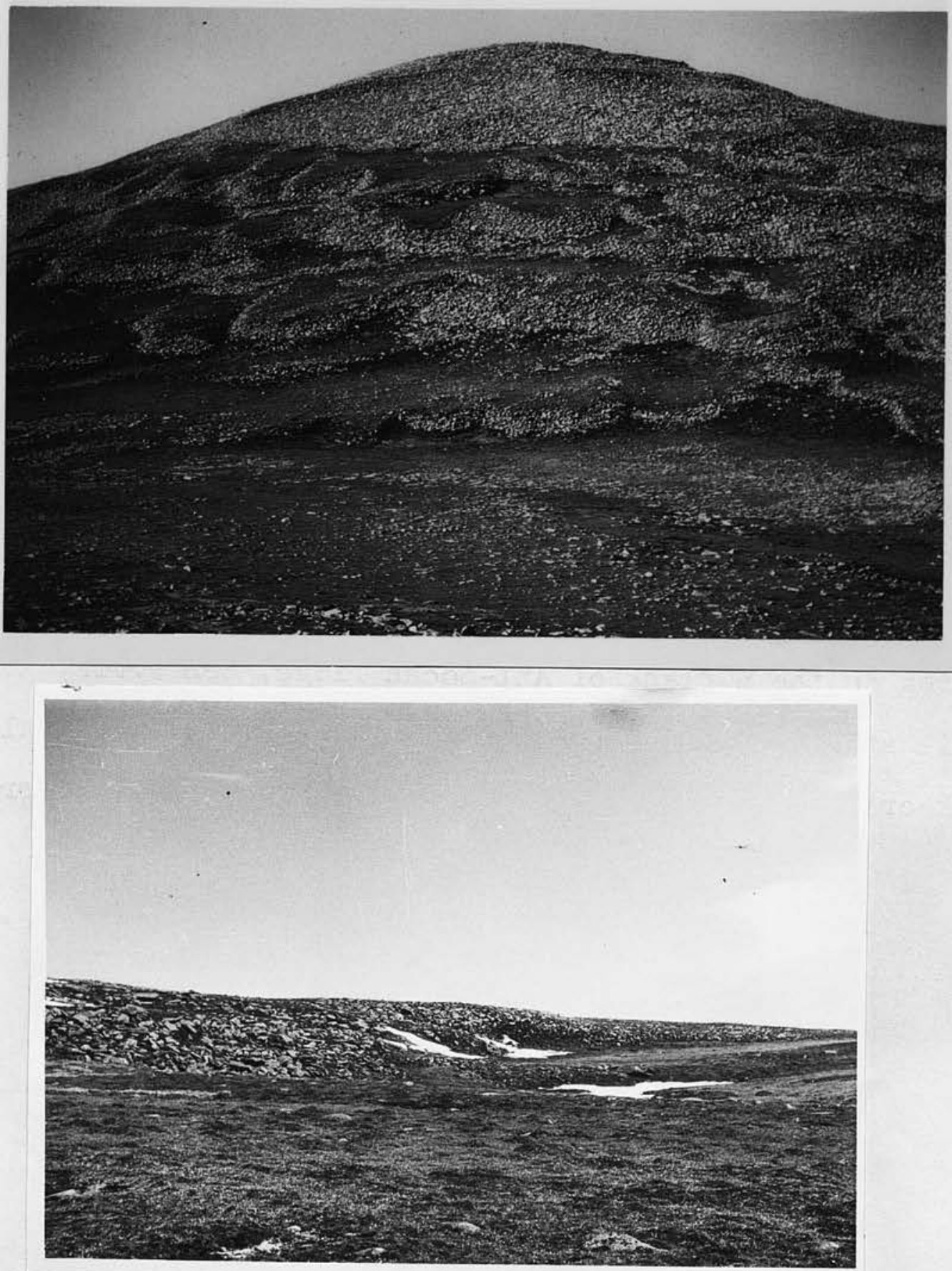


\section{Photograph 42 .}

Ill-defined lobe of rounded boulders with few fines on $W$ side of Ben Macdhui.

Photograph 43.

Large stone fronted lobes, summit block field, and altiplanation benches on the SE side of Lochnagar.

Photograph 44 .

Front of large solifluction terrace on the SW side of the White Mounth. (cf. figure 37). 

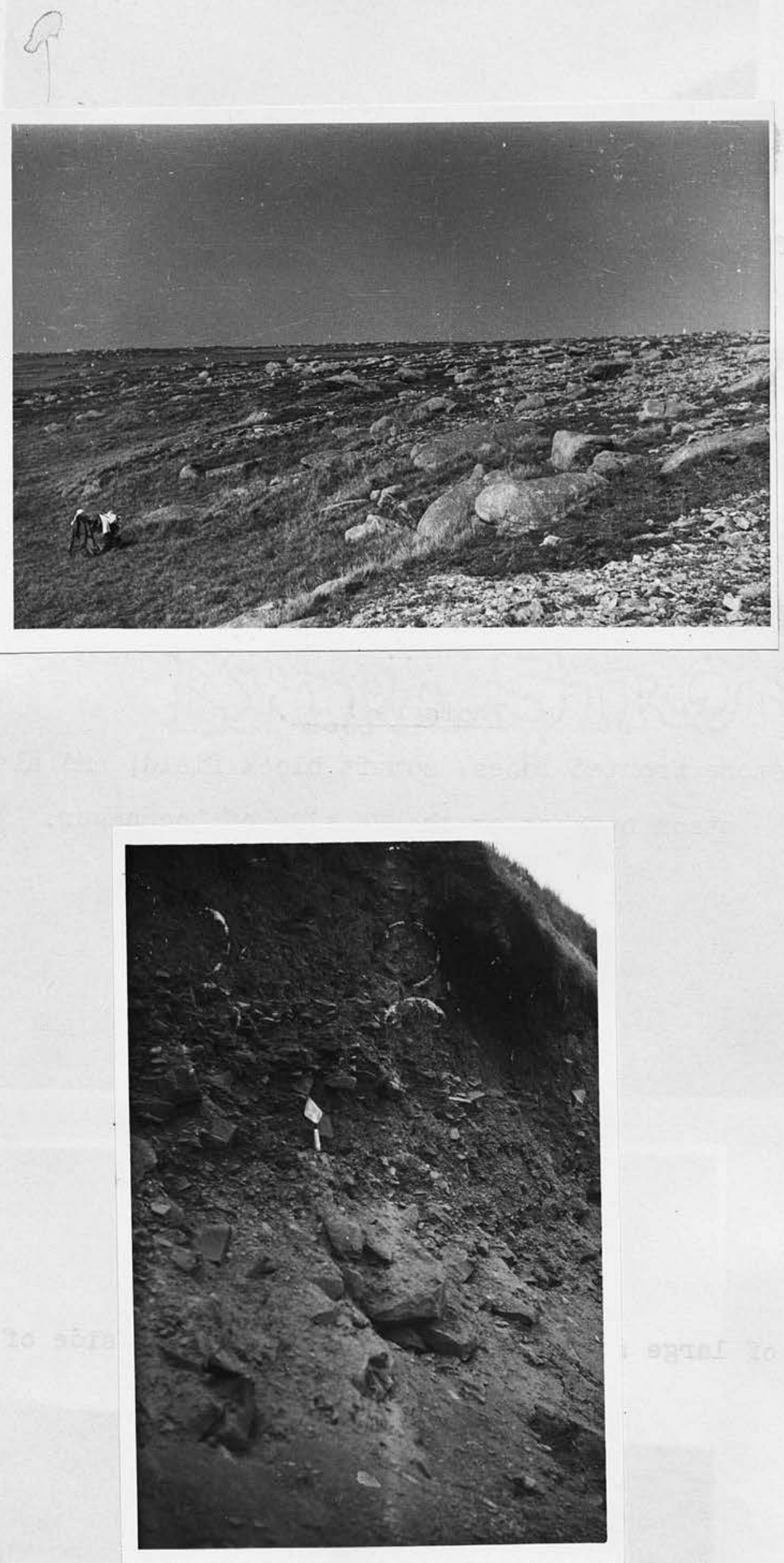
Photograph 45 .

Block field and terrace front on the summit of Ronas Hill, Shetland.

Photograph 46 .

Solifluction deposits overlying shattered bedrock by the Gatehopeknowe Burn, Peeblesshire. (G.R. 3738 or 3739). 

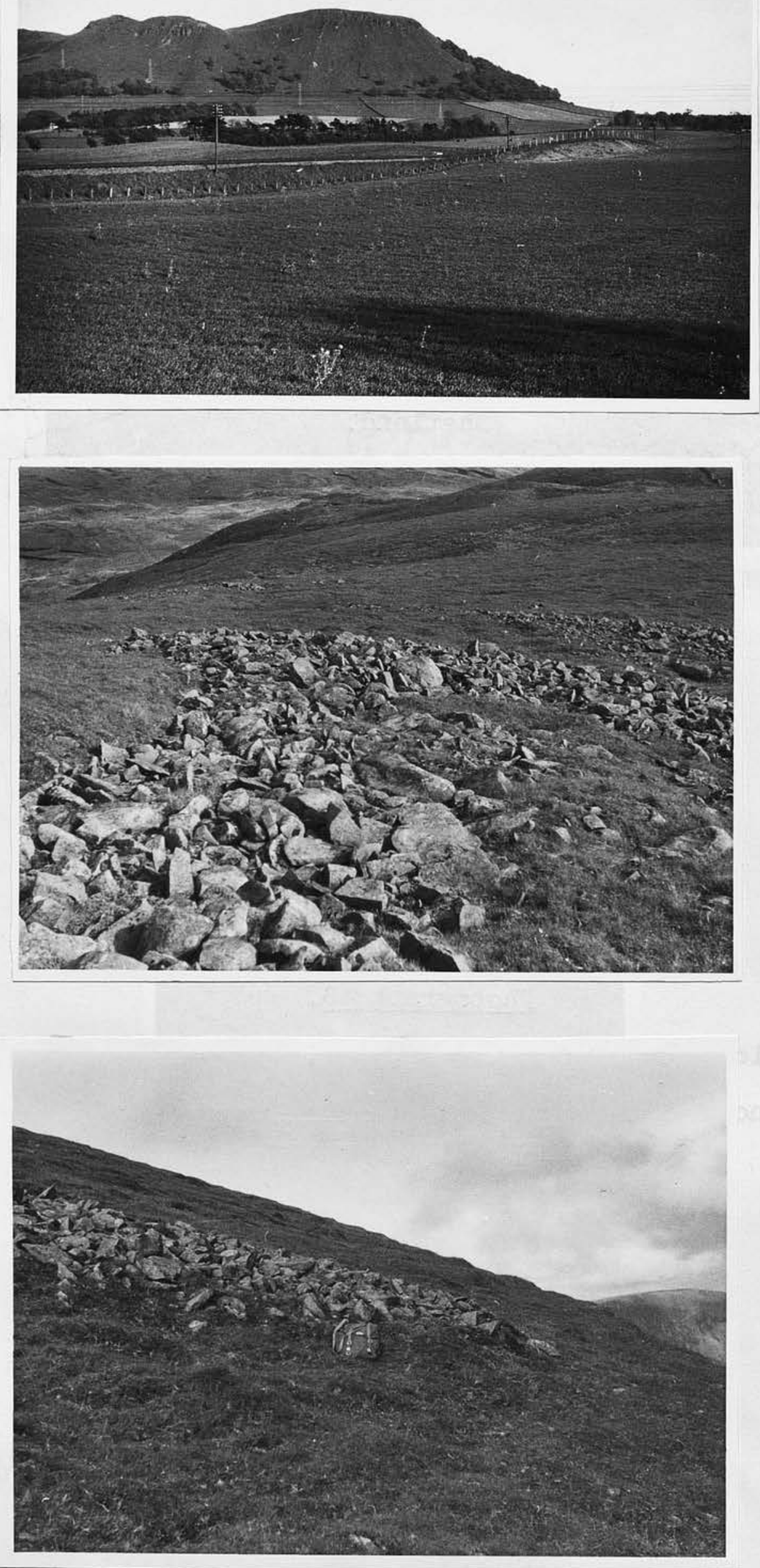


\section{Photograph 47.}

N face of Benartney Hill from the Edinburgh-Kinross road.

Photograph 48.

Lobate-fronted block stream on White Coomb, Dumries. Altitude c. 2,000 feet. (cf. photograph 49).

Photograph 49.

Turf banked front of lobate stone stream on White Coomb, Dumfriesshire. (cf. photograph 48). 

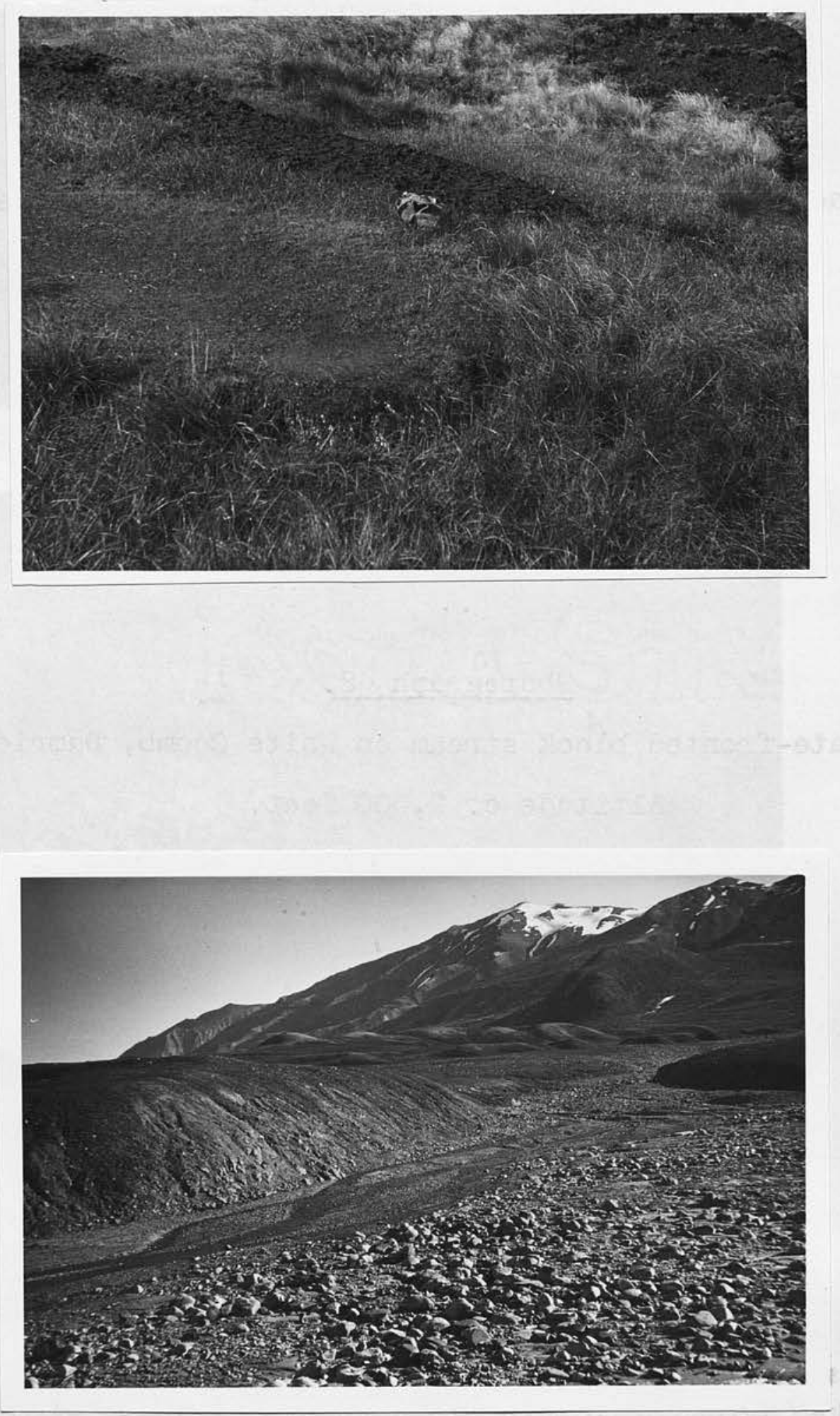
Photograph 50 .

Two actively moving lobes of sodden peat on the $\mathbb{N}$ side of White Coomb, Dumfriesshire.

Photograph 50 a.

Braided stream at Mesters Vig, E Greenland, undercutting a straight mass wasting slope. 

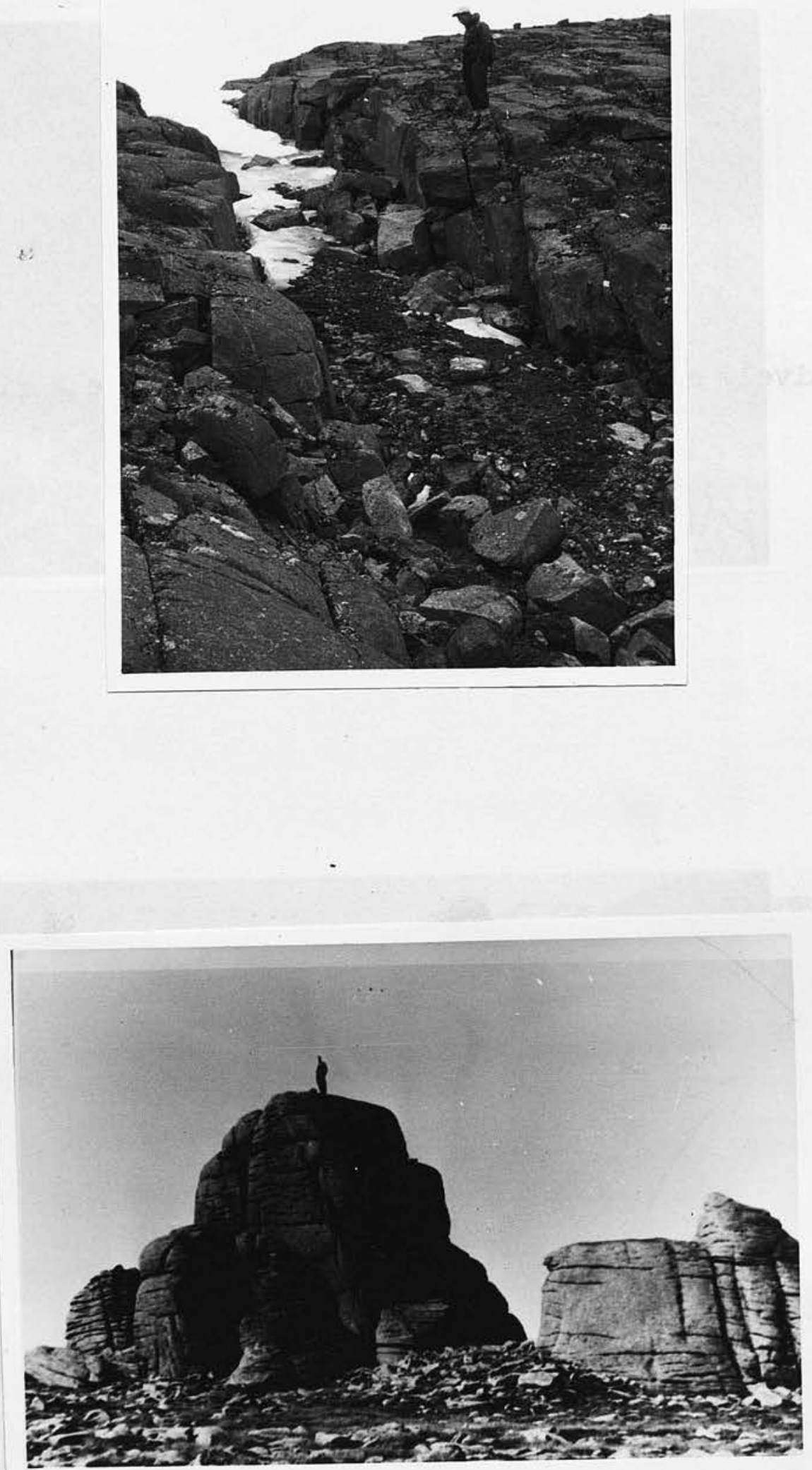


\section{Photograph 51 .}

Form resembling a "ravin de gelivation" in $\mathrm{E}$ Greenland, but probably the product of initial subglacial plucking, now being modified by periglaciation.

Photograph 52.

Large tor on Bein Mheadhoin, Cairngorms. (N.B. This example is more coherent than most). 

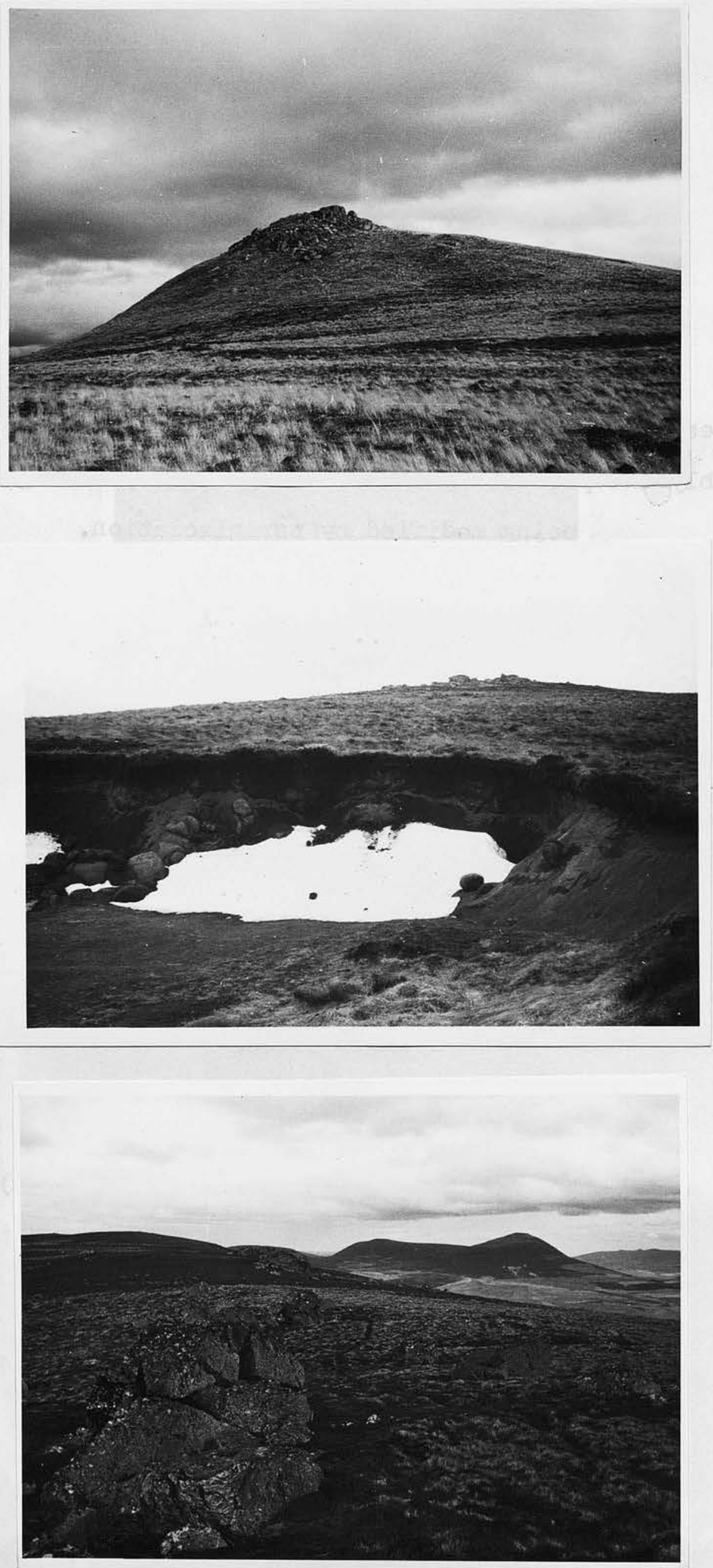
Photograph 53.

Tor on summit of unidentified hill w of Rhynie, Strathbogie, Aberdeenshire.

Photograph 54.

Resistant core stones in a matrix of weathered 'growan' exposed by the road between Rhynie and Cabrach, Strathbogie. (G.R.4226). Removal of the growan by mass wasting has exposed the core stones to form a tor on the skyline.

Photograph 55 .

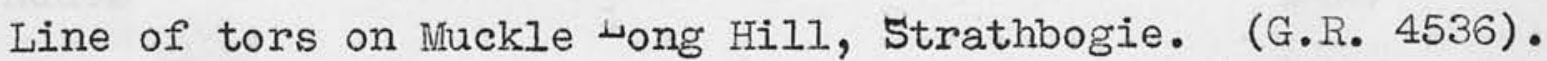



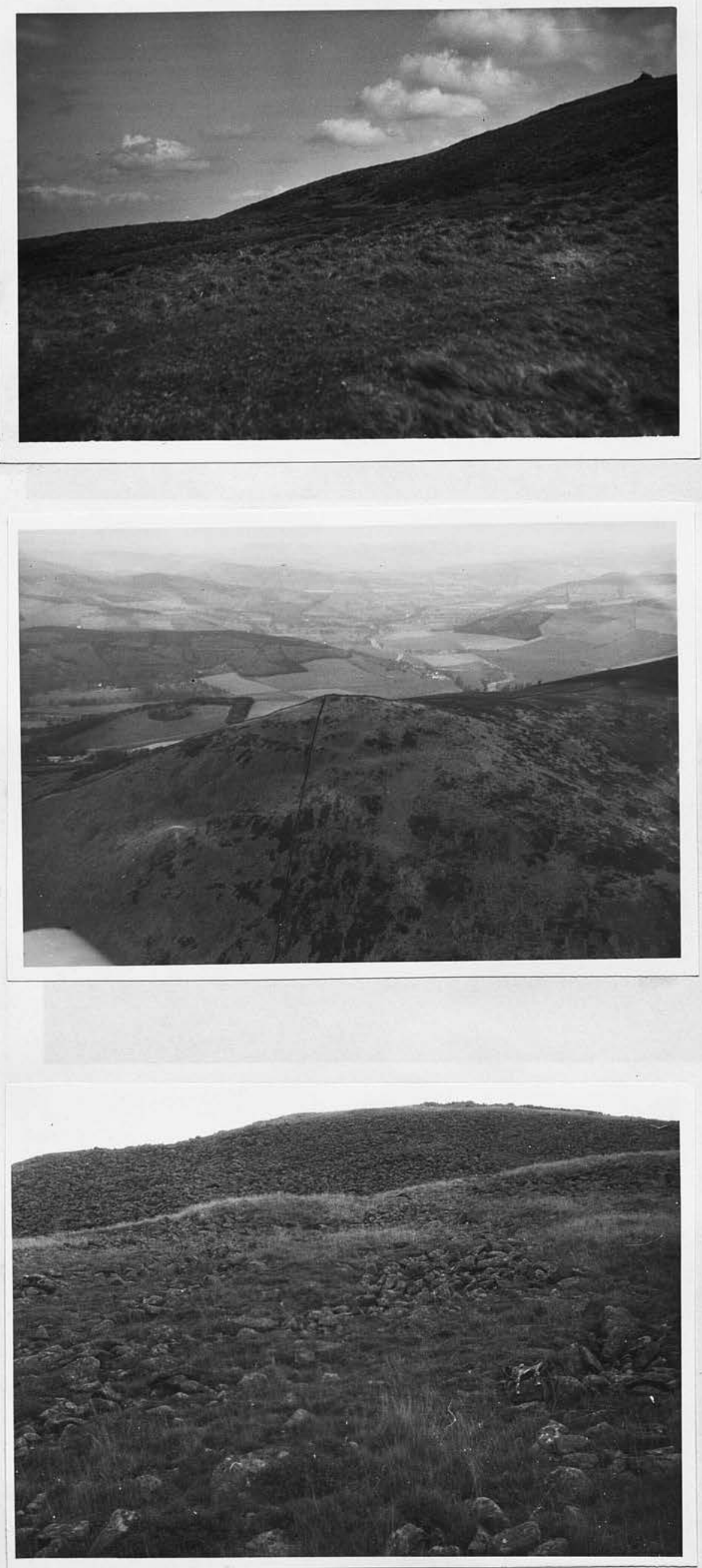
Photograph 56 .

Altiplanation bench (?) on the $\mathbb{N}$ face of Preistlaw Hill, in the Lammermuirs.

Photograph 57.

Summit of Lee Pen, Peeblesshire from the air.

Photograph 58 .

Benches, lobes and block field on the summit of Lee Ben, Peeblesshire. 

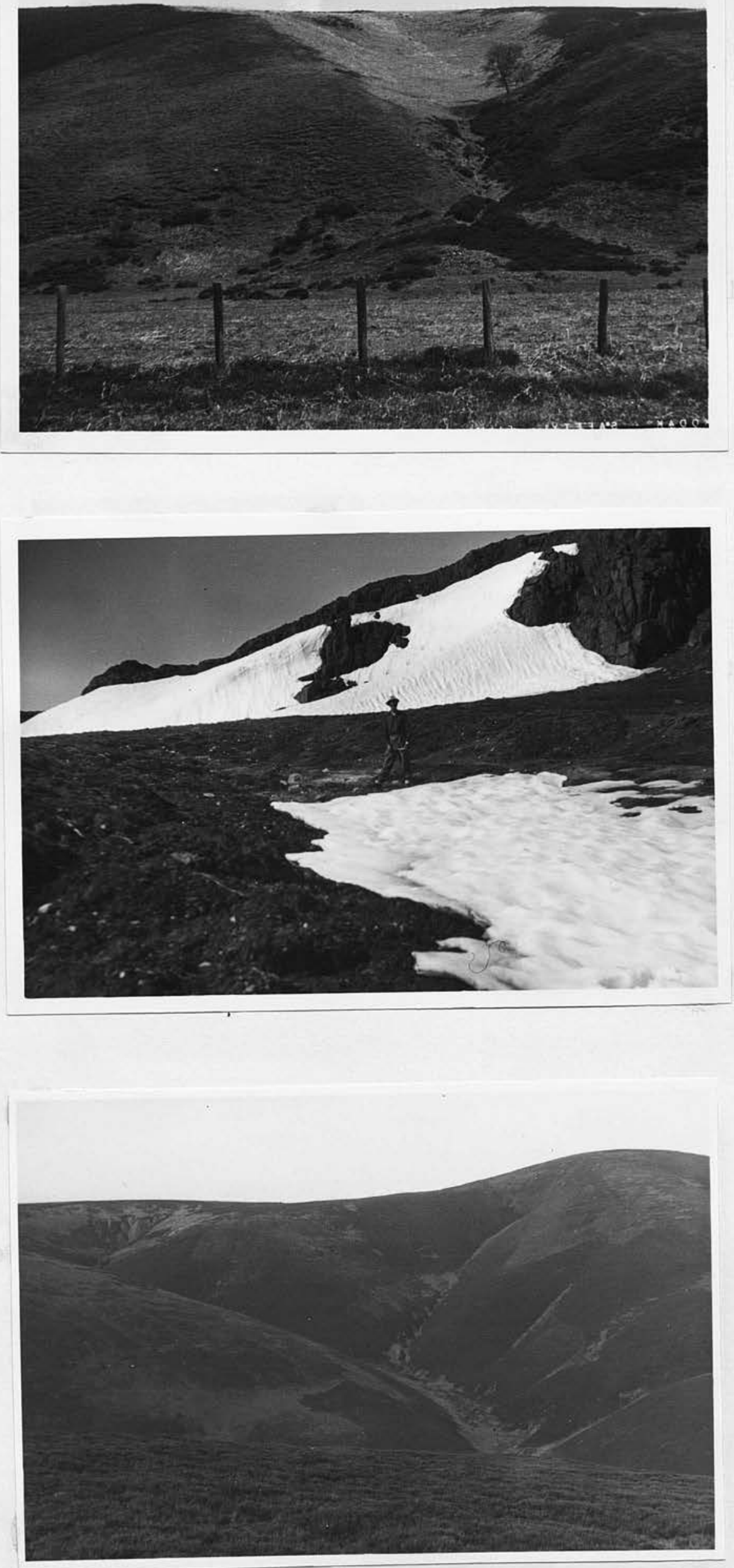


\section{Photograph 59 .}

Corrasion niche on the E side of the Monynut Water near the junction with the Back Burn, Lammermuirs. (G.R. 708658).

$$
\text { (cf. Figure 44). }
$$

Photograph 60.

Niche currently developing in stony silt at Mesters Vig, E Greenland by slumping and earth flow over permafrost.

Photograph 61.

The headwater's of the Leithen Water, Peeblesshire. 

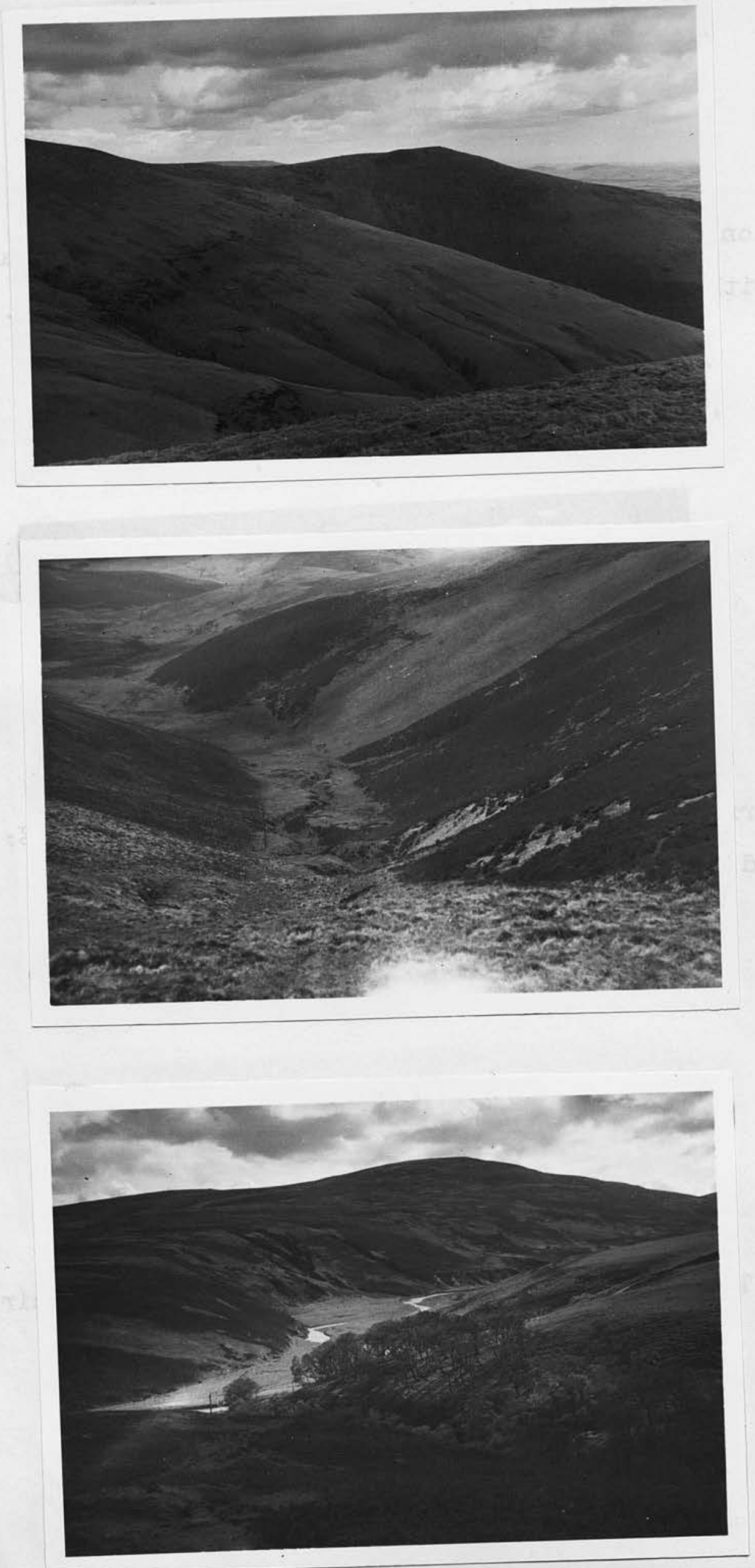


\section{Photograph 62.}

Smooth, rectilinear slopes on the S side of Bencleugh, The Ochils. Swelling on the slope corresponds to the outcrop of a more resistant bed of lava, while post glacial gullies have locally entrenched the slope.

Photograph 63.

Straight slopes of mass wasting at the amphitheatric head of the Soonhope Burn, Peebles.

Photograph 64.

View looking $W$ to Priestlaw Hill, in the Lammermuirs. cf. Fig.47. 

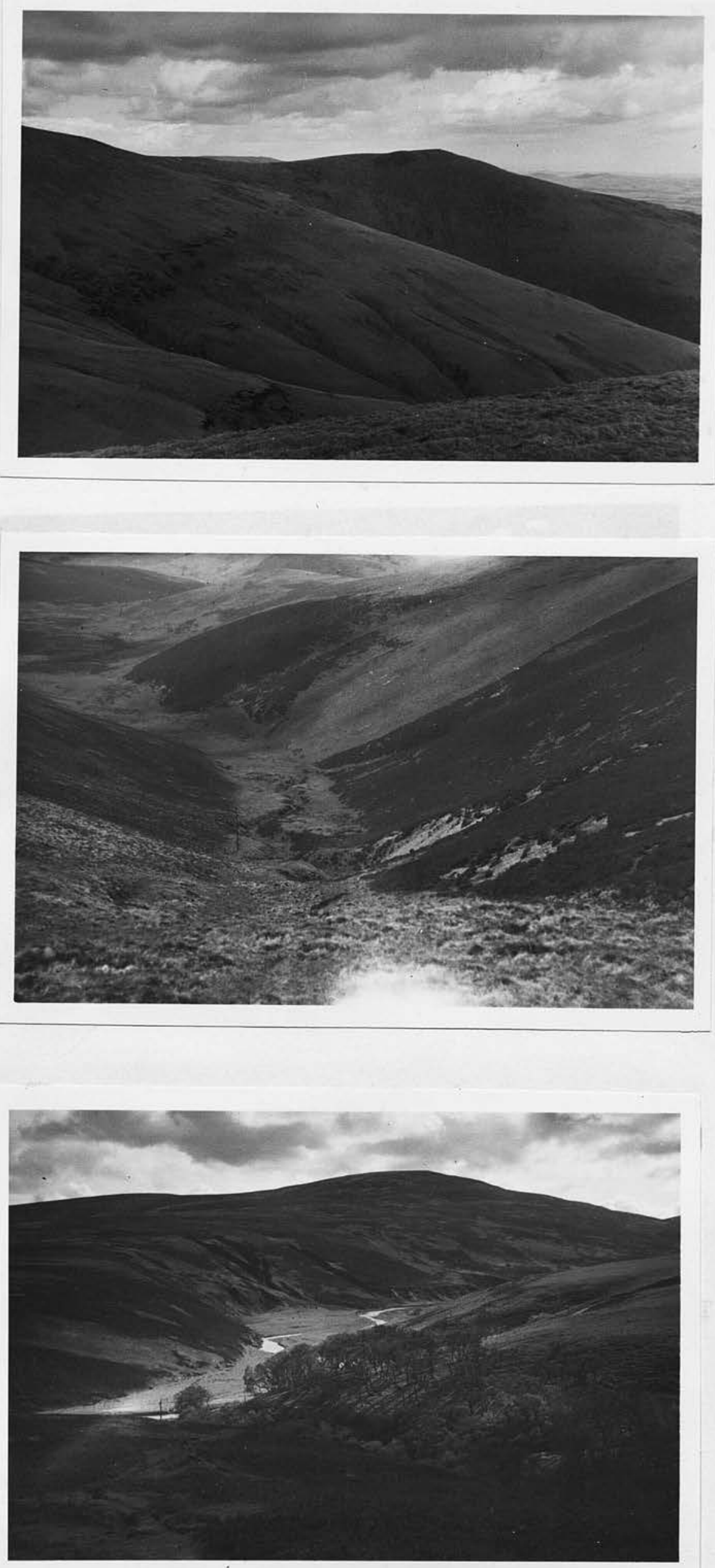
Photograph 62.

Smooth, rectilinear slopes on the S side of Bencleugh, The Ochils. Swelling on the slope corresponds to the outcrop of a more resistant bed of lava, while post glacial gullies have locally entrenched the slope.

Photograph 63.

Straight slopes of mass wasting at the amphitheatric head of the Soonhope Burn, Peebles.

Photograph 64.

View looking $W$ to Priestlaw Hill, in the Lammermuirs. cf. Fig.47. 


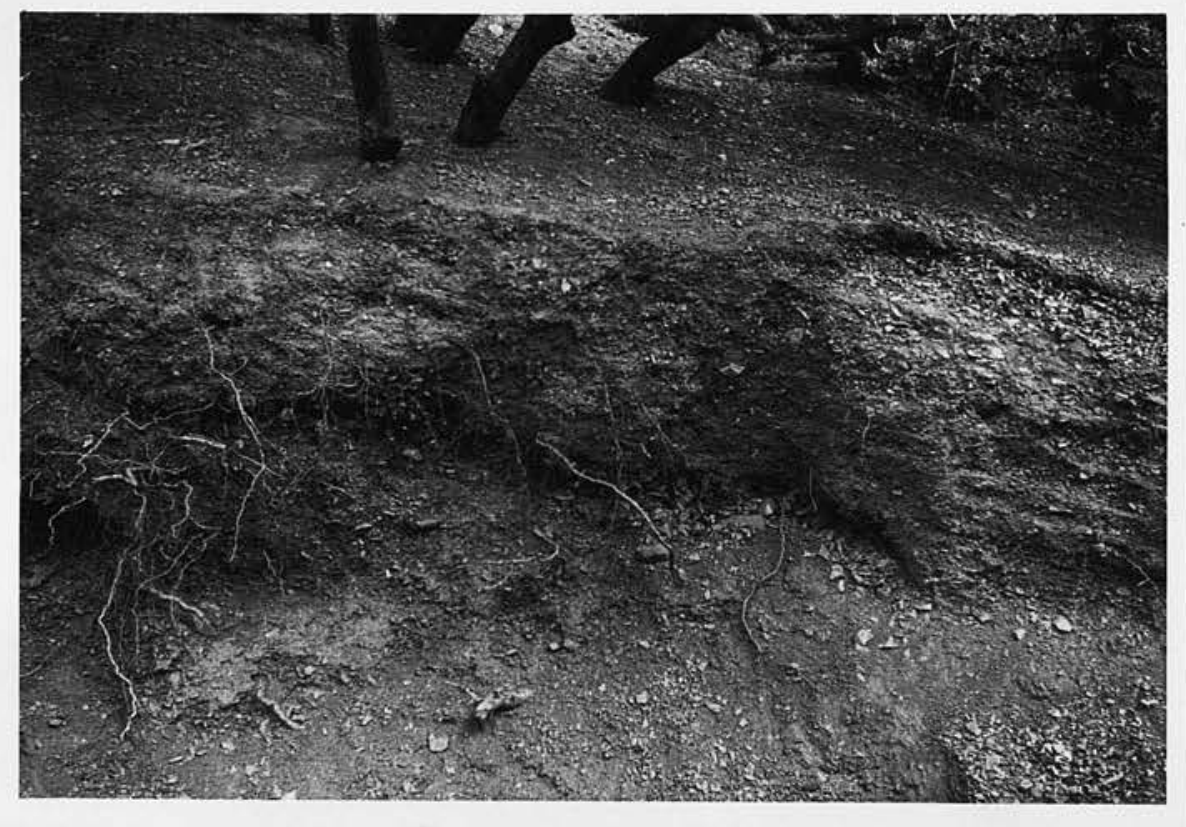


Photograph 65.

Rapid contemporary mass wasting at Blackford Hill, Edinburgh. This very recent accumulation closely resembles a periglacial solifluction deposits. 